\title{
Changing lifestyle behaviors with personalized feedback delivered via the Internet
}

Citation for published version (APA):

Marsaux, C. F. M. (2016). Changing lifestyle behaviors with personalized feedback delivered via the Internet: focus on physical activity and body weight. [Doctoral Thesis, Maastricht University]. Uitgeverij BOXPress. https://doi.org/10.26481/dis.20160420cm

Document status and date:

Published: 01/01/2016

DOI:

$10.26481 /$ dis. $20160420 \mathrm{~cm}$

Document Version:

Publisher's PDF, also known as Version of record

\section{Please check the document version of this publication:}

- A submitted manuscript is the version of the article upon submission and before peer-review. There can be important differences between the submitted version and the official published version of record.

People interested in the research are advised to contact the author for the final version of the publication, or visit the DOI to the publisher's website.

- The final author version and the galley proof are versions of the publication after peer review.

- The final published version features the final layout of the paper including the volume, issue and page numbers.

Link to publication

\footnotetext{
General rights rights.

- You may freely distribute the URL identifying the publication in the public portal. please follow below link for the End User Agreement:

www.umlib.nl/taverne-license

Take down policy

If you believe that this document breaches copyright please contact us at:

repository@maastrichtuniversity.nl

providing details and we will investigate your claim.
}

Copyright and moral rights for the publications made accessible in the public portal are retained by the authors and/or other copyright owners and it is a condition of accessing publications that users recognise and abide by the legal requirements associated with these

- Users may download and print one copy of any publication from the public portal for the purpose of private study or research.

- You may not further distribute the material or use it for any profit-making activity or commercial gain

If the publication is distributed under the terms of Article $25 \mathrm{fa}$ of the Dutch Copyright Act, indicated by the "Taverne" license above, 
Changing lifestyle behaviors with personalized feedback delivered via the Internet

Focus on physical activity and body weight

Cyril F. M. Marsaux 

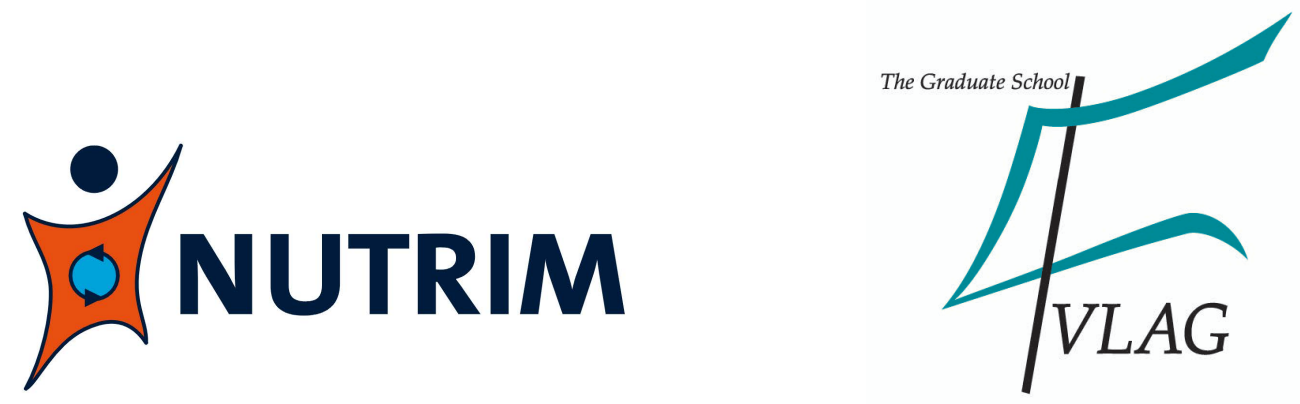

The studies presented in this thesis were performed within NUTRIM School for Nutrition and Translational Research in Metabolism, which participates in the Graduate School VLAG (Food Technology, Agrobiotechnology, Nutrition and Health Sciences), accredited by the Royal Netherlands Academy of Arts and Sciences.

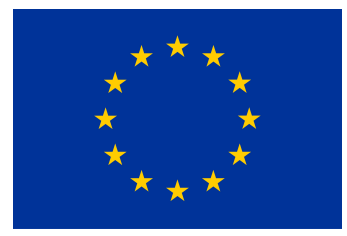

The studies described in this thesis were supported by a grant from the European Union's Seventh Framework Programme for research, technological development and demonstration (Contract $n^{\circ} 265494$ ).

Cover design: Proefschriftmaken.nl II Uitgeverij BOXPress

Layout: Cyril Marsaux

Printed by: Proefschriftmaken.nl II Uitgeverij BOXPress

(C) Cyril Marsaux, Maastricht 2016

ISBN: 9789462954731 


\title{
Changing lifestyle behaviors with personalized feedback delivered via the Internet
}

Focus on physical activity and body weight

\author{
DISSERTATION \\ To obtain the degree of doctor at the Maastricht University, \\ on the authority of the Rector Magnificus, \\ Prof. dr. L.L.G. Soete, \\ in accordance with the decision of the Board of Deans, \\ to be defended in public \\ on Wednesday 20 April 2016 at 12:00 hours
}

by

Cyril François Marie Marsaux

born in Nantes, France, on May $6^{\text {th }} 1987$ 


\section{Supervisor}

Prof. dr. W.H.M Saris

Co-supervisor

Prof. dr. J.C. Mathers, Newcastle University

\section{Assessment Committee}

Prof. dr. M.A. van Baak, chair

Prof. dr. E.E. Blaak

Prof. dr. S. Kremers

Prof. dr. W. van Mechelen, VU University Medical Center

Prof. dr. J-M. Oppert, Université Pierre et Marie Curie, Paris, France 


\section{Table of Contents}

$\begin{array}{lll}\text { Chapter } 1 & \text { General Introduction } & 7\end{array}$

Chapter 2 Objectively measured physical activity in European adults:

cross-sectional findings from the Food4Me Study

Chapter 3 Effects of a Web-based personalized intervention on physical activity in European adults: a randomized controlled trial

Chapter 4 Physical activity attenuates the effect of the FTO genotype on obesity traits in European adults: findings from the Food4Me Study

Chapter 5 Changes in physical activity following a genetic-based Internetdelivered personalized intervention: randomized controlled trial (Food4Me)

Chapter 6 Disclosure of FTO genotype and change in obesity-related markers: results from the Food4Me pan-European randomized controlled trial

Chapter 7 General Discussion

English Summary

French Summary

Dutch Summary

Valorization

Acknowledgements

About the author

Publications 



\section{CHAPTER 1}

General Introduction 


\section{Noncommunicable diseases, physical inactivity and obesity}

Today, most deaths are due to noncommunicable diseases (NCDs) -38 million in 2012, a number projected to reach 52 million by 2030 [1-3]. NCDs are chronic diseases; they usually progress slowly, last relatively long, and are not passed from person to person. The four main types of NCDs are cardiovascular diseases (CVDs), cancers, chronic respiratory diseases, and diabetes. Together, they represent $82 \%$ of all NCD deaths, with CVDs accounting for most [4]. An important part of NCD deaths should be preventable: $42 \%$ affect people under the age of 70 and are therefore considered premature deaths. NCDs do not occur only in high-income countries but rather disproportionately affect low- and medium-income countries-nearly $75 \%$ of NCD deaths, as well as the majority of premature deaths, occur in those countries [1]. Although they form a heterogeneous group of diseases, NCDs share four common risk factors: tobacco use, harmful use of alcohol, unhealthy diet, and insufficient physical activity (PA).

PA can be defined as any bodily movement produced by skeletal muscles that results in energy expenditure, such as during one's daily work, household activities, commuting, purposeful health-enhancing activities, and so forth [5]. Recent estimates suggest that physical inactivity was responsible for more than 5.3 million deaths $(9.3 \%)$ worldwide in 2008 [6], and, among European men and women, approximately $7.3 \%$ of deaths were attributable to inactivity [7]. Considerable evidence shows that frequent PA is associated with a reduced risk for all-cause mortality, CVD, diabetes, and several cancers [8-15]. Health benefits of frequent PA include healthier body composition (more muscle mass and less body fat) and lower blood pressure [11,13-15]. Data also accumulate indicating that even small increases in PA could have large health benefits [7,12]. Yet, so far, levels of PA across populations remain (too) low. Globally, $31 \%$ of adults aged 15 years or older were physically inactive in 2008. In Europe, this prevalence reached $35 \%$, and $40.5 \%$ in the Unites States of America [16]. This led a number of researchers, such as Steven Blair, to claim in 2009 that insufficient PA might be the biggest public health problem of the $21^{\text {st }}$ century [17]-a claim which they renewed 5 years later [18]. Physical inactivity, along with smoking, too much alcohol, and unhealthy diet, leads to physiological changes that increase the risk of NCDs: raised blood pressure, hyperglycemia, hyperlipidemia, and overweight/obesity [4].

Worldwide obesity has more than doubled since 1980. In 2014, 39\% of adults aged 18 years or older were overweight (>1.9 billion) and $13 \%$ were obese ( $>600$ million) globally [19]. When energy intake exceeds energy expenditure, a state of positive energy balance occurs, and the consequence is increased body mass, of which 60 to 
$80 \%$ is usually body fat [20], leading to overweight, and, if weight gain continues, obesity. Being overweight has been associated with several co-morbidities including type 2 diabetes mellitus (T2D) [21-23], and obesity and T2D so frequently occur together that Eleazar Shafrir coined the term "diabesity" almost two decades ago [24]. The pathogenesis of T2D is characterized by the development of both insulin resistance in peripheral tissues and pancreatic $\beta$-cell failure (defect in insulin secretion) $[25,26]$. Combined dietary and PA intervention may greatly reduce the incidence of T2D [27-30].

\section{Global noncommunicable diseases targets}

In the context described above, the World Health Organization (WHO) Member States have recently agreed on a set of nine voluntary global targets for prevention and control of NCDs to be attained by 2025 . The third target is a $10 \%$ relative reduction in the prevalence of insufficient PA and the seventh target is to halt the rise in T2D and obesity [31].

Treating overweight and obesity (as well as certain co-morbidities such as T2D), is a two-step process: assessment and management. Assessment requires determination of the degree of obesity and absolute risk status. Management includes both weight control or reducing excess body weight and maintaining that weight loss as well as instituting other measures to control associated risk factors [32]. Initial weight loss is usually not a major difficulty; it can be achieved by targeting both energy intake (dietary intervention) and energy expenditure (increased PA). Long-term weight loss maintenance however, although possible, is much more challenging and often not successful [33-35].

Food restriction produces an increase in hunger feelings [36,37], which makes it difficult to continue eating little. Moreover, weight loss is accompanied by a decrease in resting metabolic rate [38-41], physical activity and activity-induced energy expenditure [42-44]. Those biological compensatory mechanisms defend body weight and appear to respond much more strongly to negative energy balance than to prevention of positive energy balance $[39,45]$. It may therefore be easier to prevent weight gain than to produce sustained reductions in body weight in individuals already overweight or obese. A population weight gain prevention strategy needs only advocate small changes in PA and energy intake to be successful. However, it will still require behavior changes from the individuals themselves and producing these behavior changes in the population is an enormous challenge [46], given the current obesogenic environments. It is equally crucial that actions be taken on obesogenic environments. As we will 
discuss in the General Discussion (Chapter 7), fighting weight gain and physical inactivity is not only an individual responsibility, but also a collective one, and governments have a key role to play.

\section{Public health strategies to promote behavior change}

\section{Public health communication strategies}

The goal of public health is to prevent disease, improve health and wellbeing, and prolong life among the population as a whole. It is to improve quality of life, as well as to reduce health inequalities. Public health interventions strive to provide conditions in which people are healthy. In trying to achieve this goal, those interventions usually focus on entire populations and not on individuals, or single diseases [47]. Their approach can be described as "one size fits all", since generic communication materials are most often used. However, in several instances, this approach has been challenged. In the text that follows, we will give examples of generic communication strategies and review whether strategies should become tailored to the individual.

\section{Generic and targeted generic health guidelines-example of physical activity recommendations}

Generic health promotion materials consist of a single, generalized body of information that should apply to the general population. Targeted generic communication is intended to reach some specific subgroup of the general population, usually based on one or more demographic characteristics shared by its members or to some demographic subgroup [48], such as adults 18-65 years of age. Generic guidelines, targeted or not, can take the form of printed brochures or booklets, can be posted on the Internet on an official website (e.g. WHO), or can be broadcast on the radio or on television. These materials are relatively inexpensive to create and provide valuable information [48]. A good example of the usefulness of such "one size fits all" approaches is the health campaign on keeping hands clean to prevent illnesses $[49,50]$. PA guidelines are another example of generic, but targeted, public health communication.

To tackle the public health issue of physical inactivity, the US Centers for Disease Control and Prevention and the American College of Sports Medicine produced some 20 years ago, for the first time, standardized PA guidelines [51]. Since then, the WHO, the European Union, and most countries around the globe, have included PA guidelines in their health policies. Quickly it became apparent that these guidelines might not be appropriate because not all individuals require the same amount of PA. 
Targeted recommendations were therefore developed. The most recent guidelines from the WHO for adults aged 18-64 years old recommend a minimum of 150 minutes of moderate-intensity aerobic (endurance) PA throughout the week, or 75 minutes of vigorous-intensity aerobic PA, or an equivalent amount of moderate and vigorous PA (MVPA). Aerobic activity should be performed in bouts of at least 10 minutes and combined with muscle-strengthening activities involving major muscle groups on 2 or more days a week [52]. But there are also guidelines for other subgroups of the population with different energy needs or capacity to perform PA: children and adolescents [52], the elderly [52], and individuals at risk of weight (re)gain [53].

Targeted generic communication is an incremental advance over the generic approach, and there is evidence that it can contribute to individual behavior change [54-59]. Unfortunately, so far, even targeted generic health messages have not been able to substantially reverse the trends towards weight gain and physical inactivity. Thanks to national campaigns on PA, public knowledge of the health benefits of PA is good and $P A$ recommendations are widely recognized. However, inactive individuals seem often unaware that their (own) current PA is inadequate [60,61]. This lack of awareness may partly explain the limited success of "one size fits all" promotion programs. We could argue that if people knew, i.e. were informed, of how poorly they did compared with recommendations, they may then make the needed behavioral changes to improve their health. Therefore, intervention programs may need to be tailored to the individuals in order for them to realize that behavioral changes are necessary and relevant-for them as an individual.

\section{Tailored health communication}

\section{What is tailored health communication?}

Tailored communication is intended to reach one specific person, based on characteristics that are unique to that person, related to an outcome of interest, and has been derived from an individual assessment [62]. In general, as the level of assessment increases: anthropometric data (e.g. body weight), phenotypic data (e.g. blood cholesterol, PA), and more recently even genotypic data (e.g. a mutation in the breast cancer 1 , early onset gene $B R C A 1$, or carriage of the risk allele in the fat mass and obesity associated gene FTO), so does the degree of individualization in the feedback provided.

The tailoring approach of conducting individual assessments and providing individualized feedback is not new. It has been commonly employed by physicians, teachers, salespersons, and so forth, all of whom have identified the needs of a 
particular individual and use that information to customize solutions. In health education, individual counseling aimed at quitting smoking, having healthier dietary habits, or being more physically active, are examples based on this approach [48].

\section{Why tailor health communication?}

Several randomized studies have shown that tailored messages are more likely to be read, remembered, discussed with others and be perceived by readers as interesting and personally relevant, compared with untailored messages [63-66]. Recently, dietary recommendations tailored based on genetics were found more understandable and useful by young Canadians than general dietary advice [67]. To assess whether there is a need for tailoring public health communication materials, Kreuter et al. [48] analyzed data from a study of disease prevention in primary care settings $[68,69]$. They imposed a tailoring algorithm on baseline data collected from all participants as if they would have received a tailored intervention. Their tailoring program included four modules designed to help people quit smoking, increase PA, reduce dietary fat consumption, and learn to read nutrition labels on foods. Their analyses showed that $98 \%$ of smokers would have received a different combination of the 1,272 different possible combinations of cessation messages, $98 \%$ of patients who could have received nutrition labels would have received a set of messages that no other participant received, and for promoting reduction of dietary fat intake and increased PA, rates of uniqueness were $86 \%$ and $78 \%$, respectively [48]. Thus, tailoring health messages may have potential, provided that it can be done at low cost, delivered to a large part of the population, and be more effective at changing behaviors than a "one size fits all" approach.

\section{Computer tailoring and the Internet}

Over the last decades, computer tailoring has proven to be an innovative and promising health education technique [70-78]. There is no denying that a skilled counselor, who can provide tailored feedback and relevant tips on how to achieve behavior change in a one on one session, would be more desirable than a computer-tailored message. However, the impact of counseling on the health of populations can be limited by cost and by the relatively limited number of individuals who can be reached by trained professionals. If the goal is to be able to reach a large number of individuals while still tailoring the feedback given, then computer tailoring can be very useful. A computertailored intervention mimics interpersonal counseling using a computerized process. It allows for individualized feedback and advice on personal behavior, personal motivation, outcome expectations, self-efficacy, social and physical environmental 
opportunities, and other behavioral determinants [79]. Unlike interpersonal counseling, it can be widely distributed through interactive media channels, such as the Internet, at a relatively low cost. A huge part of the world population now has Internet access, e.g. $78.5 \%$ of EU citizens use the Internet [80]. Moreover, the Internet has become a primary source for obtaining health information by the public $[81,82]$. Thus, it is not surprising that the number of Internet-based behavior change interventions has greatly increased in the last decade. Compared with more traditional methods of delivery, using the Internet is convenient-an intervention could be available to the participant when and where she/he wishes to use it and be available on computers as well as tablets or smart phones. Furthermore, it is scalable-an intervention is not restricted to any geographical location and, in theory, could be available to unlimited numbers of participants, nation- or even worldwide. Finally, combined with computer tailoring, it allows health professionals to provide interactive, individualized interventions that can match each visitor's unique characteristics, circumstances, beliefs, motivation to change, and behavior [48,83-87].

\section{Effectiveness of eHealth tailored interventions?}

There is a wealth of studies examining the effectiveness of a computer-tailored intervention to change a certain behavior, but such intervention may not necessarily be using eHealth technologies (i.e. the Internet and related technologies) as means for delivery. There are also numerous studies testing whether an eHealth program is effective in changing behavior, but the program may not be tailored to the individual. Whether an intervention is effective or not also depends on the behavior studied, e.g. smoking cessation, fruit and vegetables consumption, fat intake, and so forth. Recently, in a meta-analysis of randomized controlled trials, Celis-Morales et al. demonstrated that eHealth tailored interventions were more effective in reducing body weight than untailored (generic) advice (weighted mean differences: $-1.83 \mathrm{~kg} 95 \% \mathrm{Cl}-2.2,-1.4$; $P<0.0001)$ [87]. With regards to $P A$, numerous studies have investigated the effectiveness of eHealth tailored interventions [88-138], but the evidence is unclear $[139,140]$. Tailoring seems to be an asset, but which works best when there is also some personal contact (e.g. face-to-face counseling or group sessions) [141]. Most studies cited measured PA with self-reports. In addition, an appropriate control group was not always included. Therefore, in the General Discussion (Chapter 7), we will discuss whether eHealth tailored programs where PA was assessed objectively are more effective at increasing PA than simply providing general PA guidelines. 


\section{How far should the tailoring go? Using genetic variants to personalize the feedback.}

The degree of individualization of the feedback given to a subject can increase with the level of assessment. Feedback can include simple anthropometric data (e.g. body weight), but also phenotypic data (e.g. PA), and more recently even genotypic data (e.g. FTO). Since the completion of the sequencing of the human genome in 2000, there has been a growing interest in using genetic information to personalize lifestyle interventions [142]. Although disclosure of such information does not seem to have unintended adverse effects, more randomized controlled trials are needed to establish whether gene-based personalized interventions are useful and promote greater behavior change than conventional "one size fits all" interventions [143] and do better than tailoring which does not use genetic-based information. In particular, data on whether providing DNA-based test results leads to an increase in PA and/or can help one's weight reduction or management are lacking.

The fat mass and obesity associated (FTO) gene has provided the strongest evidence to date, in relation to the genetic susceptibility to obesity. Polymorphisms in this gene located in intron 1 and exon 2 have been shown to be consistently and strongly associated with obesity-related markers [144,145]. For instance, individuals homozygous for the higher-risk allele AA of single nucleotide polymorphism (SNP) rs9939609 in FTO weighed on average $3 \mathrm{~kg}$ more and had 1.7-fold increased odds of having obesity compared with those homozygous for the lower-risk allele TT [146]. Moreover, there is increasing evidence that the FTO genetic susceptibility to obesity can be modulated by lifestyle factors such as PA [147-152]. Adding information about whether one carries the risk allele for FTO could potentially motivate individuals to make healthy lifestyle changes (e.g. increase PA, achieve or maintain a healthy body weight). In a recent study, Meisel et al. reported that adding FTO feedback to weight control advice enhanced readiness to control weight, but had no more effect on behavior than weight control advice alone [153]. FTO feedback has not yet been used to promote increases in PA. More studies in that area are definitely needed.

\section{Food4Me}

The Food4Me 'Proof of Principle' Study was a 6-month, 4-arm, randomized controlled trial conducted across seven European countries (Germany, Greece, Ireland, The Netherlands, Poland, Spain, and the United Kingdom) to compare the effects of three levels of personalized advice with standard population advice on health-related outcomes. Full details of the study protocol have been described elsewhere [154]. 
The intervention was designed to emulate an Internet-based and personalized service (www.food4me.org), and the study aimed to answer the following primary questions: (i) does personalization of dietary advice and PA improve diet and PA in comparison with non-personalized, conventional healthy eating and lifestyle guidelines? And (ii) is personalization based on individualized phenotypic and/or genotypic information more effective in assisting and/or motivating study participants to make, and to sustain, appropriate healthy changes, than personalization based on analysis of baseline diet and PA alone? To answer these questions participants were randomized to a control group (Level 0 ) or to one of three personalized intervention groups with increasingly more detailed personalized advice (Levels 1-3) for a 6-month period.

- Level 0 (LO; 'control group'): non-personalized dietary and PA advice based on (European) population (generic) guidelines.

- Level 1 (L1): personalized dietary and PA advice based on individual dietary intake and PA data alone.

- Level 2 (L2): personalized dietary and PA advice based on individual dietary intake, PA, and phenotypic data.

- Level 3 (L3): personalized dietary and PA advice based on individual dietary intake, PA, phenotypic, and genotypic data.

\section{Outline of this thesis}

Within the Food4Me project, the objective of this thesis was to determine whether a personalized intervention delivered via the Internet was more effective in improving PA and obesity-related traits than providing online standardized (non-personalized) guidelines.

The PA levels of the European adults included in our trial, measured objectively with accelerometers, are described in Chapter 2 and compared with results of other large cohorts. Given the prevalence of physical inactivity in Europe, we test in Chapter 3 whether personalized feedback on measured PA via the Internet can promote an increase in PA in European adults. In Chapter 4, we investigate whether the genetic predisposition to obesity can be modified PA, when PA is measured objectively by accelerometers. Given the probable interaction between FTO and PA on obesityrelated traits, we look in more detail at the potential impact of disclosing genetic risk information on change in PA (Chapter 5) and weight, BMI and waist circumference (Chapter 6) in FTO risk and non-risk carriers. Finally, we summarize and discuss the main results of this thesis in Chapter 7 , as well as provide an outlook on future research in the field. 


\section{References}

1. World Health Organization. Global Health Estimates: Deaths by Cause, Age, Sex and Country, 2000-2012. Geneva: 2014.

2. Mathers CD, Loncar D. Projections of global mortality and burden of disease from 2002 to 2030 . PLoS Med. 2006;3(11):e442.

3. Health statistics and information systems - Projections of mortality and causes of death, 2015 and 2030 [Internet]. 2015 [cited 18 Aug 2015]. Available from: http://www.who.int/healthinfo/global_burden_disease/projections/en/.

4. World Health Organization. Noncommunicable diseases 2015 [cited 201518 Aug]. Available from: http://www.who.int/mediacentre/factsheets/fs355/en/.

5. Montoye HJ, Kemper HC, Saris WH, Washburn RA. Measuring Physical Activity and Energy Expenditure: Human Kinetics; 1996. 190 p.

6. Lee IM, Shiroma EJ, Lobelo F, Puska P, Blair SN, Katzmarzyk PT, et al. Effect of physical inactivity on major non-communicable diseases worldwide: an analysis of burden of disease and life expectancy. Lancet. 2012;380(9838):219-29.

7. Ekelund U, Ward HA, Norat T, Luan J, May AM, Weiderpass E, et al. Physical activity and all-cause mortality across levels of overall and abdominal adiposity in European men and women: the European Prospective Investigation into Cancer and Nutrition Study (EPIC). The American journal of clinical nutrition. 2015;101(3):613-21.

8. He D, Xi B, Xue J, Huai P, Zhang M, Li J. Association between leisure time physical activity and metabolic syndrome: a meta-analysis of prospective cohort studies. Endocrine. 2014;46(2):231-40.

9. Li J, Siegrist J. Physical activity and risk of cardiovascular disease--a meta-analysis of prospective cohort studies. International journal of environmental research and public health. 2012;9(2):391407.

10. Milton K, Macniven R, Bauman A. Review of the epidemiological evidence for physical activity and health from low- and middle-income countries. Global public health. 2014;9(4):369-81.

11. Reiner M, Niermann C, Jekauc D, Woll A. Long-term health benefits of physical activity--a systematic review of longitudinal studies. BMC public health. 2013;13:813.

12. Hupin D, Roche F, Gremeaux V, Chatard JC, Oriol M, Gaspoz JM, et al. Even a low-dose of moderate-to-vigorous physical activity reduces mortality by $22 \%$ in adults aged $>l=60$ years: a systematic review and meta-analysis. British journal of sports medicine. 2015.

13. Warburton DE, Nicol CW, Bredin SS. Health benefits of physical activity: the evidence. CMAJ : Canadian Medical Association journal $=$ journal de l'Association medicale canadienne. 2006;174(6):801-9.

14. Brown WJ, Burton NW, Rowan PJ. Updating the evidence on physical activity and health in women. American journal of preventive medicine. 2007;33(5):404-11.

15. Bauman AE. Updating the evidence that physical activity is good for health: an epidemiological review 2000-2003. Journal of science and medicine in sport / Sports Medicine Australia. 2004;7(1 Suppl):6-19.

16. Hallal PC, Andersen LB, Bull FC, Guthold R, Haskell W, Ekelund U, et al. Global physical activity levels: surveillance progress, pitfalls, and prospects. Lancet. 2012;380(9838):247-57.

17. Blair SN. Physical inactivity: the biggest public health problem of the 21 st century. British journal of sports medicine. 2009;43(1):1-2.

18. Trost SG, Blair SN, Khan KM. Physical inactivity remains the greatest public health problem of the 21st century: evidence, improved methods and solutions using the ' 7 investments that work' as a framework. British journal of sports medicine. 2014;48(3):169-70.

19. World Health Organization. Obesity and overweight 2015 [cited 201525 Aug]. Available from: http://www.who.int/mediacentre/factsheets/fs311/en/.

20. Hill JO, Commerford R. Physical activity, fat balance, and energy balance. Int J Sport Nutr. 1996;6(2):80-92. 
21. Visscher TL, Seidell JC. The public health impact of obesity. Annual review of public health. $2001 ; 22: 355-75$.

22. Field AE, Coakley EH, Must A, Spadano JL, Laird N, Dietz WH, et al. Impact of overweight on the risk of developing common chronic diseases during a 10-year period. Archives of internal medicine. 2001;161(13):1581-6.

23. Nguyen NT, Nguyen XM, Lane J, Wang P. Relationship between obesity and diabetes in a US adult population: findings from the National Health and Nutrition Examination Survey, 1999-2006. Obesity surgery. $2011 ; 21(3): 351-5$.

24. Shafrir E. Development and consequences of insulin resistance: lessons from animals with hyperinsulinaemia. Diabetes Metab. 1996;22(2):122-31.

25. Bergman RN, Ader M, Huecking K, Van Citters G. Accurate assessment of beta-cell function: the hyperbolic correction. Diabetes. 2002;51 Suppl 1:S212-20.

26. Relimpio F. "The relative contributions of insulin resistance and beta-cell dysfunction to the pathophysiology of Type 2 diabetes", by Kahn SE. Diabetologia. 2003;46(12):1707.

27. Roumen C, Blaak EE, Corpeleijn E. Lifestyle intervention for prevention of diabetes: determinants of success for future implementation. Nutr Rev. 2009;67(3):132-46.

28. Tuomilehto J. Nonpharmacologic therapy and exercise in the prevention of type 2 diabetes. Diabetes care. 2009;32 Suppl 2:S189-93.

29. Mensink M, Blaak EE, Wagenmakers AJ, Saris WH. Lifestyle intervention and fatty acid metabolism in glucose-intolerant subjects. Obes Res. 2005;13(8):1354-62.

30. Penn L, White M, Lindstrom J, den Boer AT, Blaak E, Eriksson JG, et al. Importance of weight loss maintenance and risk prediction in the prevention of type 2 diabetes: analysis of European Diabetes Prevention Study RCT. PloS one. 2013;8(2):e57143.

31. World Health Organization. Global status report on noncommunicable diseases 2014: WHO; 2014.

32. Clinical Guidelines on the Identification, Evaluation, and Treatment of Overweight and Obesity in Adults--The Evidence Report. National Institutes of Health. Obes Res. 1998;6 Suppl 2:51S-209S.

33. Wing RR, Phelan S. Long-term weight loss maintenance. The American journal of clinical nutrition. 2005;82(1 Suppl):222S-5S.

34. Thomas JG, Bond DS, Phelan S, Hill JO, Wing RR. Weight-loss maintenance for 10 years in the National Weight Control Registry. American journal of preventive medicine. 2014;46(1):17-23.

35. Kraschnewski JL, Boan J, Esposito J, Sherwood NE, Lehman EB, Kephart DK, et al. Long-term weight loss maintenance in the United States. Int J Obes (Lond). 2010;34(11):1644-54.

36. Anton SD, Han H, York E, Martin CK, Ravussin E, Williamson DA. Effect of calorie restriction on subjective ratings of appetite. Journal of human nutrition and dietetics : the official journal of the British Dietetic Association. 2009;22(2):141-7.

37. Schwartz MW, Woods SC, Porte D, Jr., Seeley RJ, Baskin DG. Central nervous system control of food intake. Nature. 2000;404(6778):661-71.

38. Camps SG, Verhoef SP, Westerterp KR. Weight loss, weight maintenance, and adaptive thermogenesis. The American journal of clinical nutrition. 2013;97(5):990-4.

39. Dulloo AG, Jacquet J. Adaptive reduction in basal metabolic rate in response to food deprivation in humans: a role for feedback signals from fat stores. The American journal of clinical nutrition. 1998;68(3):599-606.

40. Leibel RL, Rosenbaum M, Hirsch J. Changes in energy expenditure resulting from altered body weight. N Engl J Med. 1995;332(10):621-8.

41. Schwartz A, Doucet E. Relative changes in resting energy expenditure during weight loss: a systematic review. Obes Rev. 2010;11(7):531-47.

42. Bonomi AG, Soenen S, Goris AH, Westerterp KR. Weight-loss induced changes in physical activity and activity energy expenditure in overweight and obese subjects before and after energy restriction. PloS one. 2013;8(3):e59641.

43. Martin CK, Heilbronn LK, de Jonge L, DeLany JP, Volaufova J, Anton SD, et al. Effect of calorie restriction on resting metabolic rate and spontaneous physical activity. Obesity (Silver Spring). 2007;15(12):2964-73. 
44. Redman LM, Heilbronn LK, Martin CK, de Jonge L, Williamson DA, Delany JP, et al. Metabolic and behavioral compensations in response to caloric restriction: implications for the maintenance of weight loss. PloS one. 2009;4(2):e4377.

45. Jebb SA, Prentice AM, Goldberg GR, Murgatroyd PR, Black AE, Coward WA. Changes in macronutrient balance during over- and underfeeding assessed by 12-d continuous whole-body calorimetry. Am J Clin Nutr. 1996;64(3):259-66.

46. Hill JO, Wyatt HR, Peters JC. Energy balance and obesity. Circulation. 2012;126(1):126-32.

47. World Health Organization. Glossary of globalization, trade and health terms: Public health 2015 [cited 20152 Sept]. Available from: http://www.who.int/trade/glossary/story076/en/.

48. Kreuter MW, Strecher VJ, Glassman B. One size does not fit all: the case for tailoring print materials. Annals of behavioral medicine : a publication of the Society of Behavioral Medicine. 1999;21(4):276-83.

49. Aiello AE, Coulborn RM, Perez V, Larson EL. Effect of hand hygiene on infectious disease risk in the community setting: a meta-analysis. American journal of public health. 2008;98(8):1372-81.

50. Centers for Disease Control and Prevention. Health Promotion Materials: handwashing 2015 [cited 20152 Sept]. Available from: http://www.cdc.gov/handwashing/resources.html.

51. Pate RR, Pratt M, Blair SN, Haskell WL, Macera CA, Bouchard C, et al. Physical activity and public health. A recommendation from the Centers for Disease Control and Prevention and the American College of Sports Medicine. Jama. 1995;273(5):402-7.

52. World Health Organization. Global recommendations on physical activity for health2010. 58 p.

53. Saris WH, Blair SN, van Baak MA, Eaton SB, Davies PS, Di Pietro L, et al. How much physical activity is enough to prevent unhealthy weight gain? Outcome of the IASO 1st Stock Conference and consensus statement. Obes Rev. 2003;4(2):101-14.

54. Rimer BK, Orleans CT. Tailoring smoking cessation for older adults. Cancer. 1994;74(7 Suppl):2051-4.

55. Morgan GD, Noll EL, Orleans CT, Rimer BK, Amfoh K, Bonney G. Reaching midlife and older smokers: tailored interventions for routine medical care. Preventive medicine. 1996;25(3):346-54.

56. Davis SW, Cummings KM, Rimer BK, Sciandra R, Stone JC. The impact of tailored self-help smoking cessation guides on young mothers. Health education quarterly. 1992;19(4):495-504.

57. Drossaert $\mathrm{CH}$, Boer $\mathrm{H}$, Seydel ER. Health education to improve repeat participation in the Dutch breast cancer screening programme: evaluation of a leaflet tailored to previous participants. Patient education and counseling. 1996;28(2):121-31.

58. Rimer BK, Orleans CT, Fleisher L, Cristinzio S, Resch N, Telepchak J, et al. Does tailoring matter? The impact of a tailored guide on ratings and short-term smoking-related outcomes for older smokers. Health education research. 1994;9(1):69-84.

59. Kristeller JL, Merriam PA, Ockene JK, Ockene IS, Goldberg RJ. Smoking intervention for cardiac patients: in search of more effective strategies. Cardiology. 1993;82(5):317-24.

60. Ronda G, Van Assema P, Brug J. Stages of change, psychological factors and awareness of physical activity levels in The Netherlands. Health promotion international. 2001;16(4):305-14.

61. Watkinson C, van Sluijs EM, Sutton S, Hardeman W, Corder K, Griffin SJ. Overestimation of physical activity level is associated with lower BMI: a cross-sectional analysis. The international journal of behavioral nutrition and physical activity. 2010;7:68

62. Kreuter MW, Lezin NA, Kreuter MW, Green LW. Community Health Promotion Ideas that Work: A Field-book for Practitioners: Jones and Bartlett Publishers; 1998.

63. Brug J, Steenhuis I, van Assema P, de Vries H. The impact of a computer-tailored nutrition intervention. Preventive medicine. 1996;25(3):236-42.

64. Campbell MK, DeVellis BM, Strecher VJ, Ammerman AS, DeVellis RF, Sandler RS. Improving dietary behavior: the effectiveness of tailored messages in primary care settings. American journal of public health. 1994;84(5):783-7.

65. Skinner CS, Strecher VJ, Hospers H. Physicians' recommendations for mammography: do tailored messages make a difference? American journal of public health. 1994;84(1):43-9. 
66. Brug J, Glanz K, Van Assema P, Kok G, van Breukelen GJ. The impact of computer-tailored feedback and iterative feedback on fat, fruit, and vegetable intake. Health education \& behavior : the official publication of the Society for Public Health Education. 1998;25(4):517-31.

67. Nielsen DE, El-Sohemy A. A randomized trial of genetic information for personalized nutrition. Genes \& nutrition. 2012;7(4):559-66.

68. Kreuter MW, Scharff DP, Brennan LK, Lukwago SN. Physician recommendations for diet and physical activity: which patients get advised to change? Preventive medicine. 1997;26(6):825-33.

69. Kreuter MW, Brennan LK, Scharff DP, Lukwago SN. Do nutrition label readers eat healthier diets? Behavioral correlates of adults' use of food labels. American journal of preventive medicine. 1997;13(4):277-83.

70. Eyles HC, Mhurchu CN. Does tailoring make a difference? A systematic review of the long-term effectiveness of tailored nutrition education for adults. Nutr Rev. 2009;67(8):464-80.

71. Krebs P, Prochaska JO, Rossi JS. A meta-analysis of computer-tailored interventions for health behavior change. Preventive medicine. 2010;51(3-4):214-21.

72. Kroeze W, Werkman A, Brug J. A systematic review of randomized trials on the effectiveness of computer-tailored education on physical activity and dietary behaviors. Annals of behavioral medicine : a publication of the Society of Behavioral Medicine. 2006;31(3):205-23.

73. Lustria ML, Cortese J, Noar SM, Glueckauf RL. Computer-tailored health interventions delivered over the Web: review and analysis of key components. Patient education and counseling. 2009;74(2):156-73.

74. Neville LM, Milat AJ, O'Hara B. Computer-tailored weight reduction interventions targeting adults: a narrative systematic review. Health promotion journal of Australia : official journal of Australian Association of Health Promotion Professionals. 2009;20(1):48-57.

75. Neville LM, O'Hara B, Milat A. Computer-tailored physical activity behavior change interventions targeting adults: a systematic review. The international journal of behavioral nutrition and physical activity. 2009;6:30.

76. Neville LM, O'Hara B, Milat AJ. Computer-tailored dietary behaviour change interventions: a systematic review. Health education research. 2009;24(4):699-720.

77. Noar SM, Benac CN, Harris MS. Does tailoring matter? Meta-analytic review of tailored print health behavior change interventions. Psychological bulletin. 2007;133(4):673-93.

78. Yap TL, Davis LS. Physical activity: the science of health promotion through tailored messages. Rehabilitation nursing : the official journal of the Association of Rehabilitation Nurses. 2008;33(2):55-62.

79. Broekhuizen K, Kroeze W, van Poppel MN, Oenema A, Brug J. A systematic review of randomized controlled trials on the effectiveness of computer-tailored physical activity and dietary behavior promotion programs: an update. Annals of behavioral medicine : a publication of the Society of Behavioral Medicine. 2012;44(2):259-86.

80. Internet World Stats: World Internet Users and 2015 Population Stats 2015 [cited 201531 Aug]. Available from: http://www.internetworldstats.com/stats.htm.

81. Leung L. Internet embeddedness: links with online health information seeking, expectancy value/quality of health information websites, and Internet usage patterns. Cyberpsychology \& behavior : the impact of the Internet, multimedia and virtual reality on behavior and society. 2008;11(5):565-9.

82. Tu HT, Cohen GR. Striking jump in consumers seeking health care information. Tracking report / Center for Studying Health System Change. 2008(20):1-8.

83. Brouwer W, Oenema A, Raat H, Crutzen R, de Nooijer J, de Vries NK, et al. Characteristics of visitors and revisitors to an Internet-delivered computer-tailored lifestyle intervention implemented for use by the general public. Health education research. 2010;25(4):585-95.

84. Brug J, Oenema A, Campbell M. Past, present, and future of computer-tailored nutrition education. The American journal of clinical nutrition. 2003;77(4 Suppl):1028S-34S.

85. Brug J, Oenema A, Kroeze W, Raat H. The internet and nutrition education: challenges and opportunities. European journal of clinical nutrition. 2005;59 Suppl 1:S130-7; discussion S8-9. 
86. Evers KE, Prochaska JM, Prochaska JO, Driskell MM, Cummins CO, Velicer WF. Strengths and weaknesses of health behavior change programs on the internet. Journal of health psychology. 2003;8(1):63-70.

87. Celis-Morales C, Lara J, Mathers JC. Personalising nutritional guidance for more effective behaviour change. Proc Nutr Soc. 2015;74(2):130-8.

88. Antypas K, Wangberg SC. An Internet- and mobile-based tailored intervention to enhance maintenance of physical activity after cardiac rehabilitation: short-term results of a randomized controlled trial. Journal of medical Internet research. 2014;16(3):e77.

89. Ashe M, Winters M, Hoppmann C, Dawes M, Gardiner P, Giangregorio L, et al. "Not just another walking program": Everyday Activity Supports You (EASY) model--a randomized pilot study for a parallel randomized controlled trial. Pilot and Feasibility Studies. 2015;1(1):4.

90. Block G, Azar KM, Romanelli RJ, Block TJ, Hopkins D, Carpenter HA, et al. Diabetes Prevention and Weight Loss with a Fully Automated Behavioral Intervention by Email, Web, and Mobile Phone: A Randomized Controlled Trial Among Persons with Prediabetes. Journal of medical Internet research. 2015;17(10):e240.

91. Bosak KA, Yates B, Pozehl B. Effects of an Internet physical activity intervention in adults with metabolic syndrome. Western journal of nursing research. 2010;32(1):5-22.

92. Carlson JA, Sallis JF, Ramirez ER, Patrick K, Norman GJ. Physical activity and dietary behavior change in Internet-based weight loss interventions: comparing two multiple-behavior change indices. Preventive medicine. 2012;54(1):50-4.

93. Carr LJ, Bartee RT, Dorozynski C, Broomfield JF, Smith ML, Smith DT. Internet-delivered behavior change program increases physical activity and improves cardiometabolic disease risk factors in sedentary adults: results of a randomized controlled trial. Preventive medicine. 2008;46(5):431-8.

94. Cheung PYP, Chow BC, Parfitt G. Using Environmental Stimuli in Physical Activity Intervention for School Teachers: A Pilot Study. International Electronic Journal of Health Education. 2008;11:4756.

95. De Cocker K, Spittaels H, Cardon G, De Bourdeaudhuij I, Vandelanotte C. Web-based, computertailored, pedometer-based physical activity advice: development, dissemination through general practice, acceptability, and preliminary efficacy in a randomized controlled trial. Journal of medical Internet research. 2012;14(2):e53.

96. Dunton GF, Robertson TP. A tailored Internet-plus-email intervention for increasing physical activity among ethnically-diverse women. Preventive medicine. 2008;47(6):605-11.

97. Fjeldsoe BS, Miller YD, Marshall AL. MobileMums: a randomized controlled trial of an SMS-based physical activity intervention. Annals of behavioral medicine : a publication of the Society of Behavioral Medicine. 2010;39(2):101-11.

98. Frederix I, Hansen D, Coninx K, Vandervoort P, Vandijck D, Hens N, et al. Medium-Term Effectiveness of a Comprehensive Internet-Based and Patient-Specific Telerehabilitation Program With Text Messaging Support for Cardiac Patients: Randomized Controlled Trial. Journal of medical Internet research. 2015;17(7):e185.

99. Glasgow RE, Kurz D, King D, Dickman JM, Faber AJ, Halterman E, et al. Outcomes of minimal and moderate support versions of an internet-based diabetes self-management support program. Journal of general internal medicine. 2010;25(12):1315-22.

100. Glasgow RE, Kurz D, King D, Dickman JM, Faber AJ, Halterman E, et al. Twelve-month outcomes of an Internet-based diabetes self-management support program. Patient education and counseling. 2012;87(1):81-92.

101. Hageman PA, Walker SN, Pullen $\mathrm{CH}$. Tailored versus standard internet-delivered interventions to promote physical activity in older women. Journal of geriatric physical therapy. 2005;28(1):28-33.

102. Hansen AW, Gronbaek M, Helge JW, Severin M, Curtis T, Tolstrup JS. Effect of a Web-based intervention to promote physical activity and improve health among physically inactive adults: a population-based randomized controlled trial. Journal of medical Internet research. 2012;14(5):e145. 
103. Huang SJ, Hung WC, Chang M, Chang J. The effect of an internet-based, stage-matched message intervention on young Taiwanese women's physical activity. Journal of health communication. 2009;14(3):210-27.

104. Hurling R, Catt M, Boni MD, Fairley BW, Hurst T, Murray P, et al. Using internet and mobile phone technology to deliver an automated physical activity program: randomized controlled trial. Journal of medical Internet research. 2007;9(2):e7.

105. Kattelmann KK, Bredbenner CB, White AA, Greene GW, Hoerr SL, Kidd T, et al. The effects of Young Adults Eating and Active for Health (YEAH): a theory-based Web-delivered intervention. Journal of nutrition education and behavior. 2014;46(6):S27-41.

106. Kirwan M, Duncan MJ, Vandelanotte C, Mummery WK. Using smartphone technology to monitor physical activity in the 10,000 Steps program: a matched case-control trial. Journal of medical Internet research. 2012;14(2):e55.

107. Kosma M, Cardinal BJ, McCubbin JA. A pilot study of a web-based physical activity motivational program for adults with physical disabilities. Disability and rehabilitation. 2005;27(23):1435-42.

108. Liebreich T, Plotnikoff RC, Courneya KS, Boule N. Diabetes NetPLAY: A physical activity website and linked email counselling randomized intervention for individuals with type 2 diabetes. The international journal of behavioral nutrition and physical activity. 2009;6:18.

109. Lorig K, Ritter PL, Laurent DD, Plant K, Green M, Jernigan VB, et al. Online diabetes selfmanagement program: a randomized study. Diabetes care. 2010;33(6):1275-81.

110. Lorig KR, Ritter PL, Laurent DD, Plant K. The internet-based arthritis self-management program: a one-year randomized trial for patients with arthritis or fibromyalgia. Arthritis and rheumatism. 2008;59(7):1009-17.

111. Mailey EL, Wojcicki TR, Motl RW, Hu L, Strauser DR, Collins KD, et al. Internet-delivered physical activity intervention for college students with mental health disorders: a randomized pilot trial. Psychology, health \& medicine. 2010;15(6):646-59.

112. Marcus BH, Lewis BA, Williams DM, Dunsiger S, Jakicic JM, Whiteley JA, et al. A comparison of Internet and print-based physical activity interventions. Archives of internal medicine. 2007;167(9):944-9.

113. Marsaux CF, Celis-Morales C, Fallaize R, Macready AL, Kolossa S, Woolhead C, et al. Effects of a Web-Based Personalized Intervention on Physical Activity in European Adults: A Randomized Controlled Trial. Journal of medical Internet research. 2015;17(10):e231.

114. Marshall AL, Leslie ER, Bauman AE, Marcus BH, Owen N. Print versus website physical activity programs: a randomized trial. American journal of preventive medicine. 2003;25(2):88-94.

115. McKay HG, King D, Eakin EG, Seeley JR, Glasgow RE. The diabetes network internet-based physical activity intervention: a randomized pilot study. Diabetes care. 2001;24(8):1328-34.

116. Mistry CD, Sweet SN, Rhodes RE, Latimer-Cheung AE. Text2Plan: Exploring changes in the quantity and quality of action plans and physical activity in a text messaging intervention. Psychology \& health. 2015;30(7):839-56.

117. Morgan PJ, Collins CE, Plotnikoff RC, Cook AT, Berthon B, Mitchell S, et al. Efficacy of a workplace-based weight loss program for overweight male shift workers: the Workplace POWER (Preventing Obesity Without Eating like a Rabbit) randomized controlled trial. Preventive medicine. 2011;52(5):317-25.

118. Morgan PJ, Lubans DR, Collins CE, Warren JM, Callister R. The SHED-IT randomized controlled trial: evaluation of an Internet-based weight-loss program for men. Obesity (Silver Spring). 2009;17(11):2025-32.

119. Motl RW, Dlugonski D, Wojcicki TR, McAuley E, Mohr DC. Internet intervention for increasing physical activity in persons with multiple sclerosis. Mult Scler. 2011;17(1):116-28.

120. Napolitano MA, Fotheringham M, Tate D, Sciamanna C, Leslie E, Owen N, et al. Evaluation of an internet-based physical activity intervention: a preliminary investigation. Annals of behavioral medicine : a publication of the Society of Behavioral Medicine. 2003;25(2):92-9.

121. Nguyen HQ, Gill DP, Wolpin S, Steele BG, Benditt JO. Pilot study of a cell phone-based exercise persistence intervention post-rehabilitation for COPD. International journal of chronic obstructive pulmonary disease. 2009;4:301-13. 
122. Oenema A, Brug J, Dijkstra A, de Weerdt I, de Vries H. Efficacy and use of an internet-delivered computer-tailored lifestyle intervention, targeting saturated fat intake, physical activity and smoking cessation: a randomized controlled trial. Annals of behavioral medicine : a publication of the Society of Behavioral Medicine. 2008;35(2):125-35.

123. Ornes L, Ransdell LB. Web-Based Physical Activity Intervention for College-Aged Women. International Electronic Journal of Health Education. 2007;10:126-37.

124. Patrick K, Calfas KJ, Norman GJ, Rosenberg D, Zabinski MF, Sallis JF, et al. Outcomes of a 12-month web-based intervention for overweight and obese men. Annals of behavioral medicine : a publication of the Society of Behavioral Medicine. 2011;42(3):391-401.

125. Plotnikoff RC, McCargar LJ, Wilson PM, Loucaides CA. Efficacy of an E-mail intervention for the promotion of physical activity and nutrition behavior in the workplace context. American journal of health promotion : AJHP. 2005;19(6):422-9.

126. Sirriyeh R, Lawton R, Ward J. Physical activity and adolescents: an exploratory randomized controlled trial investigating the influence of affective and instrumental text messages. British journal of health psychology. 2010;15(Pt 4):825-40.

127. Slootmaker SM, Chinapaw MJ, Schuit AJ, Seidell JC, Van Mechelen W. Feasibility and effectiveness of online physical activity advice based on a personal activity monitor: randomized controlled trial. Journal of medical Internet research. 2009;11(3):e27.

128. Smith DT, Carr LJ, Dorozynski C, Gomashe C. Internet-delivered lifestyle physical activity intervention: limited inflammation and antioxidant capacity efficacy in overweight adults. J Appl Physiol (1985). 2009;106(1):49-56.

129. Spittaels H, De Bourdeaudhuij I, Brug J, Vandelanotte C. Effectiveness of an online computertailored physical activity intervention in a real-life setting. Health education research. 2007;22(3):385-96.

130. Spittaels H, De Bourdeaudhuij I, Vandelanotte C. Evaluation of a website-delivered computertailored intervention for increasing physical activity in the general population. Preventive medicine. 2007;44(3):209-17.

131. Thorndike AN, Sonnenberg L, Healey E, Myint UK, Kvedar JC, Regan S. Prevention of weight gain following a worksite nutrition and exercise program: a randomized controlled trial. American journal of preventive medicine. 2012;43(1):27-33.

132. van den Berg MH, Ronday HK, Peeters AJ, le Cessie S, van der Giesen FJ, Breedveld FC, et al. Using internet technology to deliver a home-based physical activity intervention for patients with rheumatoid arthritis: A randomized controlled trial. Arthritis and rheumatism. 2006;55(6):935-45.

133. van Genugten L, van Empelen P, Boon B, Borsboom G, Visscher T, Oenema A. Results from an online computer-tailored weight management intervention for overweight adults: randomized controlled trial. Journal of medical Internet research. 2012;14(2):e44.

134. Wanner M, Martin-Diener E, Braun-Fahrlander C, Bauer G, Martin BW. Effectiveness of activeonline, an individually tailored physical activity intervention, in a real-life setting: randomized controlled trial. Journal of medical Internet research. 2009;11(3):e23.

135. Wijsman CA, Westendorp RG, Verhagen EA, Catt M, Slagboom PE, de Craen AJ, et al. Effects of a web-based intervention on physical activity and metabolism in older adults: randomized controlled trial. Journal of medical Internet research. 2013;15(11):e233.

136. Winett RA, Anderson ES, Wojcik JR, Winett SG, Bowden T. Guide to health: nutrition and physical activity outcomes of a group-randomized trial of an Internet-based intervention in churches. Annals of behavioral medicine : a publication of the Society of Behavioral Medicine. 2007;33(3):25161.

137. Winett RA, Anderson ES, Wojcik JR, Winett SG, Moore S, Blake C. Guide to Health: A Randomized Controlled Trial of the Effects of a Completely WEB-Based Intervention on Physical Activity, Fruit and Vegetable Consumption, and Body Weight. Translational behavioral medicine. 2011;1(1):165-74.

138. Zutz A, Ignaszewski A, Bates J, Lear SA. Utilization of the internet to deliver cardiac rehabilitation at a distance: a pilot study. Telemedicine journal and e-health : the official journal of the American Telemedicine Association. 2007;13(3):323-30. 
139. Davies CA, Spence JC, Vandelanotte C, Caperchione CM, Mummery WK. Meta-analysis of internet-delivered interventions to increase physical activity levels. The international journal of behavioral nutrition and physical activity. 2012;9:52.

140. Franklin NC, Lavie CJ, Arena RA. Personal health technology: A new era in cardiovascular disease prevention. Postgraduate medicine. 2015;127(2):150-8.

141. Bock C, Jarczok MN, Litaker D. Community-based efforts to promote physical activity: a systematic review of interventions considering mode of delivery, study quality and population subgroups. Journal of science and medicine in sport / Sports Medicine Australia. 2014;17(3):27682.

142. Collins F. Has the revolution arrived? Nature. 2010;464(7289):674-5.

143. Marteau TM, French DP, Griffin SJ, Prevost AT, Sutton S, Watkinson C, et al. Effects of communicating DNA-based disease risk estimates on risk-reducing behaviours. The Cochrane database of systematic reviews. 2010(10):CD007275.

144. Loos RJ, Bouchard C. FTO: the first gene contributing to common forms of human obesity. Obes Rev. 2008;9(3):246-50.

145. Loos RJ, Yeo GS. The bigger picture of FTO: the first GWAS-identified obesity gene. Nature reviews Endocrinology. 2014;10(1):51-61.

146. Frayling TM, Timpson NJ, Weedon MN, Zeggini E, Freathy RM, Lindgren CM, et al. A common variant in the FTO gene is associated with body mass index and predisposes to childhood and adult obesity. Science. 2007;316(5826):889-94.

147. Andreasen $\mathrm{CH}$, Stender-Petersen KL, Mogensen MS, Torekov SS, Wegner L, Andersen G, et al. Low physical activity accentuates the effect of the FTO rs9939609 polymorphism on body fat accumulation. Diabetes. 2008;57(1):95-101.

148. Demerath EW, Lutsey PL, Monda KL, Linda Kao WH, Bressler J, Pankow JS, et al. Interaction of FTO and physical activity level on adiposity in African-American and European-American adults: the ARIC study. Obesity (Silver Spring). 2011;19(9):1866-72.

149. Jonsson A, Renstrom F, Lyssenko V, Brito EC, Isomaa B, Berglund G, et al. Assessing the effect of interaction between an FTO variant (rs9939609) and physical activity on obesity in 15,925 Swedish and 2,511 Finnish adults. Diabetologia. 2009;52(7):1334-8.

150. Kilpelainen TO, Qi L, Brage S, Sharp SJ, Sonestedt E, Demerath E, et al. Physical activity attenuates the influence of FTO variants on obesity risk: a meta-analysis of 218,166 adults and 19,268 children. PLoS Med. 2011;8(11):e1001116.

151. Rampersaud E, Mitchell BD, Pollin TI, Fu M, Shen H, O'Connell JR, et al. Physical activity and the association of common FTO gene variants with body mass index and obesity. Archives of internal medicine. 2008;168(16):1791-7.

152. Vimaleswaran KS, Li S, Zhao JH, Luan J, Bingham SA, Khaw KT, et al. Physical activity attenuates the body mass index-increasing influence of genetic variation in the FTO gene. The American journal of clinical nutrition. 2009;90(2):425-8.

153. Meisel SF, Beeken RJ, van Jaarsveld $\mathrm{CH}$, Wardle J. Genetic susceptibility testing and readiness to control weight: Results from a randomized controlled trial. Obesity (Silver Spring). 2015;23(2):305-12.

154. Celis-Morales C, Livingstone KM, Marsaux CF, Forster H, O'Donovan CB, Woolhead C, et al. Design and baseline characteristics of the Food4Me study: a web-based randomised controlled trial of personalised nutrition in seven European countries. Genes \& nutrition. 2015;10(1):450. 


\section{CHAPTER}

\section{Objectively measured physical activity in European adults: cross-sectional findings from the Food4Me Study}

Marsaux CF, Celis-Morales C, Hoonhout J, Claassen A, Goris A, Forster $\mathrm{H}$, Fallaize $\mathrm{R}$, Macready AL, Navas-Carretero S, Kolossa S, Walsh MC, Lambrinou CP, Manios Y, Godlewska M, Traczyk I, Lovegrove JA, Martinez JA, Daniel H, Gibney M, Mathers JC, Saris WH

Accepted for publication in PLOS ONE 


\section{Abstract}

Background: Comparisons of objectively measured physical activity (PA) between residents of European countries measured concurrently with the same protocol are lacking. We aimed to compare PA between the seven European countries involved in the Food4Me Study, using accelerometer data collected remotely via the Internet. Methods: Of the 1607 participants recruited, 1287 (539 men and 748 women) provided at least 3 weekdays and 2 weekend days of valid accelerometer data (TracmorD) at baseline and were included in the present analyses. Results: Men were significantly more active than women (physical activity level $=1.74$ vs. $1.70, P<0.001$ ). Time spent in light PA and vigorous PA differed significantly between countries but only for women. Adherence to the World Health Organization recommendation to accumulate at least 150 min of moderate-equivalent PA weekly was similar between countries for men (range: 54-65\%) but differed significantly between countries for women (range: 26$49 \%$ ). Prevalence estimates decreased substantially for men and women in all seven countries when PA guidelines were defined as achieving $30 \mathrm{~min}$ of moderate and vigorous PA per day. Conclusions: We were able to obtain valid accelerometer data in real time via the Internet from $80 \%$ of participants. Although our estimates are higher compared with data from Sweden, Norway, Portugal and the US, there is room for improvement in PA for all countries involved in the Food4Me Study.

\section{Introduction}

Physical inactivity has been estimated to be responsible for more than 5.3 million deaths worldwide [1]. Moreover, among European men and women, approximately $7.3 \%$ of all deaths in 2008 might be attributable to inactivity compared with $3.7 \%$ to obesity [2] and there is strong evidence to suggest that even small increases in physical activity (PA) would lower the risk for many non-communicable diseases [1-3]. Yet, levels of PA across populations remain low [4]. To tackle this public health issue, the US Centers for Disease Control and Prevention and the American College of Sports Medicine produced standardized PA guidelines 20 years ago [5]. Since then, the World Health Organization (WHO), the European Union, and most countries around the world, have included PA guidelines in their health policies. Guidelines for Americans and Europeans have been updated to include recommendations for adolescents and for older adults [6-9]. For adults aged 18-64 years old, the WHO recommends a minimum of 150 min of moderate intensity PA per week, 75 min of vigorous intensity PA or an equivalent amount of moderate and vigorous PA (MVPA) [9]. 
In 2008, 34.8\% of adults 15 years or older were insufficiently active in Europe [4]. Regular surveillance is needed to update these prevalence estimates and to evaluate the effectiveness of PA policies and promotion programs in European countries. In this context, the objective assessment of PA is a key issue. Prevalence of physical inactivity has been mainly derived from self-reported measures such as the Baecke questionnaire [10] or the International Physical Activity Questionnaire (IPAQ) [11]. These questionnaires have been, and still are, widely used due to their simple administration and low cost [12]. However, PA is frequently misreported, which leads to considerable measurement error [13-15]. Accelerometers offer a potential solution because they measure PA objectively. Given that they are small and easy to wear, store data up to several weeks and are acceptable in terms of reliability, these devices are now used increasingly in large studies to assess PA in children, adolescents and adults [16]. Although some European countries have reported adherence to PA guidelines using accelerometers in large cohorts [17-19], comparisons between European countries measured according to the same standardized protocols and concurrently are lacking.

Between 2012 and 2014, PA was assessed objectively by accelerometry in the participants of the Food4Me Proof-of-Principle (PoP) study. The Food4Me Study was a web-based randomized controlled trial on personalized nutrition, across seven European countries: Germany, Greece, Ireland, The Netherlands, Poland, Spain and the United Kingdom. The aim of the current paper is to describe and compare PA in adults from these countries, and evaluate adherence to PA guidelines, using baseline data from the Food4Me PoP study.

\section{Methods}

\section{Subjects}

Subjects were participants in the Food4Me Proof-of-Principle (PoP) study (www.food4me.org), a multi-center randomized controlled trial on personalized nutrition (ClinicalTrials.gov, registration number: NCT01530139). A total of 1607 healthy adults (653 men and 954 women) from seven European countries (Germany, Greece, Ireland, The Netherlands, Poland, Spain, and the United Kingdom) were randomized to the study between August 2012 and August 2013. As outlined elsewhere [20], subjects were ineligible to take part in the study if they were $<18$ years of age, had no or limited access to the Internet, were following a prescribed diet, or had altered nutritional requirements because of medical conditions. Subjects were recruited locally and 
nationally via the Internet, radio, newspapers, posters, flyers, social media and word of mouth. The ethics committee from each recruiting center (Technische Universität München, Harokopio University, University College Dublin, Maastricht University, Instytut Żywności i Żywienia, University of Navarra and University of Reading) approved the study protocol. All subjects provided informed written consent digitally before participating in the study.

\section{Study design}

The design of the Food4Me PoP study has been described elsewhere [20]. Briefly, the study was web-based and therefore participants did not visit the recruiting centers. Anthropometric measurements were completed at home and questionnaires completed online. Participants received study kits by post, containing all necessary materials (including an accelerometer) to perform measurements at home, but used their own scales to measure body weight. Printed instructions were included in the kits and participants were reminded that explanatory videos demonstrating each measurement were also available on the Food4Me website. On the morning of their baseline measurement day, fasted participants self-measured their height, weight and waist circumference, and uploaded their measurement values directly on their personal Food4Me web page. In addition, they started wearing an accelerometer. The baseline PA assessment period lasted 2-3 weeks at which time participants were instructed to upload their accelerometer data to the Food4Me website using their own computer (See the 'objective PA assessment' section below). Validation of self-reported sociodemographic and anthropometric measures has been reported previously [21].

\section{Objective physical activity assessment}

\section{Physical activity monitoring}

PA was objectively assessed using the TracmorD tri-axial accelerometer (Philips Consumer Lifestyle, The Netherlands; http://www.directlife.philips.com) [22]. The device is small $(3.2 \times 3.2 \times 0.5 \mathrm{~cm})$, light $(12.5 \mathrm{~g})$, waterproof to a depth of $30 \mathrm{~m}$, has a battery life of 3 weeks and an internal memory that can store data for up to 22 weeks. The accelerometer registers accelerations in the mediolateral ( $x$-axis), longitudinal ( $y$-axis) and anterioposterior (z-axis) axes [22] as the number of activity counts per minute.

In the present study, participants received the TracmorD accelerometer by post and activated it by creating an account online, installing an application on their computer and connecting the device to the computer using the USB-adapter provided. Upon activation, men could choose between three wearing positions (pocket, belt or 
necklace) and women between four wearing positions (pocket, belt, necklace or bra). Participants were instructed to wear the accelerometer every day during waking hours, except when taking a shower. Participants uploaded data by connecting their monitor to their computer. The data transferred were stored on a secured server.

\section{Physical activity data processing}

Data were recorded with a time sampling interval of 1 min (i.e. 1-min epochs). Sufficient PA data to be included in the analyses was defined as having at least 3 valid weekdays and 2 valid weekend days of accelerometer wear, since PA patterns may vary between week and weekend $[23,24]$. A day was considered valid if the participant had worn the TracmorD between 10-18 hours. Wear time was defined as 24 hours minus non-wear time. To define non-wear time, we adapted the recommendations of Choi et al. [25] to the TracmorD. Physical activity level (PAL) per minute and per day were estimated from activity counts [22]. Non-wear time was then defined by an interval of at least 90 consecutive minutes of PAL per minute values below 1.3889, allowing for 2-min interval of values above the threshold with the upstream or downstream 30-min window of consecutive values below the threshold for detection of artifactual movements. The $R$ software [26] version 3.1.2 was used for all data handling.

\section{Physical activity variables}

PA is presented in several ways: 1 ) daily PAL, 2) estimates of time spent in different PA intensities according to metabolic equivalent thresholds (METs), and 3) estimates of adherence to the latest WHO physical activity recommendation [9] and of adherence to

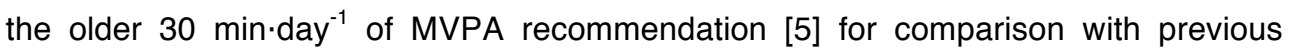
studies.

PAL per day calculations are based upon that described by Bonomi et al. [22]. Mean PAL was calculated using all valid week and weekend days, as follows: mean = (mean for weekdays $\times 5+$ mean for weekend days $\times 2$ ) $/ 7$.

Times spent in sedentary behavior, light PA, moderate PA, and vigorous PA were based on the application of thresholds for activity energy expenditure (AEE) corresponding to 1.5, 3 and 6 metabolic equivalents (METs). A MET represents the ratio of energy expended divided by resting energy expenditure and was estimated as 1 $\mathrm{kcal} \cdot \mathrm{kg}^{-1} \cdot \mathrm{h}^{-1}$ [27]. 1.5, 3 and 6 METs were therefore assumed to equal $1.5,3$ and 6 $\mathrm{kcal} \cdot \mathrm{kg}^{-1} \cdot \mathrm{h}^{-1}$ respectively or $0.025,0.05$ and $0.1 \mathrm{kcal} \cdot \mathrm{kg}^{-1} \cdot \mathrm{min}^{-1}$. AEE per minute data were calculated as: $(0.9 \times \mathrm{PAL}$ per minute -1$) \times \mathrm{BMR} / 1440$, where PAL per minute was derived from accelerometer activity counts per minute, and BMR is the daily basal metabolic rate estimated using the Oxford equations developed by Henry, based on the 
participants' sex, age and weight at baseline [28]. Sedentary time and light, moderate, and vigorous PA were then determined by summing minutes in a day where AEE per minute met the criterion for the appropriate intensity, and mean data were calculated using all valid week and weekend days as follows: mean $=$ (mean for weekdays $\times 5+$ mean for weekend days $\times 2$ ) $/ 7$.

Finally, to examine adherence to PA guidelines, moderate PA and vigorous PA duration data were also calculated for activity occurring in modified bouts of $10 \mathrm{~min}$. A modified 10 -min activity bout was defined as 10 or more consecutive minutes above the relevant threshold ( 3 or 6 METs), with allowance for interruptions of 1 or 2 min below threshold [29]. Adherence to the WHO PA recommendation was then examined by estimating the proportion of participants who accumulated at least $150 \mathrm{~min} \cdot \mathrm{wk}^{-1}$ of moderate PA or 75 min. $\mathrm{wk}^{-1}$ of vigorous PA or an equivalent combination of MVPA, in modified 10-min bouts [9]. This can be more simply formulated as achieving at least $150 \mathrm{~min} \cdot \mathrm{wk}^{-1}$ of moderate-equivalent PA, in modified 10-min bouts, where moderate-equivalent PA is defined as moderate $\mathrm{PA}+(2 \times$ vigorous $\mathrm{PA})$. For comparison with studies that defined adherence to PA guidelines as accumulating $30 \mathrm{~min} \cdot \mathrm{day}^{-1}$ of MVPA in modified 10-min bouts, the proportion of participants achieving such amount of MVPA was also estimated. MVPA was calculated as moderate PA + vigorous PA.

\section{Statistical analyses}

Data are presented by country for men and women separately. Categorical variables are given as percentages and continuous variables as adjusted mean \pm standard deviation (SD) unless otherwise stated. For all continuous variables, differences between men and women were examined using robust multiple linear regression models, based on computation of MM-type estimators [30], to account for the violation of the normality assumption. Differences in PA outcomes between countries were assessed with robust regression analyses stratified by sex. Models were adjusted for age, waist circumference (WC), season, accelerometer wear time and smoking. Significant associations between PA outcomes and country were further investigated using Tukey's post hoc tests between adjusted means, to correct for multiple testing. For men and women separately, differences in adherence to PA guidelines between countries were tested using binary logistic regression, with adjustments for age, WC, season, accelerometer wear time and smoking. Sensitivity analyses to compare dropouts with starters and compliant with less compliant individuals were carried out using robust t-tests (continuous variables) and chi-square tests (categorical variables). All analyses were performed using the $R$ software version 3.1 .2 [26] and the significance level was set at $P<0.05$. 


\section{Results}

\section{Compliance}

From the original 1607 eligible participants recruited into the PoP study, 127 (8\%) dropped out before the start of the intervention. These dropouts were more likely to be women $(P=0.014)$ and were significantly younger than the individuals who actually started the trial $(P<0.001)$. Neither group differed in BMI (data not shown). Of those who started the study, $43(3 \%)$ did not wear the accelerometer-mainly due to incompatibilities between the accelerometer software and their personal computer at home or work. Thus, 1437 participants wore the monitors and had at least one day of accelerometer data available.

Of these 1437 individuals, 1092 (76\%) had at least 3 valid weekdays and 2 valid weekend days of accelerometer wear in the 2 weeks baseline assessment period, (average number of valid days $=12$ days, consisting of 9 weekdays and 3 weekend days). To maximize sample size, we extended the assessment period to 3 weeks for participants with insufficient valid days, allowing 195 (14\%) additional individuals (average number of valid days $=9$ days, 6 weekdays and 3 weekend days). These 195 additional individuals were more likely to be men $(P=0.012)$. They were younger $(P<$ 0.003), had a slightly higher BMI $(P=0.05)$ and had lower PAL $(P<0.001)$ compared with individuals who had sufficient valid PA data in the 2 weeks assessment period (data not shown). The proportion of individuals requiring 3 weeks assessment period was highest in Greece and lowest in The Netherlands $(P<0.001$, data not shown).

In total, 1287 individuals (age range: 18-79 years) were therefore included in the analyses $(90 \%$ of participants who started wearing the accelerometer). Dutch participants were the most compliant with $>97 \%$ having sufficient valid accelerometer data. In almost all countries, younger individuals (18-33 years) were less compliant than older participants (See Supplementary Material 2.1). Mean daily accelerometer wear time of the 1287 individuals included in the analyses was $14.4 \mathrm{~h}$. Wear time was similar between countries and between men and women. However, participants aged $49+$ years wore their accelerometer for more hours compared with younger individuals (data not shown). Compared with participants with sufficient PA data, individuals with some but insufficient data were younger $(P<0.001)$, but otherwise similar in BMI and were as likely to be men as women. However, the odds of having insufficient data were higher in Greece and lower in The Netherlands $(P=0.003)$. The characteristics of the analyzed sample are presented by sex and country in Table 2.1. 


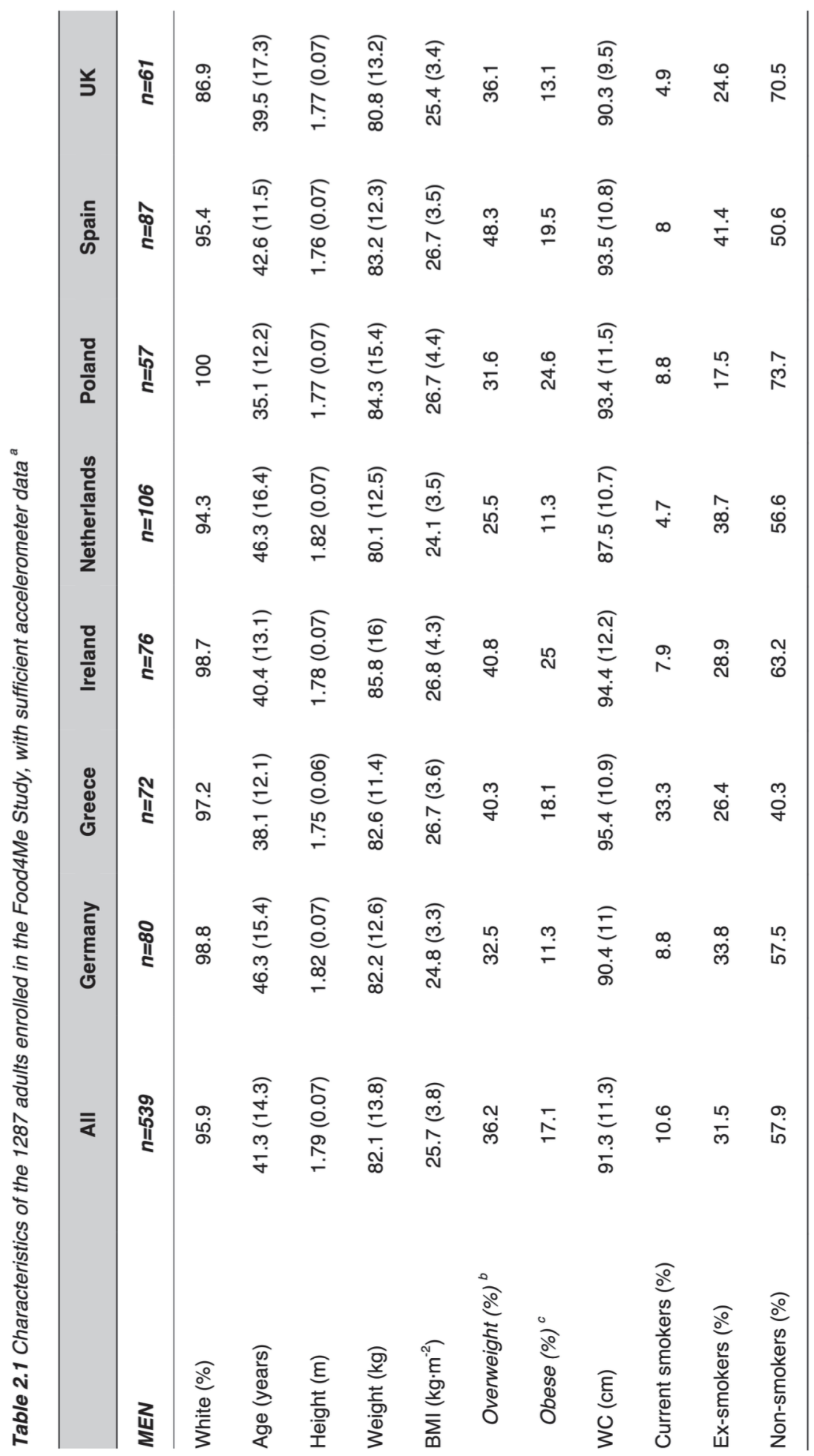




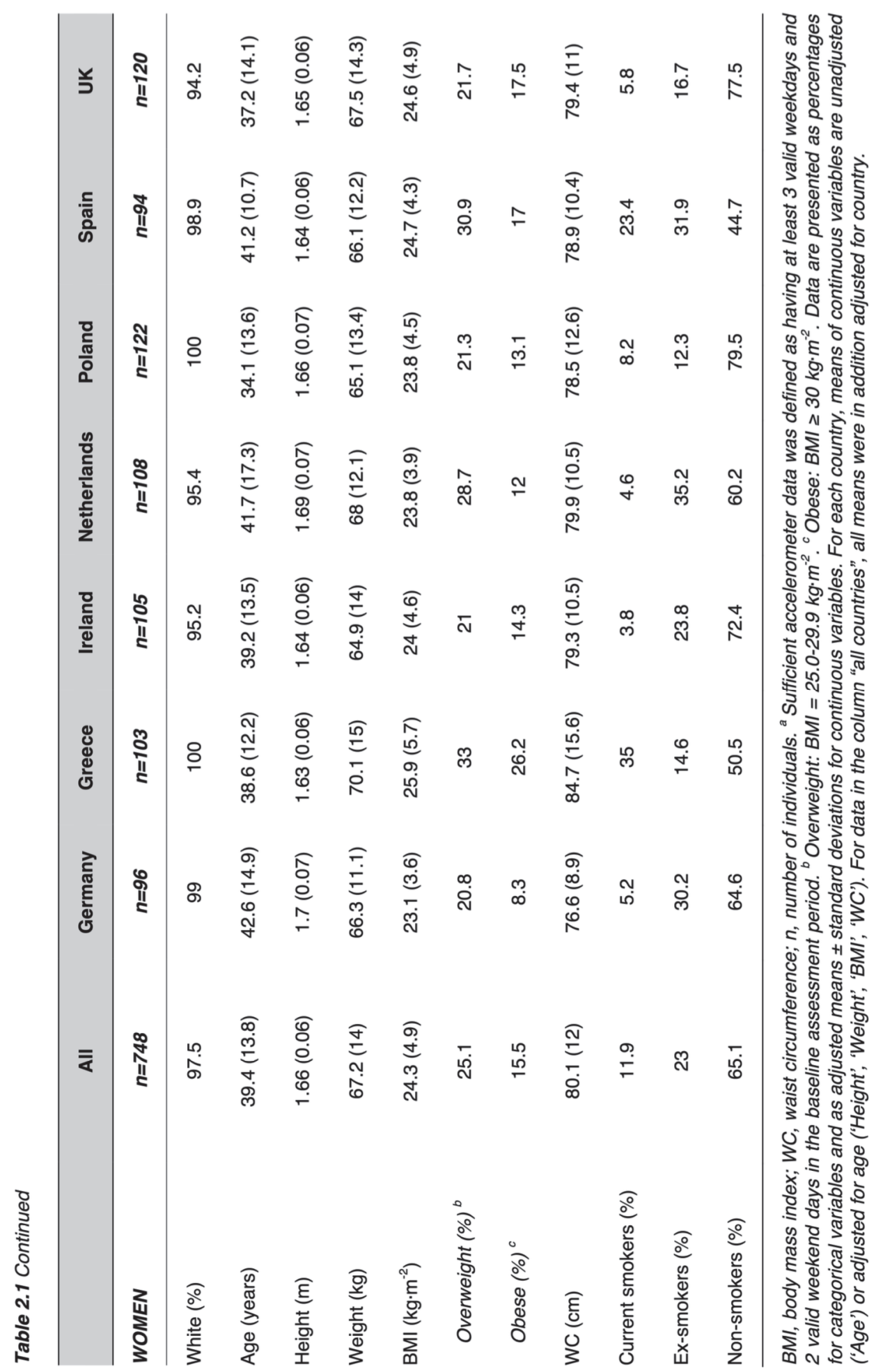




\section{Daily PAL}

Men in the Food4Me cohort had significantly higher PAL than women (1.74 \pm 0.19 vs. $1.70 \pm 0.15$, respectively, $P<0.001)$. For both sexes, there were no significant differences in PAL between countries (Figure 2.1a).

\section{Minutes of activity at different intensities}

Women spent more time in sedentary behaviors $(P<0.0001)$ and less time in light PA $(P=0.003)$, moderate PA and vigorous PA $(P<0.0001)$ daily compared with men, achieving for example on average $4 \pm 9 \mathrm{~min} \cdot \mathrm{d}^{-1}$ vigorous $P A$ compared with $11 \pm 25$ $\min \cdot \mathrm{d}^{-1}$ for men (Figure 2.1b). For both sexes, less than half MVPA occurred in modified 10-min bouts (data not shown). Although all participants recorded some moderate PA, $3.2 \%$ of men and $6.1 \%$ of women had $0 \mathrm{~min} \cdot \mathrm{d}^{-1}$ of vigorous PA. Furthermore, $7.1 \%$ of men and $10.6 \%$ of women did not achieve any moderate PA in modified $10-\mathrm{min}$ bouts, and $34.5 \%$ of men and $56.4 \%$ of women did not accumulate any vigorous PA in modified 10-min bouts (data not shown). Greek and Polish women achieved significantly less vigorous PA than women in the UK (Figure 2.1b, $P=0.026$ and $P=0.019$, respectively). In addition, for women, there were some borderline significant inter-country differences in light PA (Figure 2.1b): light PA ranged from 66 $\min \cdot d^{-1}$ in Spain and the UK to $77 \mathrm{~min} \cdot \mathrm{d}^{-1}$ in The Netherlands (NL) (Spain vs. NL, $P=$ 0.065 and UK vs. NL, $P=0.053)$. No significant differences between countries were observed for men (Figure 2.1b).

\section{Adherence to the PA guidelines}

\section{WHO PA recommendation}

Among adults, $46.9 \%$ achieved the amount of PA recommended by the WHO [9], i.e. at least 150 min.wk ${ }^{-1}$ of moderate-equivalent PA in modified 10-min bouts (men: $57.7 \%$ vs. women: $37.2 \% ; P<0.0001$, Figure 2.2). Women in Poland and Greece appeared less likely, while women in Ireland were more likely, to meet the WHO PA recommendations (borderline significance: $P=0.06$ and $P=0.1$, respectively; Figure 2 and see Supplementary Material 2.2). 


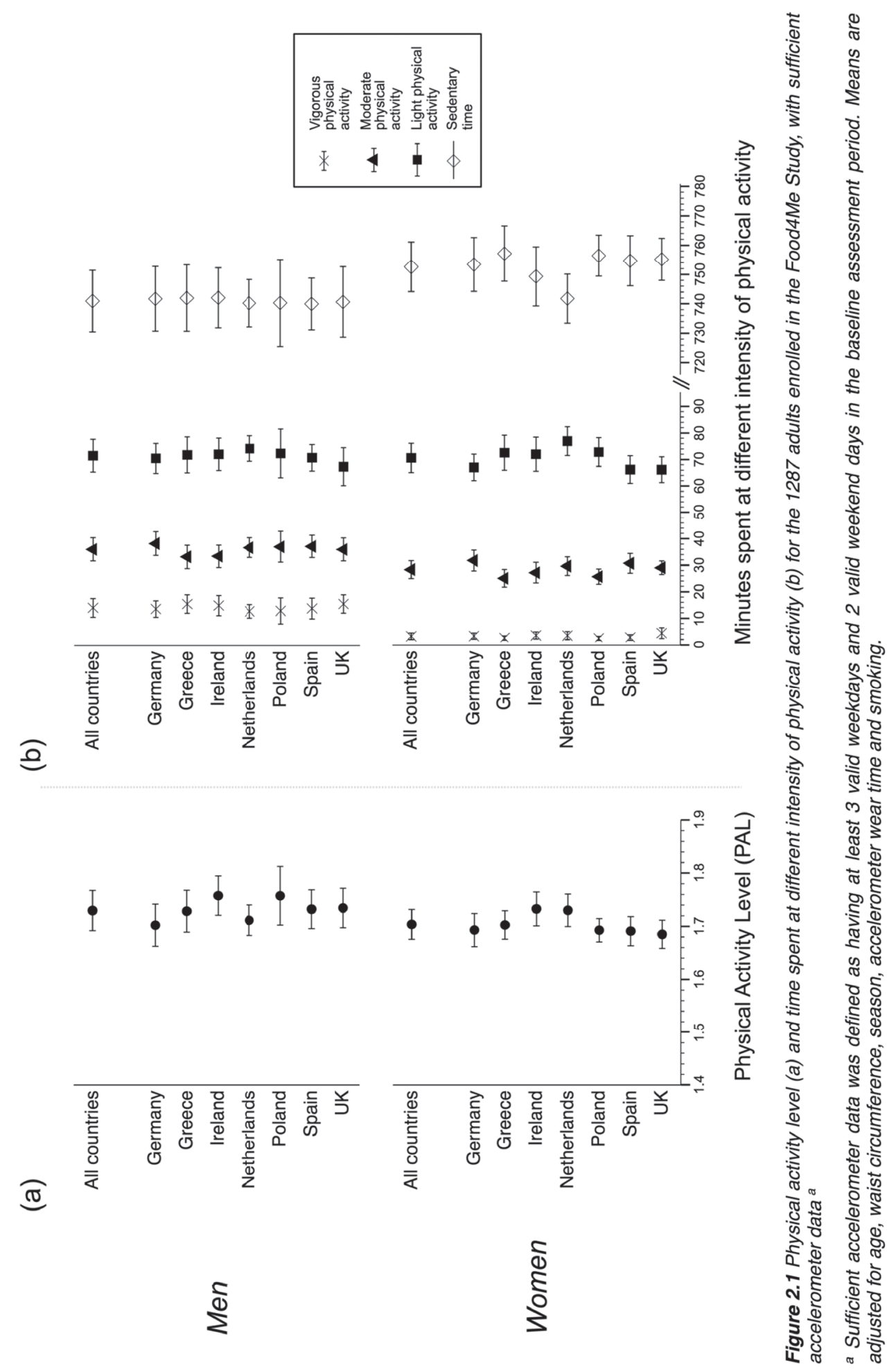




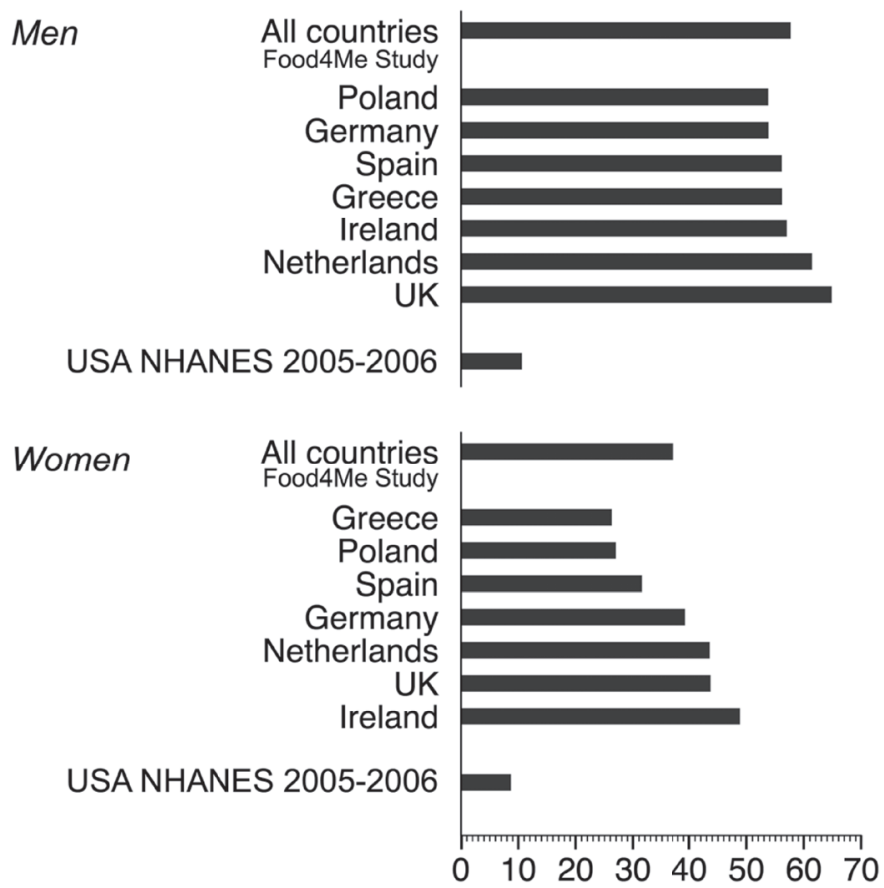

$(\%)$

Figure 2.2 Proportion of subjects meeting the World Health Organization (WHO) Physical Activity (PA) recommendations by country

WHO PA recommendations are defined as accumulating a minimum of $150 \mathrm{~min} \cdot \mathrm{wk}^{-1}$ of moderate $P A$ or $75 \mathrm{~min} \cdot \mathrm{wk}^{-1}$ of vigorous $P A$ or an equivalent combination of moderate and vigorous $P A$, in modified 10min bouts, i.e. bouts of 8-10 min. Mean prevalence estimates from the present study are adjusted for age, waist circumference, season, accelerometer wear time and smoking. Reference for USA NHANES 2005-2006: [31].

\section{$30 \mathrm{~min} \cdot \mathrm{d}^{-1} \mathrm{PA}$ recommendation}

When PA guidelines were defined as at least $30 \mathrm{~min} \cdot \mathrm{d}^{-1}$ of MVPA [5], prevalence estimates of meeting these guidelines were lower and ranged from $27.1 \%$ (Greece) to $46 \%$ (UK) for men and from $10.4 \%$ (Greece) to $25.6 \%$ (Ireland) for women. None of the inter-country differences reached statistical significance (Figure 2.3 and see Supplementary Material 2.3). 


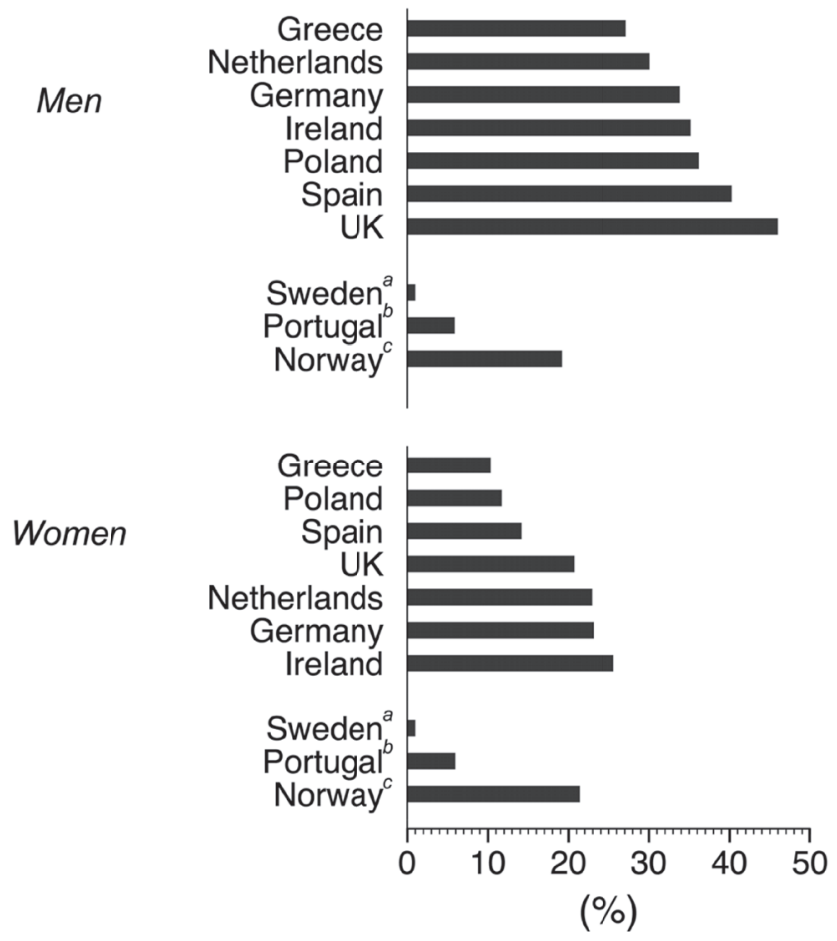

Figure 2.3 Proportion of subjects meeting the $30 \mathrm{~min} \cdot \mathrm{d}^{-1}$ physical activity recommendations by country

${ }^{a}$ Swedish data: Hagstömer et al. [18]; ${ }^{b}$ Portuguese data: Baptista et al. [17]; ${ }^{c}$ Norwegian data: Hansen et al. [19]; Prevalence estimates from the present study are adjusted for age, waist circumference, season, accelerometer wear time and smoking.

\section{Discussion}

The Food4Me Study demonstrated the feasibility of using Internet-collected and objectively measured physical activity data in large multi-country studies. In this trial we used the TracmorD accelerometer to compare PA among adults in 7 European countries.

The activity levels in our cohort are in line with what is expected for the average EU population. In 2010, Speakman and Westerterp described PAL data for more than 500 Dutch men and women above 18 years, using the gold standard doubly labeled water technique [32]. They showed an average PAL of 1.83 and 1.71 for men and women aged 18-69, respectively. Earlier, Black et al. had published similar PAL values after summarizing most doubly labeled water data available worldwide at the time (PAL of 1.79 and 1.69 for men and women aged 18-64, respectively) [33]. These data are comparable with our results. We found sex differences in PAL as well as in time spent 
in different activities. Men spent more time in MVPA and less time in sedentary behaviors than women, which is in line with the literature [4].

Furthermore, for women, we observed some between-country differences especially in vigorous PA. Consequently, there was a trend for women in Poland and Greece to be less likely to meet the WHO PA guidelines, compared with Irish women. Women in Greece and Poland reported doing less sport and being less active at work, compared with women in Ireland, which may explain in part these differences. Notably, $23 \%$ of female participants in Greece were housewives compared with $3-15 \%$ in the other countries data not shown).

The prevalence estimates of meeting the WHO guidelines reported for our sample are much higher than the $10.6 \%$ and $8.7 \%$ reported for US men and women respectively by Tucker et al. [31] using NHANES 2005-2006 data (Fig. 2). European adults may be more active than US adults [34]. For example, it has been shown that people in The Netherlands and Germany, but also UK and Ireland walk or cycle to work substantially more than in the USA [4]. However, part of the large differences observed may be because our sample is composed of self-selected individuals, interested in personalized nutrition and likely to be more health conscious and therefore more active, whereas the NHANES cohort is more representative of the general US population and includes a wider variety of individuals in terms of ethnicities, and socioeconomic status. In addition, prevalence of overweight and obesity, which is associated with lower PA, is higher in the USA than in most European countries.

Recent studies of proportions of European individuals meeting PA recommendations based on objectively measured PA are scarce. Estimates of adherence to PA guidelines based on accelerometers have been reported for Sweden [18], Norway [19], and Portugal [17]. However, meeting PA guidelines in these studies was defined as achieving $30 \mathrm{~min}$ of MVPA daily in 10-min bouts. Thus, for comparison purposes, we also calculated our estimates based on this definition because results have been shown to vary according to how meeting the guidelines is defined [31]. We observed that substantially more men in the Food4Me Study achieved $30 \mathrm{~min} \cdot \mathrm{d}^{-1}$ of MVPA, but our results were comparable with the Portuguese [17] and Norwegian [19] studies for women (Fig. 3). The Swedish study was conducted in 2001, which may partly explain the lower prevalence estimates of adherence [18]. Public awareness of increasing PA may have increased since then.

Running a large-scale study remotely is challenging, especially when there is an absence of face-to-face contact with the participants. Yet, compliance was good $(90 \%$ of participants completed the measurement). The number of issues was acceptable 
( $<15 \%$ of participants reported issues on average across all seven centers, range 5$20 \%$ ): there were very few logistical problems in the distribution of the monitors directly to participants' homes across seven European countries (5 monitors lost during shipment across all centers); accelerometers were tested before shipment and $<1 \%$ were returned and replaced due to malfunction (battery problem or defect USB adapter); the widest majority of participants could activate their device without support beyond the instructions provided $(90 \%)$ - there were some cases $(<10 \%)$ where the invitation email to activate the monitor had to be resent, or where the antivirus program on a participant's personal computer would not allow him/her to install the application required, but issues were rapidly solved. Researchers' quick responsiveness to participants' email enquiries, and their routine checks that monitors were activated and recording data properly, were key elements in the success of implementing this remote collection of accelerometer data via the Internet among participants recruited nationwide in seven European countries.

\section{Strengths and limitations}

Use of objective measurement monitors, remotely uploaded data and a high compliance rate were strengths of this study. Overall, our study shows that it is feasible to use accelerometers to collect PA data using the Internet in a large group of individuals, in multiple countries.

A limitation of our study is that the participants who joined the study were self-selected resulting in an element of selection bias as in many lifestyle intervention studies, including those which are web-based [35]. In the French NutriNet-Santé study, the recruited sample included proportionally 3 times as many individuals of relatively high socio-economic status as compared with national estimates [36]. The Food4Me PoP study required that participants be able to use a computer and Internet. Furthermore, by design, we recruited "health-seeking" individuals with an interest in personalized nutrition. These individuals are likely more active than the general population, which makes our results less generalizable compared with a European-wide, population representative, survey. Being part of the study and doing the measurements (e.g. selfweighing, wearing the accelerometer) could have influenced participants' physical activity pattern. However, this is a common reaction to behavioral interventions.

In addition, although accelerometry is an objective measure of PA, it does not capture well muscle-strengthening activities (such as lifting weights), which are, next to aerobic activities, another important dimension of PA recommendations. Accelerometers can also underestimate activities such as cycling. This may affect our results especially when making comparisons between countries, as people cycle more in The 
Netherlands, for example [4]. Whilst the TracmorD was able to measure body movement in three axes, it does not discriminate between walking uphill or on a flat surface. The device is waterproof however, and was used during swimming, but this activity may also be underestimated in terms of activity intensity. Furthermore, as pointed out by Troiano and colleagues in a recent review, evaluation of PA guidelines adherence based on accelerometer outcomes may be inappropriate because current guidelines were developed based on self-reports and not on accelerometer data [37]. Although this matters less when comparing between countries, PA guidelines based on accelerometer-derived measures are still urgently needed. A global repository of the rapidly growing pool of accelerometry data may be very helpful in this respect [16]. Selfreported PA and accelerometer-measured PA are not interchangeable but, in general, accelerometers provide more reliable data than self-reports [13,14]. The TracmorD used in this study has been validated against doubly labeled water and compared with other accelerometers such as those used in the studies mentioned above, and several publications show that it is a reliable and accurate monitor [22,38-40]. Accelerometers are becoming more pervasive as a tool for both surveys and for interventions aiming to promote public health and may be useful in motivating individuals to increase their PA.

\section{Conclusions}

We observed some inter-country differences in PA in participants in the Food4Me Study. The majority of men but not women met the WHO recommendations for PA. For all countries, fewer individuals achieved 30 minutes of MVPA daily. Thus, a large part of participants, especially women, would benefit from greater levels of PA. Finally, we showed that using accelerometers is feasible and the resultant data can be collected remotely via the Internet in large multi-country surveys and interventions.

Acknowledgments: The authors wish to thank all participants of the Food4Me Proof-ofPrinciple study as well as all staff involved in data collection. The authors also wish to acknowledge Dr. Florian Caiment for programming support. 


\section{References}

1. Lee IM, Shiroma EJ, Lobelo F, Puska P, Blair SN, Katzmarzyk PT, et al. Effect of physical inactivity on major non-communicable diseases worldwide: an analysis of burden of disease and life expectancy. Lancet. 2012;380(9838):219-29.

2. Ekelund U, Ward HA, Norat T, Luan J, May AM, Weiderpass E, et al. Physical activity and all-cause mortality across levels of overall and abdominal adiposity in European men and women: the European Prospective Investigation into Cancer and Nutrition Study (EPIC). Am J Clin Nutr. 2015.

3. Blair SN, Cheng Y, Holder JS. Is physical activity or physical fitness more important in defining health benefits? Medicine and science in sports and exercise. 2001;33(6 Suppl):S379-99; discussion S419-20.

4. Hallal PC, Andersen LB, Bull FC, Guthold R, Haskell W, Ekelund U, et al. Global physical activity levels: surveillance progress, pitfalls, and prospects. Lancet. 2012;380(9838):247-57.

5. Pate RR, Pratt M, Blair SN, Haskell WL, Macera CA, Bouchard C, et al. Physical activity and public health. A recommendation from the Centers for Disease Control and Prevention and the American College of Sports Medicine. Jama. 1995;273(5):402-7.

6. Nelson ME, Rejeski WJ, Blair SN, Duncan PW, Judge JO, King AC, et al. Physical activity and public health in older adults: recommendation from the American College of Sports Medicine and the American Heart Association. Medicine and science in sports and exercise. 2007;39(8):1435-45.

7. Physical Activity Guidelines Advisory Committee. Physical Activity Guidelines Advisory Committee Report. Washington DC: U.S. Department of Health and Human Services, 2008.

8. EU Working Group "Sport \& Health". EU Physical Activity Guidelines - Recommended Policy Actions in Support of Health-Enhancing Physical Activity. Brussels 2008.

9. World Health Organization. Global recommendations on physical activity for health2010. 58 p.

10. Baecke JA, Burema J, Frijters JE. A short questionnaire for the measurement of habitual physical activity in epidemiological studies. Am J Clin Nutr. 1982;36(5):936-42.

11. Craig CL, Marshall AL, Sjostrom M, Bauman AE, Booth ML, Ainsworth BE, et al. International physical activity questionnaire: 12-country reliability and validity. Medicine and science in sports and exercise. 2003;35(8):1381-95.

12. Bauman A, Bull F, Chey T, Craig CL, Ainsworth BE, Sallis JF, et al. The International Prevalence Study on Physical Activity: results from 20 countries. The international journal of behavioral nutrition and physical activity. 2009;6:21.

13. Celis-Morales CA, Perez-Bravo F, Ibanez L, Salas C, Bailey ME, Gill JM. Objective vs. self-reported physical activity and sedentary time: effects of measurement method on relationships with risk biomarkers. PloS one. 2012;7(5):e36345.

14. Hagstromer M, Ainsworth BE, Oja P, Sjostrom M. Comparison of a subjective and an objective measure of physical activity in a population sample. Journal of physical activity \& health. 2010;7(4):541-50.

15. Prince SA, Adamo KB, Hamel ME, Hardt J, Connor Gorber S, Tremblay M. A comparison of direct versus self-report measures for assessing physical activity in adults: a systematic review. The international journal of behavioral nutrition and physical activity. 2008;5:56.

16. Wijndaele K, Westgate K, Stephens SK, Blair SN, Bull FC, Chastin SF, et al. Utilization and Harmonization of Adult Accelerometry Data: Review and Expert Consensus. Medicine and science in sports and exercise. 2015.

17. Baptista F, Santos DA, Silva AM, Mota J, Santos R, Vale S, et al. Prevalence of the Portuguese population attaining sufficient physical activity. Medicine and science in sports and exercise. 2012;44(3):466-73.

18. Hagstromer M, Oja P, Sjostrom M. Physical activity and inactivity in an adult population assessed by accelerometry. Medicine and science in sports and exercise. 2007;39(9):1502-8.

19. Hansen BH, Kolle E, Dyrstad SM, Holme I, Anderssen SA. Accelerometer-determined physical activity in adults and older people. Medicine and science in sports and exercise. 2012;44(2):266-72. 
20. Celis-Morales C, Livingstone KM, Marsaux CF, Forster H, O'Donovan CB, Woolhead C, et al. Design and baseline characteristics of the Food4Me study: a web-based randomised controlled trial of personalised nutrition in seven European countries. Genes \& nutrition. 2015;10(1):450.

21. Celis-Morales C, Livingstone KM, Woolhead C, Forster H, O'Donovan CB, Macready AL, et al. How reliable is internet-based self-reported identity, socio-demographic and obesity measures in European adults? Genes \& nutrition. 2015;10(5):476.

22. Bonomi AG, Plasqui G, Goris AH, Westerterp KR. Estimation of free-living energy expenditure using a novel activity monitor designed to minimize obtrusiveness. Obesity (Silver Spring). 2010;18(9):1845-51.

23. Matthews CE, Ainsworth BE, Thompson RW, Bassett DR, Jr. Sources of variance in daily physical activity levels as measured by an accelerometer. Medicine and science in sports and exercise. 2002;34(8):1376-81.

24. Van Domelen DR, Koster A, Caserotti P, Brychta RJ, Chen KY, McClain JJ, et al. Employment and physical activity in the U.S. American journal of preventive medicine. 2011;41(2):136-45.

25. Choi L, Liu Z, Matthews CE, Buchowski MS. Validation of accelerometer wear and nonwear time classification algorithm. Medicine and science in sports and exercise. 2011;43(2):357-64.

26. R Core Team. R: A language and Environment for Statistical Computing. R Foundation for Statistical Computing. 3.1.2 ed. Vienna, Austria2014.

27. Montoye HJ, Kemper HC, Saris WH, Washburn RA. Measuring Physical Activity and Energy Expenditure: Human Kinetics; 1996. 190 p.

28. Henry CJ. Basal metabolic rate studies in humans: measurement and development of new equations. Public health nutrition. 2005;8(7A):1133-52.

29. Troiano RP, Berrigan D, Dodd KW, Masse LC, Tilert T, McDowell M. Physical activity in the United States measured by accelerometer. Medicine and science in sports and exercise. 2008;40(1):181-8.

30. Rousseeuw P, Croux C, Todorov V, Ruckstuhl A, Salibian-Barrera M, Verbeke T, et al. robustbase: Basic Robust Statistics. R package version 0.92-5. 2015.

31. Tucker JM, Welk GJ, Beyler NK. Physical activity in U.S.: adults compliance with the Physical Activity Guidelines for Americans. American journal of preventive medicine. 2011;40(4):454-61.

32. Speakman JR, Westerterp KR. Associations between energy demands, physical activity, and body composition in adult humans between 18 and 96 y of age. The American journal of clinical nutrition. 2010;92(4):826-34.

33. Black AE, Coward WA, Cole TJ, Prentice AM. Human energy expenditure in affluent societies: an analysis of 574 doubly-labelled water measurements. Eur J Clin Nutr. 1996;50(2):72-92.

34. Hagstromer M, Troiano RP, Sjostrom M, Berrigan D. Levels and patterns of objectively assessed physical activity--a comparison between Sweden and the United States. American journal of epidemiology. 2010;171(10):1055-64.

35. Rothman KJ, Greenland S, Lash TL. Modern epidemiology: Lippincott Williams \& Wilkins; 2008.

36. Kesse-Guyot E, Andreeva V, Castetbon K, Vernay M, Touvier M, Mejean C, et al. Participant profiles according to recruitment source in a large Web-based prospective study: experience from the Nutrinet-Sante study. Journal of medical Internet research. 2013;15(9):e205.

37. Troiano RP, McClain JJ, Brychta RJ, Chen KY. Evolution of accelerometer methods for physical activity research. British journal of sports medicine. 2014;48(13):1019-23.

38. Dannecker KL, Sazonova NA, Melanson EL, Sazonov ES, Browning RC. A comparison of energy expenditure estimation of several physical activity monitors. Medicine and science in sports and exercise. 2013;45(11):2105-12.

39. Plasqui G, Bonomi AG, Westerterp KR. Daily physical activity assessment with accelerometers: new insights and validation studies. Obes Rev. 2013;14(6):451-62.

40. Valenti G, Camps SG, Verhoef SP, Bonomi AG, Westerterp KR. Validating measures of free-living physical activity in overweight and obese subjects using an accelerometer. Int J Obes (Lond). 2014;38(7):1011-4. 


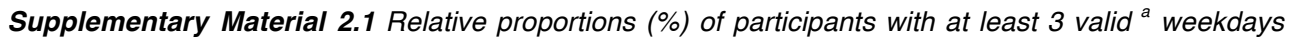
and 2 valid weekend days of accelerometer wear from the total number of participants with any accelerometer data (1437 individuals)

\begin{tabular}{lcccccccc}
\hline & All & Germany & Greece & Ireland & NL & Poland & Spain & UK \\
\hline MEN & & & & & & & & \\
\hline Total & 89.8 & 87.9 & 87.8 & 90.5 & 96.4 & 96.6 & 84.5 & 85.9 \\
Age (years) & & & & & & & & \\
18-33 & 84.1 & 84.6 & 81.1 & 89.7 & 88.9 & 96.6 & 73.1 & 75.8 \\
34-48 & 91.5 & 85 & 93.3 & 87.1 & 96.9 & 100 & 89.1 & 90 \\
49+ & 94.3 & 91.1 & 93.3 & 95.8 & 100 & 90 & 87.1 & 100 \\
BMI (kg.m ${ }^{-2}$ ) & & & & & & & & \\
$<25.0$ & 89.7 & 91.8 & 83.3 & 86.7 & 94.4 & 96.2 & 84.8 & 86.1 \\
$25.0-29.9$ & 87.1 & 78.8 & 87.9 & 88.6 & 100 & 94.7 & 85.7 & 78.6 \\
$30+$ & 92.9 & 100 & 100 & 100 & 100 & 100 & 73.9 & 88.9 \\
\hline WOMEN & & & & & & & & \\
\hline Total & 89.4 & 88.9 & 84.4 & 84.7 & 98.2 & 87.8 & 93.1 & 90.2 \\
Age (years) & & & & & & & & \\
18-33 & 86.3 & 82.1 & 84 & 75.9 & 97.4 & 88.2 & 93.3 & 87.1 \\
34-48 & 90 & 90.3 & 82.9 & 86.1 & 100 & 91.2 & 93 & 89.7 \\
$49+$ & 93.2 & 94.7 & 87.1 & 97.1 & 97.8 & 82.8 & 92.9 & 96.9 \\
BMI (kg.m ${ }^{-2}$ ) & & & & & & & & \\
$<25.0$ & 89.2 & 89.5 & 80.8 & 84 & 100 & 87.9 & 92.5 & 90.1 \\
$25.0-29.9$ & 89 & 90.9 & 87.2 & 80.8 & 100 & 76.5 & 100 & 89.7 \\
$30+$ & 80 & 87.1 & 94.1 & 86.7 & 80 & 84.2 & 91.3 \\
\hline
\end{tabular}

BMI, body mass index; NL, Netherlands; UK, United Kingdom.

${ }^{a} A$ valid day was defined as having 10 to 18 hours of accelerometer wear. 
Supplementary Material 2.2 Results from the binary logistic regression model examining the association between meeting the World Health Organization (WHO) physical activity recommendations and predictor variables in 539 males and 748 females

\begin{tabular}{|c|c|c|c|c|}
\hline & \multicolumn{2}{|r|}{ MEN } & \multicolumn{2}{|c|}{ WOMEN } \\
\hline & Odds & ratio $(95 \% \mathrm{Cl})$ & Odds & ratio $(95 \% \mathrm{Cl})$ \\
\hline Intercept & & - & & - \\
\hline Country: Netherlands & & Ref & & Ref \\
\hline Country: Germany & 0.73 & $(0.39,1.39)$ & 0.84 & $(0.45,1.54)$ \\
\hline Country: Greece & 0.81 & $(0.4,1.64)$ & 0.46 & $(0.23,0.89)$ \\
\hline Country: Ireland & 0.83 & $(0.42,1.66)$ & 1.24 & $(0.64,2.37)$ \\
\hline Country: Poland & 0.73 & $(0.33,1.61)$ & 0.48 & $(0.26,0.88)$ \\
\hline Country: Spain & 0.80 & $(0.43,1.5)$ & 0.60 & $(0.32,1.11)$ \\
\hline Country: UK & 1.16 & $(0.56,2.45)$ & 1.01 & $(0.56,1.8)$ \\
\hline Age & 1.00 & $(0.99,1.02)$ & 0.98 & $(0.96,0.99)$ \\
\hline Waist circumference & 0.95 & $(0.94,0.97)$ & 0.94 & $(0.92,0.96)$ \\
\hline Season: winter & & Ref & & Ref \\
\hline Season: autumn & 0.56 & $(0.2,1.5)$ & 1.57 & $(0.77,3.27)$ \\
\hline Season: spring & 1.47 & $(0.93,2.32)$ & 1.42 & $(0.98,2.07)$ \\
\hline Season: summer & 1.05 & $(0.47,2.36)$ & 1.44 & $(0.71,2.89)$ \\
\hline Accelerometer wear time & 0.80 & $(0.67,0.96)$ & 1.08 & $(0.92,1.28)$ \\
\hline Smoking: non-smokers & & Ref & & Ref \\
\hline Smoking: ex-smokers & 0.84 & $(0.55,1.28)$ & 1.21 & $(0.8,1.83)$ \\
\hline Smoking: current smokers & 0.24 & $(0.12,0.47)$ & 0.59 & $(0.32,1.04)$ \\
\hline
\end{tabular}

$\mathrm{Cl}$, confidence interval

MEN: Model X2(14)=81.73, $P<0.0001 ;$ WOMEN: Model $\chi 2(14)=131.91, P<0.0001$ 
Supplementary Material 2.3 Results from the binary logistic regression model examining the association between meeting the $30 \mathrm{~min} . \mathrm{d}^{-1}$ physical activity recommendation and predictor variables in 539 males and 748 females

\begin{tabular}{|c|c|c|c|c|}
\hline & \multicolumn{2}{|r|}{ MEN } & \multicolumn{2}{|c|}{ WOMEN } \\
\hline & \multicolumn{2}{|c|}{ Odds ratio $(95 \% \mathrm{Cl})$} & \multicolumn{2}{|c|}{ Odds ratio $(95 \% \mathrm{Cl})$} \\
\hline Intercept & & - & & - \\
\hline Country: Netherlands & & Ref & & Ref \\
\hline Country: Germany & 1.19 & $(0.63,2.25)$ & 1.01 & $(0.51,2)$ \\
\hline Country: Greece & 0.86 & $(0.41,1.78)$ & 0.39 & $(0.16,0.89)$ \\
\hline Country: Ireland & 1.26 & $(0.63,2.52)$ & 1.16 & $(0.56,2.37)$ \\
\hline Country: Poland & 1.32 & $(0.59,2.9)$ & 0.45 & $(0.22,0.9)$ \\
\hline Country: Spain & 1.57 & $(0.84,2.93)$ & 0.55 & $(0.25,1.18)$ \\
\hline Country: UK & 1.98 & $(0.99,4)$ & 0.88 & $(0.45,1.7)$ \\
\hline Age & 1.01 & $(0.99,1.03)$ & 0.99 & $(0.97,1)$ \\
\hline Waist circumference & 0.95 & $(0.93,0.97)$ & 0.94 & $(0.92,0.96)$ \\
\hline Season: winter & & Ref & & Ref \\
\hline Season: autumn & 0.40 & $(0.12,1.2)$ & 1.78 & $(0.82,3.84)$ \\
\hline Season: spring & 1.48 & $(0.93,2.37)$ & 1.77 & $(1.14,2.8)$ \\
\hline Season: summer & 1.37 & $(0.6,3.1)$ & 1.86 & $(0.81,4.12)$ \\
\hline Accelerometer wear time & 0.85 & $(0.71,1.02)$ & 1.15 & $(0.95,1.4)$ \\
\hline Smoking: non-smokers & & Ref & & Ref \\
\hline Smoking: ex-smokers & 0.81 & $(0.53,1.24)$ & 1.01 & $(0.62,1.62)$ \\
\hline Smoking: current smokers & 0.40 & $(0.18,0.84)$ & 0.37 & $(0.15,0.82)$ \\
\hline
\end{tabular}

Cl, confidence interval

MEN: Model X2(14)=64.66, $P<0.0001 ;$ WOMEN: Model $\chi 2(14)=102.20, P<0.0001$ 


\section{CHAPTER}

\section{Effects of a Web-based personalized intervention on physical activity in European adults: a randomized controlled trial}

Marsaux CF, Celis-Morales C, Fallaize R, Macready AL, Kolossa S, Woolhead C, O'Donovan CB, Forster H, Navas-Carretero S, San-Cristobal R, Lambrinou C-P, Moschonis G, Surwillo A, Godlewska M, Goris A, Hoonhout J. Drevon CA, Manios Y, Traczyk I, Walsh MC, Gibney ER, Brennan L, Martinez JA, Lovegrove JA, Gibney MJ, Daniel H, Mathers JC, Saris WH

Journal of Medical Internet Research. 2015;17(10):e231 


\section{Abstract}

Background: The high prevalence of physical inactivity worldwide calls for innovative and more effective ways to promote physical activity (PA). There are limited objective data on the effectiveness of Web-based personalized feedback on increasing PA in adults. It is hypothesized that providing personalized advice based on PA measured objectively alongside diet, phenotype, or genotype information would lead to larger and more sustained changes in PA, compared with nonpersonalized advice. Methods: A total of 1607 adults in seven European countries were randomized to either a control group (nonpersonalized advice, Level 0, LO) or to one of three personalized groups receiving personalized advice via the Internet based on current PA plus diet (Level 1, L1), PA plus diet and phenotype (Level 2, L2), or PA plus diet, phenotype, and genotype (Level 3, L3). PA was measured for 6 months using triaxial accelerometers, and self-reported using the Baecke questionnaire. Outcomes were objective and selfreported PA after 3 and 6 months. Results: While 1270 participants (85.81\% of 1480 actual starters) completed the 6-month trial, 1233 (83.31\%) self-reported PA at both baseline and month 6 , but only $730(49.32 \%)$ had sufficient objective PA data at both time points. For the total cohort after 6 months, a greater improvement in self-reported total PA $(P=0.02)$ and PA during leisure (nonsport) $(P=0.03)$ was observed in personalized groups compared with the control group. For individuals advised to increase PA, we also observed greater improvements in those two self-reported indices ( $P=0.006$ and $P=0.008$, respectively) with increased personalization of the advice (L2 and L3 vs L1). However, there were no significant differences in accelerometer results between personalized and control groups, and no significant effect of adding phenotypic or genotypic information to the tailored feedback at month 3 or 6 . After 6 months, there were small but significant improvements in the objectively measured physical activity level $(P<0.05)$, moderate PA $(P<0.01)$, and sedentary time $(P<0.001)$ for individuals advised to increase $P A$, but these changes were similar across all groups. Conclusions: Different levels of personalization produced similar small changes in objective PA. We found no evidence that personalized advice is more effective than conventional "one size fits all" guidelines to promote changes in PA in our Web-based intervention when PA was measured objectively. Based on self-reports, PA increased to a greater extent with more personalized advice. Thus, it is crucial to measure PA objectively in any PA intervention study. 


\section{Introduction}

Physical inactivity is one of the major risk factors for noncommunicable diseases [1]. It has been estimated that in 2008, approximately $7.3 \%$ of the 9.2 million deaths occurring in Europe were attributed to physical inactivity compared with $3.7 \%$ attributed to obesity [2]. Increasing physical activity (PA) continues to be a public health priority. Although public knowledge of the health benefits of regular PA is good and the recommendation of "30 min per day of activity most days of the week" is recognized widely, recent data from the World Health Organization (WHO) suggest that $35 \%$ of European adults do not meet PA recommendations [3].

Finding effective ways to increase PA is challenging. The limited success of "one size fits all" PA promotion programs may be partly due to the fact that inactive individuals are unaware that their current PA is inadequate [4,5]. Thus, providing personalized PA feedback may be more effective in increasing PA than a nonpersonalized conventional approach. Internet-based interventions for PA may have potential to increase levels of PA because large numbers of physically inactive individuals can be reached. However, it has been pointed out that positive effects were quite small, and might not be sustained in the long term. Furthermore, objective PA measurements and greater sample sizes are required [6-9].

Although many studies have used self-reports, such as the Baecke questionnaire or the International Physical Activity Questionnaire (IPAQ) [10], objective measurements of $\mathrm{PA}$ are more reliable [11]. Developments of PA measurement devices in the last decade have improved quantification of PA in free-living subjects. Accelerometers, for instance, have become popular because they can be worn without major inconvenience, require little effort by the user, and are compatible with most daily activities. Because they can record data for up to several weeks and measure PA accurately [12,13], they are useful research tools. In spite of this, few studies comparing tailored PA advice with nontailored or no advice have included these objective measures of PA [14-17].

Whether personalized PA feedback promotes behavioral change remains unclear. We used data collected during the Food4Me Study, which was registered at ClinicalTrials.gov (NCT01530139), to investigate the impact of different levels of personalization on PA change, using phenotypic and genotypic information to tailor the PA advice. We hypothesized that individually tailored advice would lead to greater and more sustained changes in PA, and that the intervention would be more effective as the level of personalization increased. 


\section{Methods}

\section{Study Design}

Full details of the study protocols have been described elsewhere [18]. Briefly, the Food4Me proof-of-principle study was a 6-month, 4-arm, randomized controlled trial (RCT) conducted across seven European countries to compare the effects of three levels of personalized advice with standard population advice on health-related outcomes. The intervention was designed to emulate an Internet-based service [19] and aimed to answer the following primary questions: (1) does personalization of dietary and PA advice result in bigger improvement in diet and PA compared with nonpersonalized, conventional guidelines? And (2) is personalization based on individualized phenotypic or genotypic information more effective in assisting and/or motivating participants to make and sustain appropriate healthy changes than personalization based on analysis of baseline diet and PA alone? To answer these questions, participants were randomized to a control group (Level 0) or to one of three personalized intervention groups with increasingly more detailed personalized advice (Levels 1 to 3 ) for 6 months. The levels are described in Textbox 1.

Textbox 3.1 Description of control and intervention groups and their levels of personalization in the Food4Me Study.

- Level 0 (LO; control group): nonpersonalized advice based on (European) general guidelines for diet and PA

- Level 1 (L1): personalized advice based on individual dietary intake and PA alone

- Level 2 (L2): personalized advice based on individual dietary intake, PA, and phenotypic data

- Level 3 (L3): personalized advice based on individual dietary intake, PA, and phenotypic and genotypic data

In the personalized groups, personalization of the PA advice was greater in L2 and L3 compared with L1: it was linked to phenotypic data (waist circumference, blood total cholesterol; L2 and L3) and genotypic data (fat mass- and obesity-associated gene, FTO; L3). See also the section Physical Activity Feedback below.

\section{Outcomes}

We focus here on PA after 3 and 6 months of intervention. PA is presented using both objective (accelerometer) and self-reported (PA questionnaire) data. Other outcomes included dietary intake, but are not within the scope of this paper. 


\section{Recruitment}

We aimed to recruit 1540 participants aged $\geq 18$ years in seven European countries Germany, Greece, Ireland, the Netherlands, Poland, Spain, and the United Kingdom [18]. Subjects were ineligible to take part in the study if they had no or limited access to the Internet, were following a prescribed diet, or had altered nutritional requirements because of a medical condition. The ethics committee from each recruiting center approved the study protocol. Between August 2012 and August 2013, 1607 adults (653 men, 40.63\%; and 954 women, 59.37\%) were randomized to the intervention. All participants gave informed consent digitally before participating in the study.

\section{Measures}

Data were collected using standard operating procedures in all seven countries [18]. Participants received study kits by post, containing all necessary materials (including an accelerometer) to perform measurements at home, but used their own scales to measure body weight. Printed and digital instructions, as well as online videos, were available for all participants in the languages of all seven countries.

\section{Objectively Measured Physical Activity}

\section{Objective Physical Activity Monitoring}

Habitual PA was assessed objectively using the TracmorD triaxial accelerometer (Philips Consumer Lifestyle, the Netherlands) [20,21]. The device is small $(3.2 \times 3.2 \times$ $0.5 \mathrm{~cm}$ ), light $(12.5 \mathrm{~g})$, waterproof to a depth of $30 \mathrm{~m}$, has a battery life of 3 weeks, and can record data for up to 22 weeks.

Participants activated the TracmorD accelerometer by creating an account online, installing an app on their computer, and connecting the device to the computer using the USB adapter provided. Upon activation, men could choose between three wearing positions-pocket, belt, or necklace-and women between four wearing positionspocket, belt, necklace, or bra. Participants could change their wearing position after informing the research team, who would update the position in the online system. Participants were instructed to wear the accelerometer every day during waking hours, except when taking a shower, for the entire duration of the study. Participants uploaded data every 2 weeks by connecting their monitor to their computer. Researchers checked this regularly and sent reminders to participants, if necessary. The data were transferred in real time and stored on a secured server. 


\section{Objective Physical Activity Data Processing}

Data were recorded with a time-sampling interval of 1 minute. A day was considered valid if the participant had worn the TracmorD for at least 10 hours but not longer than 18 hours. Wear time was defined as 24 hours minus nonwear time. To define nonwear time, we adapted the recommendations of Choi et al [22] to the TracmorD. Physical activity level (PAL) - the ratio of total energy expenditure to basal metabolic rate-data per minute were estimated from activity counts [20]. Nonwear time was defined by an interval of at least 90 consecutive minutes of PAL per minute values below 1.3889, allowing for 2-minute intervals of values above the threshold, with the upstream or downstream 30 consecutive values below the threshold (for detection of artifactual movements). R software version 3.1.2 [23] was used for all data handling.

\section{Objective Physical Activity Variables}

Daily PAL, activity energy expenditure (AEE), and time spent in different PA intensities were derived from the accelerometer.

PAL-per-day calculations were based on the work by Bonomi et al [20]:

$\mathrm{PAL}=1.354+\left(256 \times 10^{-9}\right) \times$ counts $_{\text {day }}(1)$

where counts day are the sum of minute-by-minute activity counts over 24 hours. However, the wearing position is taken into account, using the belt position as a reference and applying a correction factor for the other positions.

AEE per day was calculated as follows:

$\mathrm{AEE}=(0.9 \times \mathrm{PAL}$ per day -1$) \times \mathrm{BMR}(2)$

where the daily basal metabolic rate (BMR) is estimated using the Oxford equations developed by Henry, based on sex, age, and weight [24].

Classification into sedentary, and light-, moderate-, and vigorous-intensity PA (LPA, MPA, and VPA, respectively) was based on the application of thresholds for AEE: $0.025,0.05$, and $0.1 \mathrm{kcal} . \mathrm{kg}^{-1} \cdot \mathrm{min}^{-1}$ corresponding to $1.5,3$, and 6 metabolic equivalents (METs), respectively. Sedentary time and time spent in LPA, MPA, and VPA were determined by summing the time during which AEE per minute met the criterion for the appropriate intensity. Finally, moderate-equivalent PA was defined as follows:

Moderate-equivalent PA $=$ MPA $+2 \times$ VPA (3) 
to account for the fact that 1 minute of VPA is equivalent to 2 minutes of MPA [25]. Moderate-equivalent PA duration data were also calculated for activity occurring in modified bouts of 10 minutes (i.e. with allowance for interruptions of $\leq 2$ minutes at a lower PA intensity) [26].

PA estimates at baseline, month 3, and month 6 were calculated over a 2-week period at each time point. This 2-week assessment period occurred before any feedback was given to participants. Sufficient PA data at each time point was defined as having at least 3 valid weekdays and 2 valid weekend days of accelerometer wear during the 2week assessment period. For individuals with sufficient PA data, mean data per day were calculated for all objective PA variables using all valid week and weekend days of the assessment period as follows:

Mean $=($ mean for weekdays $\times 5+$ mean for weekend days $\times 2) / 7(4)$.

For sedentary time and time spent in LPA, MPA, VPA, and moderate-equivalent PA, weekly estimates were also calculated as follows:

Mean $=($ mean for weekdays $\times 5+$ mean for weekend days $\times 2)(5)$.

\section{Self-Reported Physical Activity}

At baseline, month 3 , and month 6, participants completed the Baecke questionnaire online [27] based on their PA during the last month. The Baecke questionnaire is a short, validated questionnaire assessing habitual PA according to the context in which it occurs and is organized into three sections: (1) PA at work, (2) sport, and (3) during leisure time excluding sport [27-29]. Indices for these three PA categories-work index, sport index, and leisure time (nonsport) index, each ranging from 1 to 5 -as well as a total activity index-sum of the three previous indices, ranging from 3 to 15 -were calculated according to the questionnaire protocol [27].

\section{Anthropometrics}

Participants self-measured their height, weight, and waist circumference, and uploaded their measurements directly onto their personal Food4Me online account [18]. Validation of self-reported sociodemographic and anthropometric measures have been described elsewhere [30]. 


\section{Genotyping}

Participants collected a buccal cell sample at baseline, using Isohelix SK-1 DNA buccal swabs and Isohelix Dri-capsules (LGC Genomics, Hertfordshire, UK). Samples were returned to their recruiting center and shipped to LGC Genomics, who extracted the DNA and used competitive allele-specific polymerase chain reaction (KASP) genotyping assays to provide biallelic scoring of single nucleotide polymorphism (SNP) rs9939609 in the FTO gene.

\section{Physical Activity Feedback}

All participants received a feedback report at months 0 and 3 via email in PDF. Reports were also available on the participant's personal Food4Me account. Participants in personalized groups ( $\mathrm{L} 1, \mathrm{~L} 2$, and $\mathrm{L} 3$ ) received personalized feedback based on accelerometer data (or self-reported data if accelerometer data were not available), whereas controls (LO) received a PDF containing general guidelines (see the following section). At each time point, researchers calculated the average PAL based on 2 weeks of accelerometer data collection for each participant and used it in the derivation of the PA feedback for personalized groups ( $L 1$ to $L 3$ ). The feedback report was sent 1 to 2 weeks after this 2-week measuring period. For LO, the same generalized advice was sent at months 0 and 3 . After completing the study, all participants received a personalized report based on the 6-month intervention.

\section{Cutoffs Definition}

PA was defined as adequate if objective $P A L$ was $\geq 1.8$. A value of $P A L \geq 1.5$ and $<1.8$ was considered low and a PAL of $<1.5$ was considered very low. If accelerometer data were not available at the time of feedback, the total activity index of the Baecke questionnaire was used instead of PAL with the following cutoffs: $\geq 8.5$ (adequate PA), $\geq 5.5$ to $<8.5$ (low), and $<5.5$ (very low).

\section{Derivation of Feedback Messages in Relation to Physical Activity}

\section{Level 0 (Controls)}

Participants in the control group received the nonpersonalized advice that they should be physically active at least 150 minutes per week. 
Feedback reports in personalized groups contained specific messages, selected according to standardized algorithms, based on subjects' characteristics and their allocated group.

\section{Level 1}

In the PA section of the personalized report, current level of PA was indicated with a mark on a three-color line, based on the cutoffs defined above: red area (very low $P A L$ ), amber (low PAL), and green (adequate PAL). The report included tailored advice to increase strongly, increase, or maintain PA based on current PAL and body mass index (BMI), as well as tips on how to be (more) physically active. Participants had access to additional information about PA and tips online on their personal Food4Me account. Hyperlinks to this section of the website were included in the tailored report and participants were encouraged to visit the webpage.

\section{Level 2}

Participants in L2 had access to the same information as those in L1. However, the specific PA message in the personalized report was based on current PAL and BMI as well as on individuals' waist circumference and blood total cholesterol.

\section{Level 3}

Participants in L3 had access to the same information as those in L1 and L2, in addition to whether they carried the risk allele (A) for the FTO gene; this information was included in the specific PA message alongside current PAL, BMI, waist circumference, and blood total cholesterol. For example, an inactive obese L3 participant with FTO risk (AA or AT genotype), high waist circumference, and high total cholesterol would receive the following advice:

Your BMI is greater than the recommended healthy range (...). Your waist circumference is also higher than recommended (...). We recommend reducing your body weight and waist circumference to a healthy normal range because you have a genetic variation that can benefit by reducing these two obesity markers (...). Also, your physical activity level is too low; improving your physical activity level will help you to reduce your weight. Your fasting cholesterol level was above the recommended level and we advise you to go to the G.P. [general practitioner] to get this re-checked (...). Become more physically active; to maintain weight loss, 60-90 minutes of moderately intense aerobic activities, such as brisk walking, swimming or cycling, on most days of the week, is recommended. This will also help to lower cholesterol levels. 
PA feedback for L3 participants not carrying the risk for FTO was similar to that of L2 participants. However, L3 participants all received information on FTO, as well as information on four other diet-related genetic variants, whereas subjects allocated to L2 did not receive any genetic-based information. More details of the feedback reports and the Food4Me website are given in the supplementary material (see Supplementary Material 3.1) and elsewhere [18].

\section{Statistical Analysis}

Data were analyzed on an intention-to-treat basis. We defined three orthogonal contrasts to answer our research questions: first comparing L0 with L1 to L3, then L1 with L2 and L3, and finally L2 with L3. More specifically, to answer the first research question-"Is personalized advice more effective than the conventional one size fits all?"-intervention effects on PA variables were assessed. We used robust multiple linear regression analysis, based on computation of SMDM estimates [31] to account for violation of the normality assumption, with baseline PA variable, sex, age, country, smoking, baseline BMI, baseline season, and change in body weight as covariates. For accelerometer-derived PA variables, change in accelerometer wear time was included as an additional covariate. The principal assessment of intervention used Contrast 1 comparing L0 with the mean of L1 to L3. First, a generic approach was used where we investigated intervention effects for the total cohort. Second, a targeted approach was used in which we investigated the intervention effects on PA only for participants who received advice to increase their PA. For this second part of the analysis, outcomes for those who received tailored advice targeting PA were compared with the subset of matched LO (control) participants (i.e. controls who would have received personalized advice to increase PA if they had been in a personalized group instead of L0). These matched LO participants were selected by applying the same algorithm used for individuals in personalized groups.

The second research question - "Is personalization based on individualized dietary, phenotypic, or genotypic information more effective in promoting changes in PA than personalization based on diet and PA alone?"-was tested using two other contrasts. For Contrast 2, comparison of L1 with L2 and L3 tested whether personalization based on phenotypic and/or genotypic information differed from that based on dietary and PA assessment only. For Contrast 3, comparison of L2 with L3 tested whether the addition of genotypic information promoted a greater increase in PA than when using phenotypic, dietary, and PA information only. The outcomes for these analyses were the same PA variables as for Contrast 1 and we also used both a generic and targeted approach. 
Sensitivity analyses were performed to compare dropouts with completers and noncompliant (i.e. those with too few valid days) with compliant participants. These analyses were performed using robust multiple linear regression for continuous variables and logistic regression for categorical variables, adjusting for sex, age, and country as well as baseline accelerometer wear time and season for accelerometer variables. When examining differences in BMI between dropouts and completers, screening data were used rather than baseline data because $38 \%$ of dropouts had no baseline data. R software version 3.1.2 [23] was used to perform all analyses and the significance level was set at $P<0.05$.

\section{Results}

\section{Study Participants}

Of the 5562 individuals who expressed an interest in the Food4Me Study between August 2012 and August 2013, 4044 (72.71\%) completed the whole screening process (Figure 3.1). Of those, 2764 (68.35\%) were eligible to take part in the intervention study. The first 1607 of the 2764 (58.14\%) participants were randomized to one of the four intervention arms and 127 (7.90\%) dropped out immediately after randomization (Figure 3.1).

The characteristics of the 1480 participants who started the trial and completed baseline measurements are given by intervention arm in Table 3.1 and see Supplementary Material 3.2, and are described elsewhere [18]. Overall, 58.45\% $(865 / 1480)$ were women, the mean age was 39.9 (SD 13.0) years, and $46.15 \%$ (683/1480) of participants were overweight or obese. Mean PAL was 1.73 (SD 0.18), and participants spent on average 12.4 (SD 1.3) h. $\mathrm{d}^{-1}$ in sedentary behaviors and 57 (SD 45) min. $\mathrm{d}^{-1}$ in moderate-equivalent PA (29 [SD 32] min. $\mathrm{d}^{-1}$ in modified 10-minute bouts). Mean self-reported total activity index was 7.80 (SD 1.48) (Table 3.1). Of the 371 participants in L3, 257 (69.3\%) and 113 (30.5\%) were carriers of the risk (AA or AT) and nonrisk (TT) genotypes for FTO, respectively (Table 3.1), and were therefore informed that they had or did not have the risk variant. A total of 807 of $1120(72.05 \%)$ individuals randomized to the personalized groups ( $L 1$ to $L 3$ ) were not sufficiently active based on baseline measurements and therefore received feedback that they should increase their level of physical activity (data not shown). 


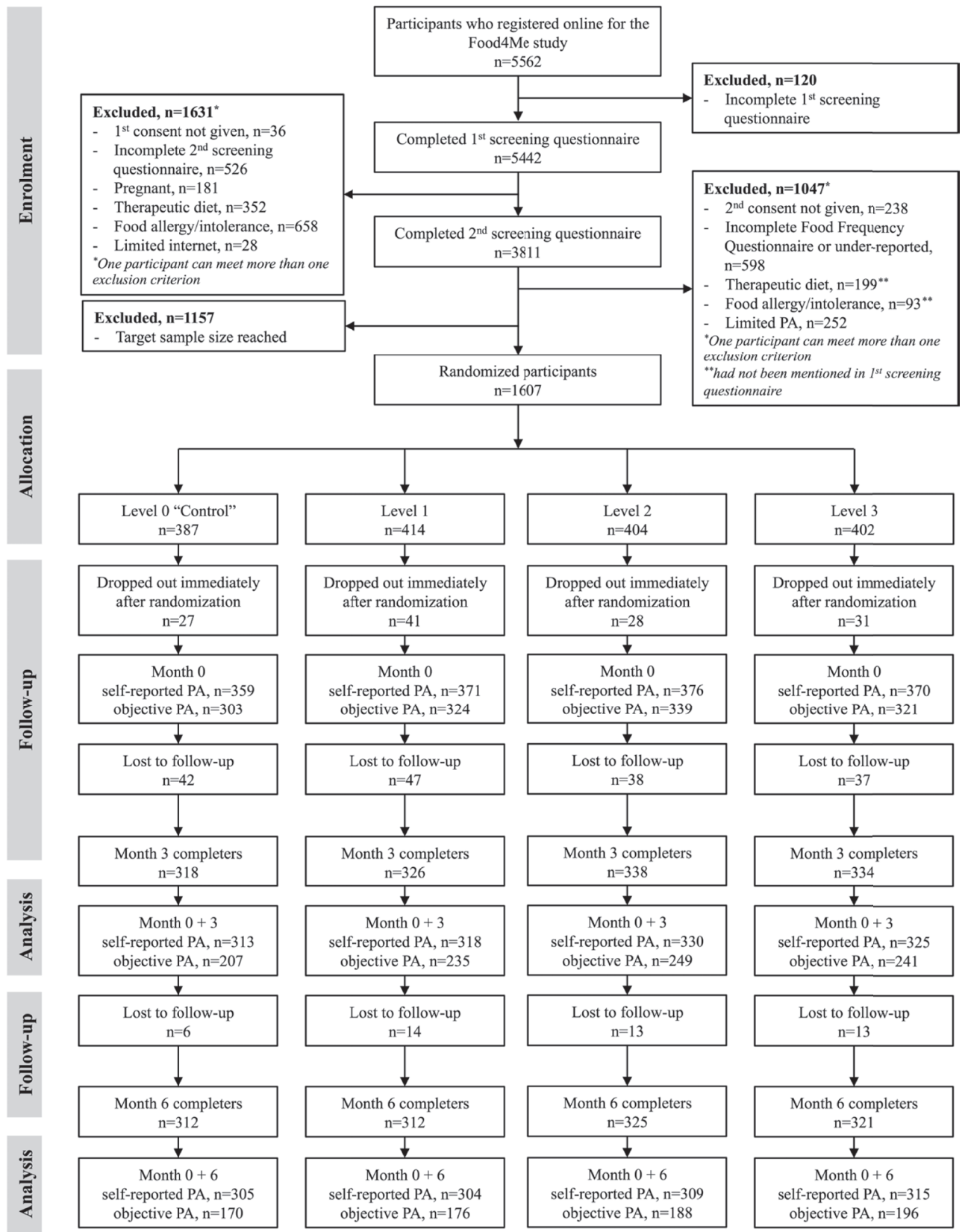

Figure 3.1 Flow of participants through the study

\section{$P A$, physical activity}


Table 3.1 Baseline characteristics ${ }^{a}$ of the Food4Me participants.

\begin{tabular}{|c|c|c|c|c|}
\hline \multirow[t]{2}{*}{ Variables } & \multirow{2}{*}{$\begin{array}{c}\text { Control } \\
\text { Level } 0(\text { Lo) } \\
(n=360)\end{array}$} & \multicolumn{3}{|c|}{ Personalized advice } \\
\hline & & $\begin{array}{l}\text { Level } 1(L 1) \\
(n=373)\end{array}$ & $\begin{array}{l}\text { Level } 2(\text { L2) } \\
\quad(n=376)\end{array}$ & $\begin{array}{c}\text { Level } 3(\text { L3) } \\
\quad(n=371)\end{array}$ \\
\hline Ethnicity (white), n (\%) & $344(95.6)$ & $363(97.3)$ & 368 (97.9) & 357 (96.2) \\
\hline Sex (women), n (\%) & $213(59.2)$ & $212(56.8)$ & $220(58.5)$ & 220 (59.3) \\
\hline Age (years), mean (SD) & 39.5 (13.3) & $39.7(12.9)$ & $40.2(12.8)$ & $40.2(13.1)$ \\
\hline \multicolumn{5}{|l|}{ Anthropometrics } \\
\hline Height (cm), mean (SD) & $171.3(9.4)$ & $171.3(9.5)$ & $170.7(9.4)$ & $171.2(9.5)$ \\
\hline Weight (kg), mean (SD) & $74.6(15.5)$ & $74.1(16.6)$ & $74.9(15.9)$ & $75.5(15.5)$ \\
\hline $\mathrm{BMI}^{\mathrm{b}}\left(\mathrm{kg} \cdot \mathrm{m}^{-2}\right)$, mean (SD) & $25.4(4.7)$ & $25.2(5.0)$ & $25.6(4.9)$ & $25.7(4.8)$ \\
\hline Overweight, n (\%) & $119(33.1)$ & $96(25.7)$ & $103(27.4)$ & $131(35.3)$ \\
\hline Obese, n (\%) & $52(14.4)$ & $57(15.3)$ & $70(18.6)$ & $55(14.8)$ \\
\hline Current smokers, n (\%) & $49(13.6)$ & $44(11.8)$ & $34(9.0)$ & $47(12.7)$ \\
\hline Ex-smokers, n (\%) & $88(24.4)$ & $98(26.3)$ & $101(26.9)$ & $91(24.5)$ \\
\hline Nonsmokers, n (\%) & $223(61.9)$ & $231(61.9)$ & $241(64.1)$ & $233(62.8)$ \\
\hline \multicolumn{5}{|l|}{ FTO $^{\mathrm{c}}$ genotype, n (\%) } \\
\hline $\mathrm{AA}$ & $60(16.7)$ & $69(18.5)$ & $66(17.6)$ & $69(18.6)$ \\
\hline AT & 187 (51.9) & $175(46.9)$ & $189(50.3)$ & $188(50.7)$ \\
\hline TT & $112(31.1)$ & $127(34.0)$ & $117(31.1)$ & $113(30.5)$ \\
\hline Objective PA ${ }^{d}$, mean (SD) & $(n=303)$ & $(n=324)$ & $(n=339)$ & $(n=321)$ \\
\hline $\mathrm{PAL}^{\mathrm{e}}$ & $1.71(0.18)$ & $1.75(0.21)$ & $1.73(0.16)$ & $1.74(0.17)$ \\
\hline AEE $^{f}\left(\right.$ kcal. $\left.^{-1}\right)$ & $832(269)$ & $896(312)$ & $869(274)$ & $874(283)$ \\
\hline Sedentary time $\left(\min . d^{-1}\right)$ & $746(76)$ & $738(75)$ & $747(78)$ & $749(77)$ \\
\hline $\operatorname{LPA}^{\mathrm{g}}\left(\min \cdot \mathrm{d}^{-1}\right)$ & $70(27)$ & $76(33)$ & $74(31)$ & $76(30)$ \\
\hline $\operatorname{MPA}^{\mathrm{h}}\left(\min \cdot \mathrm{d}^{-1}\right)$ & $30(19)$ & $35(20)$ & $33(21)$ & $34(22)$ \\
\hline $\operatorname{VPA}^{i}\left(\min \cdot d^{-1}\right)$ & $11(16)$ & $14(20)$ & $11(14)$ & $10(14)$ \\
\hline Moderate-equivalent $P A^{j}\left(\min \mathrm{d}^{-1}\right)$ & $53(43)$ & $63(50)$ & $56(42)$ & $55(45)$ \\
\hline $\begin{array}{l}\text { Moderate-equivalent PA in bouts } \\
\left(\min . \mathrm{d}^{-1}\right)\end{array}$ & $27(32)$ & $34(38)$ & $28(28)$ & $28(30)$ \\
\hline Self-reported PA, mean (SD) & $(n=359)$ & $(n=371)$ & $(n=376)$ & (370) \\
\hline Total activity index & $7.71(1.47)$ & $7.94(1.48)$ & $7.78(1.43)$ & $7.80(1.54)$ \\
\hline Work index & $2.26(0.59)$ & $2.30(0.61)$ & $2.28(0.62)$ & $2.29(0.62)$ \\
\hline Sport index & $2.70(0.87)$ & $2.85(0.89)$ & $2.73(0.85)$ & $2.74(0.88)$ \\
\hline Leisure time (nonsport) index & $2.75(0.69)$ & $2.81(0.70)$ & $2.78(0.69)$ & $2.78(0.67)$ \\
\hline
\end{tabular}

${ }^{a}$ Data are presented as unadjusted means (SD) for continuous variables and absolute numbers (\%) for categorical variables. Levels 1 to 3 received personalized advice; only participants in Level 3 were informed whether they carried or did not carry the risk allele for FTO (A). ${ }^{b}$ Body mass index (BMI); ${ }^{c}$ Fat mass and obesity associated (FTO); ${ }^{d}$ Physical activity (PA); ${ }^{e}$ Physical activity level (PAL); ${ }^{f}$ Activity energy expenditure (AEE); ${ }^{g}$ Light-intensity PA (LPA); ${ }^{h}$ Moderate-intensity PA (MPA); 'Vigorousintensity PA (VPA); ${ }^{j}$ Moderate-equivalent PA is (MPA + $\left.2 \times V P A\right)$. 
Of the 1607 randomized participants, 1270 (79.03\%) completed the 6-month intervention and $1233(76.73 \%)$ had self-reported data on PA for both baseline and month 6 , whereas only $730(45.43 \%)$ had sufficient valid accelerometer data for both time points (Figure 3.1). Dropouts were more likely to be women (odds ratio [OR] 1.34, 95\% Cl 1.05-1.75, $P=0.03$ ), were younger than completers $(P<0.001)$, and had a higher $\mathrm{BMI}$ at screening than completers $(P=0.02)$. Smoking habits did not differ significantly between dropouts and completers, and the dropout rate was similar in all four groups, L0 to L3 (data not shown). Among completers, those who were not compliant with objective PA measurement at month 6 were younger $(P<0.001)$, had a higher baseline BMI $(P=0.04)$, and a lower baseline PAL $(P=0.03)$. There were no significant differences in smoking habits between those who were compliant and those who were not, and compliance was similar for men and women and in all four groups, L0 to L3 (data not shown).

\section{Effect of Different Levels of Personalized Advice on Objective Physical Activity}

\section{Total Cohort: Generic Approach}

At month 3 (see Supplementary Material 3.3), participants increased their PAL (LO: $+0.02, P=0.008$ and L1 to L3: $+0.02, P<0.001)$ and AEE (L0: $+24.2 \mathrm{kcal}^{-1} \mathrm{~d}^{-1}, P=0.03$ and L1 to L3: $\left.+19.5 \mathrm{kcal}^{-1} \mathrm{~d}^{-1}, P=0.001\right)$, and spent significantly more time in MPA (L0: +18 $\min . \mathrm{wk}^{-1}, P=0.01$ and $\mathrm{L} 1$ to $\left.\mathrm{L} 3:+17 \mathrm{~min} \cdot \mathrm{wk}^{-1}, P<0.001\right)$ and less time in sedentary

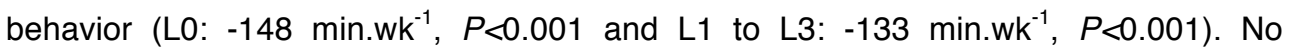
significant change in PA was observed at month 6 (see Supplementary Material 3.4),

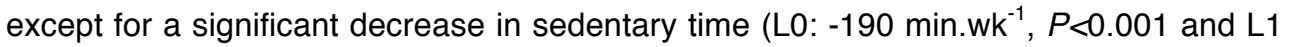
to L3: -155 min. $\left.w^{-1}, P<0.001\right)$. Furthermore, we found no significant differences in objectively measured PA between control and personalized groups, or between personalized groups, at month 3 or 6 (see Supplementary Materials 3.3 and 3.4).

Participants Who Received Advice to Increase Physical Activity and Matched Controls: Targeted Approach

At month 3, we observed significant improvements in all components of PA for participants in personalized groups as well as for matched controls (see Supplementary Material 3.5). Although changes were attenuated at month 6 (Figure 3.2) these remained significant for $P A L(L 0:+0.02, P=0.04$ and $L 1$ to $L 3:+0.01$, $P=0.006$ ), sedentary time (L0: $-199 \mathrm{~min} \cdot \mathrm{wk}^{-1}, P<0.001$ and L1 to L3: $-179 \mathrm{~min} \cdot \mathrm{wk}^{-1}$, $P<0.001$ ), and MPA (LO: +27 min. $w^{-1}, P=0.002$ and L1 to L3: +18 min. $\left.w^{-1}, P<0.001\right)$. 
However, there were no significant differences in objectively measured PA between individuals in personalized groups and matched controls (Table 3.2 and Figure 3.2).
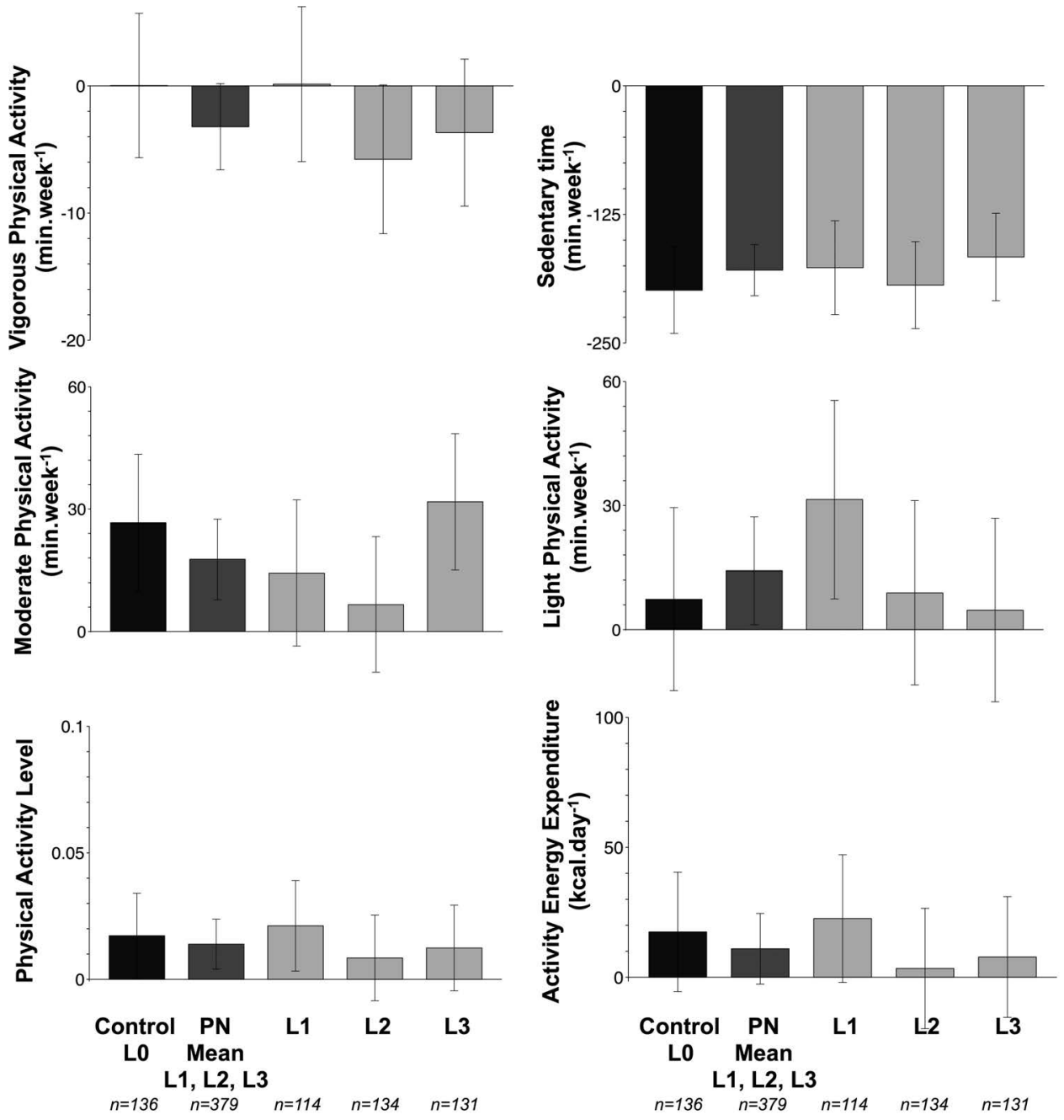

Figure 3.2 Changes from baseline to month 6 in physical activity measured objectively, for participants who received advice to increase physical activity (personalized groups Levels 1, 2, and 3) and matched controls (Level 0)-targeted approach.

Data are presented as adjusted changes from baseline. Error bars represent $95 \%$ confidence intervals. Models were adjusted for baseline values, sex, age, country, smoking, baseline BMI, baseline season, change in body weight, and change in accelerometer wear time. Individuals in Levels 1 (L1), 2 (L2), and 3 (L3) received personalized physical activity feedback based on current physical activity level (L1 to L3), phenotypic information (L2 and L3), and genotypic information (L3), whereas controls (LO) received nonpersonalized guidelines on physical activity. 
Table 3.2 Effect of targeted intervention on physical activity at month $6^{a}$.

\begin{tabular}{|c|c|c|c|c|}
\hline PA ${ }^{b}$ components & $\begin{array}{c}\text { Matched } \\
\text { control, } \\
\text { Lo }{ }^{c}(n=136), \\
\text { mean (SD) }\end{array}$ & $\begin{array}{c}\text { Personalized } \\
\text { advice, } \\
\text { L1 to } \text { L3 }^{d}(n=379), \\
\text { mean (SD) }\end{array}$ & $\begin{array}{l}\text { Intervention effects, } \\
\text { (L1 to L3) - L0 (95\% Cl) }\end{array}$ & $\begin{array}{c}P, \\
\text { L0 vs } \\
\text { (L1 to L3) }\end{array}$ \\
\hline \multicolumn{5}{|l|}{ Objective PA } \\
\hline $\mathrm{PAL}^{\mathrm{e}}$ & $1.68(0.10)$ & $1.68(0.10)$ & $-0.003(-0.020$ to 0.020$)$ & 0.73 \\
\hline $\operatorname{AEE}^{f}\left(\right.$ kcal. $\left.^{-1}\right)$ & $785(137)$ & $778(135)$ & $-6(-34$ to 21$)$ & 0.64 \\
\hline $\begin{array}{l}\text { Sedentary time } \\
\left(\min . w^{-1}\right)\end{array}$ & $5182(250)$ & $5202(247)$ & $20(-30$ to 69$)$ & 0.44 \\
\hline $\operatorname{LPA}^{\mathrm{g}}\left(\min \cdot w^{-1}\right)$ & $479(132)$ & $486(129)$ & $7(-19$ to 33$)$ & 0.59 \\
\hline MPA $^{h}\left(\min . w^{-1}\right)$ & $216(100)$ & $207(98)$ & $-9(-29$ to 11$)$ & 0.36 \\
\hline VPA $^{i}\left(\min \cdot w^{-1}\right)$ & $48(34)$ & $45(34)$ & $-3(-10$ to 3$)$ & 0.33 \\
\hline $\begin{array}{l}\text { Moderate- } \\
\text { equivalent PA } \\
\left(\min . \mathrm{wk}^{-1}\right)\end{array}$ & $323(154)$ & $310(154)$ & $-14(-45$ to 17$)$ & 0.35 \\
\hline $\begin{array}{l}\text { Moderate- } \\
\text { equivalent PA in } \\
\text { bouts (min. } \mathrm{wk}^{-1} \text { ) }\end{array}$ & $140(103)$ & $131(102)$ & $-10(-30$ to 11$)$ & 0.35 \\
\hline \multicolumn{5}{|l|}{ Self-reported PA } \\
\hline Total activity index ${ }^{k}$ & $7.58(0.87)$ & $7.77(0.87)$ & $0.18(0.05$ to 0.32$)$ & $0.009^{1}$ \\
\hline Work index ${ }^{k}$ & $2.24(0.30)$ & $2.27(0.30)$ & $0.03(-0.02$ to 0.07$)$ & 0.26 \\
\hline Sport index ${ }^{m}$ & $2.58(0.50)$ & $2.65(0.50)$ & $0.070(-0.005$ to 0.150$)$ & 0.07 \\
\hline $\begin{array}{l}\text { Leisure time } \\
\text { (nonsport) index }\end{array}$ & $2.77(0.48)$ & $2.87(0.48)$ & $0.10(0.03$ to 0.17$)$ & $0.009^{1}$ \\
\hline
\end{tabular}

${ }^{a}$ Analysis is restricted to participants randomized to Levels 1 to 3 (L1, L2, and L3) who received personalized advice to increase $P A$, and to matched control group (LO) participants who would have received personalized advice to increase PA if they had been in a personalized group and not in $L O$. Data are presented as adjusted means and as the difference between the personalized groups (mean $L 1, L 2, L 3)$ and control with the corresponding $95 \%$ confidence interval. Differences between levels of personalized advice are presented in Supplementary Material 3.6. All analyses were adjusted for baseline values, sex, age, country, smoking, baseline BMI, baseline season, and change in body weight. In addition, for objective PA variables analyses were adjusted for change in accelerometer wear time. ${ }^{b}$ Physical activity (PA); ${ }^{\circ}$ Level $O$ (LO); ${ }^{d}$ Level 1 to Level 3 (L1 to L3); ${ }^{e}$ Physical activity level (PAL); ${ }^{f}$ Activity energy expenditure (AEE); ${ }^{g}$ Light-intensity PA (LPA); ${ }^{h}$ Moderate-intensity PA (MPA); Vigorous-intensity PA (VPA); ${ }^{j}$ Moderate-equivalent PA is (MPA $+2 \times$ VPA); ${ }^{k}$ Participant numbers within each group are as follows: $n=220$ (L0), 198 (L1), 210 (L2), 207 (L3), and 615 (pooled L1, L2, and L3). For retired or unemployed individuals, work index, and therefore total index, cannot be calculated; ' Values in italics represent significant results; ${ }^{m}$ Participant numbers within each group are as follows: $n=232$ (LO), 217 (L1), 230 (L2), 223 (L3), and 670 (pooled L1, L2, and L3);

At month 6, the change from baseline in MPA was significantly larger for L3 compared with L2 (L3: +32 min. $\mathrm{wk}^{-1}$ vs L2: $+7 \mathrm{~min} . \mathrm{wk}^{-1}, P=0.04$ ), but there were no other significant differences in PA between personalized groups (see Figure 3.2 and Supplementary Material 3.6). Results were unchanged when analyzing men and women separately (data not shown). 


\section{Effect of Different Levels of Personalized Advice on Self-Reported Physical Activity}

Total Cohort: Generic Approach

Participants reported significant improvements in PA after the 6-month intervention (see Supplementary Material 3.7). Compared with the control group, individuals in personalized groups had significantly higher leisure time (nonsport) index $(2.4 \%$, $P=0.02)$ and total activity index scores $(1.6 \%, P=0.03)$ (see Supplementary Material 3.7). However, no significant differences were found between personalized groups (see Supplementary Material 3.7). Similar results were found at month 3 (see Supplementary Material 3.8).

Participants Who Received Advice to Increase Physical Activity and Matched Controls: Targeted Approach

After 6 months, there were significant improvements in self-reported PA during sport, leisure time (nonsport), and total PA among participants who received tailored advice (Figure 3.3). Compared with the control group, scores reported in personalized groups were significantly higher for leisure time (nonsport) index $(3.6 \%, P=0.009)$ and total activity index (2.5\%, $P=0.009$ ) (see Table 3.2 and Figure 3.3). Similar results were found at month 3 (see Supplementary Material 3.9). Finally, we also observed significant differences between personalized groups at month 6 , scores for both indices being higher $(3.9 \%, P=0.006$ and $2.9 \%, P=0.008$, respectively) for participants in $\mathrm{L} 2$ and L3 compared with L1 (see Figure 3.3 and Supplementary Material 3.6).

Results were unchanged when analyzing men and women separately. Importantly, results were also similar when including only individuals with both objective and selfreported PA (i.e. completers, compliant with wearing the accelerometer and who have self-reported data) in the analysis (data not shown). 

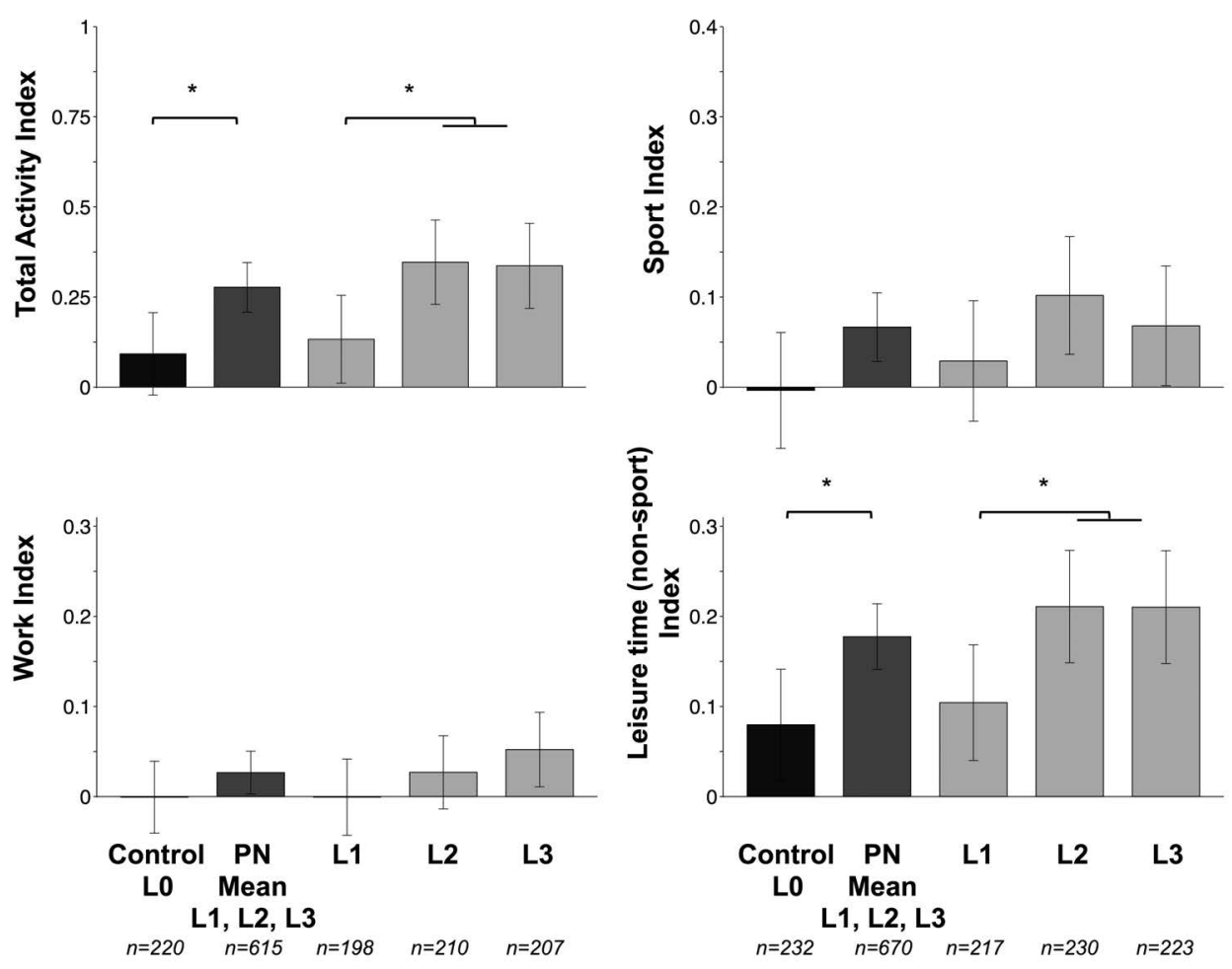

Figure 3.3 Changes from baseline to month 6 in self-reported physical activity (Baecke questionnaire) for participants who received advice to increase physical activity (personalized groups Levels 1, 2, and 3) and matched controls (Level 0)-targeted approach.

Data are presented as adjusted changes from baseline. Error bars represent $95 \%$ confidence intervals. Models were adjusted for baseline values, sex, age, country, smoking, baseline BMI, baseline season, and change in body weight. *Significant differences at $P<.01$. Individuals in Levels 1 (L1), 2 (L2), and 3 (L3) received personalized physical activity feedback based on current physical activity level (L1 to L3), phenotypic information (L2 and L3), and genotypic information (L3), whereas controls (LO) received nonpersonalized guidelines on physical activity.

\section{Discussion}

\section{Principal Findings}

For individuals who were not sufficiently active at baseline, as well as for the total cohort, personalized PA advice delivered via the Internet was more effective in improving self-reported PA compared with conventional "one size fits all" populationbased advice. In addition, after 6 months of intervention, including phenotypic and/or genotypic information in the derivation of personalized PA advice led to bigger changes in self-reported PA than personalization based on diet and PA alone. However, these findings were not confirmed when PA was assessed objectively using accelerometers. 
Although we found some small significant improvements in objectively measured PA over the 6-month intervention, these changes were similar in all interventions groups.

\section{Comparison With Previous Work}

Most studies that have investigated the effectiveness of eHealth computer-tailored PA interventions have relied on self-reports [8], and their findings should be interpreted with caution. Few studies were identified that used objective PA outcome measures based on accelerometry [14-17,32]. Godino et al [15] noted that personalized PA feedback increased awareness of PA but did not promote change in PA after 2 months of follow-up. However, Hurling et al [32] found that participants who had access to a fully automated Internet, email, and mobile phone behavior change system-which included feedback on activity level and modules designed to help participants identify their perceived barriers and offered tailored solutions-had significantly higher objectively measured PA during the 9-week intervention compared with controls, who received verbal recommendations on PA but had no access to the behavior change system and received no feedback. Self-reported leisure PA was also significantly higher and time spent sitting significantly lower in the intervention group compared with the controls, but overall self-reported PA was similar in both groups [32]. In a study of older adults, Wijsman et al [17] observed that participants in an Internet program aiming to increase PA by monitoring and feedback by accelerometer and digital coaching had a significant increase of 11 minutes per day in moderate and vigorous PA after 3 months, whereas the wait-listed controls showed no change in PA. Ashe et al [14] found significant increases in PA, as well as group differences at month 6 , but their sample was small-13 participants in the intervention group and 12 in the control group-and group-based education and social support was included in addition to their Web-based intervention. Finally, Wanner et al [16] reported some improvements in self-reported PA after 6 weeks and 13 months of follow-up, but no differences between individuals in tailored and control groups, and no improvement in objectively measured PA for any group. These discrepancies between self-reported and objectively measured PA results are in line with our study. However, we found greater improvements in self-reported PA in tailored groups as compared with the controls. It could be that participants desired to comply with recommendations and that receiving more personalized feedback (Levels 2 and 3) increased this desire further in our study. It could also be that participants truly believed that they became more active when they actually did not. Contrary to Wanner et al, objective PA also improved, slightly but significantly, after 6 months of intervention, especially in participants who were inactive at baseline, in line with the 
results of Wijsman et al and Ashe et al. Yet in our study, those changes in objective PA were similar across all groups.

The number of studies testing the effectiveness of personalized feedback versus conventional population-based guidelines is limited. However, most authors stress the need for new ways to increase compliance and engagement of participants to ultimately successfully improve PA. Of those who started the Food4Me Study, $85.81 \%$ (1270/1480) completed the trial, indicating that our Web-based intervention was effective in retaining participants. However, only $49.32 \%(730 / 1480)$ of the starters had sufficient valid accelerometer data after 6 months. Thus, compliance with the study protocol in wearing the accelerometer remains a major issue, especially because those who were less compliant in our study had significantly lower baseline PAL.

\section{Strengths and Limitations}

The Food4Me Study is the largest Internet-based RCT to date to test the effects of personalized feedback on PA, using objectively measured PA with accelerometers. To our knowledge, it is also the first study to assess the effects of different levels of personalization including tailored phenotypic and genotypic information. Another strength is the inclusion of seven European centers that delivered the intervention with the same standardized protocol $[18,33]$.

An important limitation is the relatively low compliance after 6 months with respect to accelerometer wear, which is lower than in other studies [16]. In our study, participants were asked to wear their accelerometer every day for the entire duration of the study, which may have been too demanding. Most participants did wear the accelerometer but not enough (i.e. fewer than 3 valid weekdays and 2 valid weekend days). In other studies, participants received a PA monitor, were asked to wear it for the measurement period only (typically, 7 days), and to return the device immediately after to the researchers [15-17]. Better compliance in wearing the monitor may be obtained by having coaches motivating participants regularly [17], but this is not always feasible in a large-scale study. Advertisement for the study was primarily focused on personalized nutrition (i.e. improving nutritional intakes) and not on PA. Moreover, the Food4Me Study was a multiple-behavior intervention including a large amount of information with extensive feedback, and many individuals may have felt they did not have time to try to make changes in both PA and diet concurrently [34].

A potential explanation as to why participants in personalized groups did not do better than controls could be that the TracmorD PA monitor used in the study constituted a basic, yet personalized, feedback by itself. That is, when the monitor is set on a flat 
surface at any time (e.g. a table), lights on the monitor turn green depending on how much activity has been registered during the day. The more activity, the more lights turn green, for all participants including controls. Ideally, there should be no feedback on PA at all in the control group. This may explain the small but significant improvement in the control group. One could argue that providing feedback every 3 months might not be sufficiently frequent. In our study, half of the participants in the personalized groups received additional feedback based on measurements after 1 and 2 months (i.e. high-intensity feedback: four feedback reports at months $0,1,2$, and 3 ) but changes in objectively and self-reported PA at 3- and 6-month follow-up were similar to the other half of participants (i.e. low-intensity feedback: feedback reports at months 0 and 3 only). Compliance in wearing the monitor did not differ between highand low-intensity participants (data not shown). Furthermore, we cannot exclude the fact that phenotypic and genotypic characterization, and therefore feedback to participants in Levels 2 and 3, may not have been optimal for PA-related outcomes. For example, our only PA-related genotypic variant was in the FTO gene and perhaps just one gene variant would be insufficient to motivate participants in Level 3 to increase PA beyond those in Level 2.

Finally, although accelerometry is an objective measure of PA, it can underestimate certain activities, such as carrying heavy loads and when the torso remains relatively static (e.g. during cycling). Accelerometry cannot (easily) distinguish PA when ascending (e.g. walking uphill) from movement on the flat yet there could be large differences in energy expenditure between the two types of movement. Our monitor was waterproof and could be worn during swimming, but underestimation of activity intensity is common. Nevertheless, the TracmorD has been validated against the doubly labeled water method and several publications show that it is a reliable and accurate monitor [12,13,20,35]. Although devices may not capture all types of PA, questionnaires have been shown repeatedly to be inaccurate, often overestimating PA $[11,36]$. The Baecke questionnaire, although extensively validated $[28,29]$, is no exception [37]. Our results support the position adopted by others that self-reported measures of PA should be interpreted with caution and preferably not be used to draw conclusions on the effectiveness of PA interventions $[8,38]$. Thus, it is better for personalized feedback to have objective measures of PA such as accelerometry. Such technologies are becoming very relevant tools for both surveys and interventions to promote public health. They are developing rapidly and are commonly available for download to mobile phones and watches, allowing greater accessibility for the general population, which may help with noncompliance. However, these new apps will need to be rigorously tested. 


\section{Conclusions}

We observed small but significant improvements in objectively measured PA after 3 and 6 months of intervention, although changes were similar across all groups. Personalized advice on PA did not promote larger and more sustained improvements in objective PA as compared with a conventional "one size fits all" approach delivered via the Internet. Furthermore, increasing the degree of personalization using phenotypic or genotypic information had no effect on changes in objectively measured PA compared with personalized feedback based on diet and PA alone. Based on self-reports, however, PA improved significantly more with higher degrees of personalized advice.

The Food4Me Study was supported by the European Commission under the Food, Agriculture, Fisheries and Biotechnology Theme of the 7th Framework Programme for Research and Technological Development (grant number 265494). JCM was the Food4Me intervention study coordinator. CFMM and WHMS drafted the paper. CFMM and CCM performed the statistical analysis for the manuscript. $C A D, E R G, L B, Y M, I T, J A L, J A M, W H M S, H D, M G$, and JCM contributed to the research design. CCM, CFMM, CW, HF, CBO, RF, ALM, JAL, SNC, RSC, SK, AS, MG, CPL, GM, MCW, JH, and JCM contributed to developing the Standardized Operating Procedures for the study. CFMM, CCM, SNC, RSC, CW, HF, COB, RF, ALM, SK, CPL, GM, AS, MG, MCW, and JCM conducted the intervention. CFMM, WHMS, CCM, AG, and JH contributed to physical activity measurements. All authors contributed to a critical review of the manuscript. All authors approved the final version to be published. $A G$ and $\mathrm{JH}$ are employed by Philips. Others have no conflicts of interest to declare.

\section{References}

1. World Health Organization. Noncommunicable Diseases Country Profiles 2011. 207 p.

2. Ekelund U, Ward HA, Norat T, Luan J, May AM, Weiderpass E, et al. Physical activity and all-cause mortality across levels of overall and abdominal adiposity in European men and women: the European Prospective Investigation into Cancer and Nutrition Study (EPIC). The American journal of clinical nutrition. 2015;101(3):613-21.

3. Hallal PC, Andersen LB, Bull FC, Guthold R, Haskell W, Ekelund U, et al. Global physical activity levels: surveillance progress, pitfalls, and prospects. Lancet. 2012;380(9838):247-57.

4. Ronda G, Van Assema P, Brug J. Stages of change, psychological factors and awareness of physical activity levels in The Netherlands. Health promotion international. 2001;16(4):305-14.

5. Watkinson C, van Sluijs EM, Sutton S, Hardeman W, Corder K, Griffin SJ. Overestimation of physical activity level is associated with lower BMI: a cross-sectional analysis. The international journal of behavioral nutrition and physical activity. 2010;7:68.

6. Broekhuizen K, Kroeze W, van Poppel MN, Oenema A, Brug J. A systematic review of randomized controlled trials on the effectiveness of computer-tailored physical activity and dietary behavior promotion programs: an update. Annals of behavioral medicine : a publication of the Society of Behavioral Medicine. 2012;44(2):259-86.

7. Davies CA, Spence JC, Vandelanotte C, Caperchione CM, Mummery WK. Meta-analysis of internet-delivered interventions to increase physical activity levels. The international journal of behavioral nutrition and physical activity. 2012;9:52. 
8. Laplante C, Peng W. A systematic review of eHealth interventions for physical activity: an analysis of study design, intervention characteristics, and outcomes. Telemedicine journal and eHealth : the official journal of the American Telemedicine Association. 2011;17(7):509-23.

9. Neville LM, O'Hara B, Milat A. Computer-tailored physical activity behavior change interventions targeting adults: a systematic review. The international journal of behavioral nutrition and physical activity. 2009;6:30.

10. Tehard B, Saris WH, Astrup A, Martinez JA, Taylor MA, Barbe P, et al. Comparison of two physical activity questionnaires in obese subjects: the NUGENOB study. Medicine and science in sports and exercise. 2005;37(9):1535-41.

11. Celis-Morales CA, Perez-Bravo F, Ibanez L, Salas C, Bailey ME, Gill JM. Objective vs. self-reported physical activity and sedentary time: effects of measurement method on relationships with risk biomarkers. PloS one. 2012;7(5):e36345.

12. Dannecker KL, Sazonova NA, Melanson EL, Sazonov ES, Browning RC. A comparison of energy expenditure estimation of several physical activity monitors. Medicine and science in sports and exercise. 2013;45(11):2105-12.

13. Plasqui G, Bonomi AG, Westerterp KR. Daily physical activity assessment with accelerometers: new insights and validation studies. Obes Rev. 2013;14(6):451-62.

14. Ashe M, Winters M, Hoppmann C, Dawes M, Gardiner P, Giangregorio L, et al. "Not just another walking program": Everyday Activity Supports You (EASY) model--a randomized pilot study for a parallel randomized controlled trial. Pilot and Feasibility Studies. 2015;1(1):4.

15. Godino JG, Watkinson C, Corder K, Marteau TM, Sutton S, Sharp SJ, et al. Impact of personalised feedback about physical activity on change in objectively measured physical activity (the FAB study): a randomised controlled trial. PLoS One. 2013;8(9):e75398.

16. Wanner M, Martin-Diener E, Braun-Fahrlander C, Bauer G, Martin BW. Effectiveness of activeonline, an individually tailored physical activity intervention, in a real-life setting: randomized controlled trial. Journal of medical Internet research. 2009;11(3):e23.

17. Wijsman CA, Westendorp RG, Verhagen EA, Catt M, Slagboom PE, de Craen AJ, et al. Effects of a web-based intervention on physical activity and metabolism in older adults: randomized controlled trial. Journal of medical Internet research. 2013;15(11):e233.

18. Celis-Morales C, Livingstone KM, Marsaux CF, Forster H, O'Donovan CB, Woolhead C, et al. Design and baseline characteristics of the Food4Me study: a web-based randomised controlled trial of personalised nutrition in seven European countries. Genes \& nutrition. 2015;10(1):450.

19. Food4Me [Internet]. 2011 [cited 2015-03-26]. Available from: http://www.food4me.org.

20. Bonomi AG, Plasqui G, Goris AH, Westerterp KR. Estimation of free-living energy expenditure using a novel activity monitor designed to minimize obtrusiveness. Obesity (Silver Spring). 2010;18(9):1845-51.

21. Philips DirectLife: fitness, health and successful weight management [Internet]. 2011 [cited 201503-26]. Available from: http://www.directlife.philips.com.

22. Choi L, Liu Z, Matthews CE, Buchowski MS. Validation of accelerometer wear and nonwear time classification algorithm. Medicine and science in sports and exercise. 2011;43(2):357-64.

23. R Core Team. R: A language and Environment for Statistical Computing. R Foundation for Statistical Computing. 3.1.2 ed. Vienna, Austria 2014.

24. Henry CJ. Basal metabolic rate studies in humans: measurement and development of new equations. Public health nutrition. 2005;8(7A):1133-52.

25. World Health Organization. Global recommendations on physical activity for health 2010. 58 p.

26. Troiano RP, Berrigan D, Dodd KW, Masse LC, Tilert T, McDowell M. Physical activity in the United States measured by accelerometer. Medicine and science in sports and exercise. 2008;40(1):181-8.

27. Baecke JA, Burema J, Frijters JE. A short questionnaire for the measurement of habitual physical activity in epidemiological studies. Am J Clin Nutr. 1982;36(5):936-42.

28. Philippaerts RM, Westerterp KR, Lefevre J. Doubly labelled water validation of three physical activity questionnaires. Int J Sports Med. 1999;20(5):284-9. 
29. Montoye HJ, Kemper HC, Saris WH, Washburn RA. Measuring Physical Activity and Energy Expenditure: Human Kinetics; 1996. 190 p.

30. Celis-Morales C, Livingstone KM, Woolhead C, Forster H, O'Donovan CB, Macready AL, et al. How reliable is internet-based self-reported identity, socio-demographic and obesity measures in European adults? Genes \& nutrition. 2015;10(5):476.

31. Rousseeuw P, Croux C, Todorov V, Ruckstuhl A, Salibian-Barrera M, Verbeke T, et al. robustbase: Basic Robust Statistics. R package version 0.92-3. 2015.

32. Hurling R, Catt M, Boni MD, Fairley BW, Hurst T, Murray $P$, et al. Using internet and mobile phone technology to deliver an automated physical activity program: randomized controlled trial. Journal of medical Internet research. 2007;9(2):e7.

33. Livingstone KM, Celis-Morales C, Navas-Carretero S, San-Cristobal R, O'Donovan CB, Forster H, et al. Profile of European adults interested in internet-based personalised nutrition: the Food4Me study. European journal of nutrition. 2015.

34. Norman GJ, Zabinski MF, Adams MA, Rosenberg DE, Yaroch AL, Atienza AA. A review of eHealth interventions for physical activity and dietary behavior change. American journal of preventive medicine. 2007;33(4):336-45.

35. Valenti G, Camps SG, Verhoef SP, Bonomi AG, Westerterp KR. Validating measures of free-living physical activity in overweight and obese subjects using an accelerometer. Int J Obes (Lond). 2014;38(7):1011-4.

36. Hagstromer M, Ainsworth BE, Oja P, Sjostrom M. Comparison of a subjective and an objective measure of physical activity in a population sample. Journal of physical activity \& health. 2010;7(4):541-50.

37. Walsh MC, Hunter GR, Sirikul B, Gower BA. Comparison of self-reported with objectively assessed energy expenditure in black and white women before and after weight loss. The American journal of clinical nutrition. 2004;79(6):1013-9.

38. Dhurandhar NV, Schoeller D, Brown AW, Heymsfield SB, Thomas D, Sorensen TI, et al. Energy balance measurement: when something is not better than nothing. Int J Obes (Lond). 2014.

Supplementary Material 3.1 Physical activity in feedback reports and on the Food4Me website

Feedback on physical activity in personalized reports

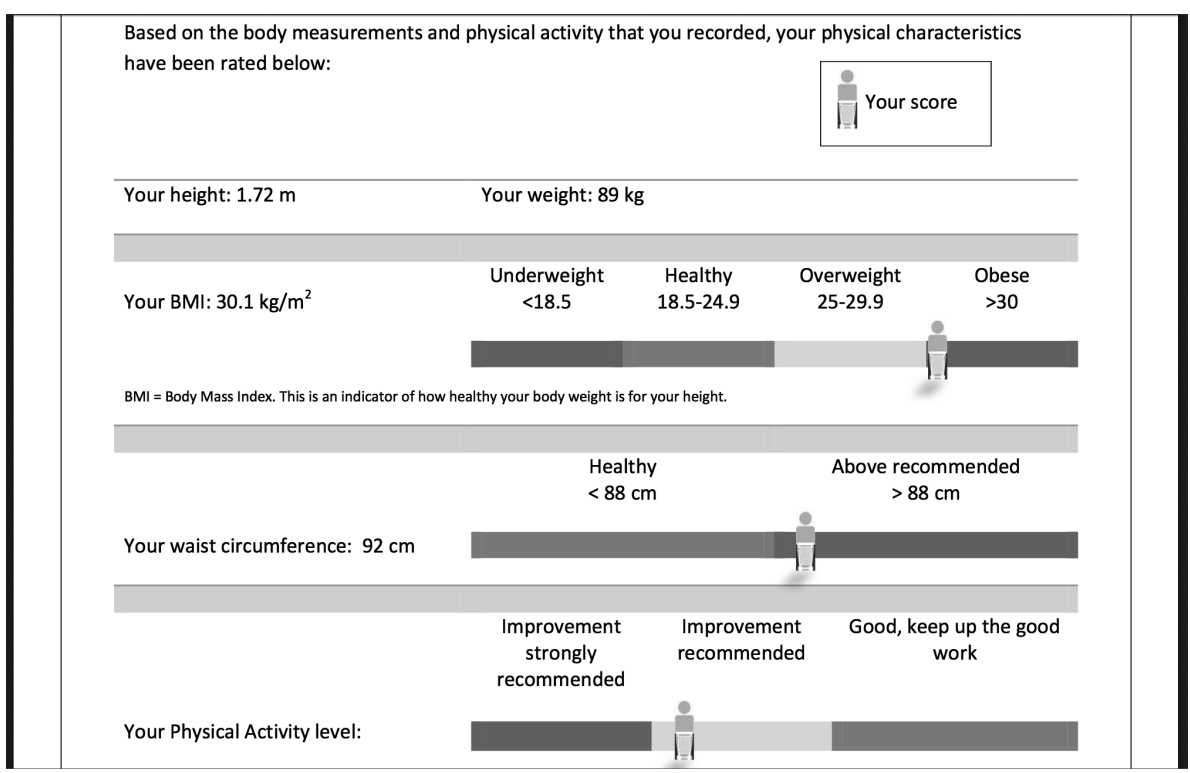




\section{Supplementary Material 3.1 Continued}

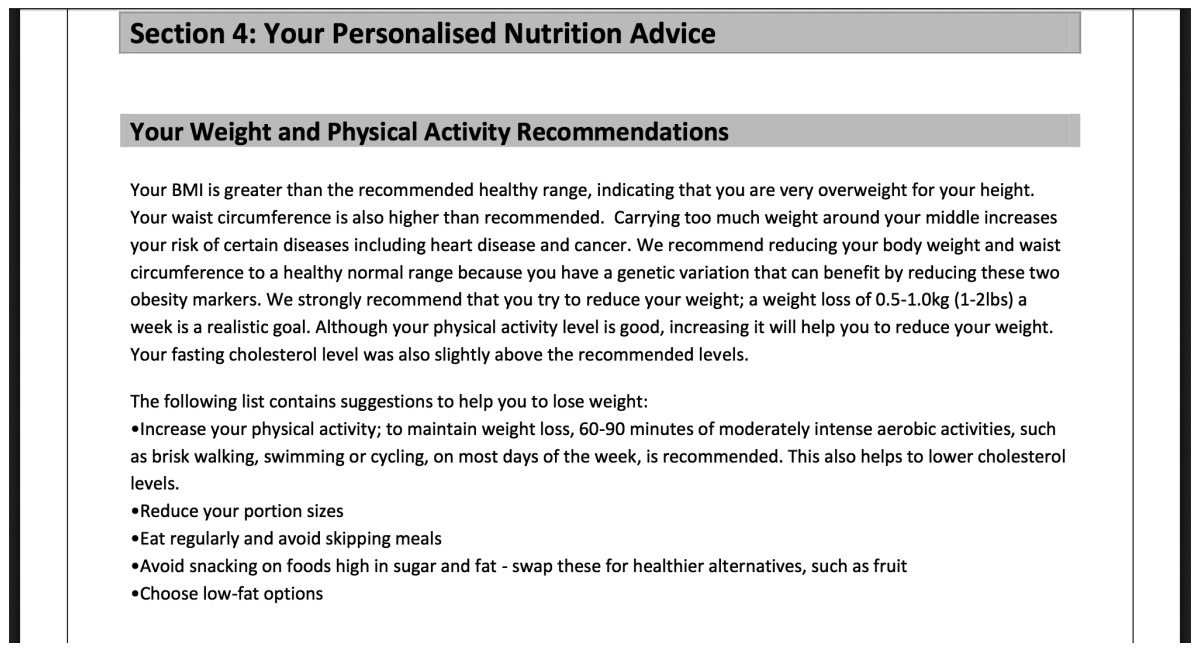

Information on physical activity and tips on the Food4Me webpage for participants in personalized nutrition $(P N)$ groups

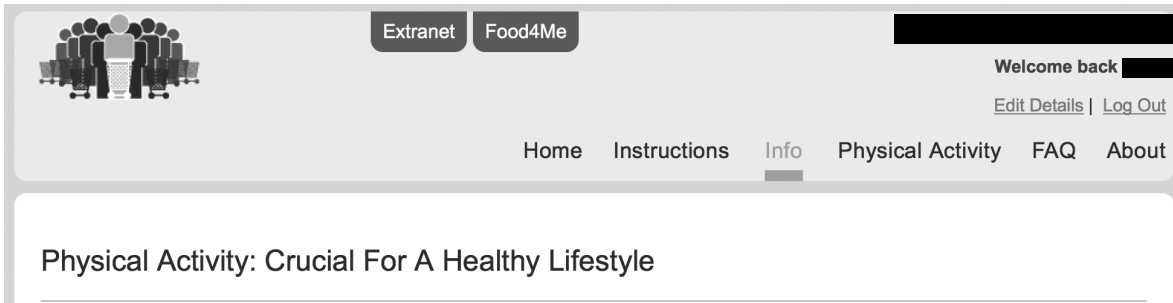

The importance of physical activity for health

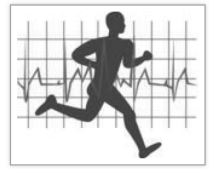

Physical activity is an essential element within a healthy lifestyle pattern. If you combine healthy, varied and balanced dietary habits with the regular practice of moderate exercise, you should be able to prevent most of cardiovascular diseases. In addition, you will manage to keep a healthy and adequate body weight.

We can divide physical activity into three categories:

- Stretching: Exercises focused on giving flexibility to muscles and joints.

- Aerobic: Exercise focused on increasing cardiovascular endurance

- Anaerobic: Exercise focused on increasing short-term muscle strength.

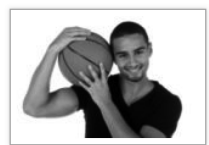

Aerobic exercise is the type of exercise with which our health will improve, and it can be graded depending on your age and physical conditions. Examples of this type of exercise are fast walking, soft running or jogging, tennis practice, swimming, etc.

Research has focused on how exercise can improve your health, and to which extent physical activity is important to help to prevent chronic diseases. The regular practice of aerobic exercise of moderate intensity has been proven to help maintain body weight, by reducing fat mass and increasing muscle strength, to build and maintain bone density, strengthen the immune system, and reduce surgical risks. It also helps to promote a physiological and psychological well-being. Aerobic exercise has also been shown to help prevent or treat serious and life-threatening chronic conditions such as high blood pressure, heart disease, Type 2 diabetes, insomnia, and depression.

According to the World Health Organization, lack of physical activity contributes to approximately $17 \%$ of heart disease and diabetes, $12 \%$ of falls in the elderly, and $10 \%$ of breast and colon cancer. 


\section{Supplementary Material 3.1 Continued}

How physically active should you be?

You need at least:

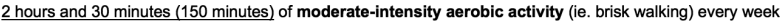

Muscle-strengthening activities on $\underline{2}$ or more davs a week that work all major muscle groups (legs, hips, back, abdomen, chest, shoulders and arms)

OR

1 hour and 15 minutes ( 75 minutes) of vigorous-intensity aerobic activity (ie. jogging/running) every week

Muscle-strengthening activities on 2 or more davs a week that work all major muscle groups (legs, hips, back, abdomen, chest, shoulders and arms)

OR

An equivalent mix of moderate and vigorous-intensity aerobic activity

Muscle-strengthening activities on $\mathbf{2}$ or more days a week that work all major muscle groups (legs, hips, back, abdomen, chest, shoulders and arms)

Tips for improving your physical activity level

10 minutes at a time is fine

We know 150 minutes each week sounds like a lot of time, but you don't have to do it all at once. Not only is it best to spread your activity out during the week, but you can break it up into smaller chunks of time during the day. As long as you're doing your activity at a moderate or vigorous effort for at least 10 minutes at a time.

Give it a try!

Try going for a 10 minute brisk walk, 3 times a day, 5 times a week. This will give you a total of 150 minutes of moderate intensity physical activity.

Remember that being active...

- Reduces risk of obesity, cardiovascular diseases, diabetes

- Helps to maintain a healthy weight

- Helps to maintain the ability to perform everyday tasks with ease

- Improves self-esteem

- Reduces symptoms of depression and anxiety

Moderate intensity aerobic activity

means you're working hard enough to raise your heart rate and start to sweat. One way to tell is that you'll be able to talk, but not sing your favourite song. Here are some examples of activities which require moderate effort:

\section{- Walking fast}

- Doing water aerobics

- Riding a bike on level ground or with few hills

- Playing doubles tennis

- Pushing a lawnmower
Vigorous intensity aerobic activity

means that you're breathing hard and fast, and your heart rate has gone up quite a bit. If you're active at this level, you won't be able to say more than a few words without pausing to catch your breath. Here are some examples of activities which require a vigorous effort:

- Jogging or running

- Swimming laps

- Riding a bike fast or on hills

- Playing singles tennis

- Playing basketball 
Supplementary Material 3.2 Baseline characteristics of the Food4Me participants who received personalized advice to increase physical activity and matched controls - targeted approach

\begin{tabular}{|c|c|c|c|c|}
\hline \multirow[t]{2}{*}{ Variables } & \multirow{2}{*}{$\begin{array}{c}\text { Matched } \\
\text { Control } \\
\text { Level } 0 \\
\end{array}$} & \multicolumn{3}{|c|}{ Personalized advice } \\
\hline & & Level 1 & Level 2 & Level 3 \\
\hline & $\mathrm{n}=275$ & $n=268$ & $n=274$ & $\mathrm{n}=265$ \\
\hline Ethnicity - White (\%) & 94.9 & 97 & 98.2 & 96.6 \\
\hline Sex - Women (\%) & 62.2 & 56 & 60.6 & 63.4 \\
\hline Age (years) & $40.2(13.2)$ & $39.4(13.1)$ & $40.8(12.9)$ & $40.1(13.2)$ \\
\hline \multicolumn{5}{|l|}{ Anthropometrics } \\
\hline Height $(\mathrm{cm})$ & $170.9(9.4)$ & $171.9(9.6)$ & $170.4(9.3)$ & $170.5(9.2)$ \\
\hline Weight $(\mathrm{kg})$ & $74.8(16)$ & $75.4(17.6)$ & $75.4(16)$ & $76.1(16.3)$ \\
\hline $\mathrm{BMI}\left(\mathrm{kg} \cdot \mathrm{m}^{-2}\right)$ & 25.6 (5) & $25.5(5.4)$ & $25.9(5.1)$ & 26.1 (5.1) \\
\hline Overweight (\%) & 32.4 & 26.5 & 27.4 & 37.7 \\
\hline Obese (\%) & 16.4 & 17.5 & 21.2 & 17.7 \\
\hline Current smokers (\%) & 14.9 & 13.4 & 9.5 & 14.7 \\
\hline Ex-smokers (\%) & 22.9 & 26.1 & 24.8 & 23 \\
\hline Non-smokers (\%) & 62.2 & 60.4 & 65.7 & 62.3 \\
\hline \multicolumn{5}{|l|}{ Objective PA } \\
\hline & $\mathrm{n}=237$ & $n=233$ & $\mathrm{n}=246$ & $n=230$ \\
\hline PAL & $1.64(0.09)$ & $1.66(0.11)$ & $1.66(0.11)$ & $1.66(0.1)$ \\
\hline AEE $\left(k\right.$ cal. $\left.d^{-1}\right)$ & $735(178)$ & $782(215)$ & $769(191)$ & 759 (182) \\
\hline Sedentary time $\left(\min \cdot d^{-1}\right)$ & $757(73)$ & $747(78)$ & $757(73)$ & $763(73)$ \\
\hline $\operatorname{LPA}\left(\min \cdot d^{-1}\right)$ & $65(24)$ & $68(28)$ & $66(24)$ & $66(24)$ \\
\hline MPA $\left(\min \cdot d^{-1}\right)$ & $26(16)$ & $30(17)$ & $27(16)$ & $27(17)$ \\
\hline $\operatorname{VPA}\left(\min \cdot d^{-1}\right)$ & $6(9)$ & $8(10)$ & $7(10)$ & $6(8)$ \\
\hline Moderate-equivalent PA $\left(\min . \mathrm{d}^{-1}\right)$ & $38(28)$ & $46(32)$ & $42(29)$ & $39(27)$ \\
\hline $\begin{array}{l}\text { Moderate-equivalent PA in bouts } \\
\left(\min . d^{-1}\right)\end{array}$ & $16(19)$ & $20(21)$ & $19(18)$ & $18(19)$ \\
\hline \multicolumn{5}{|l|}{ Self-reported PA } \\
\hline & $\mathrm{n}=275$ & $n=268$ & $n=274$ & $\mathrm{n}=264$ \\
\hline Total activity index & $7.32(1.25)$ & $7.64(1.36)$ & $7.49(1.3)$ & $7.35(1.4)$ \\
\hline Work index & $2.21(0.56)$ & $2.3(0.62)$ & $2.23(0.58)$ & $2.22(0.59)$ \\
\hline Sport index & $2.49(0.75)$ & $2.63(0.79)$ & $2.59(0.8)$ & $2.53(0.8)$ \\
\hline Leisure time (non-sport) index & $2.63(0.65)$ & $2.73(0.65)$ & $2.67(0.64)$ & $2.64(0.64)$ \\
\hline
\end{tabular}

Data are presented as unadjusted means (SD) for continuous variables and percentages for categorical variables. Levels 1-3 received personalized advice. Matched control group (Level 0) participants are controls who would have received personalized advice to increase PA if they had been in a PN group and not LO. PA, physical activity; PAL, physical activity level; AEE, activity energy expenditure; $L P A$, light PA; MPA, moderate PA; VPA, vigorous PA; Moderate-equivalent PA is (MPA $+2 \times V P A)$. 
Supplementary Material 3.3 Changes from baseline to month 3 in objectively measured physical activity for the total cohort-generic approach.
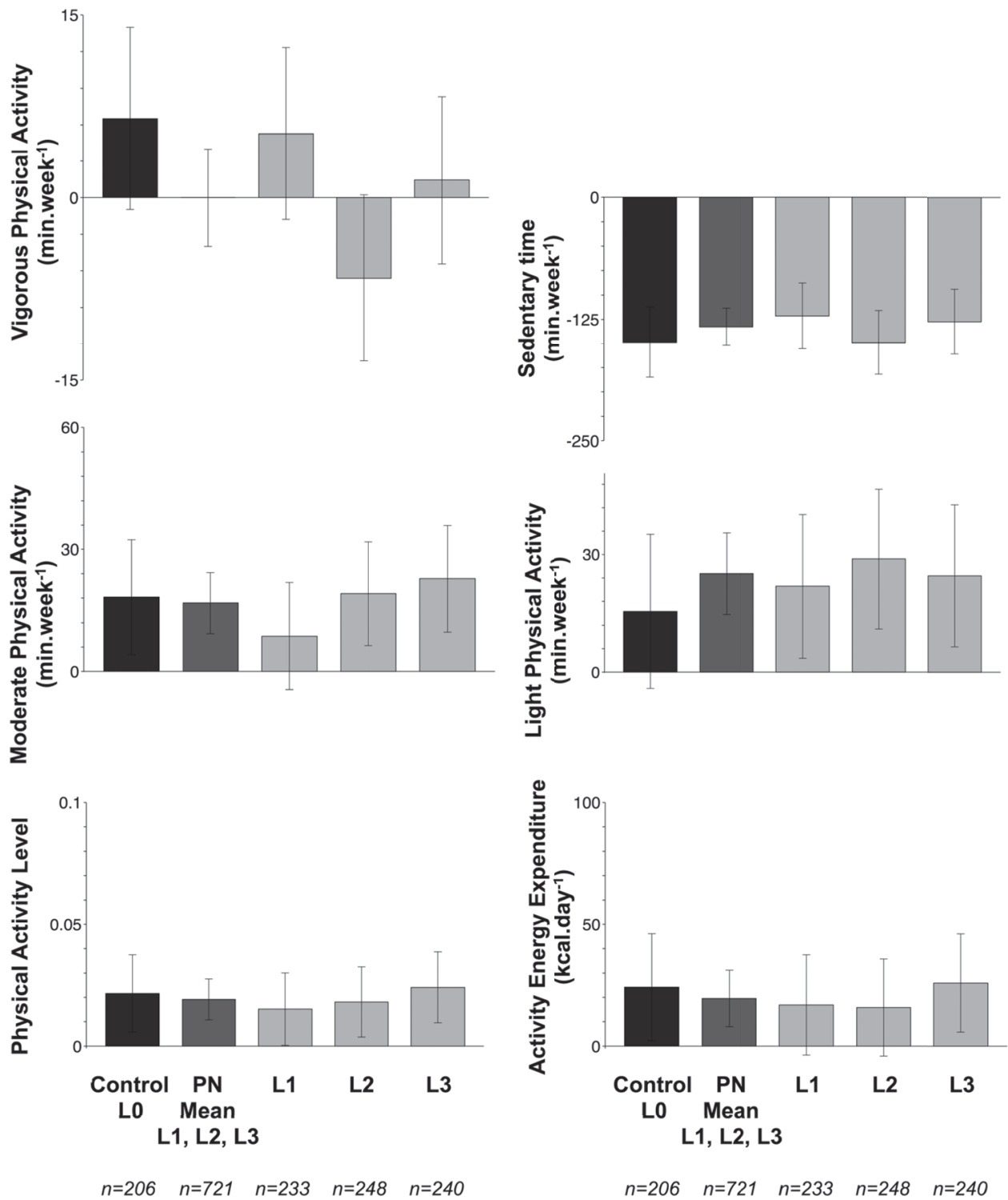

Data are presented as adjusted changes from baseline. Error bars represent $95 \%$ confidence intervals. Models were adjusted for baseline values, sex, age, country, smoking, baseline BMI, baseline season, change in body weight, and change in accelerometer wear time 
Supplementary Material 3.4 Changes from baseline to month 6 in objectively measured physical activity for the total cohort-generic approach.

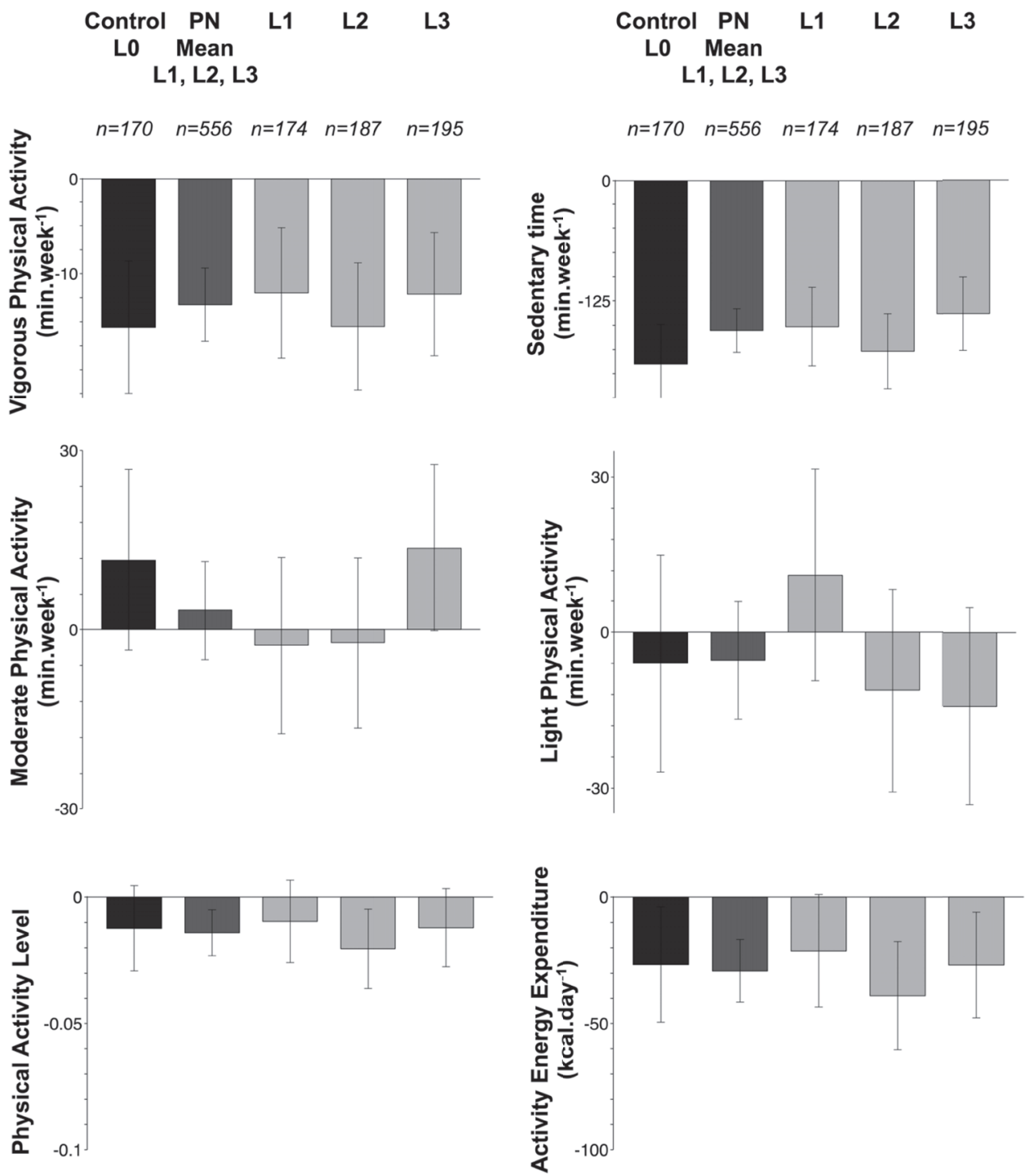

Data are presented as adjusted changes from baseline. Error bars represent $95 \%$ confidence intervals. Models were adjusted for baseline values, sex, age, country, smoking, baseline BMI, baseline season, change in body weight, and change in accelerometer wear time. 
Supplementary Material 3.5 Changes from baseline to month 3 in objectively measured physical activity for participants who received advice to increase PA (L1 to L3) and matched controls (LO)targeted approach.
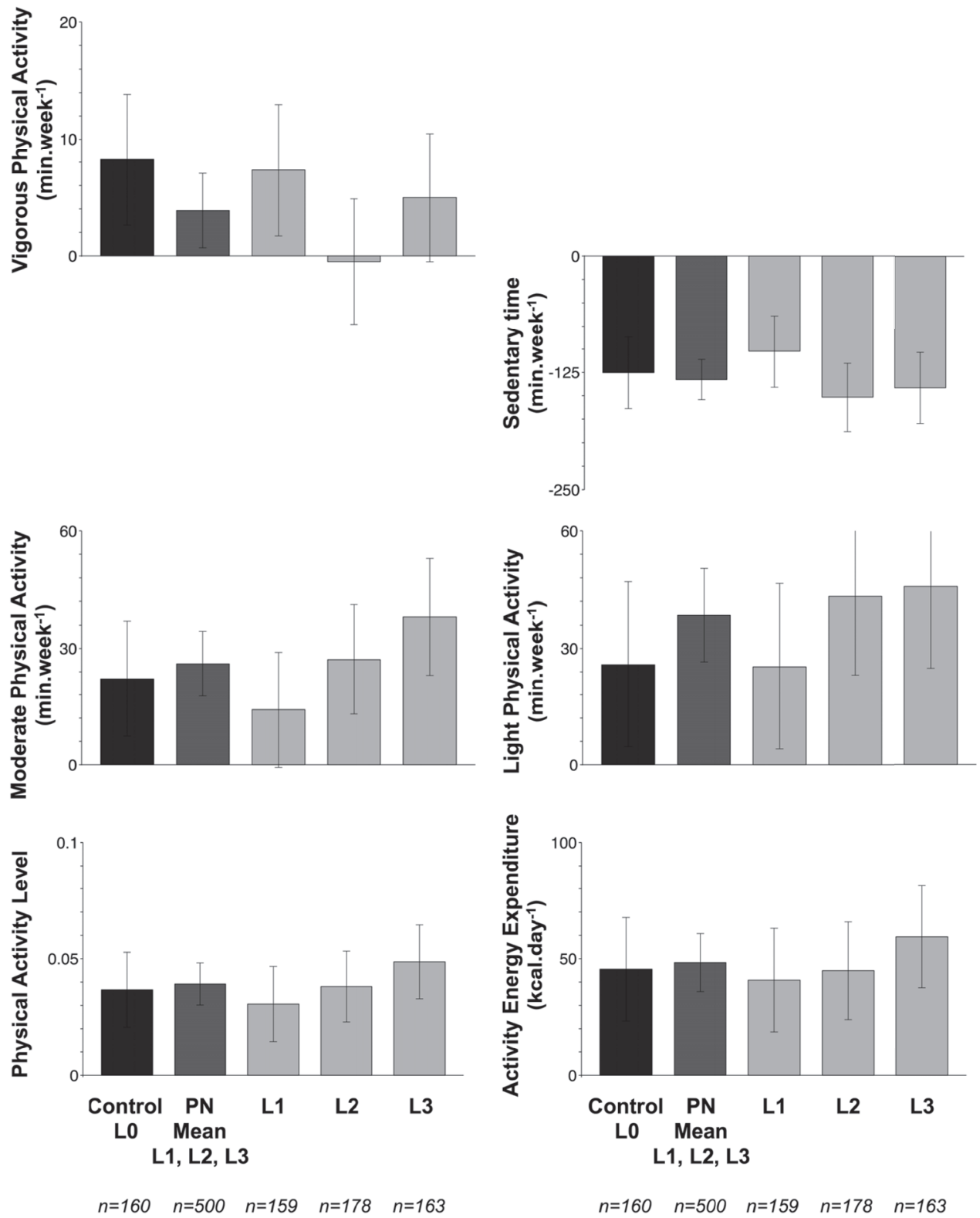

Data are presented as adjusted changes from baseline. Error bars represent $95 \%$ confidence intervals. Models were adjusted for baseline values, sex, age, country, smoking, baseline BMI, baseline season, change in body weight, and change in accelerometer wear time 
Supplementary Material 3.6 Effect of targeted intervention on physical activity for personalized groups at month 6

\begin{tabular}{|c|c|c|c|c|c|}
\hline \multirow[t]{3}{*}{ PA components } & \multicolumn{3}{|c|}{ Personalized advice } & \multicolumn{2}{|c|}{$P$} \\
\hline & $\begin{array}{l}\text { Level } 1 \\
(n=114)\end{array}$ & $\begin{array}{l}\text { Level } 2 \\
(n=134)\end{array}$ & $\begin{array}{l}\text { Level } 3 \\
(=131)\end{array}$ & $\begin{array}{l}\text { L1 } \\
\text { vs }\end{array}$ & $\begin{array}{l}\text { L2 } \\
\text { vs }\end{array}$ \\
\hline & & & & $\mathrm{L} 2+\mathrm{L} 3$ & L3 \\
\hline \multicolumn{6}{|l|}{ Objective PA } \\
\hline PAL & $1.68(0.1)$ & $1.67(0.1)$ & $1.67(0.1)$ & 0.33 & 0.75 \\
\hline AEE $\left(\right.$ kcal. $\left.^{-1}\right)$ & $790(134)$ & $770(137)$ & $775(136)$ & 0.26 & 0.79 \\
\hline $\begin{array}{l}\text { Sedentary time } \\
\left(\min \cdot w^{-1}\right)\end{array}$ & $5204(248)$ & 5187 (249) & $5215(248)$ & 0.91 & 0.37 \\
\hline LPA (min. $\left.w k^{-1}\right)$ & $503(131)$ & $480(132)$ & $476(130)$ & 0.10 & 0.79 \\
\hline MPA $\left(\min \cdot w^{-1}\right)$ & $203(97)$ & $196(98)$ & $221(98)$ & 0.66 & 0.04 \\
\hline VPA $\left(\min \cdot w^{-1}\right)$ & $48(33)$ & $42(35)$ & $44(34)$ & 0.20 & 0.61 \\
\hline $\begin{array}{l}\text { Moderate-equivalent } \\
\left.\text { PA (min.wk }{ }^{-1}\right)\end{array}$ & 307 (152) & 297 (157) & $323(154)$ & 0.88 & 0.18 \\
\hline $\begin{array}{l}\text { Moderate-equivalent } \\
\text { PA in bouts (min.wk }{ }^{-1} \text { ) }\end{array}$ & $134(101)$ & $123(104)$ & $136(102)$ & 0.68 & 0.32 \\
\hline \multicolumn{6}{|l|}{ Self-reported PA } \\
\hline Total activity index ${ }^{a}$ & $7.62(0.87)$ & $7.84(0.87)$ & $7.83(0.87)$ & 0.006 & 0.91 \\
\hline Work index ${ }^{a}$ & $2.24(0.3)$ & $2.27(0.3)$ & $2.29(0.3)$ & 0.13 & 0.39 \\
\hline Sport index ${ }^{b}$ & $2.62(0.5)$ & $2.69(0.51)$ & $2.66(0.51)$ & 0.18 & 0.48 \\
\hline $\begin{array}{l}\text { Leisure time (non- } \\
\text { sport) index }\end{array}$ & $2.79(0.48)$ & $2.9(0.48)$ & $2.9(0.48)$ & 0.008 & 0.99 \\
\hline
\end{tabular}

$P A$, physical activity; $L O$, level 0; $L 1$, level 1; $L 2$, level 2; $L 3$, level 3; $P A L$, physical activity level, $A E E$, activity energy expenditure; $L P A$, light $P A ; M P A$, moderate $P A ; V P A$, vigorous $P A ;$ Moderate-equivalent $P A$ is $(M P A+2 \times V P A)$.

a $n=220$ (LO), 198 (L1), 210 (L2), 207 (L3), 615 (pooled L1, L2, L3). For retired or unemployed individuals, work index, and therefore total index, cannot be calculated.

${ }^{b} n=232$ (LO), 217 (L1), 230 (L2), 223 (L3), 670 (pooled L1, L2, L3).

Analysis is restricted to participants randomized to Levels 1-3 $(L 1, L 2, L 3)$ receiving personalized advice to increase PA. Data are presented as adjusted means with the corresponding $95 \%$ confidence interval. All analyses were adjusted for baseline values, sex, age, country, smoking, baseline BMI, baseline season and change in body weight. In addition for objective PA variables, analyses were adjusted for change in accelerometer wear time. 
Supplementary Material 3.7 Changes from baseline to month 6 in self-reported physical activity (Baecke questionnaire) for the total cohort-generic approach.
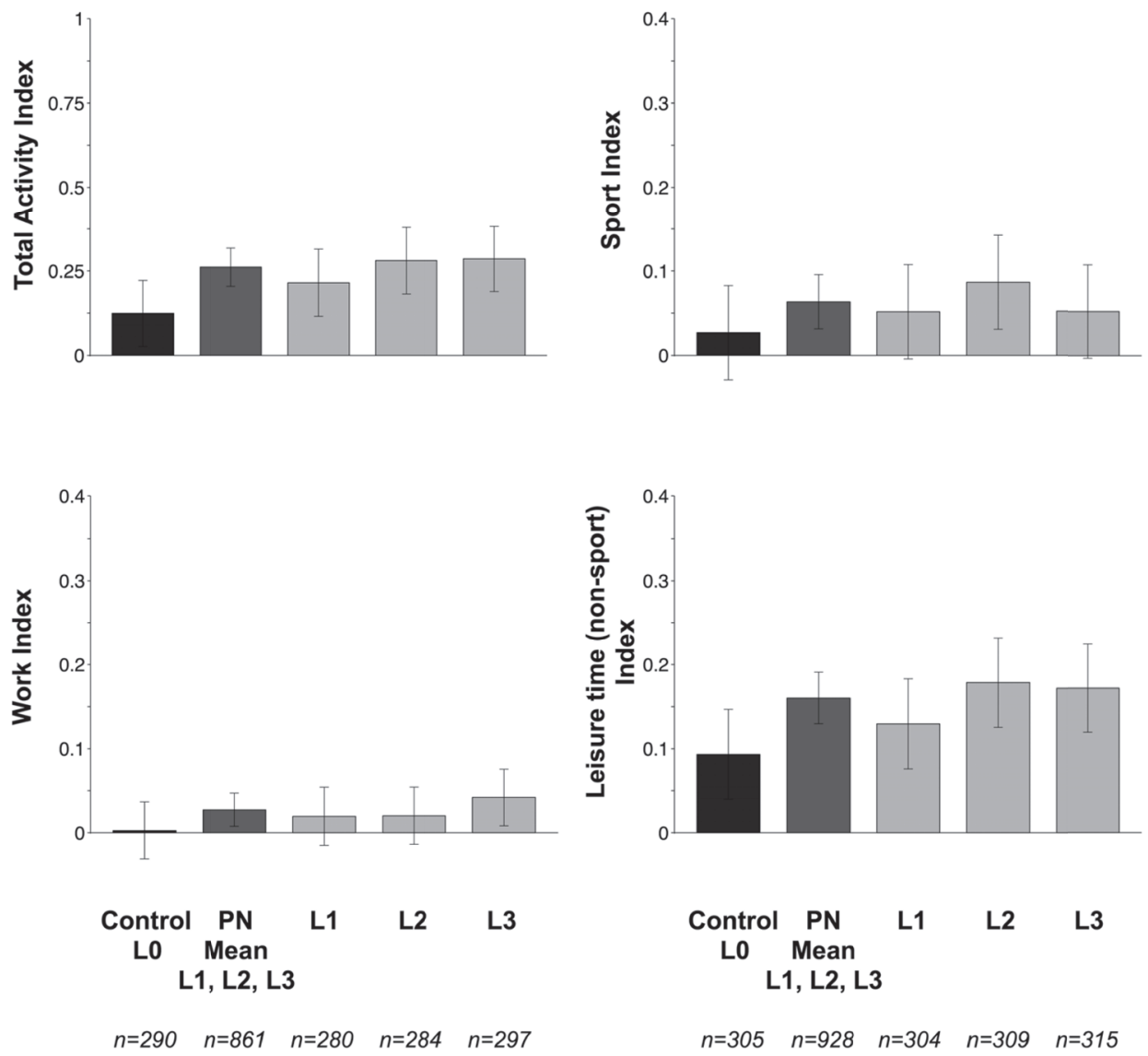

Data are presented as adjusted changes from baseline. Error bars represent $95 \%$ confidence intervals. Models were adjusted for baseline values, sex, age, country, smoking, baseline BMI, baseline season, and change in body weight 
Supplementary Material 3.9 Changes from baseline to month 3 in self-reported physical activity (Baecke questionnaire) for the total cohort-generic approach.
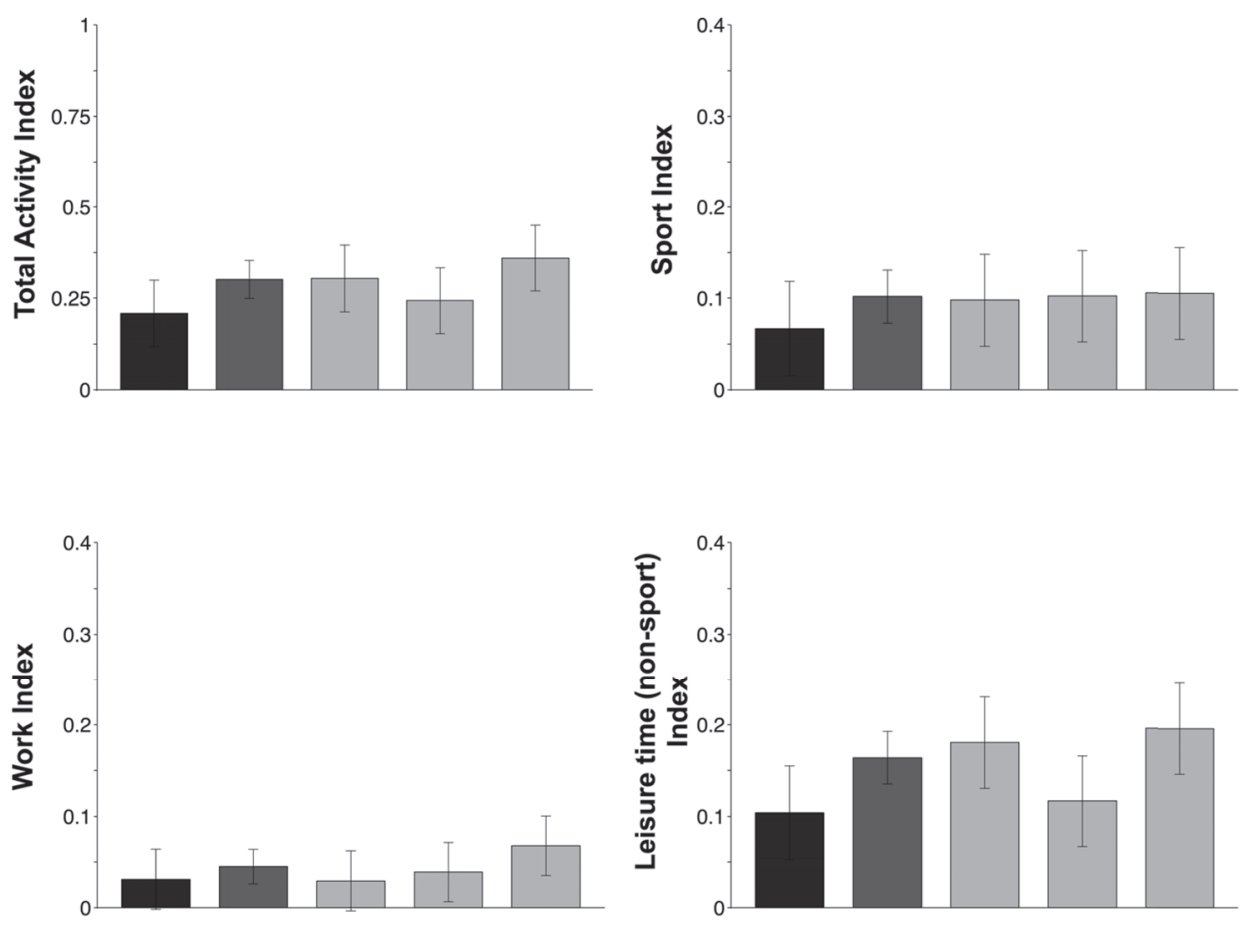

$$
\begin{aligned}
& \underset{\substack{\text { Control } \\
\text { L0 }} \underset{\text { Mean }}{\text { L1, L2, L3 }} \text { L1 }}{\text { Pe2 }} \quad \text { L3 } \\
& n=299 \quad n=902 \quad n=291 \quad n=303 \quad n=308
\end{aligned}
$$

$$
\begin{aligned}
& \underset{\substack{\text { Control } \\
\text { L0 }} \underset{\text { Mean }}{\text { L1, L2, L3 }} \text { L1 }}{\text { PN }} \quad \text { L2 } \\
& n=313 \quad n=973 \quad n=318 \quad n=330 \quad n=325
\end{aligned}
$$

Data are presented as adjusted changes from baseline. Error bars represent $95 \%$ confidence intervals. Models were adjusted for baseline values, sex, age, country, smoking, baseline BMI, baseline season, and change in body weight 
Supplementary Material 3.9 Changes from baseline to month 3 in self-reported physical activity (Baecke questionnaire) for participants who received advice to increase physical activity (L1 to L3) and matched controls (LO)-targeted approach.
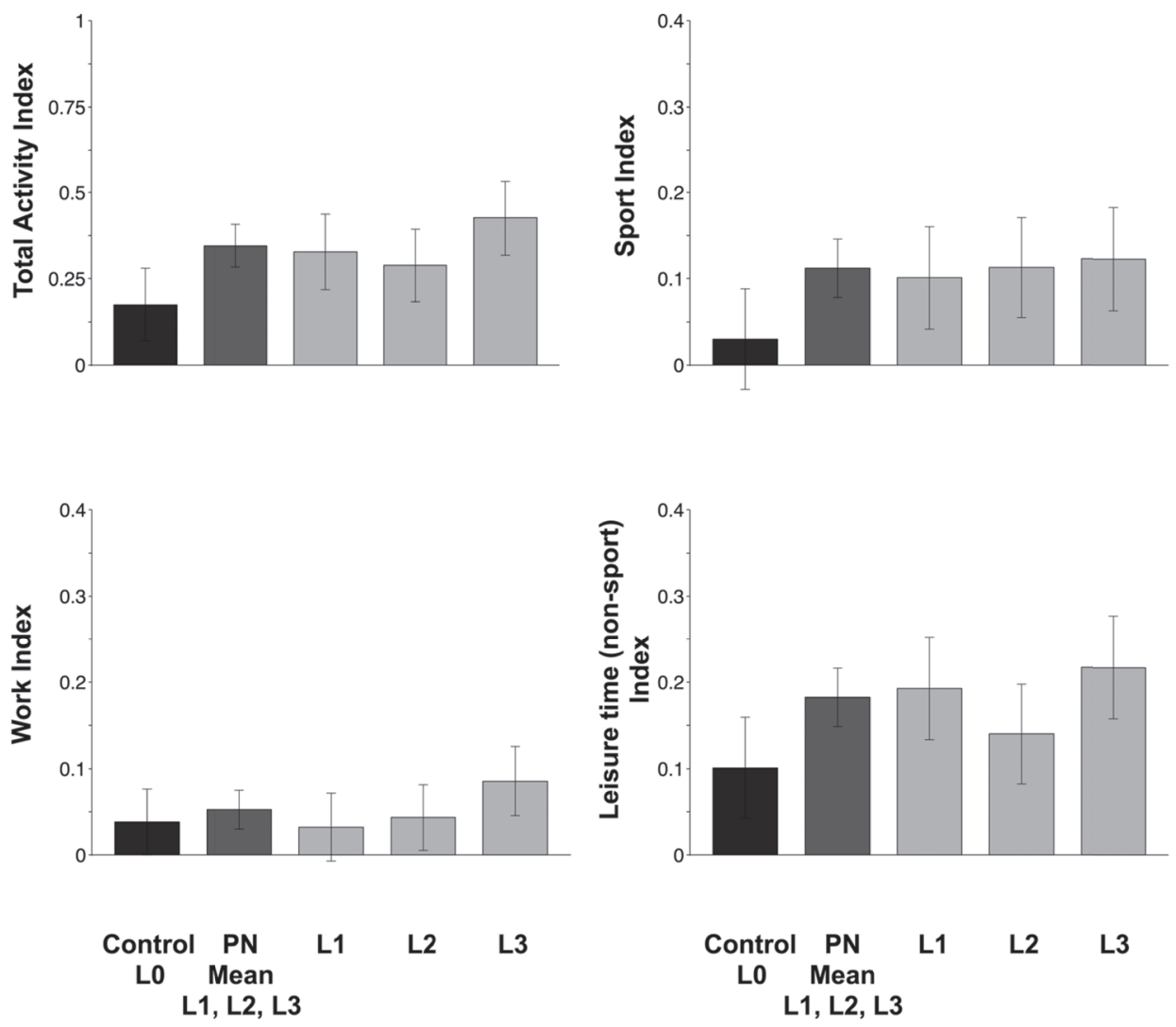

$n=227 \quad n=646 \quad n=208 \quad n=224 \quad n=214$

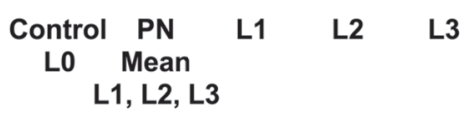

$n=239 \quad n=699 \quad n=228 \quad n=243 \quad n=228$

Data are presented as adjusted changes from baseline. Error bars represent 95\% confidence intervals. Models were adjusted for baseline values, sex, age, country, smoking, baseline BMI, baseline season, and change in body weight 


\section{CHAPTER 4}

\section{Physical activity attenuates the effect of the FTO genotype on obesity traits in European adults: findings from the Food4Me Study}

Celis-Morales $\mathrm{C}^{*}$, Marsaux $\mathrm{CF}^{*}$, Livingstone KM, Navas-Carretero S, SanCristobal R, O'Donovan CB, Forster $\mathrm{H}$, Woolhead C, Fallaize $\mathrm{R}$, Macready AL, Kolossa S, Hallmann J, Tsirigoti L, Lambrinou C-P, Moschonis G, Godlewska M, Surwillo A, Grimaldi K, Bouwman J. Manios Y, Traczyk I, Drevon CA, Parnell LD, Daniel H, Gibney ER, Brennan L, Walsh MC, Gibney M, Lovegrove JA, Martinez JA, Saris WH, Mathers JC 


\section{Abstract}

Background: We aimed to examine whether the effect of FTO loci on obesity-related traits could be modified by physical activity (PA) levels in European adults. Methods: Of 1,607 Food4Me participants randomised, 1,280 were genotyped for the FTO (rs9939609) and had available PA data. PA was measured objectively using accelerometers (TracmorD, Philips), whereas anthropometric measures (BMI, and waist circumference; WC) were self-reported via the Internet. Results: FTO risk genotype was associated with a higher body weight $(\beta: 1.09 \mathrm{~kg}$ per risk allele, $[95 \% \mathrm{Cl}$ : 0.14-2.04]; $P=0.024)$, BMI ( $\beta: 0.54$ kg.m $\left.{ }^{-2},[0.23-0.83] ; P<0.0001\right)$ and $W C(\beta: 1.07 \mathrm{~cm}$, [0.24-1.90]; $P=0.011)$. Moderate-equivalent $\mathrm{PA}$ attenuated the effect of $F T O$ on BMI $\left(P_{[\text {interaction] }}=0.020\right)$. Among inactive individuals, $F T O$ increased BMI by $1.06 \mathrm{~kg} \cdot \mathrm{m}^{-2}$ per allele $(P=0.024)$ whereas the increase in BMI was substantially attenuated among active individuals $\left(0.16 \mathrm{~kg} \cdot \mathrm{m}^{-2}, \quad P=0.388\right)$. We observed similar effects for WC $\left(P_{\text {[interaction] }}=0.005\right)$ : the $F T O$ risk allele increased $W C$ by $2.72 \mathrm{~cm}$ per allele among inactive individuals but by only $0.49 \mathrm{~cm}$ in active individuals. Conclusions: PA attenuates the effect of FTO genotype on BMI and WC. This may have important public health implications because genetic susceptibility to obesity in the presence of FTO variants may be reduced by adopting a physically active lifestyle.

\section{Introduction}

Changes in lifestyle, including higher energy intake and lack of physical activity (PA), have been the driving force behind the dramatic increase in obesity prevalence over the past three decades [1,2]. The prevalence of obesity has increased markedly, with $16.6 \%$ of European adults [3] and $9.3 \%$ of adults globally now having obesity [4]. However, epidemiological studies show that genetic factors play an important role in the development of obesity [5], suggesting that obesity is a multifactorial condition influenced by a complex interplay between lifestyle and genetics $[2,5,6]$.

Recent genome wide association studies have identified single nucleotide polymorphisms (SNPs) in genes [7], including the fat mass and obesity-associated gene (FTO), that are strongly associated with the development of obesity [7-10]. A study of 38,759 individuals revealed that subjects homozygous for the FTO (rs9939609) risk allele weighed on average $3 \mathrm{~kg}$ more and had 1.7-fold increased odds of being obese compared with individuals homozygous for the lower-risk allele [10]. Although the evidence for an effect of FTO, or other obesity-related loci, on obesity is strong, the variance in BMI explained by genetic variants is small $(2.7 \%)[11,12]$. This is in stark contrast with earlier studies of the heritability of BMI, which was estimated to be 
$40-70 \%[5,13]$. Gene-lifestyle interactions may contribute to the unexplained heritability of BMI and obesity [14,15], and numerous such interactions for many different cardiometabolic phenotypes, including obesity anthropometrics, were recently catalogued from 386 published scientific reports [16]. Much work remains to determine how robust these interactions are. Still, modulation of FTO-obesity associations by self-reported (SR) PA is one of the most replicated [16].

Although genetically predisposed individuals may be more susceptible to obesity in an obesogenic environment, with a higher risk of over-consumption as was shown in twin studies [13], there has been limited evidence of genotype-lifestyle interactions on adiposity outcomes [6,17]. Importantly, most of the studies to date have focused on the interplay between genes and self-reported (SR) PA, where measurement error in SR PA may have attenuated the true strength of the gene-PA interaction [18]. To date, only very few studies have used objectively measured PA to examine the FTO-PA interaction in adults $[19,20]$. Therefore, in the current study, we investigated whether the effect of the FTO loci on obesity-related traits was modified by objectively measured PA in European adults from the Food4Me study.

\section{Methods}

\section{Study population}

The Food4Me Proof of Principle (PoP) study was a 6-month, 4-arm, Internet-based, randomized controlled trial (RCT) conducted across seven European countries (www.food4me.org) [21]. 1,607 participants from the following recruitment sites: University College Dublin (Ireland), Maastricht University (The Netherlands), University of Navarra (Spain), Harokopio University (Greece), University of Reading (United Kingdom, UK), National Food and Nutrition Institute (Poland), and Technical University of Munich (Germany), were randomized into the RCT. The number of participants recruited and randomized in each country has been reported previously [21,22]. Participants aged $\geq 18$ years of age were included in the study. To keep the cohort as representative as possible of the adult European population, a minimal set of exclusion criteria were applied as described elsewhere [21].

\section{Study measures}

Participants consented to self-report their measures via the Internet and to send biological samples (Dried Blood Spot cards and buccal swabs) by post, using pre-paid, stamped addressed envelopes. To ensure that procedures were similar in all recruiting 
centres, standardised operating procedures were prepared for all measurements, and researchers underwent centralised training. Moreover, to enable participants to collect and report the required information and to collect, process and dispatch the biological samples correctly, participants were given printed detailed instructions, and video demonstrations of key procedures were available online. All instructions were provided in the language of the country of recruitment [21].

\section{Collection of demographic and anthropometric data}

An online screening questionnaire collected detailed SR information on demographic, food choices, health-related and anthropometric data. At baseline, body weight, height and waist circumference (WC) were self-measured and self-reported by participants via the Internet. Participants were instructed to measure body weight after an overnight fast, without shoes and wearing light clothing using a home or commercial scale, and to measure height, barefoot, using a standardised measuring tape provided by Food4Me [21]. WC was measured at the mid-point between the lower rib and the iliac crest using the provided tape measure. Central obesity was defined as WC $>88 \mathrm{~cm}$ for women and $>102 \mathrm{~cm}$ for men. BMI was calculated from body weight and height. Adiposity status was defined using WHO criteria for BMI (underweight $<18.5 \mathrm{~kg} \cdot \mathrm{m}^{-2}$, normal weight $\geq 18.5$ $\mathrm{kg} \cdot \mathrm{m}^{-2}$ to $\leq 24.9 \mathrm{~kg} \cdot \mathrm{m}^{-2}$, overweight $\geq 25.0 \mathrm{~kg} \cdot \mathrm{m}^{-2}$ to $\leq 29.9 \mathrm{~kg} \cdot \mathrm{m}^{-2}$ and obese $\geq 30.0 \mathrm{~kg} \cdot \mathrm{m}^{-}$ $\left.{ }^{2}\right)$. SR measurements were validated in a sub-sample of the participants $(n=140)$ and showed a high degree of reliability [23].

\section{Physical activity measures and analysis}

Physical activity levels (PAL) and time spent in sedentary behaviours were measured objectively using tri-axial accelerometers (TracmorD, Philips Consumer Lifestyle, The Netherlands) [24]. All participants were instructed to wear the accelerometer every day during waking hours, except when taking a shower, for the whole duration of the study. For the analyses reported in this paper, data collected over 2 weeks at baseline were used. Participants were instructed to upload their PA data into the study server via the Internet.

Data were recorded with a time sampling interval of 1 min (i.e. 1-min epochs). A day was considered valid if the volunteer had worn the TracmorD for at least 10 hours, but not longer than 18 hours. Wear time was defined as 24 hours minus non-wear time. To define non-wear time, we adapted the recommendations of Choi et al. [25] to the TracmorD. The R software version 3.1.2 was used for PA data processing. 
PA domains were based on application of thresholds for activity energy expenditure (AEE) and included time spent in sedentary behaviours (corresponding to <1.5 METs), light ( 1.5 to $<3$ METs), moderate ( 3 to $<6$ METs), vigorous ( $\geq 6$ METs) or moderateequivalent intensity PA [26]. Moderate-equivalent PA was derived using the following equation [moderate PA + (vigorous PA * 2)] [27].

Adherence to the WHO physical activity recommendations was examined by estimating the proportion of volunteers who accumulated at least 150 minutes per week of moderate PA or 75 minutes of vigorous PA or an equivalent combination of moderate and vigorous PA, in bouts of at least 10 minutes [27]. This translates to at least 150 minutes per week of moderate-equivalent PA. Three-categorical variables were created for all PA variables. For the moderate-equivalent PA variable, 150 and 300 min.week $^{-1}$ of moderate-equivalent PA were used to create 3 relevant categories. Similarly, for the

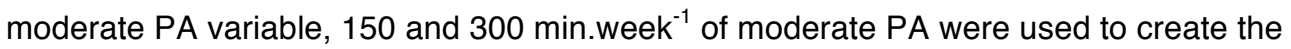
3 categories. For all other PA variables, categories were tertiles derived from STATA.

\section{Genotypic analyses}

Buccal cell samples were collected from participants at baseline using Isohelix SK-1 DNA buccal swabs and Isohelix dried-capsules and posted to each recruiting centre for shipment to LGC Genomics (Hertfordshire, United Kingdom). LGC Genomics extracted DNA and genotyped specific loci using $\mathrm{KASP}^{\mathrm{TM}}$ genotyping assays. FTO SNPs (rs9939609 and rs1121980) were genotyped and showed a high linkage disequilibrium $\left(r^{2}=0.96\right)$. Therefore, results for $r s 1121980$ are not reported. Accuracy of the genotyping analysis has been assessed and described elsewhere [23].

A goodness-of-fit chi-square test was performed to examine if the observed genotype counts were in Hardy-Weinberg equilibrium. Genotype frequency for the FTO rs9939609 variant did not deviate from Hardy-Weinberg equilibrium (TT=469, TA=739 and $\mathrm{AA}=264, P=0.345)$.

\section{Ethics approval and participant consent}

The Research Ethics Committees at each University or Research Centre delivering the intervention granted ethics approval for the study. The Food4Me trial was registered as a RCT (NCT01530139) at www.clinicaltrials.gov. All participants who expressed an interest in the study were asked to sign online consent forms at two stages in the screening process. These forms were automatically directed to the local study investigators to be counter-signed and archived [21]. 


\section{Statistical analysis}

Baseline data were used for the present analyses. Results from descriptive analyses are presented as means and SD for continuous variables and as percentages for categorical variables.

Robust Linear Regression analyses were used to test for associations between the main outcomes (weight, BMI and WC) and FTO genotype. FTO was coded using an additive genetic model $(T T=0, A T=1, A A=2)$ and $P A$ was categorized and coded as ordinal variable $(0=$ Lower, $1=$ Middle, $2=$ Higher). The interplay between PA and FTO genotype was investigated by including an interaction term in the models, with PA and FTO variables coded as specified above. For categorical outcomes (\% of participants with overweight or obesity), Robust Logistic Regression was used and FTO and PA (coded as ordinal variables) were included in the model using an interaction term. Analyses were adjusted for age, sex, country, season and monitor wearing time, as appropriate. Results were deemed significant at $P<0.05$. Data were analysed using Stata (version 13; StataCorp. College Station, TX, USA).

\section{Results}

\section{Cohort characteristics}

Of the 1,607 individuals randomised into the Food4Me study, data at baseline on FTO genotype and PA were available for 1,280 participants (58\% were women and $97 \%$ were Caucasians). As summarised in Table 4.1, 30\% of individuals had overweight and $16 \%$ had obesity. In addition, WC was above the healthy limit $(>102 \mathrm{~cm}$ for males and $88 \mathrm{~cm}$ for females) for $23 \%$ of males and $26 \%$ of females. Although $57 \%$ of men and $40 \%$ of women met the PA recommendation ( $\geq 150$ minutes of moderate-equivalent PA a week), $28 \%$ of the participants recorded less than 1 minute of vigorous intensity PA daily. All PA variables were significantly associated with obesity-related markers (Supplementary Material 4.1).

\section{Association of FTO genotype with obesity measures}

Carriage of the A allele of the FTO rs9939609 variant was associated with higher body weight [ $\beta$ : $1.09 \mathrm{~kg}$ increase per risk allele, $95 \% \mathrm{Cl}(0.14$ to 2.04$), P=0.024]$, $\mathrm{BMI}$ [ $\beta$ : 0.54 $\mathrm{kg} \cdot \mathrm{m}^{-2}, 95 \% \mathrm{Cl}(0.23$ to 0.83$\left.), P<0.0001\right]$, and $\mathrm{WC}[\beta: 1.07 \mathrm{~cm}, 95 \% \mathrm{Cl}(0.24$ to 1.90$)$, $P=0.011$ ] (Figure 4.1). Participants with the FTO risk allele $(A)$ had significantly higher odds of having overweight (OR: 1.27 (1.06 to 1.51 ), $P=0.007$ ) or obesity (OR: 1.41 
(1.13 to 1.75); $P=0.003$ ) than individuals with the $T$ allele, but no significant association was found for central obesity (Table 4.2).

Table 4.1 Characteristics of Food4Me Study participants

\begin{tabular}{|c|c|c|c|}
\hline Variables & Overall & Men & Women \\
\hline $\mathrm{n}$ & 1280 & 537 & 743 \\
\hline Age (years) & $39.9(13.0)$ & $41.6(13.4)$ & $38.7(12.5)$ \\
\hline \multicolumn{4}{|l|}{ Anthropometric } \\
\hline Height (m) & $1.71(0.09)$ & $1.79(0.07)$ & $1.65(0.06)$ \\
\hline Body weight (kg) & $74.7(15.8)$ & $83.4(13.5)$ & $68.5(14.3)$ \\
\hline $\mathrm{BMI}\left(\mathrm{kg} \cdot \mathrm{m}^{-2}\right)$ & $25.5(4.8)$ & $26.1(4.1)$ & $24.9(5.2)$ \\
\hline Underweight (<18.5 kg.m $\left.\mathrm{m}^{-2} ; \%\right)$ & 2.6 & 0.8 & 3.8 \\
\hline Normal weight ( $\geq 18.5$ to $<25.0 \mathrm{~kg} \cdot \mathrm{m}^{-2} ; \%$ ) & 51.3 & 44.7 & 56.0 \\
\hline Overweight ( $\geq 25.0$ to $<30.0$ kg.m $\left.{ }^{-2} ; \%\right)$ & 30.3 & 38.4 & 24.6 \\
\hline Obese ( $\left.\geq 30.0 \mathrm{~kg} \cdot \mathrm{m}^{-2} ; \%\right)$ & 15.8 & 16.1 & 15.6 \\
\hline Waist Circumference $(\mathrm{cm})$ & $85.7(13.8)$ & $92.7(12.1)$ & $80.7(12.8)$ \\
\hline Central obesity* (\%) & 24.3 & 22.8 & 25.6 \\
\hline \multicolumn{4}{|l|}{ Physical Activity } \\
\hline PAL & $1.73(0.18)$ & $1.74(0.2)$ & $1.72(0.2)$ \\
\hline Sedentary time $\left(\min \cdot\right.$ day $\left.^{-1}\right)$ & $744.8(76.6)$ & $738.9(82.3)$ & $749.1(71.5)$ \\
\hline Light PA (min.day ${ }^{-1}$ ) & $73.9(30.4)$ & $74.0(29.8)$ & $73.9(30.9)$ \\
\hline Moderate PA (min.day ${ }^{-1}$ ) & $33.3(20.4)$ & $37.3(21.1)$ & $30.3(19.4)$ \\
\hline Vigorous PA (min.day ${ }^{-1}$ ) & $11.8(16.1)$ & $16.7(18.1)$ & $8.17(13.1)$ \\
\hline Moderate-equivalent PA (min.day ${ }^{-1}$ ) & $56.9(45.0)$ & $70.9(49.1)$ & $46.7(38.4)$ \\
\hline $\begin{array}{l}\text { Moderate-equivalent PA } 10 \mathrm{~min} \text { bouts } \\
\left(\text { min.day }^{-1}\right)\end{array}$ & $29.2(32.3)$ & $36.5(35.9)$ & $23.8(28.1)$ \\
\hline $\begin{array}{l}\text { Active individuals ( } \geq 150 \text { min.week } \\
\text { moderate-equivalent PA in bouts; \%) }\end{array}$ & 47.0 & 56.5 & 40.0 \\
\hline
\end{tabular}

Data presented as Mean (SD) for continuous variables and as \% for categorical variables. PAL Physical activity level. ${ }^{*}$ Central obesity was defined as waist circumference $>88 \mathrm{~cm}$ for women and $>102 \mathrm{~cm}$ for men. 

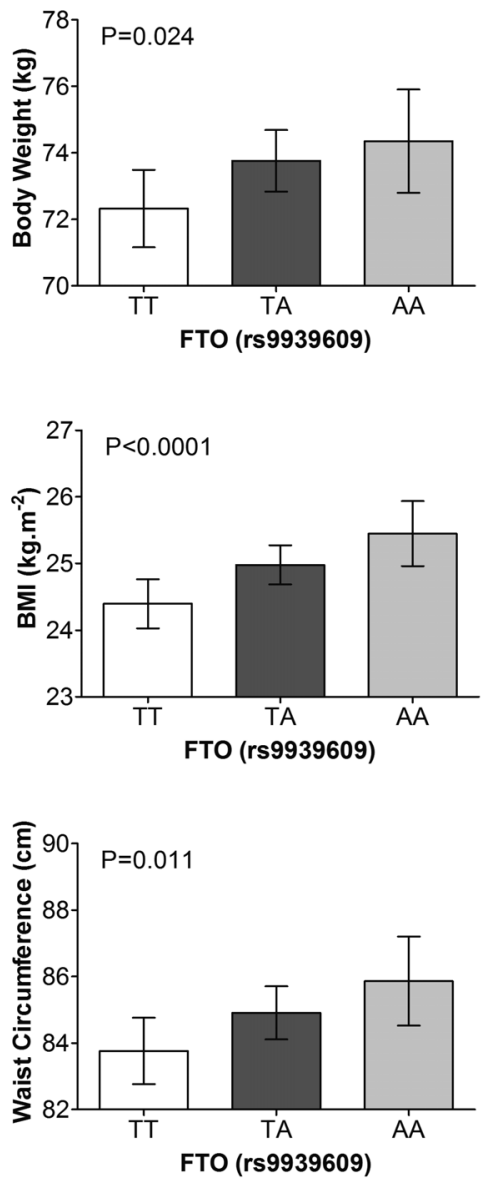

Figure 4.1 Association between FTO rs9939609 genotype and adiposity measures

Least-squares means of genotypes were calculated by using Robust Linear Regression, with adjustment for age, sex and country.

Table 4.2 Association of FTO rs9939609 genotype with obesity-related traits

\begin{tabular}{lcc}
\hline Variables & Beta or OR (95\% Cl) & $\boldsymbol{P}$ \\
\hline Anthropometric & $1.09(0.14$ to 2.04$)$ & 0.024 \\
Body weight $(\mathrm{kg})$ & $0.54(0.23$ to 0.83$)$ & $<0.0001$ \\
BMI $\left(\mathrm{kg} \cdot \mathrm{m}^{-2}\right)$ & $1.07(0.24$ to 1.90$)$ & 0.011 \\
Waist Circumference $(\mathrm{cm})_{\text {Overweight or obese }^{\dagger}}$ & $1.32(1.12$ to 1.54$)$ & 0.001 \\
Central obesity $^{\dagger}$ & $1.13(0.95$ to 1.36$)$ & 0.158 \\
\hline
\end{tabular}

Data presented as beta coefficient or odds ratio $(O R)^{\ddagger}$ with their corresponding $95 \% \mathrm{Cl}$. Models were adjusted for age, sex and country. Physical activity variables were additionally adjusted for monitor wear time and season. Allele frequencies were TT ( $n=469), T A(n=739)$ and AA $(n=264)$. Overweight or obesity was defined as $B M I \geq 25.0 \mathrm{~kg} \cdot \mathrm{m}^{-2}$ (normal weight was used as reference group). Central obesity was defined as waist circumference $>88 \mathrm{~cm}$ for women and $>102 \mathrm{~cm}$ for men (individuals with no central obesity were used as reference group). 


\section{Interaction between FTO genotype and PA levels on adiposity}

We found significant interactions between FTO genotype and category of moderateequivalent PA on body weight, BMI and WC (Table 4.3 and Figure 4.2). The strength of the association between FTO and body weight decreased with increasing moderateequivalent PA: the relationship declined from $3.53 \mathrm{~kg}(95 \% \mathrm{Cl}: 0.93$ to 6.11$)$ per copy of the FTO risk allele in participants with lower levels of PA $\left(<150\right.$ min.week $\left.^{-1}\right)$ to $-0.28 \mathrm{~kg}$ $(95 \% \mathrm{Cl}:-1.48$ to 0.91$)$ in participants with higher levels of PA (>300 min.week $\left.{ }^{-1}\right)$, as shown in Table 4.3 and Figure 4.2. Similar results were found for BMI (lower PA: 1.06 $\mathrm{kg} \cdot \mathrm{m}^{-2}$ vs higher PA: $0.16 \mathrm{~kg} \cdot \mathrm{m}^{-2}$ per copy of the risk allele, $\left.P_{\text {(interaction) }}=0.020\right)$ and $\mathrm{WC}$ (lower PA: $2.72 \mathrm{~cm}$ vs higher PA: $-0.49 \mathrm{~cm}$ per copy of the risk allele, $P_{\text {(interaction) }}=0.005$ ).

Table 4.3 Association between the FTO rs9939609 genotype and obesity-measures by category of moderate-equivalent physical activity (PA).

\begin{tabular}{|c|c|c|c|c|c|c|c|}
\hline Variables & $\begin{array}{l}\text { Low PA } \\
(n=288)\end{array}$ & & $\begin{array}{l}\text { Middle PA } \\
(n=306)\end{array}$ & & $\begin{array}{c}\text { High PA } \\
(n=686)\end{array}$ & & \\
\hline & $\begin{array}{c}\text { Beta or OR } \\
(95 \% \mathrm{Cl})\end{array}$ & $P$ & $\begin{array}{c}\text { Beta or OR } \\
(95 \% \mathrm{Cl})\end{array}$ & $P$ & $\begin{array}{c}\text { Beta or OR } \\
(95 \% \mathrm{Cl})\end{array}$ & $P$ & $P_{\left(F T O^{*} \mathrm{PA}\right)}$ \\
\hline $\begin{array}{l}\text { Body } \\
\text { weight }(\mathrm{kg})\end{array}$ & $\begin{array}{c}3.53 \\
(0.93 \text { to } 6.11)\end{array}$ & 0.008 & $\begin{array}{c}1.42 \\
(-0.84 \text { to } 3.67)\end{array}$ & 0.217 & $\begin{array}{c}-0.28 \\
(-1.48 \text { to } 0.91)\end{array}$ & 0.644 & 0.003 \\
\hline $\begin{array}{l}\mathrm{BMI} \\
\left(\mathrm{kg} \cdot \mathrm{m}^{-2}\right)\end{array}$ & $\begin{array}{c}1.06 \\
(0.14 \text { to } 1.99)\end{array}$ & 0.024 & $\begin{array}{c}0.68 \\
(-0.08 \text { to } 0.15)\end{array}$ & 0.082 & $\begin{array}{c}0.16 \\
(-0.21 \text { to } 0.52)\end{array}$ & 0.388 & 0.020 \\
\hline $\begin{array}{l}\text { Waist Circ. } \\
(\mathrm{cm})\end{array}$ & $\begin{array}{c}2.72 \\
(0.43 \text { to } 5.01)\end{array}$ & 0.019 & $\begin{array}{c}1.81 \\
(-0.22 \text { to } 2.84)\end{array}$ & 0.081 & $\begin{array}{c}-0.49 \\
(-1.62 \text { to } 0.64)\end{array}$ & 0.393 & 0.005 \\
\hline $\begin{array}{l}\text { Overweight } \\
\text { or obese }^{\ddagger}\end{array}$ & $\begin{array}{c}1.65 \\
(1.10 \text { to } 2.45)\end{array}$ & 0.014 & $\begin{array}{c}1.30 \\
\text { (0.94 to } 1.79)\end{array}$ & 0.112 & $\begin{array}{c}1.22 \\
\text { (0.93 to } 1.56)\end{array}$ & 0.102 & 0.173 \\
\hline $\begin{array}{l}\text { Central } \\
\text { obesity }^{\dagger}\end{array}$ & $\begin{array}{c}1.04 \\
(0.71 \text { to } 1.51)\end{array}$ & 0.824 & $\begin{array}{c}1.22 \\
(0.84 \text { to } 1.76)\end{array}$ & 0.285 & $\begin{array}{c}1.02 \\
(0.73 \text { to } 1.39)\end{array}$ & 0.923 & 0.902 \\
\hline
\end{tabular}

Data presented as adjusted beta coefficient or odds ratio $(\mathrm{OR})^{\dagger}$ with their corresponding $95 \% \mathrm{Cl}$. All models are adjusted for age, sex, country, season and monitor wear time. Beta or OR is the increase in trait per each copy of the risk allele; $P$ value for FTO and PA category interaction is the difference in trait per minor allele of rs9939069 comparing individuals with lower $\left(<150\right.$ min.week $\left.^{-1}\right)$, middle (150-300 min.wee $\left.{ }^{-1}\right)$ and higher ( $>300$ min. wee $^{-1}$ ) levels of moderate-equivalent $P A$. Overweight or obesity was defined as $B M I \geq 25.0 \mathrm{~kg} \cdot \mathrm{m}^{-2}$ (normal weight was used as reference group). Central obesity was defined as waist circumference $>88 \mathrm{~cm}$ for women and $>102 \mathrm{~cm}$ for men (individuals with no central obesity were used as reference group). Waist Circ., waist circumference.

When the relationship between FTO genotype and other PA domains (vigorous, moderate and light intensity PA) were studied, we observed significant interactions between FTO*vigorous intensity PA (Supplementary Material 4.2 and Supplementary Material 4.3) and $F T O^{\star}$ moderate intensity PA (Supplementary Material 4.4 and Supplementary Material 4.5) on body weight, BMI and WC. However, no significant FTO*light intensity PA interactions were identified (Supplementary Material 4.6 and Supplementary Material 4.7). 


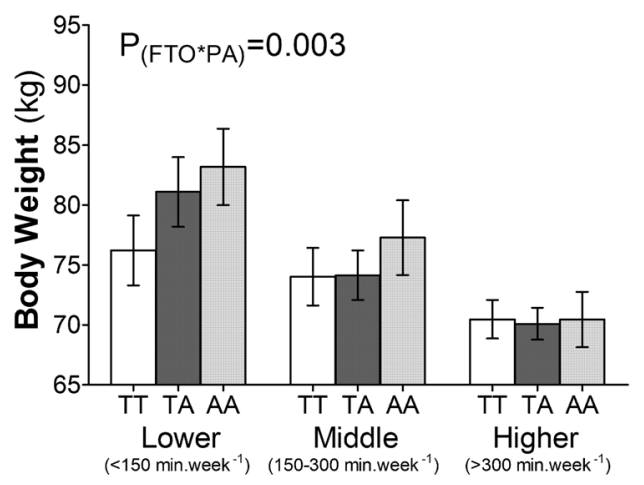

Category of Moderate-equivalent PA

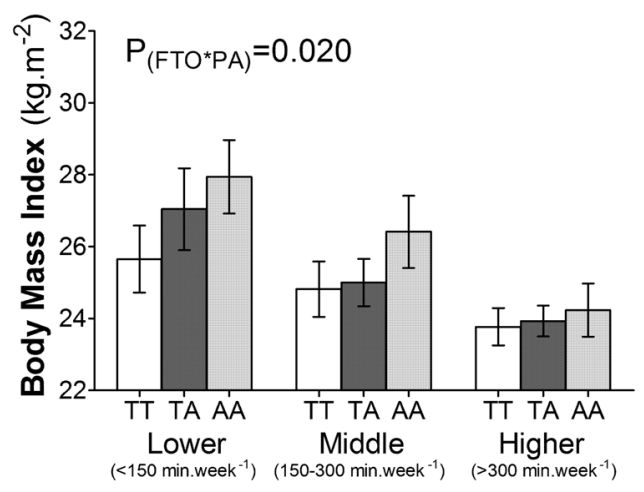

Category of Moderate-equivalent PA

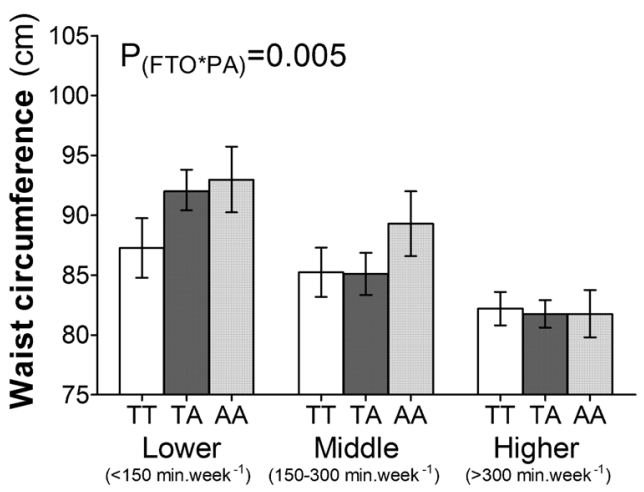

Category of Moderate-equivalent PA

Figure 4.2 Effect of the FTO rs9939609 genotype on adiposity-measures by category of moderateequivalent physical activity

$P$ values are for the interaction between the FTO variant and PA category; Least-squares means of different genotypes across all PA groups were calculated by using Robust Linear Regression Analysis, with adjustment for age, sex, country, monitor wear time and season. Allele frequency by PA category was (Lower: 71/158/59; Middle: 103/142/61; Higher: 231/342/113) for TT, TA and AA genotypes, respectively. 
Although there were no significant interactions between FTO genotype and sedentary behaviour on obesity measures (body weight, BMI and WC), these increased with increasing time spent in sedentary behaviour (Supplementary Material 4.8 and Supplementary Material 4.9). The effect size of FTO on BMI and WC was $60 \%$ and $320 \%$ greater in individuals with longer, than shorter, time spent in sedentary behaviour, respectively. When additional analyses were performed and PA was included in the interaction models as a continuous variable, we saw a similar trend for the interaction between FTO and PA-related variables but these interaction effects were no longer significant ( $P>0.05)$ for any of the outcomes. No associations were found between PA variables and FTO genotype (Supplementary Material 4.10). Removing participants of non-white ethnic origin $(<3 \%)$ in sensitivity analyses did not modify any of our findings.

\section{Discussion}

\section{Main findings}

Our main findings are that, on average, each additional copy of the FTO risk allele at rs9939609 was associated with significant increases in body weight, BMI and WC of $1.09 \mathrm{~kg}, 0.54 \mathrm{~kg} \cdot \mathrm{m}^{-2}$ and $1.07 \mathrm{~cm}$, respectively. Consistently, each copy of the risk allele increased the odds of having overweight or obesity by $32 \%$. Our results provide further evidence to support the interplay between genes and lifestyle. We showed that the effect sizes of the FTO associations on BMI and WC for active individuals

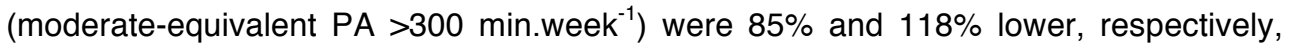

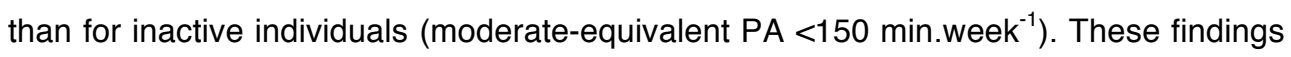
emphasise the importance of PA in the prevention of obesity especially in subjects carrying the FTO risk allele.

\section{Comparison with other studies}

Our results are consistent with the findings of previous studies showing associations between FTO variants and obesity-related traits [10,28,29]. Although the effect size of the FTO rs9939609 is relatively modest, it is consistent across studies conducted in Caucasian populations [10,28-31]. Our FTO effect size estimates are in agreement with previous findings where each copy of the risk allele was associated with an increase in adiposity measures ranging from 0.76 to $2.4 \mathrm{~cm}$ for WC, and from 0.31 to $0.66 \mathrm{~kg} \cdot \mathrm{m}^{-2}$ for $\mathrm{BMI}$, which is equivalent to $\sim 1.3$ to $2.1 \mathrm{~kg}$ in body weight for an individual $1.80 \mathrm{~m}$ tall $[8-10,28,30]$. Similarly, the odds of having overweight or obesity reported in previous 
studies ranged from $\sim 1.19$ to 1.69 per additional copy of the risk allele [8-10,28,29], which is in agreement with our estimates (OR: 1.27 (1.06 to 1.51) for overweight and OR: 1.41 (1.13 to 1.75$)$ for obesity per copy of the risk allele).

Furthermore, our study suggests that an active lifestyle may attenuate the FTO genetic susceptibility to obesity $[19,20,32,33]$. A meta-analysis of cross-sectional studies, including 218,166 adults [19], reported a significant $F T O^{\star} P A$ interaction $(P=0.001)$, where the minor A FTO allele of the rs9939609 variant increased the odds of being obese less in physically active individuals [OR: $1.22(95 \% \mathrm{Cl} 1.19-1.25)]$ than among inactive individuals (OR: 1.30 (1.24-1.36)]. Moreover, the latter meta-analysis reported that the association of the FTO genotype with BMI and WC was attenuated in physically active individuals $\left(0.32 \mathrm{~kg} \cdot \mathrm{m}^{-2}\right.$ and $0.68 \mathrm{~cm}$ per copy of the risk allele, respectively) compared with inactive individuals $\left(0.46 \mathrm{~kg} \cdot \mathrm{m}^{-2}\right.$ and $1.01 \mathrm{~cm}$ per copy of the risk allele). Although our study showed qualitatively similar findings, we observed a bigger attenuation by PA of the effect of FTO on obesity-related traits. This quantitative difference between studies may be explained by the relative precision of PA measurements.

Our results are based on objectively measured PA data whereas the earlier metaanalysis [19] used primarily SR PA data. SR PA can be subject to optimistic bias leading to PA overestimation [34]. Furthermore, SR PA is prone to random error, which leads to regression dilution bias [35]. This can obscure the true effect of PA on the interplay between genes and environment [36]. Moreover, the use of categories of PA may provide better knowledge of the dose-response relationship between FTO genotype and PA on adiposity, which may assist in identifying the minimum amount of PA necessary to overcome the genetic effect of $F T O$ genotype on obesity-related traits. We found that the influence of the FTO risk allele on BMI was $36 \%$ and $84 \%$ lower in individuals achieving between 150-300 min.week ${ }^{-1}$ or above 300 min.week $^{-1}$ of moderate equivalent PA, respectively, than in inactive individuals ( $<150$ min.week ${ }^{-1}$ ). The attenuating effect of PA on FTO related adiposity was similar when WC was used as an outcome (the FTO risk allele effect on WC was 1.5 and 6.5-fold lower for active and highly active individuals than in inactive individuals).

Although previous studies have reported a significant FTO*PA interaction [20,3033,37], most of these studies used SR PA [19]. Objectively measured PA allowed us to investigate whether sedentary behaviours or other PA domains, such as light, moderate and vigorous intensity PA, modulate the effect of the FTO genotype on obesity-related traits. We identified that achieving between 10 to 90 minutes of vigorous PA per week mitigated the effect of FTO genotype on obesity measures. However, higher levels of moderate intensity PA appear to be needed (150 to 300 min.week $^{-1}$ ) to 
achieve similar attenuating effects on the association between FTO genotype and obesity.

The mechanism by which the FTO gene may have an impact on obesity outcomes remains unclear. Recent evidence suggests that genetic variants within introns 1 and 2 of FTO may change the basic function of human adipocytes from substrate storage to fuel utilization through enhanced thermogenesis [38]. Claussnitzer et al. proposed that noncoding variants in FTO influence the thermogenic capacity of beige cells, which results in phenotypic differences in BMI. They identified a large enhancer region in the FTO locus of adipocytes that has long-range control over two homeobox regulatory genes, IRX3 and IRX5, and demonstrated cell-autonomous effects of these genes by means of genetic knockdown of $I R X 3$ and $I R X 5$ to restore thermogenesis in adipocytes from persons at high genetic risk for obesity. In contrast, overexpression of the encoded proteins in adipocytes from persons without this genetic risk resulted in decreased mitochondrial function and thermogenesis [38]. Some attempts have been made to explain the relationship between FTO and PA energy expenditure [39], but there is inconclusive evidence on whether this may be due to epistatic gene interactions with other genes that may control PA or dietary intake, or to geneenvironment interaction [39].

The strengths of our study include the objective measure of PA in a large European cohort. This is important because the identification of convincing gene-lifestyle interactions requires accurate measures of the environmental exposure [18] if experimental data are to translate into public health action. Moreover, our estimate of PA allowed us to create categories of PA domains, which revealed the dose-response relationship for gene-environment interaction. A potential limitation of our study is that anthropometric data were self-measured and self-reported via the Internet, which may have introduced measurement error. Nonetheless, the accuracy of Internet-based, selfreported anthropometric data is high [40] and this has been confirmed in our study [23]. However, we cannot completely discard any confounding effect of self-reported data on our main outcomes. Another factor that should be considered as a limitation is the lack of information on relatedness of the individuals. Additionally, when interactions between FTO and PA were assessed by fitting PA as a continuous variable in the model, the trend remained similar but the interactions were no longer statistically significant (P>0.05). A larger sample size will be needed to confirm our findings using PA as a continuous variable. Furthermore, by design, we recruited individuals interested in taking part in a personalized intervention on nutrition and lifestyle, which is less representative than a European-wide survey. Nonetheless, our participants were 
broadly representative of the European adult population, most of whom had adequate nutrient intakes but could benefit from improved dietary choices and greater PA [22].

\section{Implications of findings}

Considering the current prevalence of overweight and obesity worldwide [4], our findings are highly relevant for improving public health. They emphasise that PA may be a particularly effective way of controlling body weight in individuals with a genetic predisposition towards obesity and thus contrast with the deterministic view that genetic influences are unmodifiable. The apparent effect of an active lifestyle on genetic predisposition to obesity ( $4 \mathrm{~kg}$ differences in the FTO-related effect size on body mass for inactive vs. active individuals) is large enough to be clinically relevant. Evidence of such gene-lifestyle interactions may empower and motivate individuals to adopt healthier lifestyle behaviours through knowledge that such behaviour change can be effective in preventing obesity and, therefore, risk of obesity-related non-communicable diseases. Gene*environment interactions for cardio-metabolic phenotypes involve physical activity more often than any other lifestyle factor, including dietary fat intakes [16].

In conclusion, despite the fact that FTO genotype is robustly associated with BMI and WC, our results show that higher PA attenuates this genetic predisposition to obesityrelated traits. These finding are relevant for public health and suggest that promoting PA, particularly in those who are genetically susceptible, is an important strategy for addressing the current obesity epidemic.

The authors thank Dr Annelies Goris and Dr Jettie Hoonhout from Philips for their support during physical activity data collection. This work was supported by the European Commission under the Food, Agriculture, Fisheries and Biotechnology Theme of the 7th Framework Programme for Research and Technological Development [265494]. YM, IT, CAD, ERG, LB, JAL, JAM, WHMS, HD, MG and $J C M$ contributed to the research design. JCM was the Food4Me Proof of Principle study coordinator. CCM, CFMM, HF, CBO, CW, AM, RF, SNC, RSC, SK, LT, CPL, MG, AS, MCW, ERG, LB and JCM contributed to the developing the Standardized Operating Procedures for the study. CCM, SNC, RSC, $C W, C B O, H F, C F M M, A M, R F, S K, L T, C P L, M G, A S, M C W$ and JCM conducted the intervention. CCM, CFMM and WHMS contributed to physical activity measurements. CCM and CFMM wrote the paper and CCM performed the statistical analysis for the manuscript. CCM and CFMM are joint first authors. All authors contributed to a critical review of the manuscript during the writing process and approved the final version to be published. The authors declare no conflict of interest. 


\section{References}

1. Hill JO. Understanding and addressing the epidemic of obesity: An energy balance perspective. Endocrine Reviews. 2006;27(7):750-61.

2. Bouchard C. Gene-Environment Interactions in the Etiology of Obesity: Defining the Fundamentals. Obesity. 2008;16:S5-S10.

3. van Vliet-Ostaptchouk JV, Nuotio M-L, Slagter SN, Doiron D, Fischer K, Foco L, et al. The prevalence of metabolic syndrome and metabolically healthy obesity in Europe: a collaborative analysis of ten large cohort studies. Bmc Endocrine Disorders. 2014;14.

4. WHO. Obesity and overweight: World Health Organization; 2013 [updated August 2014; cited 2014 December]. Available from: http://www.who.int/mediacentre/factsheets/fs311/en/.

5. Maes HHM, Neale MC, Eaves LJ. Genetic and environmental factors in relative body weight and human adiposity. Behavior Genetics. 1997;27(4):325-51.

6. Huang T, Hu FB. Gene-environment interactions and obesity: recent developments and future directions. BMC medical genomics. 2015;8:530-

7. Locke AE, Kahali B, Berndt SI, Justice AE, Pers TH, Day FR, et al. Genetic studies of body mass index yield new insights for obesity biology. Nature. 2015;518(7538):197-206.

8. Loos RJF, Bouchard C. FTO: the first gene contributing to common forms of human obesity. Obesity Reviews. 2008;9(3):246-50.

9. Loos RJF, Yeo GSH. The bigger picture of FTO-the first GWAS-identified obesity gene. Nat Rev Endocrinol. 2014;10(1):51-61.

10. Frayling TM, Timpson NJ, Weedon MN, Zeggini E, Freathy RM, Lindgren CM, et al. A common variant in the FTO gene is associated with body mass index and predisposes to childhood and adult obesity. Science. 2007;316(5826):889-94.

11. Li S, Zhao JH, Luan Ja, Luben RN, Rodwell SA, Khaw K-T, et al. Cumulative effects and predictive value of common obesity-susceptibility variants identified by genome-wide association studies. American Journal of Clinical Nutrition. 2010;91(1):184-90.

12. Yang J, Loos RJF, Powell JE, Medland SE, Speliotes EK, Chasman DI, et al. FTO genotype is associated with phenotypic variability of body mass index. Nature. 2012;490(7419):267-+.

13. Bouchard C, Tremblay A, Despres JP, Nadeau A, Lupien PJ, Theriault G, et al. The response to long-term overfeeding in identical-twins. New England Journal of Medicine. 1990;322(21):1477-82.

14. Eichler EE, Flint J, Gibson G, Kong A, Leal SM, Moore JH, et al. VIEWPOINT Missing heritability and strategies for finding the underlying causes of complex disease. Nature Reviews Genetics. 2010;11(6):446-50.

15. Manolio TA, Collins FS, Cox NJ, Goldstein DB, Hindorff LA, Hunter DJ, et al. Finding the missing heritability of complex diseases. Nature. 2009;461(7265):747-53.

16. Parnell LD, Blokker BA, Dashti HS, Nesbeth P-D, Cooper BE, Ma Y, et al. CardioGxE, a catalog of gene-environment interactions for cardiometabolic traits. Biodata Mining. 2014;7.

17. Richardson AS, North KE, Graff M, Young KL, Mohlke KL, Lange EM, et al. The interaction between physical activity and obesity gene variants in association with BMI: Does the obesogenic environment matter? Faseb Journal. 2013;27.

18. Wong MY, Day NE, Luan JA, Chan KP, Wareham NJ. The detection of gene-environment interaction for continuous traits: should we deal with measurement error by bigger studies or better measurement? International Journal of Epidemiology. 2003;32(1):51-7.

19. Kilpelaeinen TO, Qi L, Brage S, Sharp SJ, Sonestedt E, Demerath E, et al. Physical Activity Attenuates the Influence of FTO Variants on Obesity Risk: A Meta-Analysis of 218,166 Adults and 19,268 Children. Plos Medicine. 2011;8(11).

20. Rampersaud E, Mitchell BD, Pollin TI, Fu M, Shen H, O'Connell JR, et al. Physical activity and the association of common FTO gene variants with body mass index and obesity. Archives of internal medicine. 2008;168(16):1791-7. 
21. Celis-Morales C, Livingstone KM, Marsaux CFM, Forster H, O'Donovan CB, Woolhead C, et al. Design and baseline characteristics of the Food4Me study: a web-based randomised controlled trial of personalised nutrition in seven European countries. Genes \& Nutrition. 2015;10(1):450.

22. Livingstone KM, Celis-Morales C, Navas-Carretero S, San-Cristobal R, O'Donovan CB, Forster H, et al. Profile of European adults interested in internet-based personalised nutrition: the Food4Me study. European journal of nutrition. 2015.

23. Celis-Morales C, Livingstone KM, Woolhead C, Forster H, O'Donovan CB, Macready AL, et al. How reliable is internet-based self-reported identity, socio-demographic and obesity measures in European adults? Genes \& nutrition. 2015;10(5):476-.

24. Bonomi AG, Plasqui G, Goris AHC, Westerterp KR. Estimation of Free-Living Energy Expenditure Using a Novel Activity Monitor Designed to Minimize Obtrusiveness. Obesity. 2010;18(9):1845-51.

25. Choi L, Liu Z, Matthews CE, Buchowski MS. Validation of Accelerometer Wear and Nonwear Time Classification Algorithm. Medicine and Science in Sports and Exercise. 2011;43(2):357-64.

26. Ainsworth BE, Haskell WL, Herrmann SD, Meckes N, Bassett DR, Jr., Tudor-Locke C, et al. 2011 Compendium of Physical Activities: A Second Update of Codes and MET Values. Medicine and Science in Sports and Exercise. 2011;43(8):1575-81.

27. WHO. Global recommendations on physical activity for health. World Health Organization, 2010.

28. Dina C, Meyre D, Gallina S, Durand E, Koerner A, Jacobson P, et al. Variation in FTO contributes to childhood obesity and severe adult obesity. Nature Genetics. 2007;39(6):724-6.

29. Peng S, Zhu Y, Xu F, Ren X, Li X, Lai M. FTO gene polymorphisms and obesity risk: a metaanalysis. Bmc Medicine. 2011;9.

30. Corella D, Carrasco P, Sorli JV, Coltell O, Ortega-Azorin C, Guillen M, et al. Education modulates the association of the FTO rs9939609 polymorphism with body mass index and obesity risk in the Mediterranean population. Nutrition Metabolism and Cardiovascular Diseases. 2012;22(8):651-8.

31. Corella D, Ortega-Azorin C, Sorli JV, Isabel Covas M, Carrasco P, Salas-Salvado J, et al. Statistical and Biological Gene-Lifestyle Interactions of MC4R and FTO with Diet and Physical Activity on Obesity: New Effects on Alcohol Consumption. Plos One. 2012;7(12).

32. Vimaleswaran KS, Li S, Zhao JH, Luan Ja, Bingham SA, Khaw K-T, et al. Physical activity attenuates the body mass index-increasing influence of genetic variation in the FTO gene. American Journal of Clinical Nutrition. 2009;90(2):425-8.

33. Andreasen $\mathrm{CH}$, Stender-Petersen KL, Mogensen MS, Torekov SS, Wegner L, Andersen G, et al. Low physical activity accentuates the effect of the FTO rs9939609 polymorphism on body fat accumulation. Diabetes. 2008;57(1):95-101.

34. Adams SA, Matthews CE, Ebbeling CB, Moore CG, Cunningham JE, Fulton J, et al. The effect of social desirability and social approval on self-reports of physical activity. American journal of epidemiology. 2005;161(4):389-98.

35. Hutcheon JA, Chiolero A, Hanley JA. Random measurement error and regression dilution bias. Bmj. 2010;340:c2289.

36. Wong MY, Day NE, Luan JA, Wareham NJ. Estimation of magnitude in gene-environment interactions in the presence of measurement error. Statistics in Medicine. 2004;23(6):987-98.

37. Demerath EW, Lutsey PL, Monda KL, Linda Kao WH, Bressler J, Pankow JS, et al. Interaction of FTO and physical activity level on adiposity in African-American and European-American adults: the ARIC study. Obesity. 2011;19(9):1866-72.

38. Claussnitzer M, Dankel SN, Kim K-H, Quon G, Meuleman W, Haugen C, et al. FTO Obesity Variant Circuitry and Adipocyte Browning in Humans. New England Journal of Medicine. 2015;373(10):895907.

39. Speakman J. The 'Fat Mass and Obesity Related' (FTO) gene: Mechanisms of Impact on Obesity and Energy Balance. Curr Obes Rep. 2015;4(1):73-91.

40. Pursey K, Burrows TL, Stanwell P, Collins CE. How Accurate is Web-Based Self-Reported Height, Weight, and Body Mass Index in Young Adults? Journal of Medical Internet Research. 2014;16(1). 
Supplementary Material 4.1 Association between physical activity (PA) and obesity-related markers

\begin{tabular}{|c|c|c|c|c|}
\hline Variables & & Weight (kg) & BMI $\left(k g \cdot m^{-2}\right)$ & Waist circumference $(\mathrm{cm})$ \\
\hline $\begin{array}{l}\text { Physical activity } \\
\text { level (PAL) }\end{array}$ & $\begin{array}{c}\text { Beta (SE) } \\
r^{2} \\
P \text {-value }\end{array}$ & $\begin{array}{c}-9.15(2.4) \\
1.1 \% \\
<0.0001\end{array}$ & $\begin{array}{c}-3.54(0.72) \\
1.8 \% \\
<0.0001\end{array}$ & $\begin{array}{c}-0.108(0.021) \\
2.0 \% \\
<0.0001\end{array}$ \\
\hline $\begin{array}{l}\text { Sedentary time } \\
\left(\min . \text { week }^{-1}\right)\end{array}$ & $\begin{array}{c}\text { Beta (SE) } \\
r^{2} \\
P \text {-value }\end{array}$ & $\begin{array}{c}0.037(0.005) \\
3.3 \% \\
<0.0001\end{array}$ & $\begin{array}{c}0.013(0.001) \\
4.9 \% \\
<0.0001\end{array}$ & $\begin{array}{c}0.0003(0.00005) \\
4.7 \% \\
<0.0001\end{array}$ \\
\hline 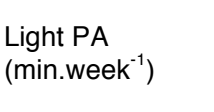 & $\begin{array}{c}\text { Beta (SE) } \\
r^{2} \\
P \text {-value }\end{array}$ & $\begin{array}{c}-0.102(0.01) \\
3.9 \% \\
<0.0001\end{array}$ & $\begin{array}{c}-0.032(0.004) \\
4.2 \% \\
<0.0001\end{array}$ & $\begin{array}{c}-0.0008(0.0001) \\
3.4 \% \\
<0.0001\end{array}$ \\
\hline $\begin{array}{l}\text { Moderate PA } \\
\left(\text { min.week }^{-1}\right)\end{array}$ & $\begin{array}{c}\text { Beta (SE) } \\
r^{2} \\
P \text {-value }\end{array}$ & $\begin{array}{c}-0.136(0.02) \\
3.1 \% \\
<0.0001\end{array}$ & $\begin{array}{c}-0.061(0.006) \\
6.9 \% \\
<0.0001\end{array}$ & $\begin{array}{c}-0.001(0.0002) \\
4.1 \% \\
<0.0001\end{array}$ \\
\hline $\begin{array}{l}\text { Vigorous PA } \\
\left(\text { min. }^{\text {week }}{ }^{-1}\right)\end{array}$ & $\begin{array}{c}\text { Beta (SE) } \\
r^{2} \\
P \text {-value }\end{array}$ & $\begin{array}{c}-0.122(0.02) \\
1.6 \% \\
<0.0001\end{array}$ & $\begin{array}{c}-0.071(0.008) \\
5.9 \% \\
<0.0001\end{array}$ & $\begin{array}{c}-0.002(0.0002) \\
3.2 \% \\
<0.0001\end{array}$ \\
\hline $\begin{array}{l}\text { Moderate- } \\
\text { equivalent PA } \\
\left(\text { min.week }^{-1}\right)\end{array}$ & $\begin{array}{c}\text { Beta (SE) } \\
r^{2} \\
P \text {-value }\end{array}$ & $\begin{array}{c}-0.059(0.009) \\
2.9 \% \\
<0.0001\end{array}$ & $\begin{array}{c}-0.031(0.002) \\
8.5 \% \\
<0.0001\end{array}$ & $\begin{array}{c}-0.0007(0.0001) \\
4.9 \% \\
<0.0001\end{array}$ \\
\hline $\begin{array}{l}\text { Moderate- } \\
\text { equivalent PA } \\
\text { (10 min bouts) } \\
\left.\text { (min.week }{ }^{-1}\right)\end{array}$ & $\begin{array}{c}\text { Beta (SE) } \\
r^{2} \\
P \text {-value }\end{array}$ & $\begin{array}{c}-0.011(0.001) \\
2.3 \% \\
<0.0001\end{array}$ & $\begin{array}{c}-0.005(0.0006) \\
5.9 \% \\
<0.0001\end{array}$ & $\begin{array}{c}-0.0001(0.00002) \\
3.9 \% \\
<0.0001\end{array}$ \\
\hline
\end{tabular}

Data presented as beta coefficients and their corresponding standard error (SE). 


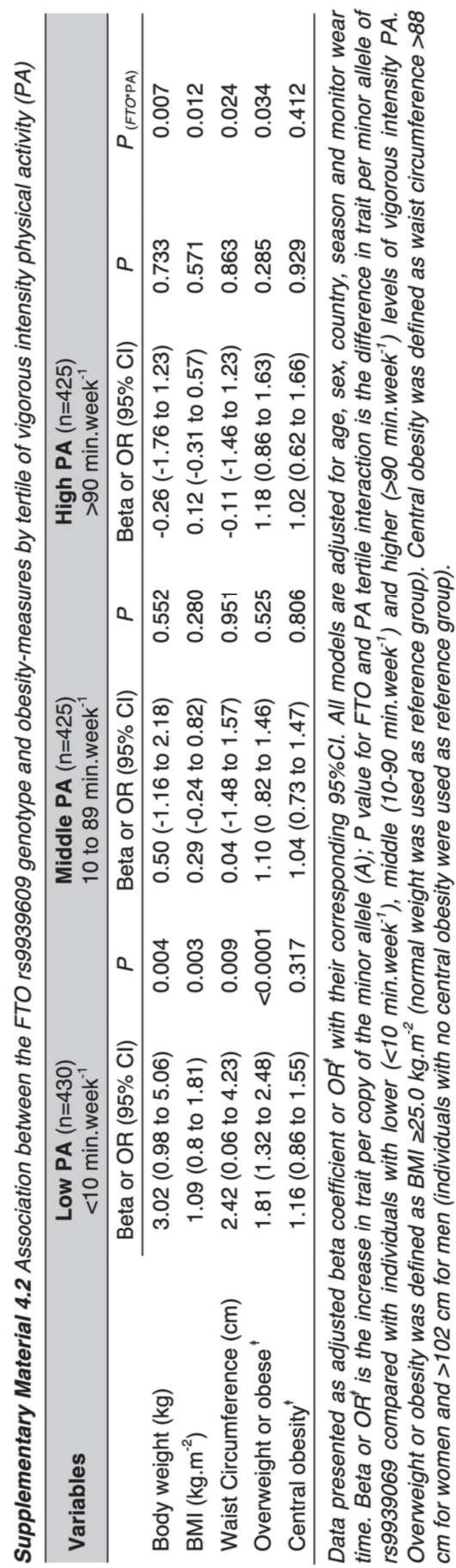

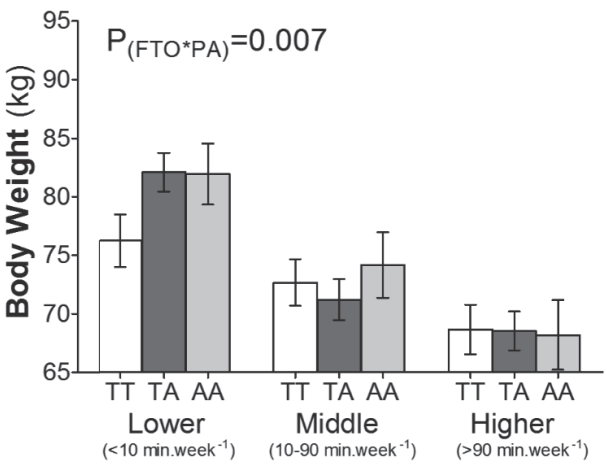

Tertiles of Vigorous Intensity PA

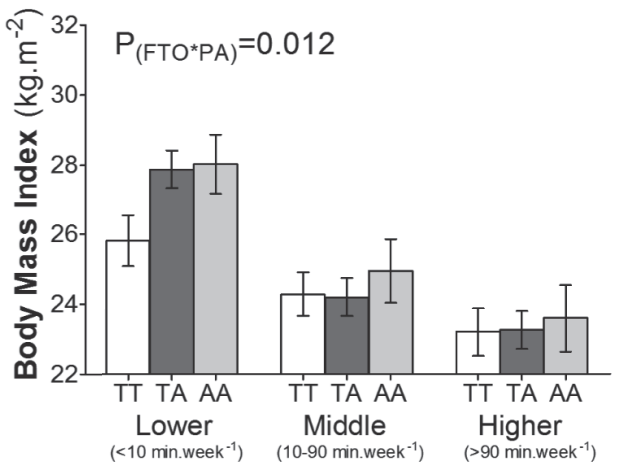

Tertiles of Vigorous Intensity PA

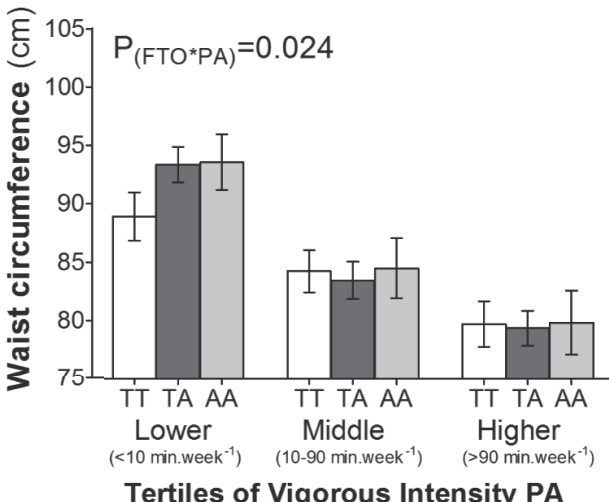

Supplementary Material 4.3 Effect of the FTO rs9939609 genotype on adiposity-measures by tertile of vigorous-intensity physical activity (PA)

$P$-values are for the interaction between the FTO variant and vigorous PA tertile; Least-squares means of different genotypes across all physical activity categories were calculated by using Robust Linear Regression Analysis, with adjustment for age, sex, country, monitor wear time and season. Allele frequency by PA tertile was (Lower: 118/223/89; Middle: 152/197/76; Higher: 135/222/68) for TT, TA and AA genotypes, respectively. 


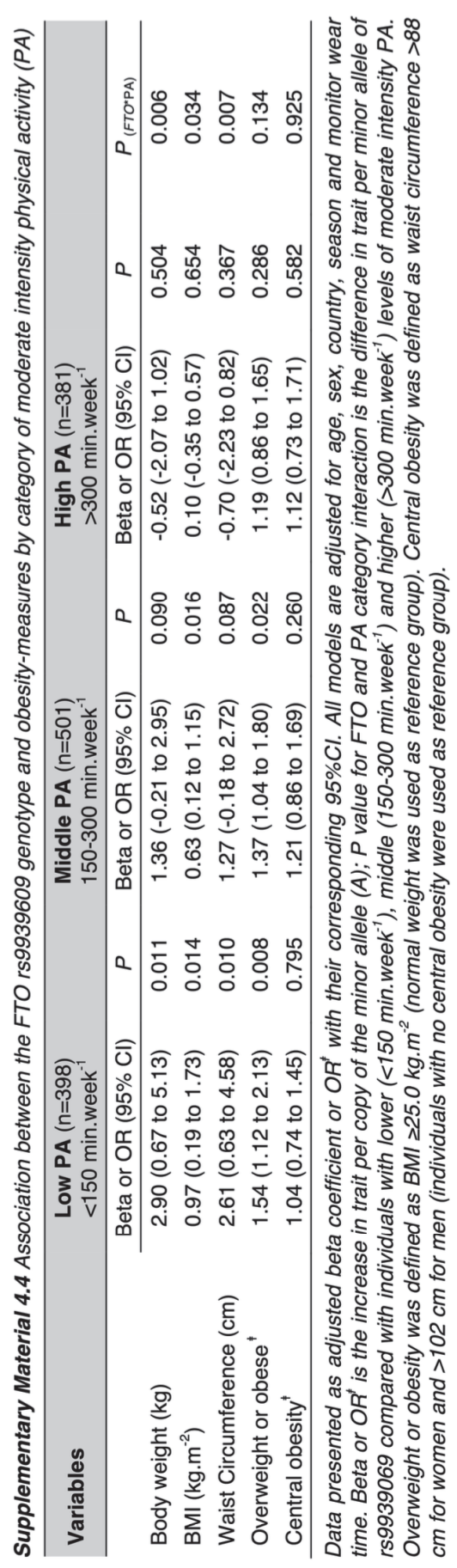

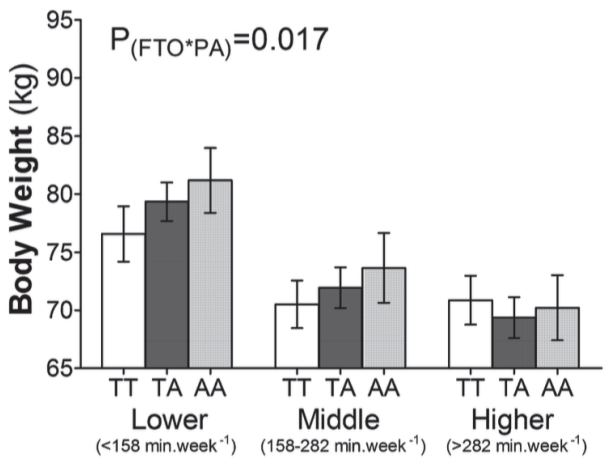

Category of Moderate Intensity PA

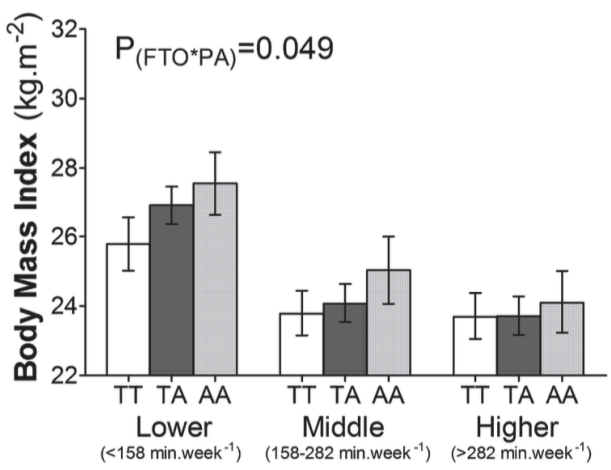

Category of Moderate Intensity PA

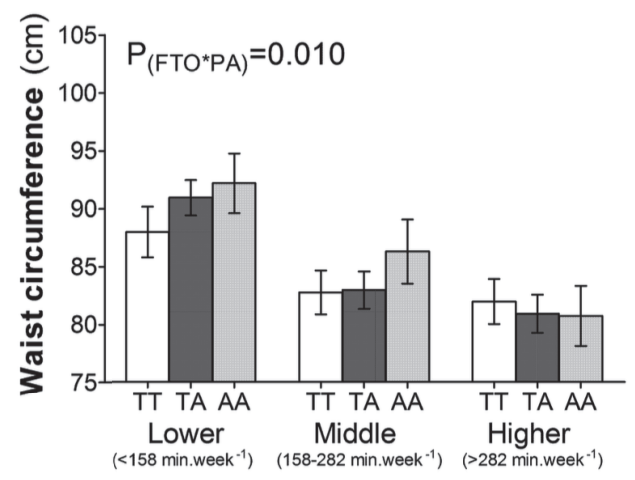

Category of Moderate Intensity PA

Supplementary Material 4.5 Effect of the FTO rs9939609 genotype on adiposity-measures by category of moderate intensity physical activity (PA)

$P$-value for interaction between the FTO variant and moderate PA category; Least-squares means of different genotypes across all physical activity levels were calculated by using by using Robust Linear Regression Analysis, with adjustment for age, sex, country, monitor wear time and season. Allele frequency by PA category was (Lower: 103/220/75; Middle: 174/240/87; Higher: 128/182/71) for TT, TA and AA genotypes, respectively. 

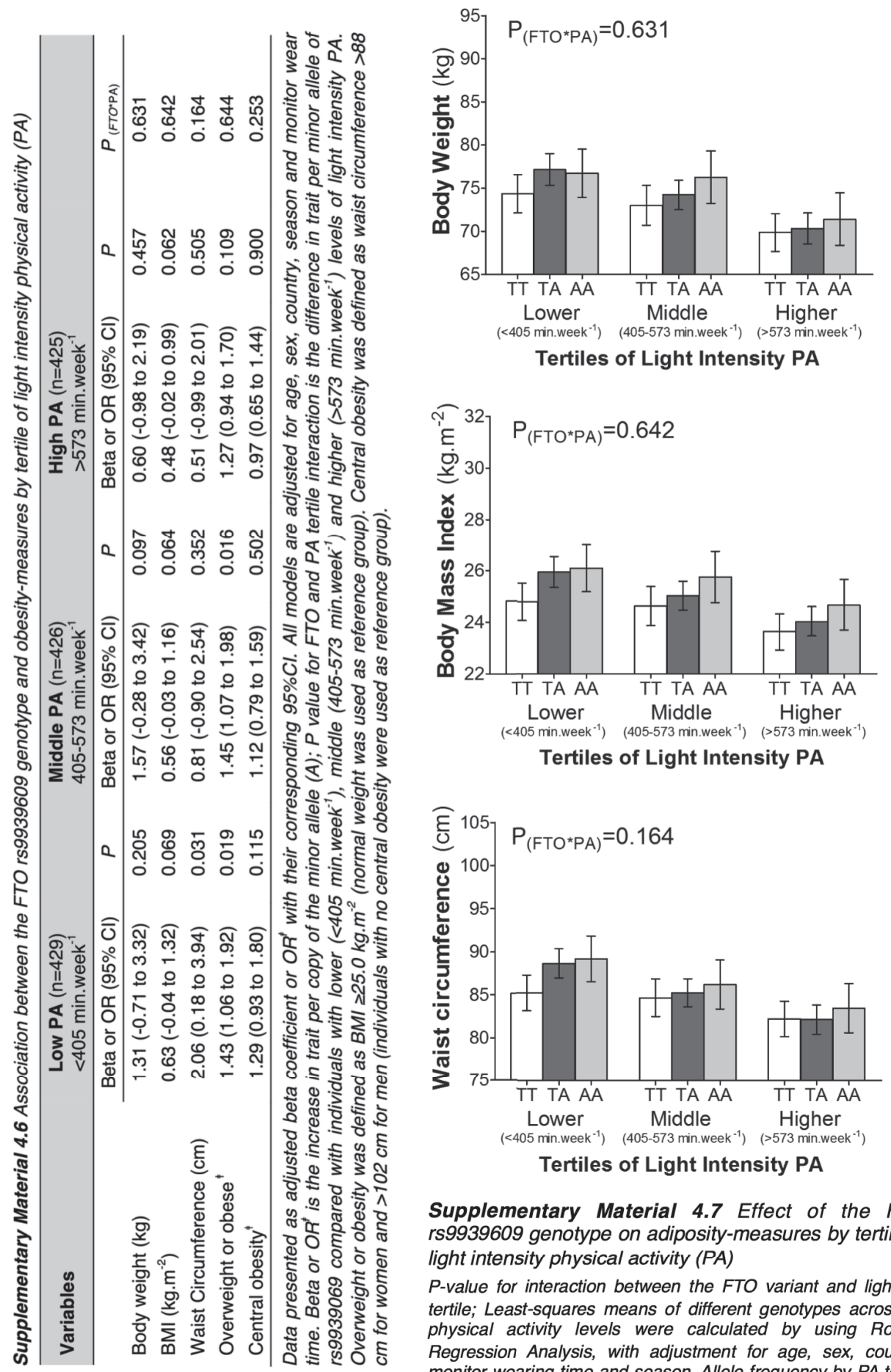

Supplementary Material 4.7 Effect of the FTO rs9939609 genotype on adiposity-measures by tertile of light intensity physical activity (PA)

$P$-value for interaction between the FTO variant and light PA tertile; Least-squares means of different genotypes across all physical activity levels were calculated by using Robust Regression Analysis, with adjustment for age, sex, country, monitor wearing time and season. Allele frequency by PA tertile were (Lower: 140/202/87; Middle: 125/228/73; Higher: 140/212/73) for TT, TA and AA genotypes, respectively. 


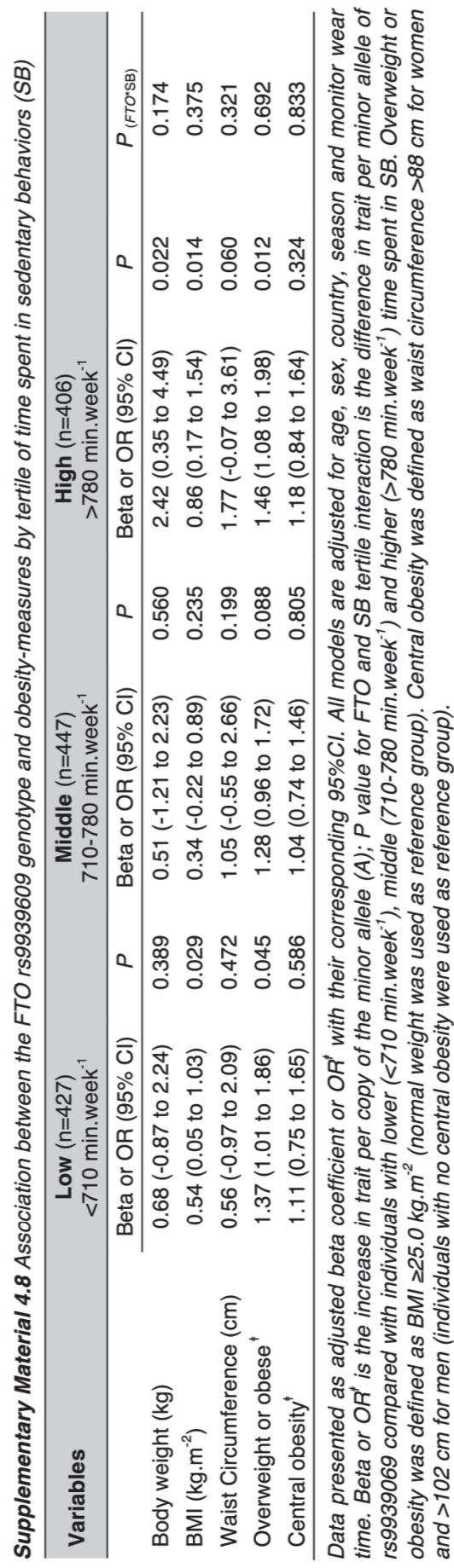

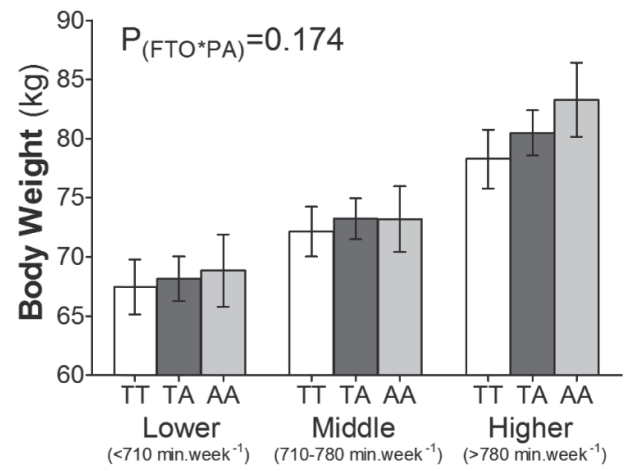

Tertiles of Sedentary Behaviours

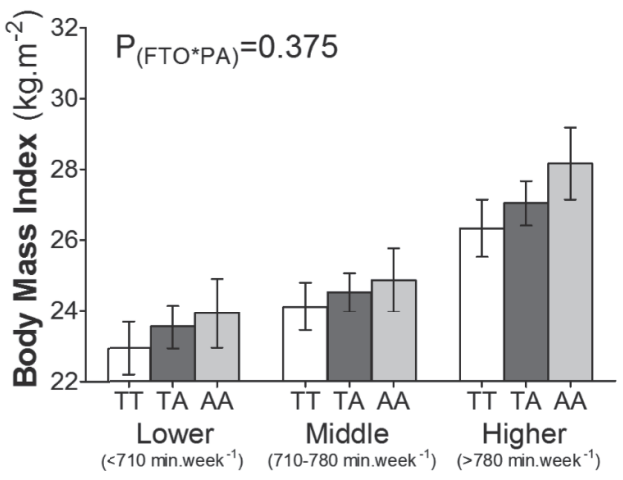

Tertiles of Sedentary Behaviours

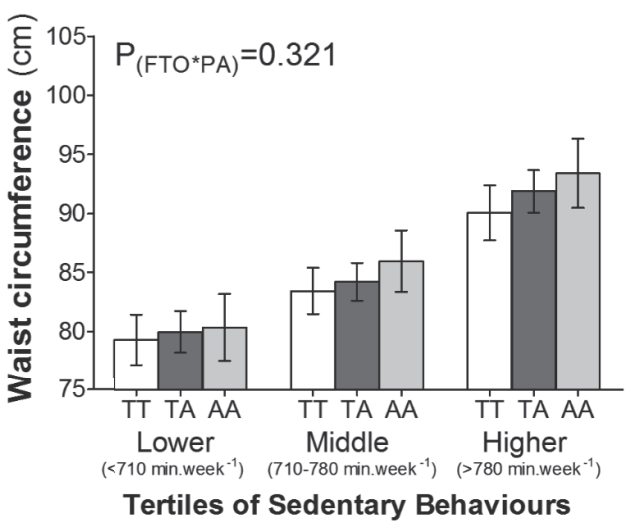

Supplementary Material 4.9 Effect of the FTO rs9939609 genotype on adiposity-measures by tertile of time spent in sedentary behaviors (SB)

$P$-value for interaction between the FTO variant and SB tertile; Least-squares means of different genotypes across all physical activity levels were calculated by using Robust Regression Analysis, with adjustment for age, sex, country, monitor wearing time and season. Allele frequency by SB tertile was (Lower: 140/202/87; Middle: 125/228/73; Higher: 140/212/73) for TT, TA and AA genotypes, respectively. 
Supplementary Material 4.10 Association between physical activity (PA) and FTO genotype

\begin{tabular}{|c|c|c|c|}
\hline Variables & & $\begin{array}{l}\text { FTO genotype vs. PA } \\
\text { (as continuous } \\
\text { variables) }^{*}\end{array}$ & $\begin{array}{c}\text { FTO genotype vs. PA } \\
\text { (as categorical } \\
\text { variables) })^{\star \star}\end{array}$ \\
\hline $\begin{array}{l}\text { Physical activity level } \\
\text { (PAL) }\end{array}$ & $\begin{array}{c}\text { Beta (SE) } \\
r^{2} \\
P \text {-value }\end{array}$ & $\begin{array}{c}0.054(0.10) \\
<0.01 \% \\
0.613\end{array}$ & $\begin{array}{c}-0.024(0.03) \\
<0.01 \% \\
0.451\end{array}$ \\
\hline $\begin{array}{l}\text { Sedentary time } \\
\left(\text { min. }^{-1} \text { week }^{-1}\right)\end{array}$ & $\begin{array}{c}\text { Beta (SE) } \\
r^{2} \\
P \text {-value }\end{array}$ & $\begin{array}{c}0.0002(0.003) \\
<0.01 \% \\
0.413\end{array}$ & $\begin{array}{c}0.027(0.03) \\
<0.01 \% \\
0.368\end{array}$ \\
\hline Light PA (min.week ${ }^{-1}$ ) & $\begin{array}{c}\text { Beta (SE) } \\
r^{2} \\
P \text {-value }\end{array}$ & $\begin{array}{c}-0.0001(0.0006) \\
<0.01 \% \\
0.841\end{array}$ & $\begin{array}{c}-0.023(0.04) \\
<0.01 \% \\
0.473\end{array}$ \\
\hline $\begin{array}{l}\text { Moderate PA } \\
\left(\text { min.week }^{-1}\right)\end{array}$ & $\begin{array}{c}\text { Beta (SE) } \\
r^{2} \\
P \text {-value }\end{array}$ & $\begin{array}{c}-0.001(0.0009) \\
<0.01 \% \\
0.181\end{array}$ & $\begin{array}{c}-0.052(0.03) \\
<0.01 \% \\
0.197\end{array}$ \\
\hline $\begin{array}{l}\text { Vigorous PA } \\
\left(\text { min.week }^{-1}\right)\end{array}$ & $\begin{array}{c}\text { Beta (SE) } \\
r^{2} \\
P \text {-value }\end{array}$ & $\begin{array}{c}-0.0002(0.001) \\
<0.01 \% \\
0.846\end{array}$ & $\begin{array}{c}-0.062(0.04) \\
<0.01 \% \\
0.456\end{array}$ \\
\hline $\begin{array}{l}\text { Moderate-equivalent } \\
\left.\text { PA (min.week }{ }^{-1}\right)\end{array}$ & $\begin{array}{c}\text { Beta (SE) } \\
r^{2} \\
P \text {-value }\end{array}$ & $\begin{array}{c}-0.0003(0.0004) \\
<0.01 \% \\
0.455\end{array}$ & $\begin{array}{c}-0.052(0.03) \\
<0.01 \% \\
0.113\end{array}$ \\
\hline $\begin{array}{l}\text { Moderate-equivalent } \\
\text { PA (10 min bouts) } \\
\text { (min.week } \text { me }^{-1} \text { ) }\end{array}$ & $\begin{array}{c}\text { Beta (SE) } \\
r^{2} \\
P \text {-value }\end{array}$ & $\begin{array}{c}-0.00005(0.00008) \\
<0.01 \% \\
0.533\end{array}$ & $\begin{array}{c}-0.041(0.03) \\
<0.01 \% \\
0.213\end{array}$ \\
\hline
\end{tabular}

Data presented as beta coefficients and their corresponding standard error (SE). FTO genotype was added in the models using ordinal coding $T T=0, A T=1, A A=2$. Physical activity variables were fitted into the model as continuous* ${ }^{*}$ or as categorical variables**. 


\section{CHAPTER 5}

\section{Changes in physical activity following a genetic-based Internet-delivered personalized intervention: randomized controlled trial (Food4Me)}

Marsaux CF*, Celis-Morales $C^{*}$, Livingstone KM, Fallaize R, Kolossa S, Hallmann J, San-Cristobal R, Navas-Carretero S, O'Donovan CB, Woolhead C, Forster H, Moschonis G, Lambrinou C-P, Surwillo A, Godlewska M, Hoonhout J, Goris A, Macready AL, Walsh MC, Gibney ER, Brennan L, Manios Y, Traczyk I, Drevon CA, Lovegrove JA, Martinez JA, Daniel H, Gibney MJ, Mathers JC, Saris WH

"Both authors contributed equally to this work and are joint first authors

Journal of Medical Internet Research. 2016;18(2):e30 


\section{Abstract}

Background: There is evidence that physical activity (PA) can attenuate the influence of the fat mass- and obesity-associated (FTO) genotype on the risk to develop obesity. However, whether providing personalized information on FTO genotype leads to changes in PA is unknown. The purpose of this study was to determine if disclosing FTO risk had an impact on change in PA following a 6-month intervention. Methods: The single nucleotide polymorphism (SNP) rs9939609 in the FTO gene was genotyped in 1279 participants of the Food4Me study, a four-arm, Web-based randomized controlled trial (RCT) in 7 European countries on the effects of personalized advice on nutrition and PA. PA was measured objectively using a TracmorD accelerometer and was self-reported using the Baecke questionnaire at baseline and 6 months. Differences in baseline PA variables between risk (AA and AT genotypes) and nonrisk (TT genotype) carriers were tested using multiple linear regression. Impact of FTO risk disclosure on PA change at 6 months was assessed among participants with inadequate PA, by including an interaction term in the model: disclosure (yes/no) $\times$ FTO risk (yes/no). Results: At baseline, data on PA were available for 874 and 405 participants with the risk and nonrisk FTO genotypes, respectively. There were no significant differences in objectively measured or self-reported baseline PA between risk and nonrisk carriers. A total of 807 (72.05\%) of the participants out of 1120 in the personalized groups were encouraged to increase PA at baseline. Knowledge of FTO risk had no impact on $\mathrm{PA}$ in either risk or nonrisk carriers, after the 6-month intervention. Attrition was higher in nonrisk participants for whom genotype was disclosed $(P=0.01)$ compared with their at-risk counterparts. Conclusions: No association between baseline PA and FTO risk genotype was observed. There was no added benefit of disclosing FTO risk on changes in PA in this personalized intervention. Further RCT studies are warranted to confirm whether disclosure of nonrisk genetic test results has adverse effects on engagement in behavior change.

\section{Introduction}

The prevalence of physical inactivity in Europe and worldwide is high [1]. Given that physical inactivity is among the top risk factors for noncommunicable diseases [2], finding effective ways to achieve long-lasting improvements in physical activity (PA) remains a major challenge [3]. While previous intervention strategies have mainly focused on a "one-size-fits-all" approach to change behavior, recent studies have used personalized approaches, such as tailored Web-based interventions [4,5]. There is inconsistent evidence on whether these personalized approaches are more effective at 
increasing PA than standard guidelines, and effects, when present, are often small and with short-term efficacy [6]. Concurrently, there has been a growing interest in using genetic information to personalize lifestyle interventions [7]. Although disclosure of such information does not appear to have unintended adverse effects, more randomized controlled trials (RCTs) are needed to establish whether gene-based personalized interventions promote greater behavior change than conventional "one-size-fits-all" interventions [8]. In particular, data on whether providing genetic information leads to an increase in PA are lacking.

The fat mass- and obesity-associated (FTO) gene has provided strong evidence of the genetic susceptibility to obesity. Polymorphisms in this gene located in intron 1 and exon 2 have been shown to be consistently and strongly associated with obesityrelated markers $[9,10]$. For instance, individuals homozygous for the higher-risk allele, AA, of single nucleotide polymorphism (SNP) rs9939609 in FTO weighed, on average, $3 \mathrm{~kg}$ more and had 1.7-fold increased odds of having obesity compared with those homozygous for the lower-risk allele, TT [11]. Moreover, there is increasing evidence that the FTO genetic susceptibility to obesity can be modulated by lifestyle factors, and that PA, for example, may attenuate the effects of the FTO genotype on obesity-related traits [12-17]. However, to our knowledge there is no data on whether disclosing information on FTO genotype can motivate individuals to increase their PA. Elucidating whether genetic-based advice can promote improvements in PA behaviors may help in the design of more effective interventions, especially when tailored to individuals who would benefit most from increasing their PA.

As part of the Food4Me study (ClinicalTrials.gov number: NCT01530139)-a Webbased RCT in seven European countries - we investigated the effects of three levels of personalized advice on changes in PA, including a level with genetic information on FTO $[18,19]$. We found that personalized feedback in general led to greater improvements in self-reported PA, but not in objectively measured PA, compared with standard guidelines [19]. However, we did not investigate the effect of disclosing genetic-based information on PA change, and whether the response differs between carriers of a genetic risk and nonrisk carriers. Thus, the aim of these analyses was to assess the impact of knowledge of FTO risk status on change in self-reported and objectively measured PA in Food4Me participants. 


\section{Methods}

\section{Subjects}

Subjects were participants of the Food4Me study, a 6-month, Web-based RCT on personalized nutrition and lifestyle conducted in seven European countries-Germany, Greece, Ireland, the Netherlands, Poland, Spain, and the United Kingdom. As outlined elsewhere [18], 1607 adults aged $\geq 18$ years were randomized to the study. Exclusion criteria included no or limited access to the Internet, following a prescribed diet, or having altered nutritional requirements because of a medical condition. The local ethics committee of each recruiting center approved the study protocol and all subjects provided informed consent digitally before participating.

\section{Study design}

Participants were randomly allocated to one of four groups-Level 0: standard, nonpersonalized, dietary and PA guidelines; Level 1: dietary and PA advice based on current diet and PA; Level 2: dietary and PA advice based on current diet, PA, and phenotype (eg, waist circumference and blood cholesterol); and Level 3: dietary and PA advice based on current diet, PA, phenotype, and genotype (eg, FTO). The randomization scheme has been described previously [18]. All data were collected remotely following standardized operating procedures. At baseline, participants received study kits by post containing all necessary materials, such as an accelerometer and DNA collection kit (see the Physical Activity Assessment and Genotyping sections below), to perform measurements at home, but used their own scales to measure body weight. Printed instructions were included and demonstration videos were available on the Food4Me website $[18,20]$.

On the allocated study day and following an 8-hour overnight fast, participants collected a buccal cell sample for DNA; measured their height, weight, and waist circumference; and started wearing an accelerometer. The buccal cell sample was returned to the research center in a prepaid stamped addressed envelope and anthropometric measurement values were self-reported online. Questionnaires to be completed online the same day included the Baecke PA questionnaire (see Physical Activity Assessment section below). Participants repeated the measurements, except DNA collection, at 3 and 6 months [18].

Following measurements at baseline and 3 months, participants received, at both time points, a personalized (Levels 1-3) or nonpersonalized (Level 0) report, including feedback on PA according to their group. The personalized feedback provided was 
based on a predefined set of algorithms, including anthropometric, PA (Levels 1-3), phenotypic (Levels 2 and 3), and genotypic (Level 3 only) data. Results in the personalized report were compared with recommendations for each anthropometric, PA (Levels 1-3), and phenotypic (Levels 2 and 3) item, using three-color graded linesgreen: good; amber: improvement recommended; and red: improvement strongly recommended. In addition, Level 3 participants received information in their report about five diet- and lifestyle-related genes [18]. For FTO, the message was "A specific variation of this gene is associated with a greater need to maintain a healthy body weight and engage in physical activity. A healthy weight combined with exercise may provide added health benefits for these individuals." Participants were informed whether they were carriers of the risk variant for the FTO SNP rs9939609 (yes or no, if they were genotyped AA or AT, or TT, respectively). Each personalized report (Levels 1-3) also contained a specific message related to body weight and PA. Additionally, for Level 3 participants this specific message referred to FTO. For example, for an AA/AT participant with increased body mass index (BMI), increased waist circumference, and low PA, the message was "We recommend reducing your body weight and waist circumference to a healthy normal range because you have a genetic variation that can benefit by reducing these two obesity markers. Also, your physical activity level is too low." Full details of the study design have been published elsewhere [18].

\section{Physical activity assessment}

\section{Objective physical activity}

PA was assessed objectively using the TracmorD triaxial accelerometer (Philips Consumer Lifestyle, the Netherlands) [21,22]. Participants were instructed to wear the accelerometer every day while awake, except when taking a shower, for the entire duration of the 6-month study. Participants uploaded data every 2 weeks onto the study server via the Internet. Data were recorded with a time-sampling interval of $1 \mathrm{~min}$. A day was considered valid if the participant had worn the TracmorD accelerometer between 10 and $18 \mathrm{~h}$. Wear time was defined as $24 \mathrm{~h}$ minus nonwear time. To define nonwear time, we adapted the recommendations of Choi et al [23] to the TracmorD accelerometer. R software version 3.1.2 (The R Foundation) [24] was used for PA data processing.

Daily PA level (PAL) - the ratio of total energy expenditure to basal metabolic ratewas derived from activity counts [21]. Time spent in sedentary behaviorcorresponding to $<1.5$ metabolic equivalents (METs) - and moderate- and vigorousintensity $\mathrm{PA}-3$ to $<6 \mathrm{MET}$ and $\geq 6 \mathrm{METs}$, respectively - were calculated based on the 
application of thresholds for activity energy expenditure (AEE) equivalent to the METs thresholds. Daily AEE was calculated as follows:

Daily AEE $=(0.9 \times$ daily $P A L-1) \times B M R(1)$

where the daily basal metabolic rate (BMR) is estimated using the Oxford equations developed by Henry, based on sex, age, and weight [25].

PA estimates were calculated over a 2-week period at baseline and 6 months. This 2week assessment period occurred before any feedback was given for the corresponding time point. Sufficient PA data at each time point was defined as having at least 3 valid weekdays and 2 valid weekend days of accelerometer wear during the 2-week period. For individuals with sufficient PA data, mean data per day were calculated based on all valid week and weekend days of the assessment period as follows:

Mean $=($ mean for weekdays $\times 5+$ mean for weekend days $\times 2) / 7$ (2).

For sedentary time and time spent in moderate PA and vigorous PA, weekly estimates were calculated as follows: ean $=($ mean for weekdays $\times 5+$ mean for weekend days $\times$ 2) (3).

\section{Self-reported physical activity}

At each time point, participants completed the Baecke questionnaire online [26] based on their PA during the last month. This short, extensively validated questionnaire [2729] is composed of three sections - work, sport, and nonsport leisure-with indices ranging from 1 to 5 and a sum total (ie, total activity index) ranging from 3 to 15 . Scores were calculated at baseline and month 6 , according to the questionnaire protocol [26].

\section{Genotyping}

Participants collected a buccal cell sample at baseline, using Isohelix SK-1 DNA buccal swabs and Isohelix Dri-capsules (LGC Genomics, Hertfordshire, UK). Samples were returned to the recruiting centers and shipped to LGC Genomics, who extracted the DNA and used competitive allele-specific polymerase chain reaction (KASP) genotyping assays to provide biallelic scoring of SNP rs9939609 in the FTO gene.

\section{Statistical analyses}

Data are presented as means (SD) for continuous variables and as percentages for categorical variables, unless otherwise stated. A chi-square test was used to test if the 
observed FTO genotype counts were in Hardy-Weinberg equilibrium [30]. To examine if there was an association between PA and FTO genotype, we used baseline data and robust multiple linear regression models, based on computation of SMDM estimates [31] to account for violation of the normality assumption. FTO genotype was operationalized as risk (AA and AT) and nonrisk (TT).

To study the impact of knowledge of FTO risk status on changes in PA, we used two approaches. In the first approach or primary analysis, we investigated whether personalized advice based on genetic information (ie, FTO risk) was more effective at increasing PA than personalized advice without genetic-based information, in FTO risk and nonrisk carriers. In this analysis, we compared Level 3 participants who received personalized advice to increase PA, including disclosure of FTO risk, with participants who received personalized advice to increase PA without any genetic-based information (pooled Levels 1 and 2). As a secondary analysis, we assessed whether personalized advice based on genetic information (ie, FTO risk) was more effective at increasing PA than standard guidelines (ie, nonpersonalized advice) in FTO risk and nonrisk carriers. This analysis compared Level 3 participants with the control groupLevel 0 , nonpersonalized guidelines. In order to match the characteristics of both groups, participants in the control group were included only if they had insufficient baseline PA (ie, they would have been advised to increase their PA if they had not been in the control group). For both primary and secondary analyses, we used robust multiple regression models, including an interaction term between FTO risk (yes or no) and disclosure of genetic information (yes or no). If there was no significant interaction, we looked at the main effects after removing the interaction term from the model. Models were adjusted for age, sex, country, BMI, season, accelerometer wear time, and baseline PA variable as appropriate. Additional sensitivity analyses were run, stratifying by sex and by tertile of baseline PA variables. Attrition rates between groups were compared using Pearson's chi-square tests. R software version 3.1.2 (The R Foundation) [24] was used to perform all analyses and the significance level was set at $P<0.05$.

\section{Results}

\section{Attrition rate and compliance}

A total of 1607 individuals were randomized into the study (see Figure 5.1) and 127 $(7.90 \%)$ of them dropped out before starting the trial; their characteristics will be reported elsewhere. 


\section{CHAPTER 5}

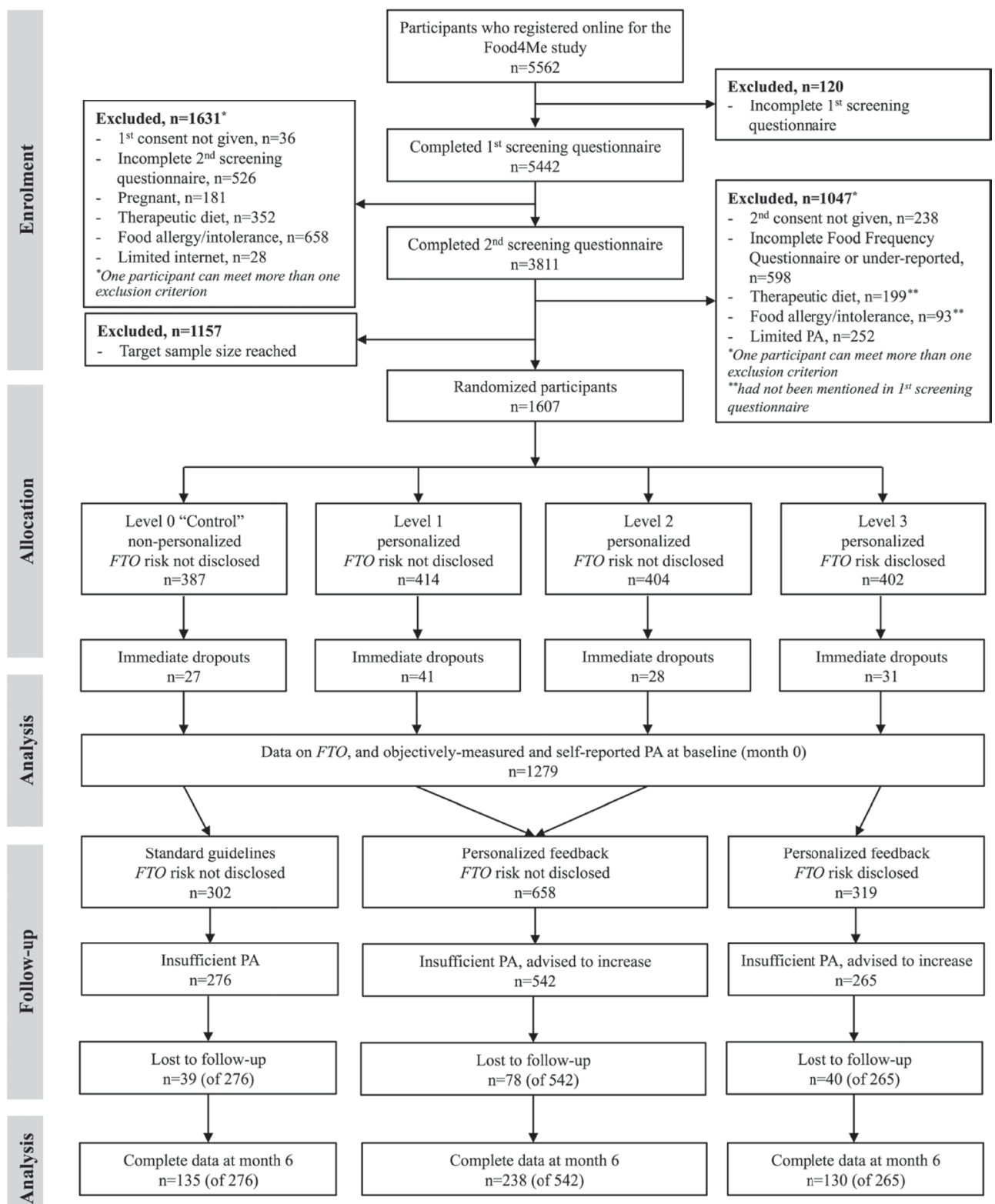

Figure 5.1 Flowchart study procedures

Participants in Level 0 (controls) received standard, non-personalized guidelines, whereas participants in Levels 1-3 received personalized advice, during the intervention. PA, physical activity; FTO, fat mass and obesity-associated gene.

Genotype and PA data were available for 1279 of the $1480(86.42 \%)$ starters, which were therefore included in the baseline analysis (see Figure 5.1). Although sufficient accelerometer data were defined as having a minimum of 3 valid weekdays and 2 valid 
weekend days of accelerometer wear, $77.56 \%$ (992/1279) of subjects had 10 or more valid days of accelerometer wear at baseline-mean 11.3 days (SD 2.4): 8.2 weekdays (SD 1.9) and 3.2 weekend days (SD 0.8). Among the 1120 participants who received personalized advice (Levels 1-3), 807 (72.05\%) were advised to increase their PA following assessment of baseline PA. Similarly, in the control group (Level 0), 276 of $360(76.7 \%)$ participants would have been advised to increase their PA if the algorithms applied to Levels 1-3 had been applied to the control group (see Figure 5.1). For these participants with inadequate PA, attrition rate was similar between groups (14-15\%, $P=0.045$ ) at month 6 (see Figure 5.1).In the group where FTO risk was disclosed (Level 3), participants with the nonrisk (TT) genotype were more likely to drop out of the intervention than the at-risk (AA/AT) participants-attrition rate $22 \%$ (TT) versus $12 \%$ (AA/AT); odds ratio (OR) $2.04,95 \% \mathrm{Cl} 0.96-4.29, P=0.004$. This was also the case when considering all participants in Level 3 (ie, not only those advised to increase their PA) - attrition rate $20 \%$ (TT) versus $11 \%$ (AA/AT); OR 2.17, 95\% Cl 1.134.17, $P=0.001$ (Table 5.1). There were no significant differences in attrition rates after 6 months between risk and nonrisk carriers in any other groups.

Table 5.1 Attrition rates after 6 months by intervention level

\begin{tabular}{|c|c|c|c|c|c|c|c|c|}
\hline & \multirow{2}{*}{\multicolumn{2}{|c|}{$\begin{array}{c}\text { Standard } \\
\text { guidelines } \\
\text { Level } 0\end{array}$}} & \multicolumn{4}{|c|}{$\begin{array}{l}\text { Personalized, non-gene-based } \\
\text { advice }\end{array}$} & \multirow{2}{*}{\multicolumn{2}{|c|}{$\begin{array}{c}\text { Personalized and } \\
\text { gene-based advice } \\
\text { Level } 3\end{array}$}} \\
\hline & & & \multicolumn{2}{|c|}{ Level 1} & \multicolumn{2}{|c|}{ Level 2} & & \\
\hline & $\mathrm{TT}^{\mathrm{a}}$ & AA/AT $^{a}$ & TT & AA/AT & TT & $\mathrm{AA} / \mathrm{AT}$ & $\mathrm{TT}$ & AA/AT \\
\hline & $n=112$ & $n=247$ & $n=127$ & $n=244$ & $n=117$ & $n=255$ & $n=113$ & $n=257$ \\
\hline $\begin{array}{l}\text { Dropouts, n } \\
(\%)\end{array}$ & $\begin{array}{c}13 \\
(11.6)\end{array}$ & $\begin{array}{c}34 \\
(13.8)\end{array}$ & $\begin{array}{c}19 \\
(15.0)\end{array}$ & $\begin{array}{c}40 \\
(16.4)\end{array}$ & $\begin{array}{c}11 \\
(9.4)\end{array}$ & $\begin{array}{c}38 \\
(14.9)\end{array}$ & $\begin{array}{c}23 \\
(20.4)^{b}\end{array}$ & $\begin{array}{c}27 \\
(10.5)^{b}\end{array}$ \\
\hline
\end{tabular}

${ }^{a}$ TT and AA/AT are the nonrisk and risk genotypes, respectively, for fat mass- and obesity-associated (FTO) rs9939609. ${ }^{b}$ Significant difference in attrition rate between FTO TT and AA/AT genotypes for Level 3 participants $(P=0.001)$.

Although only 157 out of 1083 (14.50\%) participants with inadequate PA had dropped out by month 6 , compliance with wearing the accelerometer decreased during the study. Thus, $46.45 \%(503 / 1083)$ of subjects had data on FTO genotype, objective PA, and self-reported PA for both baseline and month 6 , and were included in the analyses on change in PA (see Figure 5.1). Of these, 85.5\% (430/503) and 68.0\% (342/503) had 10 days of valid accelerometer wear at baseline and month 6 , respectively. Mean number of valid days of accelerometer wear for these participants was 11.9 days (SD 2.1 ) at baseline -8.6 weekdays (SD 1.7) and 3.3 weekend days (SD 0.7 )-and 10.4 days (SD 3.0) at month 6-7.7 weekdays (SD 2.3) and 2.7 weekend days (SD 1.1). This was similar for all intervention groups (data not shown for Levels 0-3). 


\section{Physical activity and FTO genotype}

The characteristics of the 1279 participants with baseline PA data both from accelerometers and self-reports, as well as data on FTO genotype, are presented in Table 5.2. Most participants were white, 743 (58.09\%) were women, and 588 (45.97\%) were overweight or obese. Genotype frequency for FTO rs9939609 did not deviate from Hardy-Weinberg equilibrium ( $\mathrm{TT}=405, \mathrm{TA}=641$, and $\mathrm{AA}=233 ; P=0.048$ ).

Table 5.2 Characteristics of the participants included in baseline analysis

\begin{tabular}{|c|c|c|c|}
\hline \multirow[b]{2}{*}{ Variables } & \multirow[b]{2}{*}{ Overall } & \multicolumn{2}{|c|}{ FTO $^{\text {a }}$ risk status } \\
\hline & & $\begin{array}{c}\text { Risk } \\
\text { (AA/AT) }\end{array}$ & $\begin{array}{l}\text { Non-risk } \\
\text { (TT) }\end{array}$ \\
\hline & $n=1279$ & $n=874$ & $n=405$ \\
\hline Ethnicity (white), n (\%) & $1239(96.87)$ & $848(97.0)$ & $391(96.5)$ \\
\hline Sex (women), n (\%) & $743(58.09)$ & $520(59.5)$ & $223(55.1)$ \\
\hline Age (years), mean (SD) & $40(13)$ & $40(13)$ & $40(13)$ \\
\hline Height $(m)$, mean $(S D)$ & $1.71(0.09)$ & $1.71(0.09)$ & $1.72(0.09)$ \\
\hline Weight $(\mathrm{kg})$, mean (SD) & $74.8(15.8)$ & $75.2(16.1)$ & $73.9(15.2)$ \\
\hline $\mathrm{BMI}^{\mathrm{b}}\left(\mathrm{kg} \cdot \mathrm{m}^{-2}\right)$, mean (SD & $25.5(4.8)$ & $25.7(4.9)$ & $25.0(4.5)$ \\
\hline Overweight (BMI 25-29.9 kg.m ${ }^{-2}$ ), n (\%) & $379(29.63)$ & $270(30.9)$ & 109 (26.9) \\
\hline Obese $\left(\mathrm{BMI} \geq 30 \mathrm{~kg} \cdot \mathrm{m}^{-2}\right), \mathrm{n}(\%)$ & $209(16.34)$ & $156(17.8)$ & $53(13.1)$ \\
\hline $\begin{array}{l}\text { Accelerometer wear time (hours), mean } \\
\text { (SD) }\end{array}$ & $14.4(1.1)$ & $14.4(1.1)$ & $14.4(1.0)$ \\
\hline Number of valid days, mean (SD) & $11.3(2.4)$ & $11.3(2.4)$ & $11.3(2.4)$ \\
\hline \multicolumn{4}{|l|}{ Participants per season, $\mathbf{n}(\%)$} \\
\hline Winter & $377(29.48)$ & $266(30.4)$ & $111(27.4)$ \\
\hline Spring & $720(56.29)$ & $480(54.9)$ & $240(59.3)$ \\
\hline Summer & $99(7.74)$ & $73(8.4)$ & $26(6.4)$ \\
\hline Autumn & $83(6.49)$ & $55(6.3)$ & $28(6.9)$ \\
\hline \multicolumn{4}{|l|}{ Participants per country, n (\%) } \\
\hline Germany & $174(13.60)$ & $116(13.3)$ & $58(14.3)$ \\
\hline Greece & $174(13.60)$ & $124(14.2)$ & $50(12.3)$ \\
\hline Ireland & $178(13.92)$ & $123(14.1)$ & $55(13.6)$ \\
\hline Netherlands & $214(16.73)$ & $148(16.9)$ & $66(16.3)$ \\
\hline Poland & $177(13.84)$ & $130(14.9)$ & $47(11.6)$ \\
\hline Spain & $181(14.15)$ & $(121$ 13.8) & $60(14.8)$ \\
\hline United Kingdom & $181(14.15)$ & $112(12.8)$ & $69(17.0)$ \\
\hline FTO genotype: AA / AT / TT, n (\%) & $\begin{array}{c}233 / 641 / 405 \\
(18.22 / 50.12 / 31.67)\end{array}$ & $N / A^{c}$ & $\mathrm{~N} / \mathrm{A}$ \\
\hline
\end{tabular}

${ }^{a}$ FTO: fat mass- and obesity-associated gene. ${ }^{b} \mathrm{BMI}$ : body mass index. ${ }^{C} \mathrm{~N} / \mathrm{A}$ : not applicable. 
We found no association between objectively measured PAL $(P=0.035)$, moderate PA $(P=0.028)$, vigorous PA $(P=0.024)$, or sedentary time $(P=0.071)$ at baseline and FTO risk status (Figure 5.2a). Similarly, there was no significant difference in baseline selfreported PA between risk and nonrisk carriers $(P=0.076)$ (Figure 5.2b).

a. Objectively measured physical activity
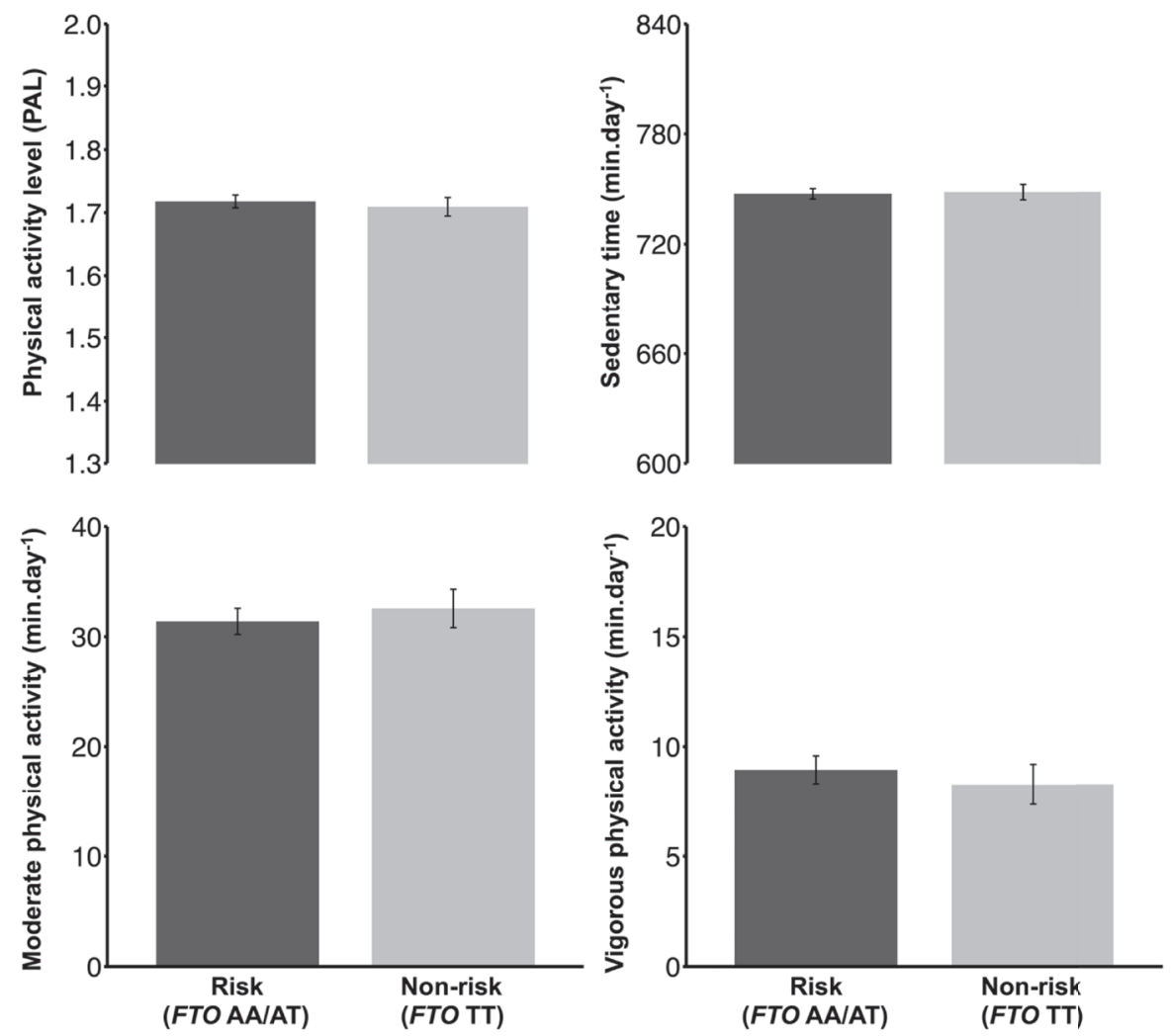

b. Self-reported physical activity

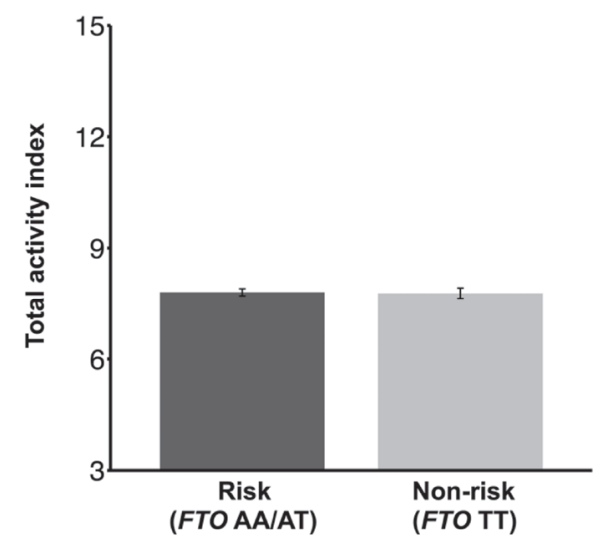

Figure 5.2 Physical activity in FTO rs9939609 risk (AA/AT) and non-risk (TT) carriers at baseline 


\section{Primary analysis: effect of disclosing FTO genotype status on change in physical activity}

Table 5.3 displays the PA characteristics of genotyped participants advised to increase their PA at baseline, with objective and self-reported PA data at baseline and month 6 .

Table 5.3 Changes in physical activity $(P A)$ from baseline to month 6 for participants receiving personalized advice to increase their $P A$

\begin{tabular}{|c|c|c|c|c|c|}
\hline \multirow[b]{2}{*}{ Variables } & & \multicolumn{2}{|c|}{ Disclosure (Level 3) } & \multicolumn{2}{|c|}{ Non-disclosure (Levels 1-2) } \\
\hline & & $\begin{array}{c}\text { FTO }^{\text {a }} \text { risk } \\
\text { AA/AT }\end{array}$ & $\begin{array}{c}\text { FTO non-risk } \\
\text { TT }\end{array}$ & $\begin{array}{c}\text { FTO risk } \\
\text { AA/AT }\end{array}$ & $\begin{array}{c}\text { FTO non-risk } \\
\text { TT }\end{array}$ \\
\hline & & $n=91$ & $n=39$ & $n=160$ & $n=78$ \\
\hline \multicolumn{6}{|l|}{ Objective $P A^{b}$} \\
\hline \multirow{2}{*}{ Daily PAL ${ }^{c}$} & Month 0 & $1.64(0.10)$ & $1.67(0.08)$ & $1.68(0.10)$ & $1.67(0.10)$ \\
\hline & Month 6 & $1.66(0.14)$ & $1.70(0.13)$ & $1.70(0.14)$ & $1.70(0.17)$ \\
\hline \multirow{2}{*}{$\begin{array}{l}\text { Moderate PA } \\
\left(\min \text { week }^{-1}\right)\end{array}$} & Month 0 & $174(124)$ & $209(98)$ & $199(111)$ & $189(112)$ \\
\hline & Month 6 & $206(146)$ & $249(120)$ & $218(145)$ & $221(130)$ \\
\hline \multirow{2}{*}{$\begin{array}{l}\text { Vigorous PA } \\
\left(\text { min. }^{\text {week }}{ }^{-1}\right)\end{array}$} & Month 0 & $37(54)$ & $48(67)$ & $54(73)$ & $49(64)$ \\
\hline & Month 6 & $49(76)$ & $57(89)$ & $64(93)$ & $61(91)$ \\
\hline \multirow{2}{*}{ 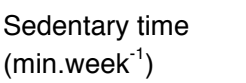 } & Month 0 & $5449(483)$ & $5391(479)$ & $5327(505)$ & $5433(485)$ \\
\hline & Month 6 & $5271(606)$ & $5153(449)$ & $5172(541)$ & $5139(579)$ \\
\hline \multicolumn{6}{|l|}{ Self-reported PA } \\
\hline \multirow{2}{*}{ Total activity index } & Month 0 & $7.46(1.49)$ & $7.51(1.31)$ & $7.49(1.37)$ & $7.69(1.30)$ \\
\hline & Month 6 & $8.00(1.37)$ & $7.89(0.99)$ & $7.84(1.29)$ & $7.99(1.44)$ \\
\hline
\end{tabular}

Data are presented as means (SD). ${ }^{a}$ FTO: fat mass- and obesity-associated gene. ${ }^{b} P A$ : physical activity. ${ }^{c}$ PAL: physical activity level.

There was no significant interaction between disclosure of genetic information and FTO risk status on change in objectively measured or self-reported PA (all P>0.25); this is illustrated in Figure 5.3. There was also no effect of knowledge of FTO genotype on objectively measured or self-reported PA (all P>0.10) (see Table 5.3 and Figure 5.3).

\section{Secondary analysis: personalized feedback including disclosure of genetic information compared with standard guidelines}

Comparisons between participants in the highest level of personalization (Level 3) who were advised to increase their PA, and control participants (Level 0) who would have been advised to increase PA if they had been in a personalized group, are given in Supplementary Material 5.1. There were no significant interactions between intervention levels and FTO risk status on change in PA. Change in objectively measured PA did not differ significantly between Level 3 and Level 0 participants for both risk and nonrisk carriers. However, Level 3 participants, irrespective of FTO risk status, had greater changes in self-reported PA than Level 0 participants (see Supplementary Material 5.1). 
a. Objectively measured physical activity
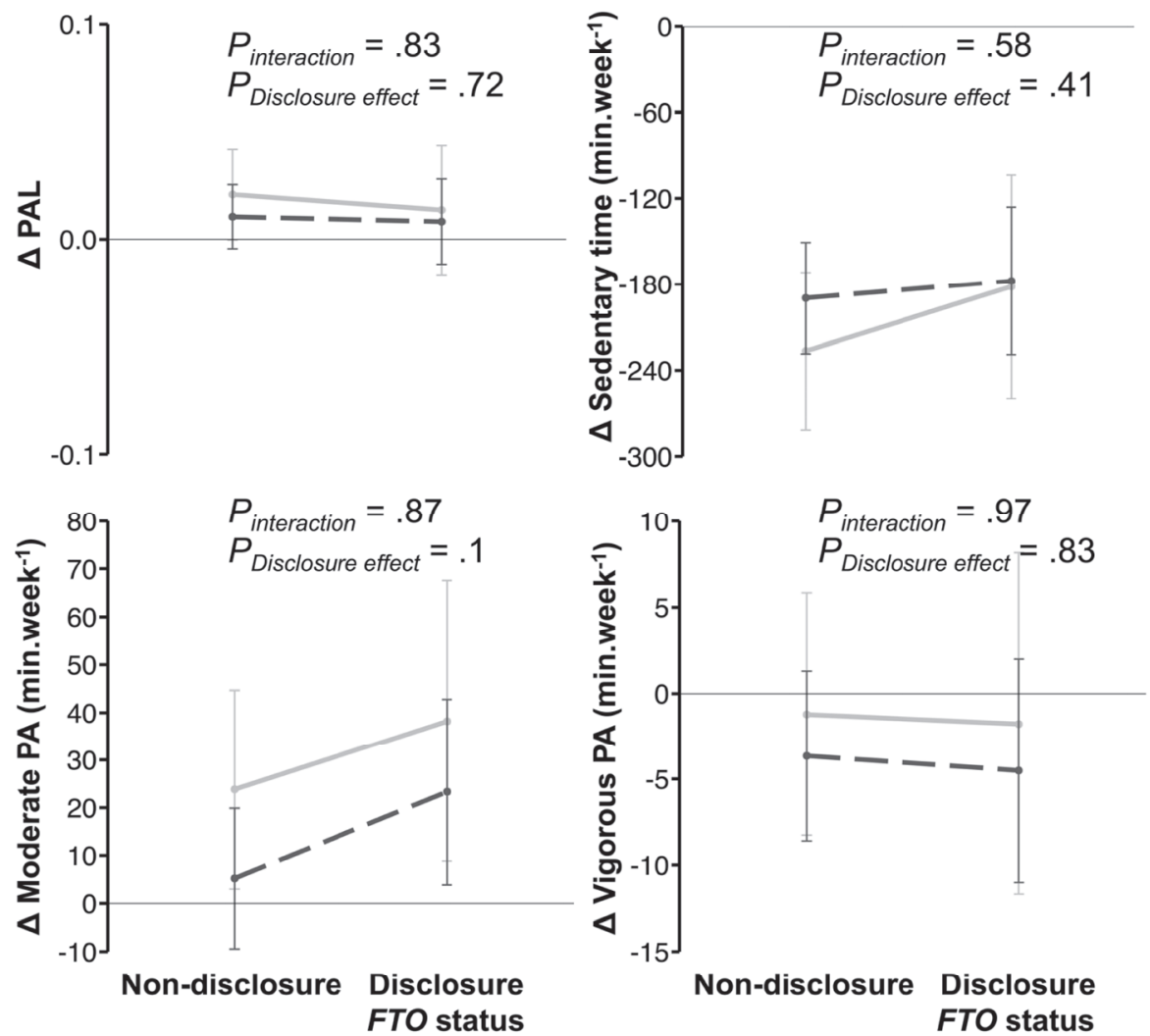

b. Self-reported physical activity

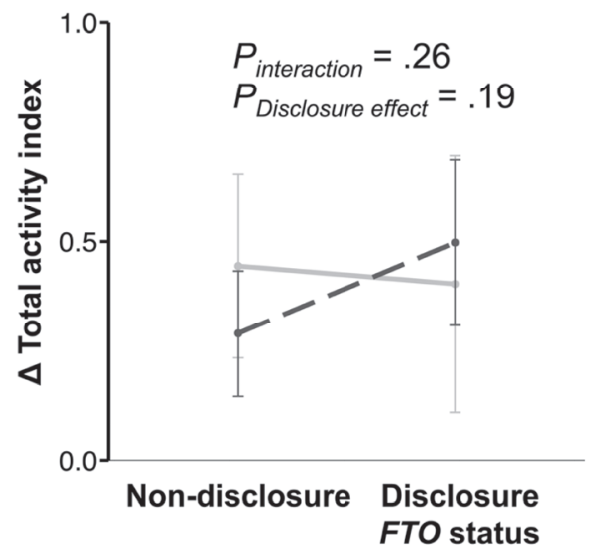

- - FTO risk carriers FTO non-risk carriers

Figure 5.3 Effect of knowledge of FTO risk status on change in physical activity (PA) in risk (AA/AT) and non-risk (TT) carriers

FTO, fat mass- and obesity-associated gene. Non-disclosure FTO risk carriers, $n=160$; Nondisclosure FTO non-risk carriers, $n=78$; Disclosure FTO risk carriers, $n=91$; Disclosure FTO non-risk carriers, $n=39$ 


\section{Sensitivity analyses}

Results and conclusions were similar when carrying out the analyses in men and women separately or after stratifying analyses by tertile of baseline PA variables (data not shown).

\section{Discussion}

\section{Principal findings}

Our main findings identified that there was no association between objectively measured or self-reported PA and FTO risk status. To our knowledge, our study is the first to investigate the impact of FTO genotype-based feedback on measured change in $\mathrm{PA}$ in the context of a personalized lifestyle intervention. We hypothesized that knowledge of carriage of FTO risk would lead to an increase in PA. However, we found no evidence that disclosing such information had any positive or negative effects on PA after a 6-month intervention.

\section{Comparison with previous work}

In the last decade, there has been a growing interest in personalizing lifestyle interventions using genetic tests. This has been done using DNA-based disease risk estimates, primarily in smokers or individuals at risk of certain conditions, such as Alzheimer's disease [8]. The hope was that providing such genetic information would motivate recipients to make beneficial behavioral changes beyond what could be achieved without such information. It is unclear whether knowledge of being predisposed to a greater genetic risk of disease would promote positive behavioral change and whether knowledge of only a small genetic risk (ie, a "lower" genetic risk) predisposition would lead to counterproductive behaviors under false reassurances [32]. In their 2010 review, Marteau et al reported no effect of adding DNA-based disease risk estimates compared with a non-DNA based approach, in terms of smoking cessation, PA, or use of medication/vitamins. A beneficial effect of DNA-based risk estimates on dietary behavior was reported, although no benefit on intention to change dietary behavior was observed [8]. Since then, Hollands et al also observed no effect of communicating DNA-based risk assessments for Crohn's disease on smoking cessation, compared with standard risk assessment [33]. Grant et al reported that diabetes genetic risk counseling did not alter self-reported motivation or adherence to a prevention program in overweight individuals at risk for diabetes [34]. Although the design of our study was different because we did not aim to recruit individuals specifically at risk of a certain disease, our results are in line with the results of most 
studies performed so far. Recently, Meisel et al showed that young healthy individuals receiving FTO feedback in their weight control advice felt more prepared to control their weight than subjects receiving weight control advice only. However, this did not translate into behavioral change [35].

Evidence in favor of disclosing genetic information is thus limited. Even the favorable findings for dietary behavior change mentioned above in the review by Marteau et al are weak [8]. They are based on only two studies [36,37], which did not find significant effects when each study was evaluated individually. More recently, Nielsen et al concluded that disclosing genetic information for personalized nutrition resulted in greater improvements in intake of some dietary components compared with general population-based dietary advice. In reality, this was true only for sodium intake, but not for caffeine, vitamin $\mathrm{C}$, or added sugars, which were also studied. In addition, only individuals with the high-risk genotype status for the $A C E$ gene reduced their sodium intake more than controls based on self-reported food intake, not on objective biomarkers of intake [38]. Similarly, Hietaranta-Luoma et al reported that personal genetic information based on $A p O E$ might have positive effects on triglyceride values and waist circumference, but this was observed only in the high-risk $\varepsilon 4+$ individuals [39].

Data suggest that providing genetic test results indicating a higher genetic risk does not lead to fatalism [8]. Furthermore, there is no indication that disclosing only a small genetic risk or a lower-risk test result promotes counterproductive behaviors. Similarly, in our study we found no differences in change in PA between individuals aware of their nonrisk FTO status and individuals aware of a risk, or not aware of their genotype. However, we did observe that the attrition rate was significantly greater among individuals informed of their nonrisk FTO status as compared to the other groups. Given the amount and variety of information provided to participants during the Food4Me study, it seems unlikely that this genetic information would be responsible for the higher number of dropouts. Nonetheless, this should be studied further, as it may indicate that such individuals felt the intervention was less relevant for them. Grant et al also reported that subjects receiving lower-risk genetic results showed lower intent to do exercise compared with controls, although there were no differences in terms of attendance to the diabetes prevention program [34].

Personalized feedback led to greater improvements in self-reported PA, but not objectively measured PA, compared with standard guidelines, as reported previously [19]. Discrepancies between self-reported and objectively measured PA have been noted by others. For instance, Wanner et al, in a Web-based tailored PA intervention, reported some improvements in self-reported PA after 6 weeks and 13 months of 
follow-up, but no differences between individuals in tailored and control groups, and no improvement in objectively measured PA for any group [40]. However, in our study we did find greater improvements in self-reported PA in tailored groups as compared with the controls. It could be that participants desired to comply with recommendations and that receiving more personalized feedback (Levels 2 and 3 ) increased this desire further. Furthermore, here we show that the bigger improvements in self-reported PA reported earlier are irrespective of FTO genotype, and are not related to knowing one's risk status for FTO. Thus, it is unlikely that subjects with the high-risk variant would feel more pressured to report that they did better, compared with those with the low-risk variant. Finally, we did not observe an association between FTO risk and PA measured objectively or self-reported. This supports studies published thus far that have used mainly self-reported data $[15,41,42]$.

\section{Strengths and limitations}

This study is the first to report the impact of disclosing information on FTO risk status on measured changes in PA. Our PA questionnaire has been validated against doubly labeled water and accelerometry $[26,29,43]$, and has been used in large European cohorts before [44,45]. However, self-reports introduce large measurement error [46] and the Baecke questionnaire is no exception [47]. Thus, a strength of this study was the objective assessment of PA using triaxial accelerometers. Although accelerometers underestimate certain activities, such as cycling, swimming, or resistance training, the TracmorD model used in this study has been validated against doubly labeled water [21] and it has been shown to be reliable and accurate [48-50].

By design, we recruited individuals interested in taking part in a personalized intervention on nutrition and lifestyle, which is less representative than a Europeanwide survey. Nonetheless, our participants were broadly representative of the European adult population, most of whom had adequate nutrient intakes but could benefit from improved dietary choices and greater PA [51]. Given that Food4Me was an intervention that targeted multiple dietary and lifestyle behaviors, the genetic results might have also been diluted by the amount of information provided. Moreover, the genetic feedback was a positive reinforcement. Participants with the higher-risk genotype would only benefit more by reducing their weight or increasing their PA. It is possible that the impact would have been greater if participants had been made more aware of the links between obesity and lifelong ill health. Furthermore, genetic feedback provided by health professionals skilled in genetic counseling might have been more effective that written feedback. However, this would have been more expensive and outside the scope of this study, which was designed to test the effects of 
an Internet-delivered intervention. Such interventions are thought to offer considerable advantages in terms of reach, scalability, and sustainability [52]. Attrition rates $(\sim 15 \%)$ were as expected and compliance with the measurements was good, except for wearing the monitor. Only half of the participants had accelerometer data for both baseline and month 6 -whereas $>75 \%$ had self-reported PA data at both time pointswhich limited the size of the sample analyzed in the PA analyses. It is possible that wearing the monitor for 6 months was too demanding for the amount of feedback given. It may be important for future studies that participants be able to visualize their activity levels, in real time, whenever desired (eg, on an accompanying website). Improvements in activity measurement may reduce participants' confusion and/or frustration. Having personalized coaches available, who can also operate online, may have motivated participants to wear their accelerometer and to improve their PA, although this also means extra costs. For the sole purpose of assessment, better compliance may be obtained by sending out monitors and collecting them back directly after assessment [53]. In spite of this, our sample size was acceptable, and the results did not change when looking at all self-reported PA data available.

\section{Conclusions}

There was no added benefit of knowledge of FTO risk on change in PA in this intervention study. Although there were no differences in outcome measures between participants informed of a nonrisk and those informed of a risk, or those not informed of their FTO risk status, the nonrisk subjects were more likely to drop out of the study by 6 months. More studies are needed to confirm whether disclosure of lower-risk genetic test results has adverse effects on engagement in behavioral changes. Before that, more effort should be devoted to identify the features necessary to engage individuals, how to frame the feedback, and how to coach effectively, especially those at risk, to reduce health inequalities.

This work was funded by the EU FP7 project Food4Me (no. 265494). JCM was the Food4Me intervention study coordinator. ERG, LB, YM, IT, CAD, JAL, JAM, WHMS, HD, MG and JCM contributed to the research design. CFMM, CCM, RSC, SNC, COD, CW, HF, RF, ALM, SK, JHa, CPL, GM, AS, MG, MCW and JCM conducted the intervention. CFMM, WHMS, CCM, AG and JHo contributed to physical activity measurements. CFMM and CCM drafted the paper. CFMM performed the statistical analysis. All authors critically reviewed the manuscript and approved the final version to be published. JH and AG are employed by Philips. The other authors have no competing interests. 


\section{References}

1. Hallal PC, Andersen LB, Bull FC, Guthold R, Haskell W, Ekelund U, et al. Global physical activity levels: surveillance progress, pitfalls, and prospects. Lancet. 2012;380(9838):247-57.

2. World Health Organization. Noncommunicable Diseases Country Profiles 20112011. 207 p.

3. Ekelund U, Ward HA, Norat T, Luan J, May AM, Weiderpass E, et al. Physical activity and all-cause mortality across levels of overall and abdominal adiposity in European men and women: the European Prospective Investigation into Cancer and Nutrition Study (EPIC). The American journal of clinical nutrition. 2015;101(3):613-21.

4. Godino JG, Watkinson C, Corder K, Marteau TM, Sutton S, Sharp SJ, et al. Impact of personalised feedback about physical activity on change in objectively measured physical activity (the FAB study): a randomised controlled trial. PLoS One. 2013;8(9):e75398.

5. Hansen AW, Gronbaek M, Helge JW, Severin M, Curtis T, Tolstrup JS. Effect of a Web-based intervention to promote physical activity and improve health among physically inactive adults: a population-based randomized controlled trial. Journal of medical Internet research. 2012;14(5):e145.

6. Broekhuizen K, Kroeze W, van Poppel MN, Oenema A, Brug J. A systematic review of randomized controlled trials on the effectiveness of computer-tailored physical activity and dietary behavior promotion programs: an update. Annals of behavioral medicine : a publication of the Society of Behavioral Medicine. 2012;44(2):259-86.

7. Collins F. Has the revolution arrived? Nature. 2010;464(7289):674-5.

8. Marteau TM, French DP, Griffin SJ, Prevost AT, Sutton S, Watkinson C, et al. Effects of communicating DNA-based disease risk estimates on risk-reducing behaviours. The Cochrane database of systematic reviews. 2010(10):CD007275.

9. Loos RJ, Bouchard C. FTO: the first gene contributing to common forms of human obesity. Obes Rev. 2008;9(3):246-50.

10. Loos RJ, Yeo GS. The bigger picture of FTO: the first GWAS-identified obesity gene. Nature reviews Endocrinology. 2014;10(1):51-61.

11. Frayling TM, Timpson NJ, Weedon MN, Zeggini E, Freathy RM, Lindgren CM, et al. A common variant in the FTO gene is associated with body mass index and predisposes to childhood and adult obesity. Science. 2007;316(5826):889-94.

12. Andreasen $\mathrm{CH}$, Stender-Petersen KL, Mogensen MS, Torekov SS, Wegner L, Andersen G, et al. Low physical activity accentuates the effect of the FTO rs9939609 polymorphism on body fat accumulation. Diabetes. 2008;57(1):95-101.

13. Demerath EW, Lutsey PL, Monda KL, Linda Kao WH, Bressler J, Pankow JS, et al. Interaction of FTO and physical activity level on adiposity in African-American and European-American adults: the ARIC study. Obesity (Silver Spring). 2011;19(9):1866-72.

14. Jonsson A, Renstrom F, Lyssenko V, Brito EC, Isomaa B, Berglund G, et al. Assessing the effect of interaction between an FTO variant (rs9939609) and physical activity on obesity in 15,925 Swedish and 2,511 Finnish adults. Diabetologia. 2009;52(7):1334-8.

15. Kilpelainen TO, Qi L, Brage S, Sharp SJ, Sonestedt E, Demerath E, et al. Physical activity attenuates the influence of FTO variants on obesity risk: a meta-analysis of 218,166 adults and 19,268 children. PLoS Med. 2011;8(11):e1001116.

16. Rampersaud E, Mitchell BD, Pollin TI, Fu M, Shen H, O'Connell JR, et al. Physical activity and the association of common FTO gene variants with body mass index and obesity. Archives of internal medicine. 2008;168(16):1791-7.

17. Vimaleswaran KS, Li S, Zhao JH, Luan J, Bingham SA, Khaw KT, et al. Physical activity attenuates the body mass index-increasing influence of genetic variation in the FTO gene. The American journal of clinical nutrition. 2009;90(2):425-8.

18. Celis-Morales C, Livingstone KM, Marsaux CF, Forster H, O'Donovan CB, Woolhead C, et al. Design and baseline characteristics of the Food4Me study: a web-based randomised controlled trial of personalised nutrition in seven European countries. Genes \& nutrition. 2015;10(1):450. 
19. Marsaux CF, Celis-Morales C, Fallaize R, Macready AL, Kolossa S, Woolhead C, et al. Effects of a Web-Based Personalized Intervention on Physical Activity in European Adults: A Randomized Controlled Trial. Journal of medical Internet research. 2015;17(10):e231.

20. Food4Me [Internet]. 2011 [cited 2015-03-26]. Available from: http://www.food4me.org.

21. Bonomi AG, Plasqui G, Goris AH, Westerterp KR. Estimation of free-living energy expenditure using a novel activity monitor designed to minimize obtrusiveness. Obesity (Silver Spring). 2010;18(9):1845-51.

22. Philips DirectLife: fitness, health and successful weight management [Internet]. 2011 [cited 201503-26]. Available from: http://www.directlife.philips.com.

23. Choi L, Liu Z, Matthews CE, Buchowski MS. Validation of accelerometer wear and nonwear time classification algorithm. Medicine and science in sports and exercise. 2011;43(2):357-64.

24. R Core Team. R: A language and Environment for Statistical Computing. R Foundation for Statistical Computing. 3.1.2 ed. Vienna, Austria2014.

25. Henry CJ. Basal metabolic rate studies in humans: measurement and development of new equations. Public health nutrition. 2005;8(7A):1133-52.

26. Baecke JA, Burema J, Frijters JE. A short questionnaire for the measurement of habitual physical activity in epidemiological studies. Am J Clin Nutr. 1982;36(5):936-42.

27. Montoye HJ, Kemper HC, Saris WH, Washburn RA. Measuring Physical Activity and Energy Expenditure: Human Kinetics; 1996. 190 p.

28. Philippaerts RM, Lefevre J. Reliability and validity of three physical activity questionnaires in Flemish males. American journal of epidemiology. 1998;147(10):982-90.

29. Philippaerts RM, Westerterp KR, Lefevre J. Doubly labelled water validation of three physical activity questionnaires. International journal of sports medicine. 1999;20(5):284-9.

30. Graffelman J. Graphical Tests for Hardy-Weinberg Equilibrium. R package version 1.5.5. 2015.

31. Rousseeuw P, Croux C, Todorov V, Ruckstuhl A, Salibian-Barrera M, Verbeke T, et al. robustbase: Basic Robust Statistics. R package version 0.92-5. 2015.

32. Evans JP, Meslin EM, Marteau TM, Caulfield T. Genomics. Deflating the genomic bubble. Science. 2011;331(6019):861-2.

33. Hollands GJ, Whitwell SC, Parker RA, Prescott NJ, Forbes A, Sanderson J, et al. Effect of communicating DNA based risk assessments for Crohn's disease on smoking cessation: randomised controlled trial. Bmj. 2012;345:e4708.

34. Grant RW, O'Brien KE, Waxler JL, Vassy JL, Delahanty LM, Bissett LG, et al. Personalized genetic risk counseling to motivate diabetes prevention: a randomized trial. Diabetes care. 2013;36(1):13-9.

35. Meisel SF, Beeken RJ, van Jaarsveld $\mathrm{CH}$, Wardle J. Genetic susceptibility testing and readiness to control weight: Results from a randomized controlled trial. Obesity (Silver Spring). 2015;23(2):30512.

36. Chao S, Roberts JS, Marteau TM, Silliman R, Cupples LA, Green RC. Health behavior changes after genetic risk assessment for Alzheimer disease: The REVEAL Study. Alzheimer disease and associated disorders. 2008;22(1):94-7.

37. Marteau T, Senior V, Humphries SE, Bobrow M, Cranston T, Crook MA, et al. Psychological impact of genetic testing for familial hypercholesterolemia within a previously aware population: a randomized controlled trial. American journal of medical genetics Part A. 2004;128A(3):285-93.

38. Nielsen DE, El-Sohemy A. Disclosure of genetic information and change in dietary intake: a randomized controlled trial. PloS one. 2014;9(11):e112665.

39. Hietaranta-Luoma HL, Akerman K, Tahvonen R, Puolijoki H, Hopia A. Using Individual, ApoE Genotype-Based Dietary and Physical Activity Advice to Promote Healthy Lifestyles in FinlandImpacts on Cardiovascular Risk Markers. Open Journal of Preventive Medicine. 2015(5):206-17.

40. Wanner M, Martin-Diener E, Braun-Fahrlander C, Bauer G, Martin BW. Effectiveness of activeonline, an individually tailored physical activity intervention, in a real-life setting: randomized controlled trial. Journal of medical Internet research. 2009;11(3):e23. 
41. Gustavsson J, Mehlig K, Leander K, Lissner L, Bjorck L, Rosengren A, et al. FTO genotype, physical activity, and coronary heart disease risk in Swedish men and women. Circulation Cardiovascular genetics. 2014;7(2):171-7.

42. Harbron J, van der Merwe L, Zaahl MG, Kotze MJ, Senekal M. Fat mass and obesity-associated (FTO) gene polymorphisms are associated with physical activity, food intake, eating behaviors, psychological health, and modeled change in body mass index in overweight/obese Caucasian adults. Nutrients. 2014;6(8):3130-52.

43. Philippaerts RM, Westerterp KR, Lefevre J. Comparison of two questionnaires with a tri-axial accelerometer to assess physical activity patterns. International journal of sports medicine. $2001 ; 22(1): 34-9$.

44. Tehard B, Saris WH, Astrup A, Martinez JA, Taylor MA, Barbe P, et al. Comparison of two physical activity questionnaires in obese subjects: the NUGENOB study. Medicine and science in sports and exercise. 2005;37(9):1535-41.

45. Larsen TM, Dalskov S, van Baak M, Jebb S, Kafatos A, Pfeiffer A, et al. The Diet, Obesity and Genes (Diogenes) Dietary Study in eight European countries - a comprehensive design for longterm intervention. Obesity Reviews. 2010;11(1):76-91.

46. Prince SA, Adamo KB, Hamel ME, Hardt J, Connor Gorber S, Tremblay M. A comparison of direct versus self-report measures for assessing physical activity in adults: a systematic review. The international journal of behavioral nutrition and physical activity. 2008;5:56.

47. Walsh MC, Hunter GR, Sirikul B, Gower BA. Comparison of self-reported with objectively assessed energy expenditure in black and white women before and after weight loss. The American journal of clinical nutrition. 2004;79(6):1013-9.

48. Dannecker KL, Sazonova NA, Melanson EL, Sazonov ES, Browning RC. A comparison of energy expenditure estimation of several physical activity monitors. Medicine and science in sports and exercise. 2013;45(11):2105-12.

49. Plasqui G, Bonomi AG, Westerterp KR. Daily physical activity assessment with accelerometers: new insights and validation studies. Obes Rev. 2013;14(6):451-62.

50. Valenti G, Camps SG, Verhoef SP, Bonomi AG, Westerterp KR. Validating measures of free-living physical activity in overweight and obese subjects using an accelerometer. Int J Obes (Lond). 2014;38(7):1011-4.

51. Livingstone KM, Celis-Morales C, Navas-Carretero S, San-Cristobal R, O'Donovan CB, Forster H, et al. Profile of European adults interested in internet-based personalised nutrition: the Food4Me study. European journal of nutrition. 2015.

52. Celis-Morales C, Lara J, Mathers JC. Personalising nutritional guidance for more effective behaviour change. Proc Nutr Soc. 2015;74(2):130-8.

53. Troiano RP, McClain JJ, Brychta RJ, Chen KY. Evolution of accelerometer methods for physical activity research. British journal of sports medicine. 2014;48(13):1019-23. 
Supplementary Material 5.1 Changes from baseline in physical activity (PA) for participants with low $P A$ who received the highest level of personalized advice (including information on the fat mass and obesity-associated (FTO) gene, Level 3), and for the controls with low PA who only received standard guidelines (Level 0)

\begin{tabular}{|c|c|c|c|c|c|c|c|c|}
\hline \multirow[b]{2}{*}{ Variables } & & \multicolumn{2}{|c|}{ Level 3} & \multicolumn{2}{|c|}{ Level 0 (controls) } & \multicolumn{3}{|c|}{ P-values } \\
\hline & & $\begin{array}{l}\text { FTO risk } \\
\text { AA/AT }\end{array}$ & $\begin{array}{c}\text { FTO non-risk } \\
\text { TT }\end{array}$ & $\begin{array}{l}\text { FTO risk } \\
\text { AA/AT }\end{array}$ & $\begin{array}{c}\text { FTO non-risk } \\
\text { TT }\end{array}$ & $\begin{array}{l}\text { Interaction } \\
\text { Level } \times \text { FTO } \\
\text { status }\end{array}$ & $\begin{array}{l}\text { Main } \\
\text { effect } \\
\text { Level }\end{array}$ & $\begin{array}{l}\text { Main } \\
\text { effect } \text { FTO } \\
\text { status }\end{array}$ \\
\hline & & $n=91$ & $n=39$ & $n=93$ & $n=42$ & & & \\
\hline \multicolumn{9}{|l|}{ Objective PA } \\
\hline \multirow{2}{*}{ Daily PAL } & MO & $1.64(0.10)$ & $1.67(0.08)$ & $1.64(0.10)$ & $1.68(0.08)$ & 0.70 & 0.65 & 0.47 \\
\hline & M6 & $1.66(0.14)$ & $1.70(0.13)$ & $1.66(0.14)$ & $1.70(0.13)$ & & & \\
\hline \multirow{2}{*}{$\begin{array}{l}\text { Moderate PA } \\
\left(\text { min. }^{-1} k^{-1}\right)\end{array}$} & MO & $174(124)$ & $209(98)$ & $167(117)$ & $214(97)$ & 0.74 & 0.90 & 0.07 \\
\hline & M6 & $206(146)$ & $249(120)$ & $201(137)$ & $258(153)$ & & & \\
\hline \multirow{2}{*}{$\begin{array}{l}\text { Vigorous PA } \\
\left(\min \cdot w^{-1}\right)\end{array}$} & MO & $37(54)$ & $48(67)$ & $44(70)$ & $54(65)$ & 0.59 & 0.68 & 0.28 \\
\hline & M6 & $49(76)$ & $57(89)$ & $46(69)$ & $63(74)$ & & & \\
\hline \multirow{2}{*}{$\begin{array}{l}\text { Sedentary time } \\
\left(\min . \mathrm{wk}^{-1}\right)\end{array}$} & MO & $5449(483)$ & 5391 (479) & $5449(519)$ & $5202(440)$ & 0.87 & 0.20 & 0.80 \\
\hline & M6 & $5271(606)$ & $5153(449)$ & $5277(516)$ & $5034(493)$ & & & \\
\hline \multicolumn{9}{|l|}{$\begin{array}{l}\text { Self-reported } \\
P A\end{array}$} \\
\hline \multirow{2}{*}{$\begin{array}{l}\text { Total activity } \\
\text { index }\end{array}$} & MO & $7.46(1.49)$ & $7.51(1.31)$ & $7.42(1.40)$ & $7.78(1.21)$ & 0.68 & 0.007 & 0.76 \\
\hline & M6 & $8.00(1.37)$ & $7.89(0.99)$ & 7.50 (1.39) & $7.94(1.16)$ & & & \\
\hline
\end{tabular}

Data are presented as means (SD). M: month. FTO status: risk/non-risk 


\section{CHAPTER 6}

\section{Disclosure of FTO genotype and change in obesity- related markers: results from the Food4Me pan- European randomized controlled trial}

Celis-Morales $C^{*}$, Marsaux $\mathrm{CF}^{*}$, Livingstone KM, San-Cristobal R, Navas-Carretero S, Fallaize $R$, Macready AL, O'Donovan CB, Woolhead C, Forster $H$, Kolossa S, Hallmann J, Daniel $H$, Moschonis G, Lambrinou C-P, Manios Y, Surwillo A, Godlewska M, Traczyk I, Drevon CA, Gibney MJ, Walsh MC, Gibney ER, Brennan L, Lovegrove JA, Martinez JA, Saris WH, Mathers JC

"Both authors contributed equally to this work and are joint first authors

Submitted for publication 


\section{Abstract}

Background: Tailored interventions aimed at weight reduction are more effective than "one size fits all" approaches. However, there is limited evidence on whether genotypetailored advice provides extra benefits in reducing obesity-related traits. The aim of the study was to determine if disclosing information on FTO genotype risk had a bigger effect on reduction of obesity-related traits in risk carriers than non-risk carriers across different levels of personalized nutrition. Methods: 683 participants (51\% women; age range 18-73 y) from the Food4Me Study, a pan-European, web-based randomized controlled trial on personalized nutrition, were included in this analysis. FTO rs9939609 single nucleotide polymorphism was genotyped at baseline. Height, weight and waist circumference (WC) were self-measured and reported at baseline, months 3 and 6, and $\mathrm{BMI}$ calculated from height and weight. Regression analyses were used to investigate changes from baseline in weight, BMI and WC, and to investigate differences within intervention arms for risk and non-risk carriers of the FTO genotype. Results: Changes in adiposity markers were larger in participants who were informed that they carried the FTO risk allele (Level 3 AT/AA carriers) compared with the non-personalized group (Level 0), but not compared with the other personalized groups (Levels 1 and 2). Reductions in weight, BMI and WC at month 6 were greater for FTO risk carriers compared with non-carriers in Level 3 (-2.27 vs. $-1.29 \mathrm{~kg}, P=0.211 ;-0.91$ vs. -0.45 kg. $\mathrm{m}^{-1}, \quad P=0.069$; and -4.44 vs. $-2.21 \mathrm{~cm}, P=0.083$, for weight, BMI and WC, respectively). However, a similar effect was observed for participants in Levels 0-2. Conclusions: Larger body weight, BMI and WC reductions were observed for risk carriers compared with non-risk carriers of the FTO gene. However, adding genotypic information to the tailored feedback did not enhance the effect of intervention compared with personalization based on diet or diet and phenotype alone. 


\section{Introduction}

Over the past 30 years the prevalence of obesity has increased markedly with $17 \%$ of European adults [1] and 9\% of adults globally now being obese [2]. Obesity is a major risk factor for non-communicable diseases (NCDs) including type 2 diabetes (T2D), cardiovascular diseases (CVDs) and many cancers [3,4]. This emphasizes the importance of initiatives aimed at changing lifestyle to prevent and to reduce excess body weight [5]. Although previous intervention strategies have mainly focused on "one size fits all" approaches to change dietary and PA behaviors, recent studies have used personalized approaches, e.g. tailored web-based interventions [6-8]. There is mixed evidence about the effect of personalized interventions compared with conventional interventions in achieving behavioral changes, but results for weight loss seem promising [9-11].

Reductions in cost and time needed for genome sequencing and enhanced ability to extract relevant information, e.g. disease risk, have fuelled interest in use of personal genetics to tailor interventions [12,13]. However, the effectiveness of genetic-based information in facilitating behavior change is unclear. A recent systematic review called for more, and larger, randomized controlled trials (RCTs) to determine whether DNAbased advice motivates people to make appropriate behavioral changes [14].

Variants in the first intron of the fat mass and obesity associated (FTO) gene are strongly associated with development of obesity [15-17]. Individuals homozygous for the FTO risk allele AA (rs9939609) weighed on average $3 \mathrm{~kg}$ more and had 1.7-fold increased odds of being obese compared with those homozygous for the lower-risk allele TT [18]. Although there is increasing evidence that the FTO genetic susceptibility to obesity can be modulated by lifestyle factors such as physical activity (PA) [19], there is a lack of evidence on whether disclosing information on FTO genotype would motivate individuals to adopt more healthy lifestyles to reduce weight. A recent study showed that feedback on FTO risk increased readiness to control weight in young and healthy adults, but no evidence of actual behavior change was found [20]. Thus, the aim of the present study was to assess the impact of disclosing FTO genotype information on change in obesity-related markers across different levels of personalized nutrition. 


\section{Methods}

\section{Subjects}

Subjects were participants of the Food4Me Proof-of-Principle Study, a 6-month webbased RCT on personalized nutrition conducted across seven European countries (Germany, Greece, Ireland, the Netherlands, Poland, Spain, and the UK). As outlined elsewhere [21], 1607 adults aged $\geq 18$ years were randomized into the study. Exclusion criteria included no or limited access to the Internet, following a prescribed diet or having altered nutritional requirements because of a medical condition.

\section{Study design}

Full details of the study design have been published elsewhere [21]. Briefly, participants were randomly allocated to one of 4 groups: Level 0: standard, nonpersonalized dietary and PA guidelines, Level 1: personalized advice based on current weight, diet and PA, Level 2: personalized advice based on current weight, diet, PA and phenotype (e.g. waist circumference [WC], blood cholesterol), and Level 3: personalized advice based on current weight, diet, PA, phenotype and genotype (e.g. FTO). All data were collected remotely (i.e. at home) at baseline, month 3 and month 6 , following standardized operating procedures [21].

Following analysis of data collected at baseline and 3 months, participants received personalized feedback on their weight, diet and PA (Levels 1-3) or non-personalized guidelines (Level 0), depending on their randomization group, at both time points. The personalized feedback provided was based on a pre-defined set of algorithms incorporating anthropometric, dietary, PA (Levels 1-3), phenotypic (Levels 2-3), and genotypic (Level 3 only) data. Results in the personalized feedback reports were indicated for each anthropometric, dietary, PA (Levels 1-3), and phenotypic (Levels 23) item, on 3-color graded lines (green: good, amber: improvement recommended, and red: improvement strongly recommended). In addition, all Level 3 participants received information on whether they carried the risk variant for 5 nutrition- and lifestyle-related genes [21]. For FTO, the following message was included In Level 3 reports:

"A specific variation of this gene is associated with a greater need to maintain a healthy body weight and engage in physical activity. A healthy weight combined with exercise may provide added health benefits for these individuals".

and Level 3 participants were informed about their FTO rs9939609 status i.e. whether they carried or not the risk allele ('yes' or 'no' respectively). 
Each personalized report (Levels 1-3) contained a specific message related to body weight, which, for Level 3 participants only, referred to FTO. For example, an AA/AT Level 3 participant with increased BMI and WC would read:

"We recommend reducing your body weight and waist circumference to a healthy normal range because you have a genetic variation that can benefit by reducing these two obesity-related markers".

\section{Data collection}

Participants consented to self-report their measures via the Internet and to send biological samples (buccal swabs for DNA extraction) by post, using pre-paid, stamped addressed envelopes. To ensure that procedures were similar in all recruiting centres, standardised operating procedures were prepared for all measurements, and researchers underwent centralised training. Moreover, to enable participants to collect and report the required information and to collect, process and dispatch the biological samples correctly, participants were given detailed instructions, and video demonstrations were available on the Food4Me website (www.food4me.org), in their own language [21].

\section{Anthropometric and lifestyle measures}

Body weight, height and WC were self-measured and self-reported by participants via the Internet. Participants were instructed to measure body weight after an overnight fast, without shoes and wearing light clothing using a home or commercial scale, and to measure height, barefoot, using a standardised measuring tape provided by the researchers. WC was measured at the mid-point between the lower rib and the iliac crest using the provided tape [21]. Central obesity was defined as WC $>88 \mathrm{~cm}$ for women and $>102 \mathrm{~cm}$ for men. BMI $\left(\mathrm{kg} \cdot \mathrm{m}^{-2}\right)$ was calculated from body weight and height. Adiposity status was defined using World Health Organization (WHO) criteria for BMI (underweight $<18.5 \mathrm{~kg} \cdot \mathrm{m}^{-2}$, normal weight $\geq 18.5 \mathrm{~kg} \cdot \mathrm{m}^{-2}$ to $\leq 24.9 \mathrm{~kg} \cdot \mathrm{m}^{-2}$, overweight $\geq 25.0 \mathrm{~kg} \cdot \mathrm{m}^{-2}$ to $\leq 29.9 \mathrm{~kg} \cdot \mathrm{m}^{-2}$ and obesity $\geq 30.0 \mathrm{~kg} \cdot \mathrm{m}^{-2}$ ). Self-reported measurements were validated in a sub-sample of the participants across seven European countries and showed a high degree of reliability [22].

Physical activity level (PAL, defined as the ratio between total energy expenditure and predicted basal metabolic rate [23]) and time spent sedentary $\left(\mathrm{min}^{-1} \mathrm{~d}^{-1}\right)$ were estimated from tri-axial accelerometers (TracmorD, Philips Consumer Lifestyle, The Netherlands). 


\section{Genotyping}

Participants collected buccal cell samples at baseline using Isohelix SK-1 DNA buccal swabs and Isohelix dried-capsules and posted samples to each recruiting centre for shipment to LGC Genomics (Hertfordshire, United Kingdom). LGC Genomics extracted DNA and genotyped specific loci using $\mathrm{KASP}^{\mathrm{TM}}$ genotyping assays to provide bi-allelic scoring of FTO single nucleotide polymorphisms (SNPs) rs9939609 and rs1121980. These two SNPs showed a high linkage disequilibrium $\left(r^{2}=0.96\right)$ and therefore results for rs1121980 are not reported. No significant deviation from the Hardy-Weinberg Equilibrium was observed for rs9939609 $\left(X^{2}=0.51 ; P=0.48\right)$.

\section{Ethical approval and participant consent}

The Research Ethics Committees at each University or Research Centre delivering the intervention granted ethical approval for the study. The Food4Me trial was registered as a RCT (NCT01530139) at Clinicaltrials.gov. All participants who expressed an interest in the study were asked to sign online consent forms at two stages in the screening process. These consent forms were automatically directed to the local study investigators to be counter-signed and archived [21].

\section{Statistical analyses}

In this analysis we included participants with $\mathrm{BMI} \geq 25.0 \mathrm{~kg} \cdot \mathrm{m}^{-2}$ and $/$ or high WC ( $>88$ or $>102 \mathrm{~cm}$, for women or men, respectively) at baseline, and for whom FTO genotype data were available, as well as anthropometrics at month 3 or month 6 (Figure 6.1). These individuals were advised to reduce their weight or WC at baseline (Levels 1-3) or would have been advised to do so (Level 0 ) if they had not been in the control group.

Results from descriptive analyses are presented as means and SD for continuous variables or as percentages for categorical variables. All models were adjusted for baseline outcome value, age, sex and country. Multiple regression analyses were used to determine significant changes from baseline to month 3 and baseline to month 6 for both FTO risk (AA/AT) and non-risk (TT) carriers. To answer our first research question ("Does knowledge of FTO genotype influence changes in body weight, BMI and WC in carriers and non-carriers of the FTO risk allele?"), we compared Level 3 risk and nonrisk carriers, for whom FTO genotype was disclosed, using contrast analysis (Level 3 risk carriers as the reference group). Our secondary research question ("Is FTO-based personalized advice more effective at reducing body weight, BMI and WC than nonpersonalized guidelines or, personalized advice based on diet or diet and phenotype 
alone?"), was tested using contrast analysis, comparing Level 3 risk carriers (reference group) with changes observed in Level 0, Level 1, and Level 2.

Further sensitivity analyses were performed to investigate whether greater changes were achieved in those participants who carried the risk variant for the FTO gene (AT/AA) compared with non-risk carriers independent of whether this information was disclosed or not. Thus, participants in Levels 0,1 and 2 were further stratified into risk (AT/AA) and non-risk carriers (TT) for the FTO genotype, and differences in changes for the main outcomes were tested within each group (Figure 6.2 and see Supplementary Material 6.1). All statistical analyses were performed using Stata (version 14; StataCorp, College Station, TX, USA) and significance was set at $P<0.05$.

\section{Results}

\section{Study participants}

A total of 5,562 participants were screened online between August 2012 and August 2013; the characteristics of these individuals have been reported elsewhere [24]. The first 1,607 volunteers meeting the inclusion criteria were recruited to the RCT and randomized to one of the four intervention arms (Figure 6.1) [21]. Here, only participants advised to reduce their body weight or WC at baseline (Levels 1-3), or controls who would have been advised to do so if they had not been in Level 0, were included ( $n=683$; Figure 6.1). Baseline characteristics of these participants by intervention arm are shown in Table 6.1. In summary, $51 \%$ of the participants were women, mean age 43.3 (range 18 to 73 ) years and mean BMI 29.3 (range 25.0 to 61.7 ) $\mathrm{kg} \cdot \mathrm{m}^{-2}$. After 3 and 6 months, $10 \%$ and $14 \%$ of participants randomized to the intervention were lost to follow-up, respectively (Figure 6.1). 


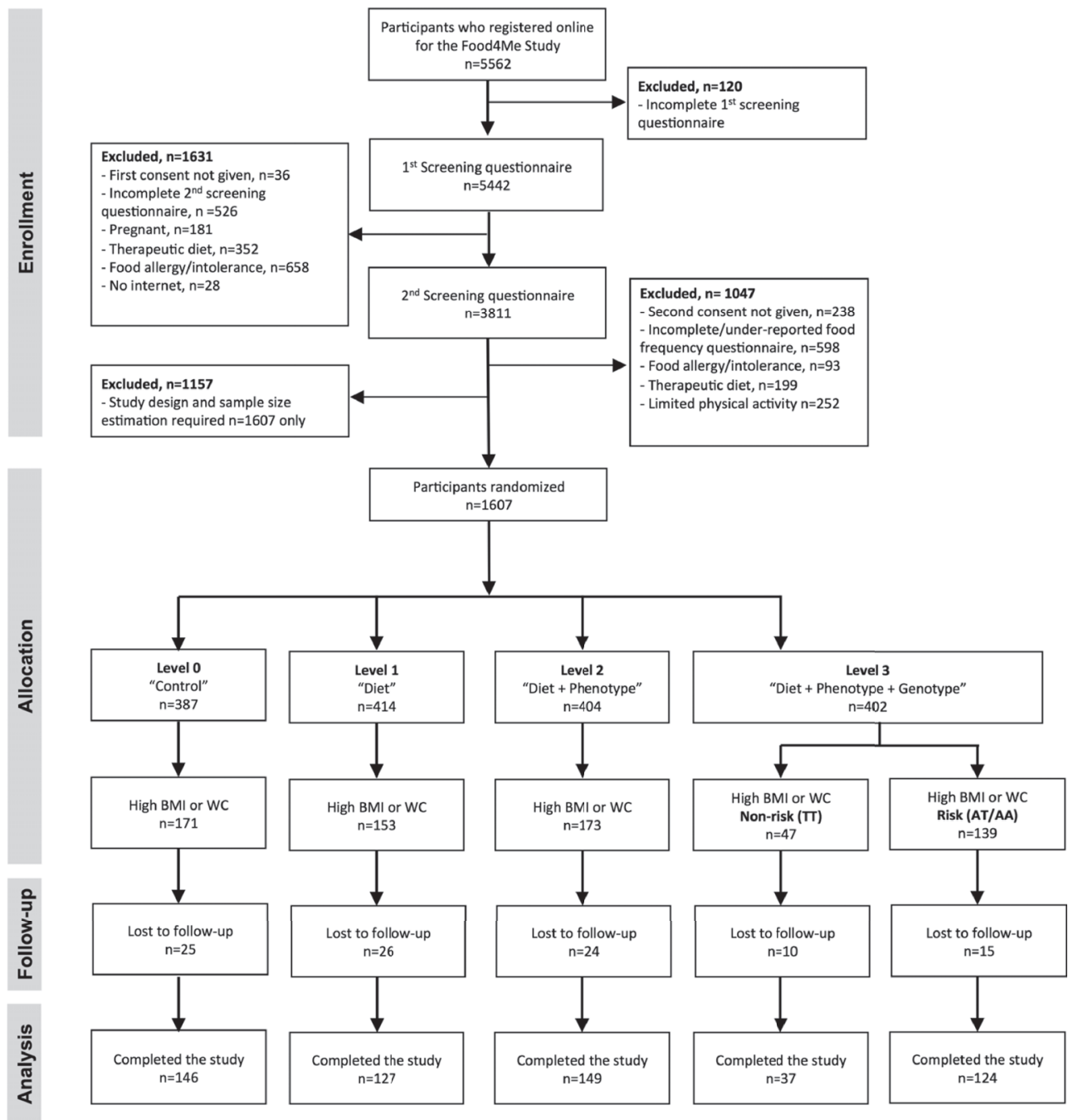

Figure 6.1 CONSORT diagram

BMI, body mass index; WC, waist circumference. Participants in Level 0 received non-personalized advice, whereas participants in Levels 1-3 received personalized advice, during the intervention. Participants in Levels 1-3 with high BMI $\left(\geq 25 \mathrm{~kg}^{-\mathrm{m}^{-2}}\right.$ ) or WC (>88 or $102 \mathrm{~cm}$ for women or men, respectively) at baseline were advised to reduce their body weight. For analyses, Level 3 was stratified based on FTO genotype (TT: non-risk and AA, AT: risk). 
Table 6.1 Baseline characteristics of the Food4Me participants with high body mass index or waist circumference, by intervention arm

\begin{tabular}{|c|c|c|c|c|c|}
\hline \multirow[t]{3}{*}{ Variables } & \multirow{3}{*}{$\begin{array}{l}\text { Control } \\
\text { Level } 0\end{array}$} & \multicolumn{4}{|c|}{ Personalized intervention arms } \\
\hline & & \multirow[t]{2}{*}{ Level 1} & \multirow[t]{2}{*}{ Level 2} & \multicolumn{2}{|c|}{ Level 3} \\
\hline & & & & $\begin{array}{c}\text { FTO } \\
\text { Non-risk } \\
\text { (TT) }\end{array}$ & $\begin{array}{c}\text { FTO } \\
\text { Risk } \\
\text { (AT/AA) }\end{array}$ \\
\hline Total $(n)$ & 171 & 153 & 173 & 47 & 139 \\
\hline Sex - women (\%) & 53.8 & 49.0 & 47.4 & 48.9 & 54.6 \\
\hline Age (years) & $42.9(12.2)$ & $44.2(11.4)$ & $43.9(12.1)$ & $42.2(13.3)$ & $43.7(11.9)$ \\
\hline \multicolumn{6}{|l|}{ Anthropometrics } \\
\hline Weight (kg) & $85.1(12.6)$ & $87.5(15.0)$ & $87.3(12.8)$ & $83.9(12.4)$ & $86.1(12.9)$ \\
\hline BMI $\left(\mathrm{kg} \cdot \mathrm{m}^{-2}\right)$ & $29.0(3.8)$ & $29.7(4.5)$ & $29.8(3.9)$ & $28.7(3.1)$ & $29.4(4.3)$ \\
\hline Overweight (\%) & 69.5 & 62.7 & 59.5 & 78.7 & 67.6 \\
\hline Obesity (\%) & 30.4 & 37.3 & 40.5 & 21.3 & 32.4 \\
\hline WC $(\mathrm{cm})$ & $95.7(11.1)$ & $96.0(0.12)$ & $96.9(11.6)$ & $94.2(10.8)$ & $96.1(11.0)$ \\
\hline $\begin{array}{l}\text { Central adiposity } \\
(\%)\end{array}$ & 48.5 & 49.6 & 51.4 & 53.2 & 49.6 \\
\hline \multicolumn{6}{|l|}{ Physical Activity } \\
\hline PAL & $1.69(0.13)$ & $1.72(0.16)$ & $1.70(0.16)$ & $1.71(0.13)$ & $1.69(0.13)$ \\
\hline $\begin{array}{l}\text { Sedentary time } \\
\left(\text { min.day }^{-1}\right)\end{array}$ & $761.9(77.5)$ & $761.9(73.9)$ & $761.0(84.2)$ & $756.5(74.7)$ & 767.7 (79.4) \\
\hline
\end{tabular}

Level 0 received non-personalized advice. Levels 1,2, and 3 received personalized advice based on Diet, Diet + Phenotype, or Diet + Phenotype + Genotype, respectively. Baseline characteristics of participants advised to reduce body weight or WC at baseline (Levels 1-3) are those who would have been advised to do so if they had received personalized advice (Level 0). Values represent percentages or means (SD). PAL, physical activity level (ratio between total energy expenditure and basal metabolic rate); Central adiposity was defined as waist circumference $>88 \mathrm{~cm}$ for women and $>102 \mathrm{~cm}$ for men; Overweight: BMI 25-29.9 kg. $\mathrm{m}^{-2}$; Obesity: BMI $>30 \mathrm{~kg} \cdot \mathrm{m}^{-2}$. WC, waist circumference.

\section{Effect of knowledge of FTO genotype on changes in obesity-related markers}

At month 3, BMI and WC were reduced significantly for both risk and non-risk carriers of the FTO gene in Level 3 (see Supplementary Material 6.2). Body weight was reduced significantly in the FTO risk carriers group only. There were no significant effects of disclosure of FTO risk on changes in obesity-related markers at month 3 (see Supplementary Materials 6.1 and 6.2). Furthermore, in Level 3, nearly twice as many participants carrying the risk allele lost at least $5 \%$ body weight as non-risk carriers (14.2 and $7.6 \%$, respectively, $P=0.013$ ) (see Supplementary Material 6.3).

Similarly, body weight, BMI and WC were significantly reduced from baseline to month 6 in both risk and non-risk carriers of the FTO risk allele. Although no significant differences were found between Level 3 risk and non-risk carriers of the FTO gene for any of the obesity-related outcomes, reductions in obesity-related traits were almost 
twice as large in Level 3 risk carriers compared with Level 3 non-risk carriers (Table 6.2). Furthermore, $16.2 \%$ of Level 3 non-risk carriers compared with $27.4 \%$ of the risk carriers achieved a weight loss $>5 \%$ at month 6 . Similar results were observed for WC (Table 6.3). Larger reductions in obesity-related traits were also observed for FTO risk carriers, compared with non-risk carriers, in Levels 0-2 where participants had no knowledge of their genotype (Figure 6.2).

Table 6.2 Changes in obesity-related markers at month 6 in participants informed of their FTO genotype (risk or non-risk)

\begin{tabular}{|c|c|c|c|c|}
\hline \multirow[t]{2}{*}{ Variables } & \multicolumn{2}{|c|}{ Level 3} & \multirow{2}{*}{\multicolumn{2}{|c|}{$\begin{array}{l}\text { Difference in changes between risk } \\
\text { and non-risk carriers }\end{array}$}} \\
\hline & $\begin{array}{c}\text { FTO non-risk (TT) } \\
(\mathrm{n}=37)\end{array}$ & $\begin{array}{c}\text { FTO risk (AT/AA) } \\
(n=124)\end{array}$ & & \\
\hline Weight (kg) & $\begin{array}{c}-1.29 \\
(-2.63 \text { to } 0.06)\end{array}$ & $\begin{array}{c}-2.27 \\
(-3.01 \text { to }-1.53)^{*}\end{array}$ & $\begin{array}{c}-0.98 \\
(-2.52 \text { to } 0.56)\end{array}$ & $P=0.211$ \\
\hline $\mathrm{BMI}\left(\mathrm{kg} \cdot \mathrm{m}^{-2}\right)$ & $\begin{array}{c}-0.45 \\
(-0.88 \text { to }-0.01)^{\neq}\end{array}$ & $\begin{array}{c}-0.91 \\
(-1.15 \text { to }-0.67)^{\star}\end{array}$ & $\begin{array}{c}-0.46 \\
(-0.96 \text { to } 0.03)\end{array}$ & $P=0.069$ \\
\hline $\mathrm{WC}(\mathrm{cm})$ & $\begin{array}{c}-2.21 \\
(-4.39 \text { to }-0.05)^{\ddagger}\end{array}$ & $\begin{array}{c}-4.44 \\
(-5.68 \text { to }-3.19)^{\star}\end{array}$ & $\begin{array}{c}-2.22 \\
(-4.73 \text { to } 0.29)\end{array}$ & $P=0.083$ \\
\hline
\end{tabular}

Data presented as delta and 95\% confidence interval. Significant changes between baseline and month 6: ${ }^{*} P<0.0001 ;{ }^{*} P<0.05$. Models were adjusted for country, age, sex, and baseline outcome measures. Deltas were calculated as [month 6 - baseline].

Table 6.3 Participants who achieved 2.5\%, 5\% and 10\% weight loss or waist circumference (WC) reduction by intervention arm at month 6

\begin{tabular}{|c|c|c|c|c|c|}
\hline & \multirow{3}{*}{$\begin{array}{l}\text { Control } \\
\text { Level } 0\end{array}$} & \multicolumn{4}{|c|}{ Personalized intervention arms } \\
\hline & & \multirow[t]{2}{*}{ Level 1} & \multirow[t]{2}{*}{ Level 2} & \multicolumn{2}{|c|}{ Level 3} \\
\hline & & & & $\begin{array}{c}\text { FTO non-risk } \\
\text { (TT) } \\
(n=37)\end{array}$ & $\begin{array}{l}\text { FTO risk } \\
\text { (AT/AA) } \\
(n=124)\end{array}$ \\
\hline \multicolumn{6}{|l|}{ Weight loss } \\
\hline $2.5 \%$ to $4.9 \%$ & $20.5(30)$ & $20.4(26)$ & $15.4(23)$ & $21.6(8)$ & $21.7(27)$ \\
\hline $5.0 \%$ to $9.9 \%$ & $13.0(19)$ & $11.8(15)$ & $18.8(28)$ & $16.2(6)$ & $21.8(27)$ \\
\hline$\geq 10 \%$ & $4.8(7)$ & $8.7(11)$ & $4.0(6)$ & $0(0)$ & $5.6(7)$ \\
\hline \multicolumn{6}{|l|}{ WC reduction } \\
\hline $2.5 \%$ to $4.9 \%$ & $20.0(29)$ & $16.7(21)$ & $24.2(36)$ & $13.5(5)$ & $16.3(20)$ \\
\hline $5.0 \%$ to $9.9 \%$ & $14.5(21)$ & $16.7(21)$ & $24.2(36)$ & $13.5(5)$ & $22.6(28)$ \\
\hline$\geq 10 \%$ & $6.2(9)$ & $9.5(12)$ & $6.8(10)$ & $2.7(1)$ & $8.1(10)$ \\
\hline
\end{tabular}

Data presented as percentages (n). 

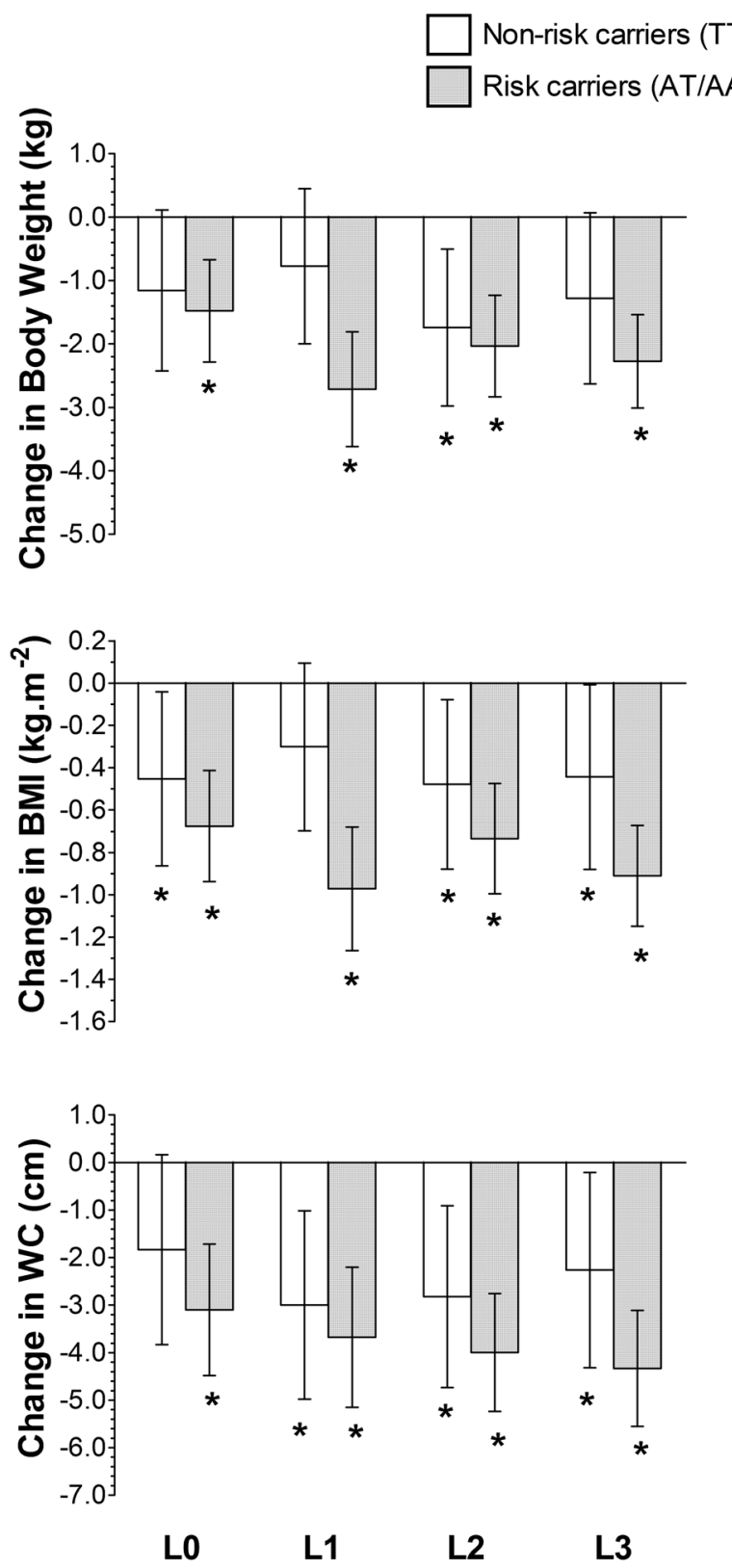

Figure 6.2 Changes in obesity-related markers at month 6 by intervention arm and FTO genotype

Data presented as mean delta from baseline and 95\% confidence interval. Significant changes from baseline are denoted with *. No significant differences were observed between FTO risk and non-risk carriers across the intervention arms. Analyses were adjusted for age, sex, country and outcome values at baseline. LO "Control group, non-personalized advice"; L1 "personalized advice based on diet"; L2 "personalized advice based on diet and phenotype"; L2 "personalized advice based on diet and phenotype and genotype". WC, waist circumference. 


\section{Effect of FTO-based personalized advice on obesity-related markers compared with other forms of personalization.}

Significant reductions in BMI and WC were observed at month 3 in Levels 0, 1 and 2 participants (similar to Level 3 risk carriers) and participants in Levels 1 and 2 also showed significant reductions in weight (see Supplementary Material 6.4). The WC reduction achieved by Level 3 risk carriers was significantly greater than that for Level $0(P=0.009)$ and for Level $1(P=0.021)$. However, no significant differences were found for weight or BMI changes between Level 3 risk carriers and the other intervention arms (see Supplementary Material 6.4).

At month 6, there were significant reductions in body weight, BMI and WC for participants in all intervention groups (Table 6.4). Although no significant differences were found for changes in body weight and BMI between Level 3 risk carriers and Level 0 , Level 1 or Level 2 (Table 6.4), reductions in body weight and BMI were larger in Level 3 risk carriers, ranging from 0.24 to $0.98 \mathrm{~kg}$ and 0.17 to $0.46 \mathrm{~kg} . \mathrm{m}^{-2}$, respectively. WC decreased by 1.3 to $2.3 \mathrm{~cm}$ more in Level 3 risk carriers than in the other groups (Levels 0-2) at month 6, and the greater reduction in WC in Level 3 risk carriers compared with Level 0 was significant $(P=0.049)$ (Table 6.4). Percentages of participants achieving $2.5-4.9 \%, 5.0-10 \%$ and $>10 \%$ of weight or WC reduction are presented in Table 6.3 by intervention arm.

Table 6.4 Changes in obesity-related markers at month 6 in FTO risk carriers compared with participants in Levels 0,1 or 2

\begin{tabular}{|c|c|c|c|c|c|c|c|}
\hline \multirow[t]{2}{*}{ Outcomes } & \multirow[b]{2}{*}{$\begin{array}{l}\text { Control } \\
\text { Level } 0 \\
(n=146)\end{array}$} & \multicolumn{3}{|c|}{ Personalized intervention arms } & \multicolumn{3}{|c|}{$P$-values } \\
\hline & & Level 1 & Level 2 & $\begin{array}{c}\text { Level } 3 \text { (L3) } \\
\text { FTO risk } \\
\text { (AT/AA) } \\
(n=124)\end{array}$ & $\begin{array}{l}\text { L3 FTO } \\
\text { risk vs. } \\
\text { Control }\end{array}$ & $\begin{array}{l}\text { L3 FTO } \\
\text { risk vs. } \\
\text { L1 }\end{array}$ & $\begin{array}{l}\text { L3 FTO } \\
\text { risk vs. } \\
\text { L2 }\end{array}$ \\
\hline Weight (kg) & $\begin{array}{c}-1.39 \\
(-2.06-0.71)^{\star}\end{array}$ & $\begin{array}{c}-2.02 \\
(-2.75-1.29)^{*}\end{array}$ & $\begin{array}{c}-1.95 \\
(-2.62-1.27)^{\star}\end{array}$ & $\begin{array}{c}-2.27 \\
(-3.01-1.53)^{\star}\end{array}$ & 0.085 & 0.647 & 0.525 \\
\hline $\mathrm{BMI}\left(\mathrm{kg} \cdot \mathrm{m}^{-2}\right)$ & $\begin{array}{c}-0.61 \\
(-0.84-0.39)^{\star}\end{array}$ & $\begin{array}{c}-0.74 \\
(-0.98-0.50)^{*}\end{array}$ & $\begin{array}{c}-0.66 \\
(-0.88-0.44)^{\star}\end{array}$ & $\begin{array}{c}-0.91 \\
(-1.15-0.67)^{\star}\end{array}$ & 0.073 & 0.313 & 0.132 \\
\hline WC (cm) & $\begin{array}{c}-2.74 \\
(-3.89-1.58)^{\star}\end{array}$ & $\begin{array}{c}-3.50 \\
(-4.74-2.25)^{\star}\end{array}$ & $\begin{array}{c}-3.91 \\
(-5.00-2.83)^{*}\end{array}$ & $\begin{array}{c}-4.44 \\
(-5.68-3.19)^{\star}\end{array}$ & 0.049 & 0.298 & 0.533 \\
\hline
\end{tabular}

Data presented as delta and 95\% confidence interval. Significant changes at between baseline and month 6: ${ }^{\star} P<0.0001 ;{ }^{\ddagger} P<0.05$. Models were adjusted for country, age, sex, and baseline outcome measures. Deltas were calculated as [month 6 - baseline]. 


\section{Discussion}

The main findings of this study were: a) both non-personalized and personalized forms of advice were effective at reducing body weight, BMI and WC after a 6-month intervention; b) the magnitude of change in body weight, BMI and WC was similar between intervention groups where personalized advice was based on diet, phenotypic and genetic information; c) larger reductions in obesity-related markers were observed in carriers of the FTO risk allele, irrespective of knowledge of FTO genotype.

In the last decade, there has been growing interest in tailoring lifestyle interventions using personal DNA information [25]. It has been hypothesized that providing lifestyle advice based on genetic information would motivate people to make behavioral changes favorable for disease prevention, beyond what could be achieved with nongene-based tailored programs. However, there is a lack of compelling evidence that receiving genetic information indicating higher disease risk would promote positive behavioral change or would lead to counterproductive behaviors because individuals may feel falsely reassured [26]. In their 2010 review, Marteau et al., reported no effect of adding DNA-based disease risk estimates compared with a non-DNA based approach, in terms of smoking cessation, PA, or medication/vitamin use. A beneficial effect of DNA-based risk estimates on dietary behavior was reported, although no benefit on intention to change dietary behavior was observed. The authors concluded that the evidence supporting gene-based interventions for behavior change is lacking and that larger and better quality studies should be performed to elucidate the real effect of personalized advice based on genetic information [14].

The evidence in favor of gene-based lifestyle advice is limited. Nielsen et al. reported that disclosing genetic information for personalized nutrition promoted greater reductions in self-reported sodium intake compared with general population-based dietary advice, in young adults carrying the higher-risk variant of the ACE gene. No effects of genotype-based advice were found for vitamin C, caffeine or added sugars [27]. In the REVEAL study, in cognitively normal adults with a family history of Alzheimer's disease, participants who were informed that they carried the APOE e4 risk genotype were more likely to report Alzheimer's disease-specific health behavior change 1 year after disclosure, when compared with non-risk carriers [28]. Others reported that knowledge of personal genetic information on APOE status, might have positive effects on triglyceride values and WC although this was observed only in the high-risk $\varepsilon 4+$ individuals [29]. With regard to weight loss, Arkadianos et al. reported that participants in a traditional weight management diet group and participants receiving a nutrigenetically tailored diet both lost similar weight up to 100-300 days of follow up. 
Thereafter, participants in the nutrigenetic group were significantly more likely to maintain their weight loss compared with the control group [30].

In contrast, there were no short-term ( $\sim 3$ months) or longer-term ( $\sim 1$ year) changes in self-reported anxiety, dietary fat intake, or exercise, in generally healthy adults receiving information from a commercial direct-to-consumer genome-wide risk test [31,32]. Hollands et al. found that communicating DNA-based risk assessments for Crohn's disease had no effect on smoking cessation, beyond the standard risk assessment [33]. Similarly, genetic risk counseling did not improve self-reported motivation or adherence to a diabetes prevention program among overweight individuals [34]. Frankwich and colleagues observed no between-group differences in weight loss in a small study of American veterans randomly assigned either to a genetics-guided therapy group, where participants received one of four diets (balanced, low-carbohydrate, low-fat or Mediterranean) based on their risk status for seven obesity-related SNPS (APOA2, ADIPOQ, FTO, KCTD10, LIPC, MMAB and PPARG), or to a standard therapy group, where participants followed a balanced diet [35]. Furthermore, Meisel et al. showed that healthy individuals receiving FTO feedback in their weight control advice felt more prepared to control their weight but this had no more effect on behavior than weight control advice alone [20]. Our results are in line with studies outlined above. We observed that the magnitude of weight, BMI and WC reductions was similar in all three groups receiving personalized advice; gene-based advice did not seem to promote behavioral changes beyond what can be achieved by tailored feedback based on diet or diet and phenotype alone.

Although differences in weight, BMI and WC reductions were almost twice as large in individuals informed of their risk for FTO, compared with those informed of their absence of $F T O$-related risk, there was no clear evidence that risk knowledge played a role. Surprisingly, FTO risk carriers, irrespective of their intervention group, had greater improvements in obesity-related markers than non-risk carriers. This was an unexpected and rather counter-intuitive finding. All other factors being equal (same environment), one would expect that individuals who are genetically (and/or epigenetically) predisposed to obesity would have to make greater efforts to counter this predisposition and to achieve similar weight loss as other obese individuals who are not genetically predisposed. For example, in a relatively small study of 51 obese or overweight U.S. veterans, Frankwich and colleagues observed that participants who had low-risk polymorphisms for obesity lost more weight than all other participants at 8 weeks and had significantly greater reductions in BMI and WC at 24 weeks [35]. 


\section{Strengths and limitations}

The Food4Me study is the largest Internet-based intervention on personalized nutrition to date. Innovative aspects of the Food4Me Study include the creation of algorithms for delivering tailored lifestyle advice based on participant characteristics including behavioral, phenotypic and genotypic information. Another strength of the study was the delivery of the intervention across seven European countries via the Internet and the application of a remote system for data and biological sample collection. Our Internet-based platform was effective in retaining participants; 85\% completed month 6 follow up and there was $>98 \%$ compliance with DNA testing, which is high compared with previous web-based survey research [36] and web-based [32] or face-to-face [20] genetic-based interventions. In a study of direct-to-consumer genomic testing, Bloss et al. reported $44 \%$ and $63 \%$ dropouts at months 3 and 12, respectively $[31,32]$. Moreover, the profile of those interested in participating in the Food4Me intervention study was similar to that of European adults [21], most of whom would benefit from improved diet and more physical activity.

Our limitations include that we did not investigate how participants perceived the DNAbased feedback. Given that Food4Me was an intervention targeting multiple, dietary and lifestyle behaviors, the impact of the genotypic results might have been diluted by the volume of other information provided. Moreover, the genetic feedback was "only" a positive reinforcement, i.e. that participants with the higher-risk genotype would benefit more by reducing their weight and WC. The greater risk for obesity and associated comorbidities was not stressed in the reports and it is possible that the impact of such feedback would have been stronger. Finally, height, weight, and WC were self-reported but a concurrent validation study showed that the self-reported anthropometric measures were reliable [22].

\section{Conclusion}

Larger reductions in body weight, BMI and WC were observed for risk carriers compared with non-risk carriers of the FTO gene. However, changes in these obesityrelated traits were similar in all groups receiving personalized advice. Adding genetic information to the tailored feedback did not enhance the effectiveness of the intervention compared with personalization based on diet or diet and phenotype alone. Our personalized Internet-based intervention was effective at recruiting and retaining participants. This offers promise as a scalable and sustainable route to improve behaviors with important public health benefits [9]. 
This work was funded by the EU FP7 project Food4Me (no. 265494). JCM was the Food4Me intervention study coordinator. ERG, LB, YM, IT, CAD, JAL, JAM, WHMS, HD, MG and JCM contributed to the research design. CCM, CFMM, RSC, SNC, COD, CW, HF, RF, ALM, SK, CPL, GM, AS, MG, MCW and JCM conducted the intervention. CFMM, WHMS, CCM contributed to physical activity measurements. CCM and CFMM performed the statistical analyses for the manuscript. CCM, CFMM, KML, WHMS and JCM drafted the paper. All authors contributed to a critical review of the manuscript during the writing process and approved the final version to be published. None of the authors had a personal or financial conflict of interest.

\section{References}

1. OECD. Health at a Glance: Europe 201220124 July 2014. Available from: http://dx.doi.org/10.1787/9789264183896-en.

2. $\mathrm{Ng} \mathrm{M}$, Fleming $\mathrm{T}$, Robinson $\mathrm{M}$, Thomson B, Graetz N, Margono C, et al. Global, regional, and national prevalence of overweight and obesity in children and adults during 1980-2013: a systematic analysis for the Global Burden of Disease Study 2013. The Lancet. 2014.

3. WHO. Global Helath Risk: mortality and burden of disease attributable to selected major risk World Health Organization, 2009.

4. Ezzati M, Riboli E. GLOBAL HEALTH Behavioral and Dietary Risk Factors for Noncommunicable Diseases. New England Journal of Medicine. 2013;369(10):954-64.

5. Ekelund U, Ward HA, Norat T, Luan J, May AM, Weiderpass E, et al. Physical activity and all-cause mortality across levels of overall and abdominal adiposity in European men and women: the European Prospective Investigation into Cancer and Nutrition Study (EPIC). The American journal of clinical nutrition. 2015;101(3):613-21.

6. Hurling R, Catt M, Boni MD, Fairley BW, Hurst T, Murray P, et al. Using internet and mobile phone technology to deliver an automated physical activity program: randomized controlled trial. Journal of medical Internet research. 2007;9(2):e7.

7. Alexander GL, McClure JB, Calvi JH, Divine GW, Stopponi MA, Rolnick SJ, et al. A randomized clinical trial evaluating online interventions to improve fruit and vegetable consumption. American journal of public health. 2010;100(2):319-26.

8. Hansen AW, Gronbaek M, Helge JW, Severin M, Curtis T, Tolstrup JS. Effect of a Web-based intervention to promote physical activity and improve health among physically inactive adults: a population-based randomized controlled trial. Journal of medical Internet research. 2012;14(5):e145.

9. Celis-Morales C, Lara J, Mathers JC. Personalising nutritional guidance for more effective behaviour change. The Proceedings of the Nutrition Society. 2015;74(2):130-8.

10. Hutchesson MJ, Rollo ME, Krukowski R, Ells L, Harvey J, Morgan PJ, et al. eHealth interventions for the prevention and treatment of overweight and obesity in adults: a systematic review with metaanalysis. Obesity reviews : an official journal of the International Association for the Study of Obesity. 2015;16(5):376-92.

11. Levine DM, Savarimuthu S, Squires A, Nicholson J, Jay M. Technology-assisted weight loss interventions in primary care: a systematic review. Journal of general internal medicine. 2015;30(1):107-17.

12. Collins FS, Varmus H. A New Initiative on Precision Medicine. New England Journal of Medicine. 2015;30:3.

13. Marteau TM, Lerman C. Genetic risk and behavioural change. Bmj. 2001;322(7293):1056-9.

14. Marteau TM, French DP, Griffin SJ, Prevost AT, Sutton S, Watkinson C, et al. Effects of communicating DNA-based disease risk estimates on risk-reducing behaviours. Cochrane Database of Systematic Reviews. 2010(10). 
15. Loos RJ, Bouchard C. FTO: the first gene contributing to common forms of human obesity. Obesity reviews : an official journal of the International Association for the Study of Obesity. 2008;9(3):24650.

16. Loos RJ, Yeo GS. The bigger picture of FTO: the first GWAS-identified obesity gene. Nature reviews Endocrinology. 2014;10(1):51-61.

17. Locke AE, Kahali B, Berndt SI, Justice AE, Pers TH, Day FR, et al. Genetic studies of body mass index yield new insights for obesity biology. Nature. 2015;518(7538):197-206.

18. Frayling TM, Timpson NJ, Weedon MN, Zeggini E, Freathy RM, Lindgren CM, et al. A common variant in the FTO gene is associated with body mass index and predisposes to childhood and adult obesity. Science. 2007;316(5826):889-94.

19. Kilpelaeinen TO, Qi L, Brage S, Sharp SJ, Sonestedt E, Demerath E, et al. Physical Activity Attenuates the Influence of FTO Variants on Obesity Risk: A Meta-Analysis of 218,166 Adults and 19,268 Children. Plos Medicine. 2011;8(11).

20. Meisel SF, Beeken RJ, van Jaarsveld $\mathrm{CH}$, Wardle J. Genetic susceptibility testing and readiness to control weight: Results from a randomized controlled trial. Obesity. 2015;23(2):305-12.

21. Celis-Morales C, Livingstone KM, Marsaux CF, Forster H, O'Donovan CB, Woolhead C, et al. Design and baseline characteristics of the Food4Me study: a web-based randomised controlled trial of personalised nutrition in seven European countries. Genes \& nutrition. 2015;10(1):450.

22. Celis-Morales C, Livingstone KM, Woolhead C, Forster H, O'Donovan CB, Macready AL, et al. How reliable is internet-based self-reported identity, socio-demographic and obesity measures in European adults? Genes \& nutrition. 2015;10(5):476-.

23. Henry CJ. Basal metabolic rate studies in humans: measurement and development of new equations. Public health nutrition. 2005;8(7A):1133-52.

24. Livingstone K, Celis-Morales C, Navas-Carretero S, San-Cristobal R, O'Donovan C, Forster H, et al. Profile of European adults interested in internet-based personalised nutrition: the Food4Me study. Eur J Nutr. 2015:1-11.

25. Nielsen DE, El-Sohemy A. Applying genomics to nutrition and lifestyle modification. Personalized Medicine. 2012;9(7):739-49.

26. Evans JP, Meslin EM, Marteau TM, Caulfield T. Genomics. Deflating the genomic bubble. Science. 2011;331(6019):861-2.

27. Nielsen DE, El-Sohemy A. Disclosure of genetic information and change in dietary intake: a randomized controlled trial. PloS one. 2014;9(11):e112665.

28. Chao S, Roberts JS, Marteau TM, Silliman R, Cupples LA, Green RC. Health behavior changes after genetic risk assessment for Alzheimer disease: The REVEAL Study. Alzheimer disease and associated disorders. 2008;22(1):94-7.

29. Hietaranta-Luoma HL, Akerman K, Tahvonen R, Puolijoki H, Hopia A. Using Individual, ApoE Genotype-Based Dietary and Physical Activity Advice to Promote Healthy Lifestyles in FinlandImpacts on Cardiovascular Risk Markers. Open Journal of Preventive Medicine. 2015(5):206-17.

30. Arkadianos I, Valdes AM, Marinos E, Florou A, Gill RD, Grimaldi KA. Improved weight management using genetic information to personalize a calorie controlled diet. Nutrition journal. 2007;6:29.

31. Bloss CS, Schork NJ, Topol EJ. Effect of Direct-to-Consumer Genomewide Profiling to Assess Disease Risk. New England Journal of Medicine. 2011;364(6):524-34.

32. Bloss CS, Wineinger NE, Darst BF, Schork NJ, Topol EJ. Impact of direct-to-consumer genomic testing at long term follow-up. Journal of Medical Genetics. 2013;50(6):393-400.

33. Hollands GJ, Whitwell SC, Parker RA, Prescott NJ, Forbes A, Sanderson J, et al. Effect of communicating DNA based risk assessments for Crohn's disease on smoking cessation: randomised controlled trial. Bmj. 2012;345:e4708.

34. Grant RW, O'Brien KE, Waxler JL, Vassy JL, Delahanty LM, Bissett LG, et al. Personalized genetic risk counseling to motivate diabetes prevention: a randomized trial. Diabetes care. 2013;36(1):13-9.

35. Frankwich KA, Egnatios J, Kenyon ML, Rutledge TR, Liao PS, Gupta S, et al. Differences in Weight Loss Between Persons on Standard Balanced vs Nutrigenetic Diets in a Randomized Controlled 
Trial. Clinical gastroenterology and hepatology : the official clinical practice journal of the American Gastroenterological Association. 2015;13(9):1625-32 e1; quiz e145-6.

36. Yetter G, Capaccioli K. Differences in responses to Web and paper surveys among school professionals. Behav Res Methods. 2010;42(1):266-72.

Supplementary Material 6.1 Changes in obesity-related markers at month 3 by intervention arm and FTO genotype
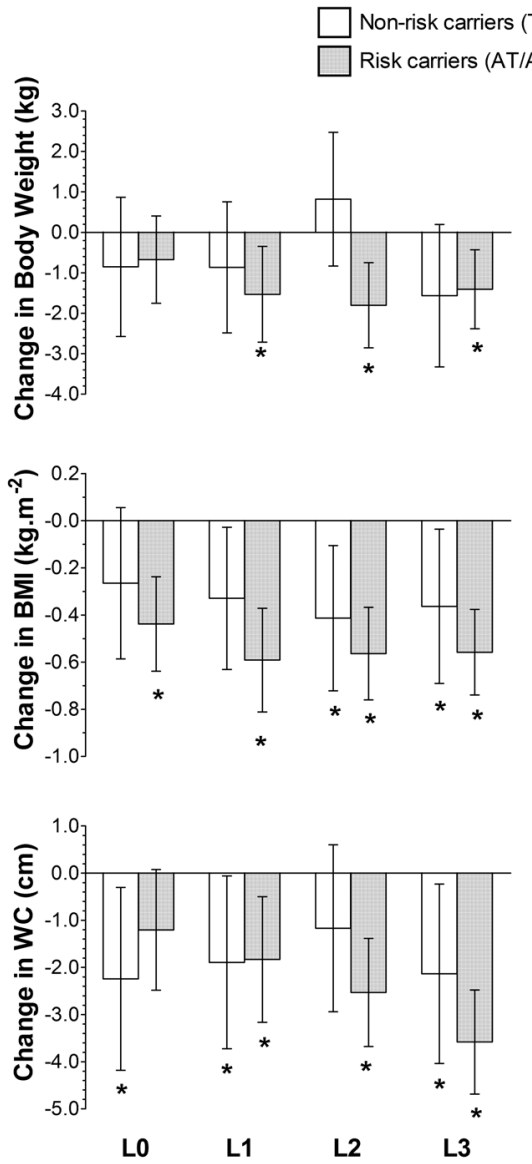

Data presented as mean delta from baseline and 95\% confidence interval. Significant changes from baseline are denoted with *. No significant differences were observed between FTO risk and non-risk carriers across the intervention arms. Analyses were adjusted for age, sex, country and outcome values at baseline. LO "Control group, non-personalized advice"; L1 "personalized advice based on diet"; L2 "personalized advice based on diet and phenotype"; L2 "personalized advice based on diet and phenotype and genotype". WC, waist circumference. 
Supplementary Material 6.2 Changes in obesity-related markers at month 3 in participants informed of their FTO genotype (risk or non-risk)

\begin{tabular}{|c|c|c|c|c|}
\hline \multirow[t]{2}{*}{ Variables } & \multicolumn{2}{|c|}{ Level 3} & \multirow{2}{*}{\multicolumn{2}{|c|}{$\begin{array}{l}\text { Difference in changes between } \\
\text { risk and non-risk carriers }\end{array}$}} \\
\hline & $\begin{array}{l}\text { FTO non-risk (TT) } \\
\qquad(\mathrm{n}=39)\end{array}$ & $\begin{array}{c}\text { FTO risk (AT/AA) } \\
(n=127)\end{array}$ & & \\
\hline Weight (kg) & $\begin{array}{c}-1.58 \\
(-3.34 \text { to } 0.18)\end{array}$ & $\begin{array}{c}-1.40 \\
(-2.38 \text { to }-0.42)^{\ddagger}\end{array}$ & $\begin{array}{c}0.17 \\
(-1.84 \text { to } 2.19)\end{array}$ & $P=0.865$ \\
\hline BMI $\left(\mathrm{kg} \cdot \mathrm{m}^{-2}\right)$ & $\begin{array}{c}-0.36 \\
(-0.69 \text { to }-0.03)^{\ddagger}\end{array}$ & $\begin{array}{c}-0.56 \\
(-0.73 \text { to }-0.37)^{\star}\end{array}$ & $\begin{array}{c}-0.19 \\
(-0.56 \text { to } 0.18)\end{array}$ & $P=0.313$ \\
\hline WC (cm) & $\begin{array}{c}-2.19 \\
(-4.21 \text { to }-0.17)^{*}\end{array}$ & $\begin{array}{c}-3.62 \\
(-4.75 \text { to }-2.48)^{*}\end{array}$ & $\begin{array}{c}-1.42 \\
(-3.74 \text { to } 0.90)\end{array}$ & $P=0.229$ \\
\hline
\end{tabular}

Data presented as delta and 95\% confidence interval. Significant changes at between baseline and month 3: ${ }^{\star} \mathrm{P}<0.0001 ;{ }^{*} \mathrm{P}<0.05$. Models were adjusted for country, age, sex, and baseline outcome measures. Deltas were calculated as [month 3 - baseline].

Supplementary Material 6.3 Participants who achieved $5 \%$ and $10 \%$ weight loss or waist circumference (WC) reduction by intervention arm at month 3

\begin{tabular}{|c|c|c|c|c|c|}
\hline & \multirow{3}{*}{$\begin{array}{l}\text { Control } \\
\text { Level } 0\end{array}$} & \multicolumn{4}{|c|}{ Personalized intervention arms } \\
\hline & & \multirow[t]{2}{*}{ Level 1} & \multirow[t]{2}{*}{ Level 2} & \multicolumn{2}{|c|}{ Level 3} \\
\hline & & & & $\begin{array}{c}\text { FTO non-risk } \\
\text { (TT) } \\
(n=39)\end{array}$ & $\begin{array}{l}\text { FTO risk } \\
\text { (AT/AA) } \\
(n=127)\end{array}$ \\
\hline \multicolumn{6}{|l|}{ Weight loss } \\
\hline $2.5 \%$ to $4.9 \%$ & $19.8(29)$ & $16.7(22)$ & $16.9(26)$ & $20.5(8)$ & $21.3(27)$ \\
\hline $5.0 \%$ to $9.9 \%$ & $9.6(14)$ & $9.1(12)$ & $17.0(26)$ & $5.1(2)$ & $12.6(16)$ \\
\hline$\geq 10 \%$ & $1.4(2)$ & $2.3(3)$ & $2.6(4)$ & $2.5(1)$ & $1.6(2)$ \\
\hline \multicolumn{6}{|l|}{ WC reduction } \\
\hline $2.5 \%$ to $4.9 \%$ & $16.7(24)$ & $16.8(22)$ & $19.6(30)$ & $28.2(11)$ & $20.5(26)$ \\
\hline $5.0 \%$ to $9.9 \%$ & $14.6(21)$ & $13.7(18)$ & $17.7(27)$ & $12.8(5)$ & $16.5(21)$ \\
\hline$\geq 10 \%$ & $2.8(4)$ & $4.6(6)$ & $3.9(6)$ & $0(0)$ & $4.7(6)$ \\
\hline
\end{tabular}

Data presented as percentages (n). 
Supplementary 6.4 Changes in obesity-related markers at month 3 in FTO risk carriers compared with participants in Levels 0, 1 or 2

\begin{tabular}{|c|c|c|c|c|c|c|c|}
\hline \multirow[t]{2}{*}{ Outcomes } & \multirow{2}{*}{$\begin{array}{l}\text { Control } \\
\text { Level } 0 \\
(n=146)\end{array}$} & \multicolumn{3}{|c|}{ Personalized intervention arms } & \multicolumn{3}{|c|}{$P$-values } \\
\hline & & Level 1 & Level 2 & $\begin{array}{c}\text { Level } 3 \text { (L3) } \\
\text { FTO risk } \\
\text { (AT/AA) } \\
(n=127)\end{array}$ & $\begin{array}{l}\text { L3 FTO } \\
\text { risk vs. } \\
\text { Control }\end{array}$ & $\begin{array}{l}\text { L3 FTO } \\
\text { risk vs. } \\
\text { L1 }\end{array}$ & $\begin{array}{l}\text { L3 FTO } \\
\text { risk vs. } \\
\text { L2 }\end{array}$ \\
\hline Weight (kg) & $\begin{array}{c}-0.72 \\
(-1.64,0.19)\end{array}$ & $\begin{array}{c}-1.30 \\
(-2.26,-0.34)^{\ddagger}\end{array}$ & $\begin{array}{c}-1.05 \\
(-1.93,-0.15)^{\ddagger}\end{array}$ & $\begin{array}{c}-1.40 \\
(-2.38,-0.42)^{\neq}\end{array}$ & 0.322 & 0.883 & 0.597 \\
\hline $\mathrm{BMI}\left(\mathrm{kg} \cdot \mathrm{m}^{-2}\right)$ & $\begin{array}{c}-0.39 \\
(-0.55,-0.21)^{*}\end{array}$ & $\begin{array}{c}-0.50 \\
(-0.67,-0.32)^{*}\end{array}$ & $\begin{array}{c}-0.52 \\
(-0.68,-0.35)^{\star}\end{array}$ & $\begin{array}{c}-0.56 \\
(-0.73,-0.37)^{\star}\end{array}$ & 0.187 & 0.667 & 0.776 \\
\hline WC (cm) & $\begin{array}{c}-1.53 \\
(-2.62,-0.44)^{*}\end{array}$ & $\begin{array}{c}-1.72 \\
(-2.85,-0.58)^{*}\end{array}$ & $\begin{array}{c}-2.29 \\
(-3.30,-1.28)^{\star}\end{array}$ & $\begin{array}{c}-3.62 \\
(-4.75,-2.48)^{\star}\end{array}$ & 0.009 & 0.021 & 0.087 \\
\hline
\end{tabular}

Data presented as delta and 95\% confidence interval. Significant changes between baseline and month 3: ${ }^{\star} \mathrm{P}<0.0001 ;{ }^{\ddagger} \mathrm{P}<0.05$. Models were adjusted for country, age, sex, and baseline outcome measures. Deltas were calculated as [month 3 - baseline]. 


\section{CHAPTER 7}

General Discussion 


\section{Introduction}

In 2030, 52 million people will die of noncommunicable diseases (NCDs), if current projections are allowed to come true [1-3]. Many of these deaths can be prevented by tackling the four risk factors common to NCDs: tobacco use, harmful use of alcohol, unhealthy diet, and insufficient physical activity (PA) [4,5], However, the current prevalence of physical inactivity worldwide is high $[6,7]$ and obesity is still a major global concern [8]. Thus, finding long-lasting strategies to help individuals manage their weight and be sufficiently physically active is a huge challenge [3,9-11].

Public health strategies usually focus on whole populations, not the individual [12]. They attempt to change unhealthy behaviors with a "one size fits all" approach, based on generic health communication materials for an entire population or a subgroup of that population [13]. Such an approach has been unsuccessful against the rise in obesity and physical inactivity. In an attempt to find additional approaches, researchers have sought to use the rapid advances in genotyping in the last two decades to tailor health-related advice to the individual [14-19]. This has posed a number of questions, among which, whether personalized interventions can indeed do better than nonpersonalized, "one size fits all, guidelines, and whether genetic information is necessary when tailoring advice. Concurrently, Internet usage has expanded rapidly [20] and so has the interest in using this medium to deliver personalized interventions [21-33], in order to reach large numbers of individuals, at relatively low costs.

The Food4Me Study aimed to test whether personalizing dietary advice and advice on physical activity via the Internet was more effective at improving health than nonpersonalized standard guidelines [33]. In this thesis, we focused on PA and obesityrelated traits. A meta-analysis on the effect of eHealth personalized randomized controlled trials (RCTs) on body weight has recently been published [34], but such information was missing for PA. Thus, we examined whether eHealth personalized advice on PA was more effective at increasing PA than non-personalized advice. We assessed how active Food4Me participants in the different European countries were and if there were differences in PA between countries. We also aimed to answer the following questions: is personalized advice on PA more effective at increasing PA than the standard PA recommendations? Is there an interaction between polymorphisms in the fat mass and obesity-associated (FTO) gene and PA on obesity-related traits? And does disclosing information on FTO lead to bigger changes in PA and obesity-related traits in risk and non-risk carriers, and compared with not disclosing this information? 


\section{Main findings}

On average, the PA level of participants enrolled in the Food4Me Study was broadly representative of that of the general European adult population. We observed some inter-country differences in PA for women in our study and found that a large proportion of participants, especially women, would benefit from greater levels of PA (Chapter 2). In our 6-month intervention, different levels of personalization produced similar small changes in PA measured by accelerometers. Based on self-reports, however, PA increased to a greater extent with more personalized advice (Chapter 3). Discrepancies between self-reported and objectively measured data will be discussed further below. Furthermore, we found in Chapter 4 that each additional copy of the FTO risk allele at rs9939609 was associated with significant increases in body weight, $\mathrm{BMI}$ and waist circumference, and consistently, each copy of the risk allele increased the odds of having overweight or obesity. In line with existing evidence [35], we identified interactions between genes and lifestyle. The effect sizes of the FTO associations on BMI and waist circumference for active individuals were substantially lower than for inactive individuals. This re-emphasises the importance of PA in the prevention of obesity especially in subjects carrying the FTO risk allele (Chapter 4). However, we found no added benefit of knowledge of FTO risk on change in PA in our intervention study (Chapter 5). Moreover, knowledge of genetic risk for obesity had no evident benefit on weight and waist circumference reductions (Chapter 6). It remains unclear whether disclosure of non-risk genetic test results has adverse effects on engagement in behavioral changes (Chapters 5 and 6). Finally, in adults with overweight or obesity, irrespective of their experimental groups, FTO risk carriers had greater reductions in weight and waist circumference than FTO non-risk carriers (Chapter 6). This unexpected finding should be replicated in other cohorts.

\section{Self-reports: friends or foes?}

Searching the Pubmed database for "((self-reported energy intake $O R$ self-reported physical activity) $A N D$ (lifestyle $O R$ disease $O R$ health))" in titles or abstracts, between January $1^{\text {st }} 2015$ and September $30^{\text {th }} 2015$, returns 67 hits ( 1.7 article/week), showing that many (most?) scientists in the fields of nutrition and PA continue to rely on selfreports to study the complex relationships existing between nutrition, PA, and health. The Food4Me Study also relied greatly on self-reports: for anthropometrics, for dietary intake, and partly for PA. In human studies, dietary intake data are mostly collected using self-report instruments, such as food frequency questionnaires, food records (or diaries) and 24-hour dietary recalls [36]. Unfortunately, there is a large body of 
evidence showing that self-reported dietary intake is poorly related to actual EI or nutrient consumption, primarily because of misreporting [37-44]. This has pushed the Energy Balance Measurement Working Group to make a strong statement in 2014 [45]:

"[...] self-reports of El [energy intake] and PAEE [PA energy expenditure] are so poor that they are wholly unacceptable for scientific research on EI and PAEE. [...] it is unacceptable to use decidedly inaccurate instruments, which may misguide health-care policies, future research and clinical judgment. The scientific and medical communities should discontinue reliance on self-reported EI and PAEE".

A review by Archer, Pavela, and Lavie [46] recently concurred (2015):

"[...] memory-based dietary assessment methods data cannot be used to inform national dietary guidelines and that the continued funding of memory-based dietary assessment methods constitutes an unscientific and major misuse of research resources".

Below, we will mainly discuss self-reported PA and anthropometric data, as dietary intake data are outside the scope of this thesis.

\section{Self-reported physical activity}

PA has been measured for decades using a wide variety of self-report instruments [47]. Because PA includes personal care, household tasks, commuting, occupational and leisure-time activities, exercise, and more, it is difficult to recall and categorize PA. Similar to self-reported EI, PA is frequently misreported [48]. Misreporting can be influenced by factors such as weight status, sex or ethnicity [49-51]. This leads to considerable measurement error [48]. In Chapter 3, we also reported discrepancies between self-reported and accelerometer-measured changes in PA, consistent with many other studies [48,49,51-54].

Pedometers, accelerometers, heart rate monitors, global positioning system devices are examples of the major technological advancements that have allowed objective assessment of PA in recent years [55], though these more objective measures are not perfect. A number of activities are not properly captured (e.g. cycling, swimming, weight-lifting), and derived estimates of energy expenditure are only approximates because they depend on body weight and energetic efficiency of movement. Nonetheless, coupling heart rate monitors [56] and/or additional movement measures [57] with accelerometers are important steps forward. Measuring sedentary behaviors 
accurately, which may be independent health risk factors, also presents additional challenges. Thus, more research should focus on these areas.

\section{Self-reported anthropometric data}

One of the additional concerns in eHealth research is the measurement error surrounding self-measures of body weight and height, reported via the Internet. Several validation studies comparing web-self-reported and measured body weight and height in healthy individuals suggest that, on average, weight is slightly under-reported (range of average under-reporting -1.2 to $-0.2 \mathrm{~kg}$ ), whereas height is over-reported (range of average over-reporting 0.19 to $1.57 \mathrm{~cm}$ ). This was observed in adults as well as adolescents [58-63]. Some differences between self-reported and measured values are not surprising. Adults do not measure their height on a regular basis; hence values reported can easily be outdated. None of the studies mentioned provided a measuring tape as well as detailed instructions on how to measure height, except for our own validation study, in which the difference between self-reported and lab-measured height $(0.19 \mathrm{~cm})$ was small and not significant. Regarding weight, part of the differences could be attributed to time between measurements ( $>1$ month in 3 studies), clothing (people cannot be measured without clothes at the lab), weighing scale used (although digital home bathroom scales may be more accurate than dial-type scales, not everyone has one [64]). In spite of this, all studies have shown that people with overweight or obesity tend to under-report more often [58-63]. It is not clear from these studies whether misreporting differs by sex or age. Detailed instructions on how to perform measurements e.g. reminding to zero dial-type scales, and providing a measuring tape are necessary for more accurate results. Daily weighing for a week may reduce misreporting. Another alternative, although costly, would be to use Bluetooth digital scales, since objective weight results can then be transferred via smartphones or tablets and to the research team.

\section{Choosing appropriate measurement tools}

Several objective measurement tools for measuring EI and PA are emerging but are still a long way from being satisfactory, especially for food intake. New tools-better tools-must be developed. Yet in the meantime, we agree with Dhurandhar et al. [45] that self-report instruments should not be used to quantify dietary intakes or PAEE. Booth and Laguna-Camacho argued that: "the problem is not 'self-report'. An awareness that an independent observer is making a record could change behavior as much or even more" [65]. We agree and disagree. Yes, the behavior to be observed is likely to be changed by awareness that it is being monitored. However, at least three 
things ought to be considered. (1) This does not change the fact that self-reports are not valid to measure actual EI and PA. (2) Longer periods of measurement, which are possible with continuous monitoring, are likely to reduce this problem of awareness of being monitored. For example, someone may consciously move more on the first days (maybe even a week) he/she is wearing the monitoring device, but is far less likely, in our opinion, to do so once settled back in his/her routine [66]. Thus, one could measure for a longer time and exclude the first week of measurement from the analysis. (3) It is probably easier to misreport than to misact. For instance, it demands very little effort to under-report when filling a questionnaire at a few time points, and it actually takes less time to do so than to try to be exhaustive. The example by Booth and Laguna-Camacho that "people could relax on a couch while knocking their wrist accelerometer in a walking rhythm" [65] is plausible, but one will admit that such 'false' behaviors take more effort and boldness than misreporting, and thus, are less likely to occur as the measurement period extends.

That being said, self-reports could still be used for other purposes than quantifying actual dietary intakes or PA. For example, self-reports can be useful to understand better the psychosocial determinants of human ingestion and movement, i.e. why people engage or do not engage in certain behaviors. This can then help build more health-promoting environments. Further, Troiano et al. are right to emphasize that there is a distinction between PA assessed by objective devices and PA assessed by selfreports, and that therefore, results should not be expected to be the same [67]. This does not change the fact that self-reports are too often misused. We recognize that novel benefits of PA are being considered that are not likely to be attributed to energy expenditure, such as benefits of yoga [68] or tai chi [69], but these activities should then be more targeted by specific questionnaires. The 2010 Workshop on Measurement of Active and Sedentary Behaviors: Closing the Gaps in Self-Report Methods also underlined that self-reported PA data can be useful for understanding health effects of behavioral choices that cannot be well represented by energy expenditure; assessing outcomes of intervention trials targeting specific types of PA in particular settings (e.g. walking in the context of active commuting); or identifying individual, social, and environmental determinants of PA behavior that may be amenable to intervention [70]. However, we do not agree with the statement that selfreports are appropriate tools for monitoring and surveillance of PA and sedentary behaviors in populations. 


\section{Physical activity monitoring and surveillance with accelerometer data}

We believe that accelerometers are more appropriate for PA surveillance in populations than are self-report instruments. It is possible to send out accelerometers across a nation and to obtain reliable measures of PA remotely in thousands of adults as well as adolescents [71-77]. In Chapter 2, we have shown that it is possible to transfer the data collected by accelerometers in real time via the Internet. Participants do not have to send their accelerometers back to the researchers, and PA can be monitored for long periods of time, i.e. as long as participants are willing to wear the devices. We think this represents an important step for global PA surveillance.

Public knowledge of the recommended amounts of PA for health benefits, i.e. 30 minutes of moderate activity most days of the week, is good. On the other hand, people are often not aware that their current level of PA is inadequate [78,79]. This may change as accelerometer-based devices become more affordable, and/or are included by default in watches, smartphones and so forth. More and more individuals may use these devices to monitor their PA and for comparison with published guidelines. However, PA recommendations [80-83] have mostly been established based on epidemiological observational studies that linked self-reported PA to health outcomes. It makes little sense that individuals should compare their device-based PA to nondevice-based guidelines and is likely to lead to confusion. Several large studies have shown that the proportion of people who achieve $>30$ minutes per day of moderate and vigorous PA most days of the week, as assessed by accelerometer, may be much lower than the proportion of individuals who self-report being moderately/vigorously physically active $>30$ minutes per day $[72,77]$. Accelerometer-based PA guidelines would also be helpful for PA surveillance, for example when estimating the prevalence of physical inactivity and associated disease risks. Physical inactivity is often defined as not meeting the (latest) PA recommendations (e.g. [6]). Therefore, as others before us [71-73,77], in Chapter 2, we used accelerometer data to estimate the proportion of adults meeting the PA recommendations, and found that $58 \%$ of men and $37 \%$ of women in our sample achieved the amount of PA recommended by the World Health Organization (WHO). This was not appropriate [67].

Recently, a review by Wijndaele and colleagues [84] highlighted the potential of accelerometry data already (or soon to be) available, i.e. data from more than 275,000 participants across 76 studies (with $\geq 400$ participants) and 36 countries. Yet, nationally representative data are still often lacking and many regions (e.g. South America, Africa) have few, or no data. Moreover, the different monitor types, models, calibration 
methods, wearing positions, and data processing procedures, make comparisons between existing studies difficult, and challenges are ever evolving as new technologies develop [85]. The paper by Wijndaele et al., from an international expert panel on the harmonization of accelerometer-based PA data [84], reported strong consensus that:

"standardization of monitor calibration, data collection, data processing, and data analytical procedures are needed. Disclosure of monitor information and protocols for data collection and processing [are] essential to enable comparison, with access to raw (i.e., unprocessed waveform) data preferred".

For results already published, reprocessing will be necessary to meta-analyze the data, which might be difficult. For example, in the present study, confidentiality issues meant that we were not entitled to receive raw data from Philips who operated the tri-axial accelerometer system (TracmorD). Furthermore, there was full consensus that a global repository of objectively measured activity monitor data would be beneficial. Finally, another priority is to increase accelerometer wear compliance, essential in order to have accurate data [84].

\section{Compliance with accelerometer wear}

"Even the most sophisticated accelerometers cannot force participants to wear them every hour of the day"

- S.G. Trost, K.L. Mclver and R.R. Pate (2005) [86].

Compliance with wearing an accelerometer is essential if one wants to measure PA accurately. To examine compliance with accelerometer wear, one needs to define what is compliant and what is not. Large epidemiological studies in adults have often used a 7-day monitoring protocol and compliance would be judged by the number of valid days of accelerometer wear (usually including one weekend day), a valid day being defined as wear time $>10$ hours. In a Swedish study of 1556 subjects, $22 \%$ had $<4$ valid days out of 7 [72]. Another 108 subjects were excluded because the monitor was lost in the mail or not returned. Although not specified, it is reasonable to assume that the proportion of lost monitors was small, and that the rest did not return their device because they did not wear it. Only $53 \%$ had 7 of 7 valid days [72]. In the American National Health and Nutrition Examination Survey (NHANES) 2003-2004, 6746 subjects (including children) took part in the accelerometer study (after excluding 430 participants with faulty monitors) [77]. Close to $28 \%$ had $<4$ valid days, while only $26 \%$ had 7 of 7 valid days of wear [77]. In NHANES 2005-2006, as many as $35 \%$ of the 
4773 adults who completed accelerometer and self-report PA measures had $<4$ valid days out of 7 [87]. In a study including 619 Chinese adults, $22 \%$ had $<3$ valid days out of 7 [75]. Baptista et al. asked 2748 Portuguese adults to wear an accelerometer for 4 days, and compliant participants were those with $\geq 3$ valid days (including one weekend day). $28 \%$ of the participants were non-compliant [71]. In the 2008 Health Survey for England, $20 \%$ of 4507 individuals over 16 years declined to wear an accelerometer. Of those who accepted to do so ( $\mathrm{N}=3586$ ), $40 \%$ wore the accelerometer $<4$ days out of 7 , for at least 10 hours per day [88]. In contrast, just $13 \%$ of the 3255 adults included in a sub-study of the Canadian Health Measures Survey (CHMS) had $<4$ valid days, although less than $49 \%$ had 7 of 7 valid days [89]. Hamer and colleagues also reported that $13 \%$ of the 510 British adults participating in a sub-study of the Whitehall II study had $<6$ of 7 valid days [90]. Compliance was much better in a Norwegian study, where $2 \%$ of a final sample of 3485 adults (i.e. after excluding individuals who did not return any data) did not wear the accelerometer and another $3 \%$ had $<4$ valid days out of 7 [73]. More recently, Van Dyck et al. reported data on the International Physical Activity and the Environment Network (IPEN) Adult study, conducted in 12 countries. Of 9065 participants, $34 \%$ had no accelerometer data. It is not entirely clear whether all of them were offered an accelerometer but did not wear it, or whether some of them were never offered a device. Of those who wore an accelerometer ( $N=5965), 4 \%$ had $<4$ valid of 7 days of wear [91].

In our study, 1480 individuals started the trial and were asked to wear an accelerometer. However, $6 \%$ never collected any accelerometer data, either because they refused to wear the device sent, or-more rarely-because of a technical issue (participants not able to install the app necessary for device registration and data upload). Of those with at least 1 valid day of wear, $28 \%$ had $<10$ valid days but only $19 \%$ had 14 valid days out of 14 . We chose an assessment period of 14 days to estimate PA at each time point, rather than the more traditional 7 days. We felt that this would represent one's habitual PA level better than one week, given the possible weekto-week variations in PA patterns. Compared with other studies, we were not limited by the number of days, because participants were asked to wear their monitor every day for the whole duration of the study, and data were transferred via the Internet so they could be analyzed without monitors being returned.

In summary, not all individuals accept to wear an accelerometer. Often, less than half the participants wear their monitor rigorously for a full week. Trost et al. have already provided some tips to promote compliance, such as asking the participant to record the time the monitor is on and off, sending reminders, thinking of situations where wearing the monitor might be a problem, creating a list of frequently asked questions (FAQs), 
and so forth [86]. In the Food4Me Study, since data were visible to the researcher as soon as the monitor was connected to the participant's computer, researchers could send kind reminders to participants for whom substantial non-wear time was identified. FAQs were available on the Food4Me website. We tried to deal efficiently with problematic situations, but should have brainstormed better, in advance, about potential barriers. Technological advancements (smaller accelerometer, waterproof, wearable at different body locations) already help to improve compliance. People should not feel discomfort or find the monitor inconvenient. People also tend to forget to put the monitor back on after taking a shower or taking it off at night. Troiano et al. have shown that providing a wrist accelerometer in the 2011-2012 NHANES cycle, which could be worn day and night, improved compliance greatly: $70-80 \%$ of participants provided $>6$ days of valid data out of 7 , and little difference by age was apparent [67]. This is promising and we encourage manufacturers to build accurate accelerometers, which are integrated into a waterproof watch, and for which data can be transferred via the Internet in order for the device to record an unlimited amount of data. We imagine a future where data could be continuously transferred in real time to surveillance institutions, without any interference with the user. Google is already doing that in Google Maps, using people's enabled smartphones to monitor traffic congestion. This could potentially be adapted to monitor health behaviors, such as PA.

Asking participants to wear an accelerometer every day for 6 months did not prove successful in our trial. We showed in Chapter 3 that compliance had decreased by month 6 . Notably, approximately $26 \%$ of study completers were no longer wearing their monitor by month 6 , and only $11 \%$ of the participants with at least 1 valid day at month 6 , had all 14 days valid. We would probably have been more successful with accelerometers integrated in watches. Long lasting batteries are also essential for longterm studies. By month 6 , it was necessary for many participants to charge their accelerometer more than once a week, which is cumbersome. We would have also been more successful if we had used the monitors only for two weeks at each time point (i.e. sent monitors out before each time point and asked them back afterward). Originally, we had planned to use the DirectLife website and all its features for 6 months. Participants in the intervention groups would have been able to receive elaborate feedback, including tips from online coaches, on a regular basis (e.g. weekly) by logging into the DirectLife website. Wearing the monitor for 6 months would have allowed participants to monitor their own progress during the study. Due to contractual issues with the company, this facility was not available and the absence of this feedback may have contributed to the higher attrition rate. 


\section{Effectiveness of tailored eHealth interventions on weight and physical activity}

\section{Weight}

A recent meta-analysis of RCTs evaluating the effectiveness of personalized eHealth interventions on weight loss found that such personalized interventions were more effective at reducing body weight than non-personalized advice (weighted mean difference: $-1.83 \mathrm{~kg} ; 95 \% \mathrm{Cl}$ : $-2.2,-1.4 ; P<0.0001$; Figure 7.1) [34].

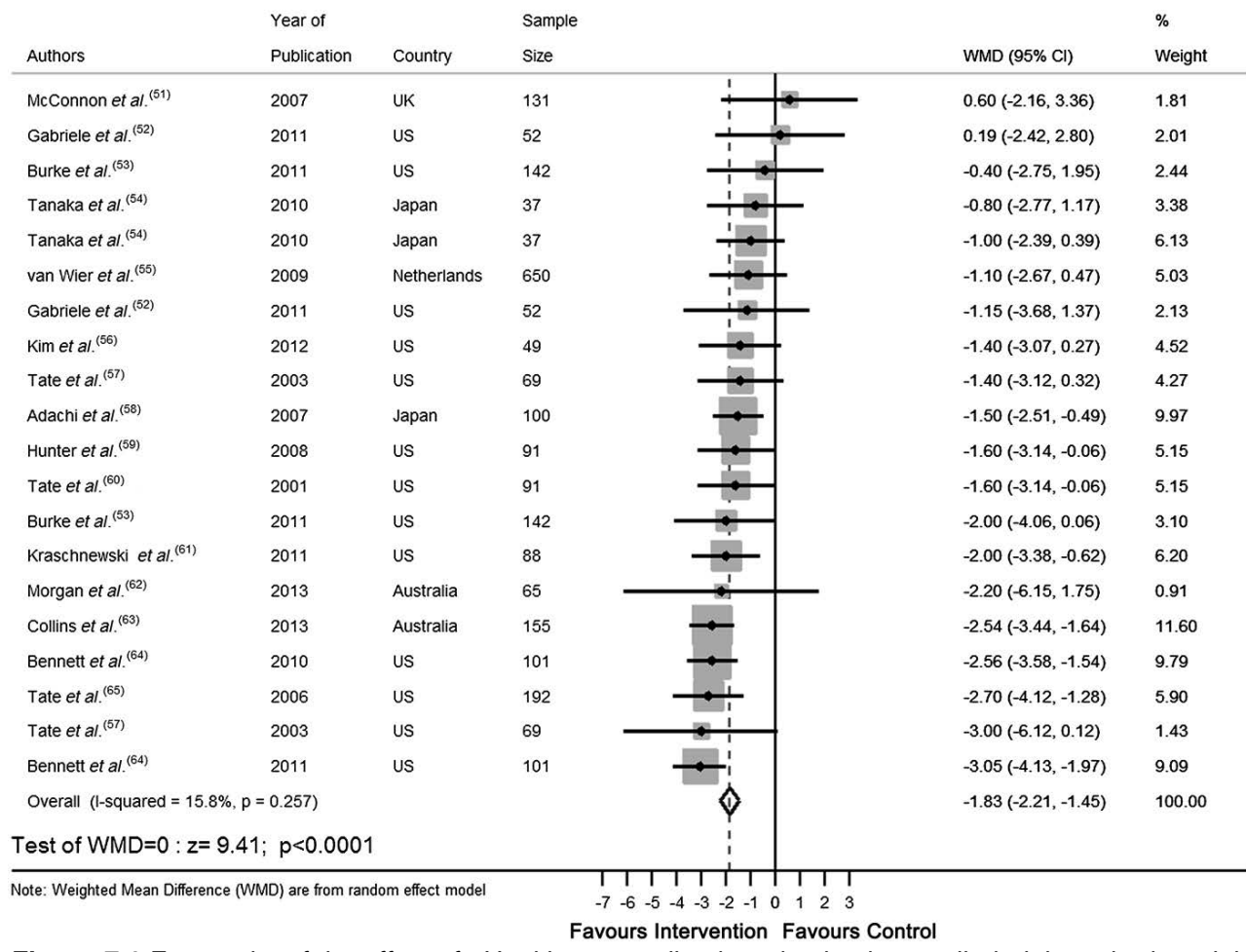

Figure 7.1 Forest plot of the effect of eHealth personalized randomized controlled trials on body weight change $(\mathrm{kg})$ in 2414 adults. Reproduced with permission from Celis-Morales et al. Reference numbers in the figure are derived from the original article by Celis-Morales et al. [34].

Levine et al [92] also found that, compared with usual care, technology-assisted interventions in the primary care setting helped patients achieve weight loss. Software assisting clinical practitioners in guiding subjects toward achieving their weight loss goals, or feedback from personnel appeared to promote more weight loss than fully automated interventions [92]. Another 2015 meta-analysis, by Hutchesson et al. [93] confirmed significantly greater weight loss in eHealth weight loss interventions compared with control (weighted mean difference: $-2.70 \mathrm{~kg} ; 95 \% \mathrm{Cl}$ : $-3.33,-2.08$, 
$P<0.001$ ) or minimal interventions (weighted mean difference: $-1.40 \mathrm{~kg} ; 95 \% \mathrm{Cl}:-1.98$, -0.82; $P<0.001$ ), and in eHealth weight loss interventions with extra components or technologies (weighted mean difference: $1.46 \mathrm{~kg} ; 95 \% \mathrm{Cl}: 0.80,2.13, P<0.001$ ) compared with standard eHealth programs [93].

Even though the results from these meta-analyses are promising, effect sizes remain quite small. Moreover, there is currently insufficient evidence on the effectiveness of eHealth interventions for weight loss maintenance or weight gain prevention [93].

In our study, participants in the personalized groups receiving tailored advice on body weight lost significantly more weight than controls at 3 months (difference in weight loss personalized vs. controls: $\sim 0.8 \mathrm{~kg}, P=0.021)$ but this was no longer significant after 6 months (difference in weight loss personalized vs. controls: $\sim 0.6 \mathrm{~kg} P=0.128$ ) (CelisMorales, Livingstone, Marsaux et al. unpublished).

\section{Physical activity}

There is a wealth of studies investigating the effectiveness of tailored eHealth PA programs. Most have used self-reported PA, and several compared a tailored eHealth intervention with either a wait-list control or no intervention, or with a group where individuals were specifically asked not to change their behavior, or with a tailored intervention using mode of delivery other than Internet technologies. We wanted to know whether tailored eHealth PA programs were more effective than "one size fits all" guidelines at improving objectively measured PA. Therefore, we reduce our discussion to these studies [23,25,27,30,31,94-97]. They are summarized in Table 7.1.

All studies but one [27], grounded their behavior change intervention in social psychological theories, such as the Social Cognitive Theory [98], Transtheoretical model (Stages of Change) [99], Theory of Planned Behavior [100], Social Comparison [101], Decisional Balance [102], Elaboration Likelihood [103], Goal theory [104], or Social Ecological Model [105], or made explicit use of Behavior Change Techniques $[106,107]$. Two studies measured PA with pedometers [25,95], three with uni-axial accelerometers [23,31,97] and four with tri-axial accelerometers [27,30,94,96]. All studies were Internet-based and provided a personalized feedback based on psychological components (e.g. barriers with regards to PA) and/or performance (i.e. current PA). However, some trials were solely eHealth [23,25,31,95-97], whereas others included face-to-face or group sessions during the study [27,30,94] (Table 7.1). Overall, the evidence in favor of tailored eHealth PA programs is weak, with only two studies suggesting small improvements beyond that achieved by the control group (Table 7.1). In the small study in healthy inactive women by Ashe et al., the intervention 
group increased-whereas the control group decreased-their daily steps. However, there were no significant between-group differences in moderate and vigorous PA or sedentary time, despite group-based education, social support and the use of the Fitbit One accelerometer [30]. In one of the most complete study, which used an elaborate Internet, email, and mobile phone behavior change system, including real time feedback on accelerometer data, in healthy, not vigorously active adults, Hurling and colleagues found that moderate PA decreased less in the intervention group compared with the controls [23]. None of the other trials found significant differences in PA change between tailored and non-tailored conditions (Table 7.1). In the Food4Me Study, we observed some small improvements in PA over the 6-month period (Chapter 3). However, in line with the literature, personalized advice did not lead to a greater increase in objectively measured PA compared with standard guidelines, coupled with wearing an accelerometer. Only self-reported PA increased more in the groups receiving personalized feedback compared with the control group. As discussed in Chapter 3, it could be that there were no true changes but that participants thought they improved or they misreported because of desirability bias, or it could be that there were some true changes and the questionnaire captured changes that the accelerometers could not. In any case, the changes reported in self-reported PA for personalized groups, although significantly larger than for controls, were small (Chapter 3). 


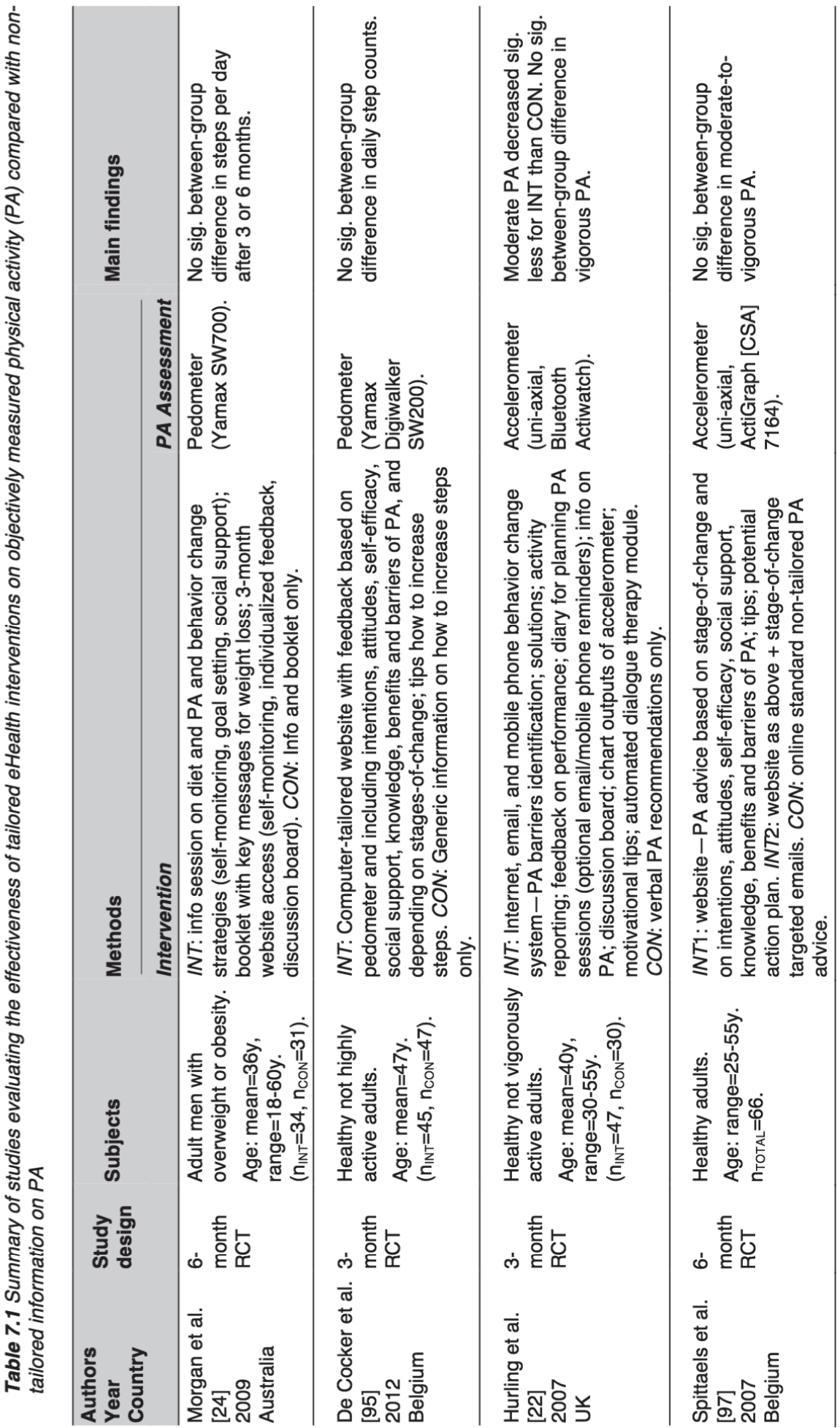




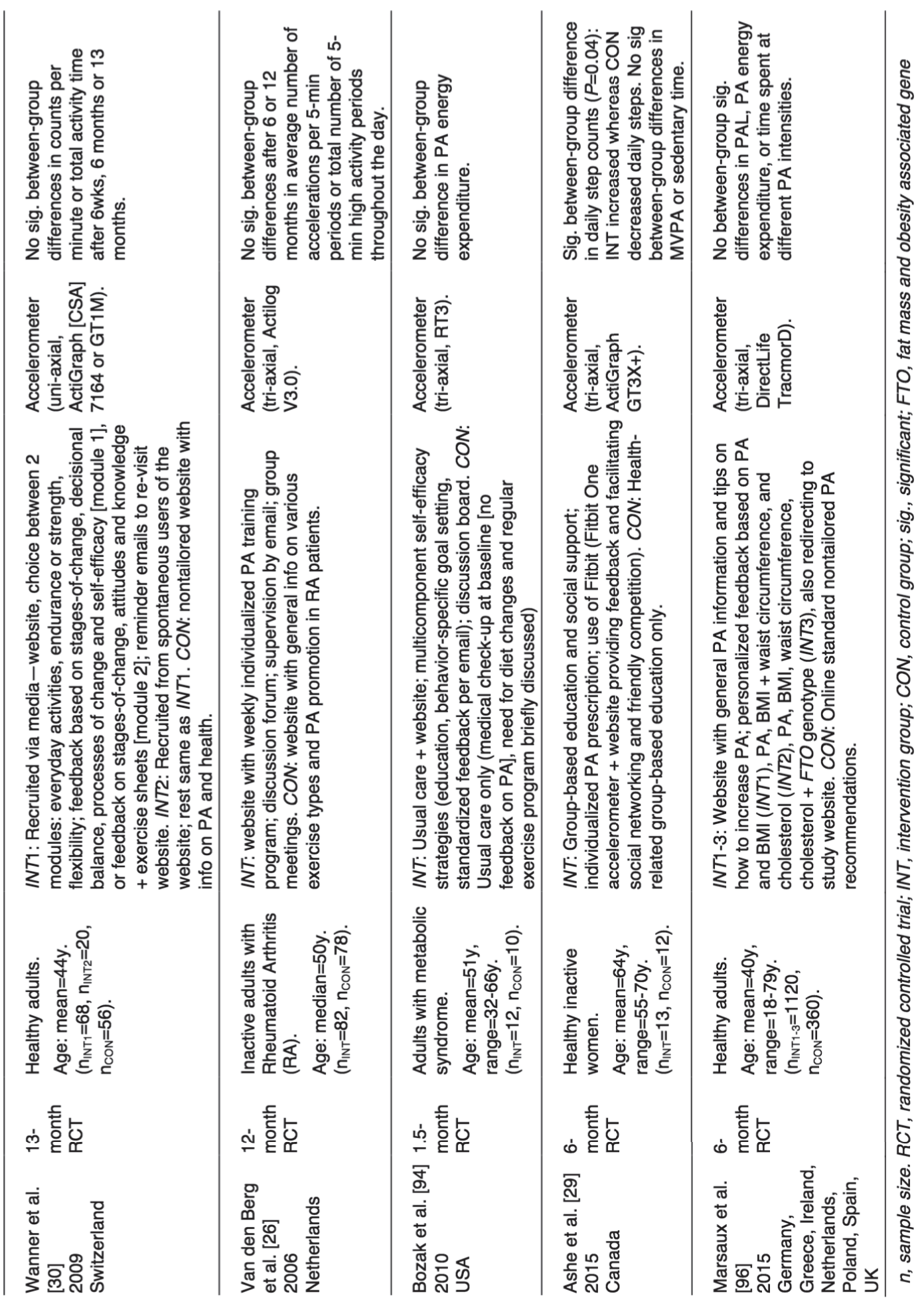




\section{Tailoring is not enough}

The impact of genetic-based feedback will be discussed in the next section. What our results suggest, is that personalized advice itself is likely not sufficient to promote substantial and sustainable behavior change, beyond what can be achieved by less personalized approached. Although self-measurement (with questionnaires, accelerometers, regular weighing) may raise awareness [108] and the tailored advice provided is relevant to the individual, additional features are necessary for people to make sustainable changes. Frequent measurements may help maintain individuals engaged, e.g. weekly weighing and recording values on one's personal webpage or smartphone to keep track of progress. Immediate feedback may be a plus, e.g. monitors giving a real time measure of daily PA such as the one used in our study. However, this raises the issue of trust, as some participants of our study complained that the PA monitor did not seem to register some of their activities very well (e.g. swimming or fitness exercises). This may have contributed to the lower compliance in wearing the device, and weakened the willingness to change.

More personal contact, e.g. online coaches may keep individuals more motivated [32], by explaining the feedback in more detail. They can promote self-efficacy by helping to set realistic goals, identify and deal with barriers, etc. Interactive platforms (forums/chats) for participants to share experiences with each other or health professionals would also be useful. Also important for web-based studies, is that the website content evolves, so that people return to it and feel more engaged. Furthermore, tailoring website content to appeal specifically to men, or specifically to women, may produce better results $[25,109]$.

Individuals often engage in more than one unhealthy behavior $[110,111]$ and multiple health behavior change interventions may have a greater impact than programs focusing on a single component [112]. However, targeting multiple behaviors comprises additional challenges, which may explain the disappointing results reported for studies of diet and PA [112]. Providing a large amount of information and extensive feedback may make it difficult for individuals to find the time to make several changes concurrently [113,114]. Thus, after an initial risk appraisal, it may be beneficial to let people self-select the behavior they wish to focus on [115]. A recent tailored eHealth lifestyle intervention [116] investigated Dutch adults' preference when offered a choice between five modules aimed at either increasing PA, increasing vegetable intake, increasing fruit intake, reducing overconsumption of alcohol, or giving up tobacco use [117]. The researchers reported that respondents who could choose between two or three modules were most likely to select the PA module, followed by the fruit module and the tobacco module [117]. Moreover, the fewer modules recommended to 
participants, the better participants adhered to the intervention modules [118]. Further, self-selecting whether one wants to attempt to make several lifestyle changes at once, or rather one at a time, might also contribute to better behavior change results. However, a recent study could not draw simple conclusions on this topic as the results depended on the targeted behaviors and most likely personal preferences and motivations [119]. In practice you could offer the possibility to switch between strategies, if it turns out individuals do not like the option chosen. More research in this area is needed.

In summary, given the usually small effect sizes and the high attrition rates [120], especially regarding PA, Web-based personalized interventions need-beside tailored advice - a variety of interactive features that can help individuals make sustainable changes. However, these necessary features may raise costs. Finally, in designing new interventions, one should strive to reach primarily those most at risk [121,122], to reduce health inequalities. More work is needed in multiple risk behavior change research, especially in low-income countries, as well as in minor ethnic groups, and in young adults in general [123].

\section{Effectiveness of gene-based advice}

In the last decade, there has been a growing interest in personalizing lifestyle interventions using gene-based feedback [14,16-19,124-128]. The hope was that providing such genetic information would motivate recipients to make beneficial behavioral changes beyond what could be achieved without such information. However, a Cochrane review concluded in 2010 that there was no effect of adding DNA-based disease risk estimates compared with a non-DNA-based approach, in terms of smoking cessation, PA, or use of medication/vitamins [126]. More recently, there were no short-term ( 3 months) or longer-term ( 1 year) changes in self-reported anxiety, dietary fat intake, or exercise, in generally healthy subjects who had received a commercially available direct-to-consumer genome-wide risk test $[129,130]$. In another study, smokers, who were first-degree relatives of patients with Crohn's disease, were informed of their own risk for Crohn's disease based on family history of the disease and smoking status alone, or with additional genetic analysis for the NOD2 genotype [16]. No effect of adding genetic information to the risk assessment was found on smoking cessation [16]. Elsewhere, diabetes genetic risk counseling did not improve motivation or adherence to a prevention program, in overweight individuals at risk for diabetes [14]. The most recent studies that we identified are those of Meisel et al. [18] and Frankwich et al. [131]. Meisel et al. reported that young healthy individuals receiving FTO feedback in their weight control advice felt more prepared to control their 
weight than subjects receiving weight control advice only, but this did not translate into behavioral change [18]. In the MOVE! study of Frankwich and colleagues, American veterans with obesity were randomly assigned either to the genetics-guided therapy group, where participants received one of 4 diets (balanced, low-carbohydrate, low-fat or Mediterranean) based on their risk status for 7 obesity-related SNPs (APOA2, $A D I P O Q, F T O, K C T D 10, \angle I P C, M M A B$ and PPARG), or to the standard therapy group, where participants all followed the balanced diet [131]. There was no significant difference between groups in the percentage of participants who lost $5 \%$ of their body weight at 8 or 24 weeks, although it should be noted that the sample size was small (26 and 20 subjects at 8 weeks, and 18 and 14 subjects at 24 weeks in the genetics-guided therapy group and standard therapy group, respectively).

On the other hand, Arkadianos et al. reported that participants in a traditional weight management diet group and participants receiving a nutrigenetically tailored diet both lost a similar amount of weight up until 100-300 days of follow up, but that, after 300 days, subjects in the nutrigenetic group were significantly more likely to maintain weight loss compared with the control group [132]. Some favorable findings for dietary behavior change were reported in the review by Marteau et al. [126]. However, they are based on two studies only $[17,125]$, which did not find significant effects when each study was evaluated individually. In the REVEAL study, in cognitively normal adults with a family history of Alzheimer's disease, participants informed they had the APOE risk genotype were more likely to report Alzheimer's disease-specific health behavior change 1 year after disclosure, compared with non-risk carriers [125]. In the second REVEAL study, risk carriers were more likely to report a change in dietary supplement use than non-risk carriers [133]. Furthermore, Nielsen et al. concluded that disclosing genetic information for personalized nutrition resulted in greater improvements in sodium intake compared with general population-based dietary advice for individuals with the high-risk genotype status for the $A C E$ gene, but there were no significant effects of gene-based advice for caffeine, vitamin C, or added sugars [19]. Similarly, Hietaranta-Luoma et al., 2015 reported that personal genetic information, based on $A P O E$, might have positive effects on triglyceride values and waist circumference but this was observed only in the high-risk carriers [15].

In summary, the evidence regarding the effectiveness of personalized advice based on genetic information is weak. In our study, we also found no additional benefit of including information on FTO in terms of change in PA or body weight (Chapters 5 and 6). We do not think that it is justified to provide feedback based on genotypic information. It may also unnecessarily raise costs. 


\section{Including cost-effectiveness analyses}

When assessing whether a health intervention is successful, critical, evidence-based evaluation of the effectiveness of the intervention is primal. Often, effectiveness is restricted to the question: does the intervention substantially improve health? Although absolutely necessary, this "clinical" effectiveness is not sufficient. Information regarding cost-effectiveness is crucial for health care decision makers and the government in making evidence-based decisions regarding large-scale implementation of such programs [134].

The Internet is thought to have several advantages in delivering health promotion - for example, time effectiveness, potential 24-hour accessibility, generation of instant personalized feedback, and cost effectiveness [134-136]. However, although most studies test the effectiveness of their eHealth intervention, fewer include a costeffectiveness analysis [134]. Searching the Pubmed database on October $1^{\text {st }} 2015$ for (web based $O R$ internet based $O R$ e health) AND physical activity AND cost effectiveness, in titles or abstracts, returned only 15 original articles, whereas removing the word "cost" from the query returned 115 original articles.

Some economic evaluations of Web-based tailored programs have been done. For example, an Australian research group compared different types of PA intervention programs, and showed that the intervention programs that encourage use of pedometers or mass media-based community campaigns are the most cost-effective strategies to implement. The Internet-based intervention program, although not the most cost-effective, was also found likely to lead to substantial improvement in population health at a cost saving to the health sector [137]. Lewis et al. [138] compared the costs associated with delivering tailored print and Internet-based interventions based on a RCT for PA promotion. The Internet-based intervention became the more cost-efficient of the two, when the number of participants was $>352$, indicating potential if large number of individuals are reached. Furthermore, in an intervention where 1279 adults over 50 years received tailored advice 3 times in 4 months on psychosocial determinants of PA, Peels et al. reported that a tailored PA intervention in a printed delivery mode, without environmental information, had the most potential for being cost-effective [139]. The monetary savings of the Web-based intervention no longer outweighed its lower effects on 10-year or lifetime horizon [139]. Moreover, in the tailored online RCT targeting multiple health behaviors mentioned in the previous section [116], where Dutch participants would receive personal advice either on one unhealthy behavior at a time or on all unhealthy behaviors, the authors reported that both experimental conditions were likely to be cost-effective regarding the 
lifestyle factor, whereas the control condition was cost effective with regards to quality of life [140].

In recent years, there have been steep reductions in the cost of genomic sequencing [141]. However, to our knowledge, there are no studies to date that investigated whether gene-based personalized advice is cost-effective. A cost-effectiveness analysis should have been included in the Food4Me Study. Nevertheless, we did not find any added health benefits of providing genetic information in the personal advice compared with non-gene-based personalized advice (Chapter 5 and Celis-Morales, Livingstone, Marsaux et al. unpublished), so gene-based advice would not have been cost-effective in our study. We can only encourage others to not forget this important aspect when examining the effectiveness of their interventions.

\section{Future perspectives}

"Tonight, I'm launching a new Precision Medicine Initiative to bring us closer to curing diseases like cancer and diabetes-and to give all of us access to the personalized information we need to keep ourselves and our families healthier."

_ President Barack Obama, State of the Union Address, January 20, 2015

"Precision medicine" (formerly "personalized medicine" [142])-which refers to the tailoring of medical treatment by classifying individuals into subpopulations that differ in their susceptibility to a particular disease, in the biology and/or prognosis of those diseases they may develop, or in their response to a specific treatment [143]-is now in the spotlight more than ever. President Obama's announcement created a mix of excitement and concern, which has divided the scientific community. We share the excitement of Collins and colleagues [144], because this initiative will certainly advance precision medicine. For example, the American National Institutes of Health (NIH) Advisory Committee to the Director has recently presented a framework for building a national research cohort of $>1$ million Americans to expand the knowledge and practice of precision medicine [145]. On the other hand, we also share the concern of Bayer and Varmus [146], that there should not be an overly disproportionate focus on precision medicine. Bayer and Varmus are right to remind us of the WHO report on Social Determinants of Health [147], which emphasized the importance to population health of improving daily living conditions and tackling the inequitable distribution of money, power, and resources. It is not clear how precision medicine will prevent the development of even larger health inequalities. Also alarming is the observation made by the authors that total support in fiscal year 2014 for research areas including the 
words "gene," "genome," or "genetic" was about 50\% greater than funding for areas including the word "prevention", in the USA [148]. We believe that prevention should be the top 1 priority. Precision medicine has been more concerned with treatment than prevention. It is likely that it will be useful for prevention, but in a future that is far ahead of us. Funds and research need to be devoted to prevention strategies, which can be implemented effectively, now. If prevention is to work, behaviors have to change and if there is an obvious individual responsibility, there is also a societal responsibility.

It is increasingly recognized that the environments in which we live in contribute largely to unhealthy behaviors, such as poor diet or physical inactivity, and that altering these environments can be a major driver for change [149]. One of the key messages of the 2011 Lancet article by Swinburn and colleagues [150] was that:

"obesity is the result of people responding normally to the obesogenic environments they find themselves in. Support for individuals to counteract obesogenic environments will continue to be important, but the priority should be for policies to reverse the obesogenic nature of these environments."

The idea that the environments shape and constrain human behavior dates back to the previous century [151,152]. It received considerable attention with the introduction of the term "nudge" by Thaler and Sunstein [153] to describe:

"any aspect of the choice architecture [the careful design of the environments in which people make choices] that alters people's behavior in a predictable way without forbidding any options or significantly changing their economic incentives."

The term "nudge" was subsequently embraced by many policy makers, e.g. [154].

Nudging can be used in a variety of ways to improve health outcomes, such as making salad the default side order rather than chips, or drawing steps on the floor that lead you to the staircase, not the elevator. Being less dependent on literacy, numeracy and self-regulatory skills, which are generally lower in those who are more deprived $[155,156]$, they may also have the potential to reduce health inequalities [157]. Unfortunately however, nudging has also been much used to the detriment of our health [158], e.g. foods are packaged, presented, and engineered to stimulate purchase, which has led to overconsumption. Whilst such choice architecture can certainly work acutely as in the examples above, few nudging interventions have been evaluated for their effectiveness in changing behavior in general populations or for their ability to achieve sustained change of the kind needed to improve health in the long term [158]. Evidence to support altering choice architecture as a population health strategy is currently weak [158], although the limitations of the evidence base are due 
not simply to an absence of evidence, but also to a prior lack of definitional and conceptual clarity concerning applications of choice architecture to public health intervention development [159]. Thus, Hollands and colleagues developed a conceptual groundwork providing a foundation for future research to investigate the effectiveness of choice architecture interventions within microenvironments, i.e. small-scale physical and social environments, for changing health behavior [159]. Their approach will facilitate the systematic assessment and synthesis of the existing evidence, a work that is very necessary.

We believe in choice architecture to promote healthier behaviors but agree with Marteau et al. [158] that regulation is necessary, especially to limit unhealthy nudges. A government that responds readily can maintain that people are responsible for their own health while also taking public health action that changes default choices to make it easier for people to stay healthy [160].

\section{References}

1. World Health Organization. Global Health Estimates: Deaths by Cause, Age, Sex and Country, 2000-2012. Geneva: 2014.

2. Mathers CD, Loncar D. Projections of global mortality and burden of disease from 2002 to 2030 . PLoS Med. 2006;3(11):e442.

3. Health statistics and information systems - Projections of mortality and causes of death, 2015 and 2030 [Internet]. 2015 [cited 18 Aug 2015]. Available from: http://www.who.int/healthinfo/global_burden_disease/projections/en/.

4. World Health Organization. Global health risks: mortality and burden of disease attributable to selected major risks. Geneva2009. 63 p.

5. World Health Organization. Global status report on noncommunicable diseases 2014: WHO; 2014.

6. Hallal PC, Andersen LB, Bull FC, Guthold R, Haskell W, Ekelund U, et al. Global physical activity levels: surveillance progress, pitfalls, and prospects. Lancet. 2012;380(9838):247-57.

7. Global Health Observatory Data Repository - Physical inactivity [Internet]. 2015 [cited 15-01-2015]. Available from: http://apps.who.int/gho/data/node.main.A893?lang=en.

8. World Health Organization. Obesity and overweight 2015 [cited 201525 Aug]. Available from: http://www.who.int/mediacentre/factsheets/fs311/en/.

9. Ekelund U, Ward HA, Norat T, Luan J, May AM, Weiderpass E, et al. Physical activity and all-cause mortality across levels of overall and abdominal adiposity in European men and women: the European Prospective Investigation into Cancer and Nutrition Study (EPIC). The American journal of clinical nutrition. 2015;101(3):613-21.

10. Trost SG, Blair SN, Khan KM. Physical inactivity remains the greatest public health problem of the 21st century: evidence, improved methods and solutions using the ' 7 investments that work' as a framework. British journal of sports medicine. 2014;48(3):169-70.

11. Visscher TL, Seidell JC. The public health impact of obesity. Annual review of public health. 2001;22:355-75.

12. World Health Organization. Glossary of globalization, trade and health terms: Public health 2015 [cited 20152 Sept]. Available from: http://www.who.int/trade/glossary/story076/en/. 
13. Kreuter MW, Strecher VJ, Glassman B. One size does not fit all: the case for tailoring print materials. Annals of behavioral medicine : a publication of the Society of Behavioral Medicine. 1999;21(4):276-83.

14. Grant RW, O'Brien KE, Waxler JL, Vassy JL, Delahanty LM, Bissett LG, et al. Personalized genetic risk counseling to motivate diabetes prevention: a randomized trial. Diabetes care. 2013;36(1):13-9.

15. Hietaranta-Luoma HL, Akerman K, Tahvonen R, Puolijoki H, Hopia A. Using Individual, ApoE Genotype-Based Dietary and Physical Activity Advice to Promote Healthy Lifestyles in FinlandImpacts on Cardiovascular Risk Markers. Open Journal of Preventive Medicine. 2015(5):206-17.

16. Hollands GJ, Whitwell SC, Parker RA, Prescott NJ, Forbes A, Sanderson J, et al. Effect of communicating DNA based risk assessments for Crohn's disease on smoking cessation: randomised controlled trial. Bmj. 2012;345:e4708.

17. Marteau T, Senior V, Humphries SE, Bobrow M, Cranston T, Crook MA, et al. Psychological impact of genetic testing for familial hypercholesterolemia within a previously aware population: a randomized controlled trial. American journal of medical genetics Part A. 2004;128A(3):285-93.

18. Meisel SF, Beeken RJ, van Jaarsveld $\mathrm{CH}$, Wardle J. Genetic susceptibility testing and readiness to control weight: Results from a randomized controlled trial. Obesity (Silver Spring). 2015;23(2):30512.

19. Nielsen DE, El-Sohemy A. Disclosure of genetic information and change in dietary intake: a randomized controlled trial. PloS one. 2014;9(11):e112665.

20. Internet World Stats: World Internet Users and 2015 Population Stats 2015 [cited 201531 Aug]. Available from: http://www.internetworldstats.com/stats.htm.

21. Dunton GF, Robertson TP. A tailored Internet-plus-email intervention for increasing physical activity among ethnically-diverse women. Preventive medicine. 2008;47(6):605-11.

22. Hageman PA, Walker SN, Pullen $\mathrm{CH}$. Tailored versus standard internet-delivered interventions to promote physical activity in older women. Journal of geriatric physical therapy. 2005;28(1):28-33.

23. Hurling R, Catt M, Boni MD, Fairley BW, Hurst T, Murray $P$, et al. Using internet and mobile phone technology to deliver an automated physical activity program: randomized controlled trial. Journal of medical Internet research. 2007;9(2):e7.

24. McKay HG, King D, Eakin EG, Seeley JR, Glasgow RE. The diabetes network internet-based physical activity intervention: a randomized pilot study. Diabetes care. 2001;24(8):1328-34.

25. Morgan PJ, Lubans DR, Collins CE, Warren JM, Callister R. The SHED-IT randomized controlled trial: evaluation of an Internet-based weight-loss program for men. Obesity (Silver Spring). 2009;17(11):2025-32.

26. Motl RW, Dlugonski D, Wojcicki TR, McAuley E, Mohr DC. Internet intervention for increasing physical activity in persons with multiple sclerosis. Mult Scler. 2011;17(1):116-28.

27. van den Berg MH, Ronday HK, Peeters AJ, le Cessie S, van der Giesen FJ, Breedveld FC, et al. Using internet technology to deliver a home-based physical activity intervention for patients with rheumatoid arthritis: A randomized controlled trial. Arthritis and rheumatism. 2006;55(6):935-45.

28. Hansen AW, Gronbaek M, Helge JW, Severin M, Curtis T, Tolstrup JS. Effect of a Web-based intervention to promote physical activity and improve health among physically inactive adults: a population-based randomized controlled trial. Journal of medical Internet research. 2012;14(5):e145.

29. Marcus BH, Lewis BA, Williams DM, Dunsiger S, Jakicic JM, Whiteley JA, et al. A comparison of Internet and print-based physical activity interventions. Archives of internal medicine. 2007;167(9):944-9.

30. Ashe M, Winters M, Hoppmann C, Dawes M, Gardiner P, Giangregorio L, et al. "Not just another walking program": Everyday Activity Supports You (EASY) model--a randomized pilot study for a parallel randomized controlled trial. Pilot and Feasibility Studies. 2015;1(1):4.

31. Wanner M, Martin-Diener E, Braun-Fahrlander C, Bauer G, Martin BW. Effectiveness of activeonline, an individually tailored physical activity intervention, in a real-life setting: randomized controlled trial. Journal of medical Internet research. 2009;11(3):e23. 
32. Wijsman CA, Westendorp RG, Verhagen EA, Catt M, Slagboom PE, de Craen AJ, et al. Effects of a web-based intervention on physical activity and metabolism in older adults: randomized controlled trial. Journal of medical Internet research. 2013;15(11):e233.

33. Celis-Morales C, Livingstone KM, Marsaux CF, Forster H, O'Donovan CB, Woolhead C, et al. Design and baseline characteristics of the Food4Me study: a web-based randomised controlled trial of personalised nutrition in seven European countries. Genes \& nutrition. 2015;10(1):450.

34. Celis-Morales C, Lara J, Mathers JC. Personalising nutritional guidance for more effective behaviour change. Proc Nutr Soc. 2015;74(2):130-8.

35. Kilpelainen TO, Qi L, Brage S, Sharp SJ, Sonestedt E, Demerath E, et al. Physical activity attenuates the influence of FTO variants on obesity risk: a meta-analysis of 218,166 adults and 19,268 children. PLoS Med. 2011;8(11):e1001116.

36. Thompson FE, Subar AF, Coulston A, Boushey C. Dietary assessment methodology. Nutrition in the Prevention and Treatment of Disease. 2008;2:3-39.

37. Archer E, Hand GA, Blair SN. Validity of U.S. nutritional surveillance:National Health and Nutrition Examination Survey caloric energy intake data, 1971-2010. PloS one. 2013;8(10):e76632.

38. Freedman LS, Commins JM, Moler JE, Arab L, Baer DJ, Kipnis V, et al. Pooled results from 5 validation studies of dietary self-report instruments using recovery biomarkers for energy and protein intake. American journal of epidemiology. 2014;180(2):172-88.

39. Goris $\mathrm{AH}$, Westerterp-Plantenga MS, Westerterp KR. Undereating and underrecording of habitual food intake in obese men: selective underreporting of fat intake. The American journal of clinical nutrition. 2000;71(1):130-4.

40. Heitmann BL, Lissner L, Osler M. Do we eat less fat, or just report so? International journal of obesity and related metabolic disorders : journal of the International Association for the Study of Obesity. 2000;24(4):435-42.

41. Lissner L, Troiano RP, Midthune D, Heitmann BL, Kipnis V, Subar AF, et al. OPEN about obesity: recovery biomarkers, dietary reporting errors and BMI. Int J Obes (Lond). 2007;31(6):956-61.

42. Schoeller DA. Limitations in the assessment of dietary energy intake by self-report. Metabolism: clinical and experimental. 1995;44(2 Suppl 2):18-22.

43. Schoeller DA, Thomas D, Archer E, Heymsfield SB, Blair SN, Goran MI, et al. Self-report-based estimates of energy intake offer an inadequate basis for scientific conclusions. The American journal of clinical nutrition. 2013;97(6):1413-5.

44. Whybrow S, Stubbs RJ, Johnstone AM, O'Reilly LM, Fuller Z, Livingstone MB, et al. Plausible selfreported dietary intakes in a residential facility are not necessarily reliable. European journal of clinical nutrition. 2015.

45. Dhurandhar NV, Schoeller D, Brown AW, Heymsfield SB, Thomas D, Sorensen TI, et al. Energy balance measurement: when something is not better than nothing. Int J Obes (Lond). 2014.

46. Archer E, Pavela G, Lavie CJ. The Inadmissibility of What We Eat in America and NHANES Dietary Data in Nutrition and Obesity Research and the Scientific Formulation of National Dietary Guidelines. Mayo Clinic proceedings. 2015;90(7):911-26.

47. Montoye HJ, Kemper HC, Saris WH, Washburn RA. Measuring Physical Activity and Energy Expenditure: Human Kinetics; 1996. 190 p.

48. Prince SA, Adamo KB, Hamel ME, Hardt J, Connor Gorber S, Tremblay M. A comparison of direct versus self-report measures for assessing physical activity in adults: a systematic review. The international journal of behavioral nutrition and physical activity. 2008;5:56.

49. Tully MA, Panter J, Ogilvie D. Individual Characteristics Associated with Mismatches between SelfReported and Accelerometer-Measured Physical Activity. PloS one. 2014;9(6):e99636.

50. Walsh MC, Hunter GR, Sirikul B, Gower BA. Comparison of self-reported with objectively assessed energy expenditure in black and white women before and after weight loss. The American journal of clinical nutrition. 2004;79(6):1013-9.

51. Dyrstad SM, Hansen BH, Holme IM, Anderssen SA. Comparison of self-reported versus accelerometer-measured physical activity. Medicine and science in sports and exercise. 2014;46(1):99-106. 
52. Hagstromer M, Ainsworth BE, Oja P, Sjostrom M. Comparison of a subjective and an objective measure of physical activity in a population sample. Journal of physical activity \& health. 2010;7(4):541-50.

53. Celis-Morales CA, Perez-Bravo F, Ibanez L, Salas C, Bailey ME, Gill JM. Objective vs. self-reported physical activity and sedentary time: effects of measurement method on relationships with risk biomarkers. PloS one. 2012;7(5):e36345.

54. Warren JM, Ekelund U, Besson H, Mezzani A, Geladas N, Vanhees L. Assessment of physical activity-a review of methodologies with reference to epidemiological research: a report of the exercise physiology section of the European Association of Cardiovascular Prevention and Rehabilitation. European Journal of Cardiovascular Prevention \& Rehabilitation. 2010;17(2):127-39.

55. Plasqui G, Bonomi AG, Westerterp KR. Daily physical activity assessment with accelerometers: new insights and validation studies. Obes Rev. 2013;14(6):451-62.

56. Villars C, Bergouignan A, Dugas J, Antoun E, Schoeller DA, Roth $\mathrm{H}$, et al. Validity of combining heart rate and uniaxial acceleration to measure free-living physical activity energy expenditure in young men. J Appl Physiol (1985). 2012;113(11):1763-71.

57. Tudor-Locke C, Martin CK, Brashear MM, Rood JC, Katzmarzyk PT, Johnson WD. Predicting doubly labeled water energy expenditure from ambulatory activity. Applied Physiology, Nutrition, and Metabolism. 2012;37(6):1091-100.

58. Ekstrom S, Kull I, Nilsson S, Bergstrom A. Web-based self-reported height, weight, and body mass index among Swedish adolescents: a validation study. Journal of medical Internet research. 2015;17(3):e73.

59. Lassale C, Peneau S, Touvier M, Julia C, Galan P, Hercberg S, et al. Validity of web-based selfreported weight and height: results of the Nutrinet-Sante study. Journal of medical Internet research. 2013;15(8):e152.

60. Bes-Rastrollo M, Sabaté J, Jaceldo-Siegl K, Fraser GE. Validation of self-reported anthropometrics in the Adventist Health Study 2. BMC public health. 2011;11(1):213.

61. Bonn SE, Lagerros YT, Bälter K. How valid are Web-based self-reports of weight? Journal of medical Internet research. 2013;15(4).

62. Pursey K, Burrows TL, Stanwell P, Collins CE. How accurate is web-based self-reported height, weight, and body mass index in young adults? Journal of medical Internet research. 2014;16(1).

63. Celis-Morales C, Livingstone KM, Woolhead C, Forster H, O'Donovan CB, Macready AL, et al. How reliable is internet-based self-reported identity, socio-demographic and obesity measures in European adults? Genes \& nutrition. 2015;10(5):476.

64. Yorkin M, Spaccarotella K, Martin-Biggers J, Quick V, Byrd-Bredbenner C. Accuracy and consistency of weights provided by home bathroom scales. BMC public health. 2013;13:1194.

65. Booth DA, Laguna-Camacho A. Physical versus psychosocial measures of influences on human obesity. Comment on Dhurandhar et al. Int J Obes (Lond). 2015;39(7):1177-8.

66. Matthews CE, Ainsworth BE, Thompson RW, Bassett DR, Jr. Sources of variance in daily physical activity levels as measured by an accelerometer. Medicine and science in sports and exercise. 2002;34(8):1376-81.

67. Troiano RP, McClain JJ, Brychta RJ, Chen KY. Evolution of accelerometer methods for physical activity research. British journal of sports medicine. 2014;48(13):1019-23.

68. Ross A, Thomas S. The health benefits of yoga and exercise: a review of comparison studies. The journal of alternative and complementary medicine. 2010;16(1):3-12.

69. Jahnke R, Larkey L, Rogers C, Etnier J, Lin F. A comprehensive review of health benefits of qigong and tai chi. American Journal of Health Promotion. 2010;24(6):e1-e25.

70. Troiano RP, Pettee Gabriel KK, Welk GJ, Owen N, Sternfeld B. Reported physical activity and sedentary behavior: why do you ask? Journal of physical activity \& health. 2012;9 Suppl 1:S68-75.

71. Baptista F, Santos DA, Silva AM, Mota J, Santos R, Vale S, et al. Prevalence of the Portuguese population attaining sufficient physical activity. Medicine and science in sports and exercise. 2012;44(3):466-73. 
72. Hagstromer M, Oja P, Sjostrom M. Physical activity and inactivity in an adult population assessed by accelerometry. Medicine and science in sports and exercise. 2007;39(9):1502-8.

73. Hansen BH, Kolle E, Dyrstad SM, Holme I, Anderssen SA. Accelerometer-determined physical activity in adults and older people. Medicine and science in sports and exercise. 2012;44(2):266-72.

74. O'Donovan G, Hillsdon M, Ukoumunne OC, Stamatakis E, Hamer M. Objectively measured physical activity, cardiorespiratory fitness and cardiometabolic risk factors in the Health Survey for England. Preventive medicine. 2013;57(3):201-5.

75. Peters TM, Moore SC, Xiang YB, Yang G, Shu XO, Ekelund U, et al. Accelerometer-measured physical activity in Chinese adults. American journal of preventive medicine. 2010;38(6):583-91.

76. Ruiz JR, Ortega FB, Martinez-Gomez D, Labayen I, Moreno LA, De Bourdeaudhuij I, et al. Objectively measured physical activity and sedentary time in European adolescents: the HELENA study. American journal of epidemiology. 2011;174(2):173-84.

77. Troiano RP, Berrigan D, Dodd KW, Masse LC, Tilert T, McDowell M. Physical activity in the United States measured by accelerometer. Medicine and science in sports and exercise. 2008;40(1):181-8.

78. Ronda G, Van Assema P, Brug J. Stages of change, psychological factors and awareness of physical activity levels in The Netherlands. Health promotion international. 2001;16(4):305-14.

79. Watkinson C, van Sluijs EM, Sutton S, Hardeman W, Corder K, Griffin SJ. Overestimation of physical activity level is associated with lower BMI: a cross-sectional analysis. The international journal of behavioral nutrition and physical activity. 2010;7:68.

80. Garber CE, Blissmer B, Deschenes MR, Franklin BA, Lamonte MJ, Lee IM, et al. American College of Sports Medicine position stand. Quantity and quality of exercise for developing and maintaining cardiorespiratory, musculoskeletal, and neuromotor fitness in apparently healthy adults: guidance for prescribing exercise. Medicine and science in sports and exercise. 2011;43(7):1334-59.

81. Haskell WL, Lee IM, Pate RR, Powell KE, Blair SN, Franklin BA, et al. Physical activity and public health: updated recommendation for adults from the American College of Sports Medicine and the American Heart Association. Circulation. 2007;116(9):1081-93.

82. Pate RR, Pratt M, Blair SN, Haskell WL, Macera CA, Bouchard C, et al. Physical activity and public health. A recommendation from the Centers for Disease Control and Prevention and the American College of Sports Medicine. Jama. 1995;273(5):402-7.

83. World Health Organization. Global recommendations on physical activity for health2010. 58 p.

84. Wijndaele K, Westgate K, Stephens SK, Blair SN, Bull FC, Chastin SF, et al. Utilization and Harmonization of Adult Accelerometry Data: Review and Expert Consensus. Medicine and science in sports and exercise. 2015.

85. Lee IM, Shiroma EJ. Using accelerometers to measure physical activity in large-scale epidemiological studies: issues and challenges. British journal of sports medicine. 2014;48(3):197201.

86. Trost SG, Mclver KL, Pate RR. Conducting accelerometer-based activity assessments in fieldbased research. Medicine and science in sports and exercise. 2005;37(11 Suppl):S531-43.

87. Tucker JM, Welk GJ, Beyler NK. Physical activity in U.S.: adults compliance with the Physical Activity Guidelines for Americans. American journal of preventive medicine. 2011;40(4):454-61.

88. Chaudhury M, Esliger DW. Accelerometry in adults. Health Survey for England 2008 Volume 1: Physical Activity and Fitness. 1. London: The NHS Information Centre for health and social care; 2009. p. 59-78.

89. Colley RC, Garriguet D, Janssen I, Craig CL, Clarke J, Tremblay MS. Physical activity of Canadian adults: accelerometer results from the 2007 to 2009 Canadian Health Measures Survey. Health reports. $2011 ; 22(1): 7-14$.

90. Hamer M, Kivimaki M, Steptoe A. Longitudinal patterns in physical activity and sedentary behaviour from mid-life to early old age: a substudy of the Whitehall II cohort. Journal of epidemiology and community health. 2012;66(12):1110-5.

91. Dyck DV, Cerin E, De Bourdeaudhuij I, Hinckson E, Reis RS, Davey R, et al. International study of objectively measured physical activity and sedentary time with body mass index and obesity: IPEN adult study. Int J Obes (Lond). 2014. 
92. Levine DM, Savarimuthu S, Squires A, Nicholson J, Jay M. Technology-assisted weight loss interventions in primary care: a systematic review. Journal of general internal medicine. 2015;30(1):107-17.

93. Hutchesson MJ, Rollo ME, Krukowski R, Ells L, Harvey J, Morgan PJ, et al. eHealth interventions for the prevention and treatment of overweight and obesity in adults: a systematic review with metaanalysis. Obes Rev. 2015;16(5):376-92.

94. Bosak KA, Yates B, Pozehl B. Effects of an Internet physical activity intervention in adults with metabolic syndrome. Western journal of nursing research. 2010;32(1):5-22.

95. De Cocker K, Spittaels H, Cardon G, De Bourdeaudhuij I, Vandelanotte C. Web-based, computertailored, pedometer-based physical activity advice: development, dissemination through general practice, acceptability, and preliminary efficacy in a randomized controlled trial. Journal of medical Internet research. 2012;14(2):e53.

96. Marsaux CF, Celis-Morales C, Fallaize R, Macready AL, Kolossa S, Woolhead C, et al. Effects of a Web-Based Personalized Intervention on Physical Activity in European Adults: A Randomized Controlled Trial. Journal of medical Internet research. 2015;17(10):e231.

97. Spittaels H, De Bourdeaudhuij I, Brug J, Vandelanotte C. Effectiveness of an online computertailored physical activity intervention in a real-life setting. Health education research. 2007;22(3):385-96.

98. Bandura A. Self-efficacy: toward a unifying theory of behavioral change. Psychological review. 1977;84(2):191-215.

99. Prochaska JO, Norcross JC, DiClemente CC. Changing for good: Avon Books New York; 1995.

100. Ajzen I. From intentions to actions: A theory of planned behavior: Springer; 1985.

101. Festinger L. A theory of social comparison processes. Human relations. 1954;7(2):117-40.

102. Janis IL, Mann L. Decision making: A psychological analysis of conflict, choice, and commitment: Free Press; 1977.

103. Petty RE, Cacioppo JT. The elaboration likelihood model of persuasion: Springer; 1986.

104. Gollwitzer PM. Goal achievement: The role of intentions. European review of social psychology. 1993;4(1):141-85.

105. Stokols D. Translating social ecological theory into guidelines for community health promotion. American journal of health promotion : AJHP. 1996;10(4):282-98.

106. Abraham C, Michie S. A taxonomy of behavior change techniques used in interventions. Health psychology : official journal of the Division of Health Psychology, American Psychological Association. 2008;27(3):379-87.

107. Michie S, Ashford S, Sniehotta FF, Dombrowski SU, Bishop A, French DP. A refined taxonomy of behaviour change techniques to help people change their physical activity and healthy eating behaviours: the CALO-RE taxonomy. Psychology \& health. 2011;26(11):1479-98.

108. Godino JG, Watkinson C, Corder K, Marteau TM, Sutton S, Sharp SJ, et al. Impact of personalised feedback about physical activity on change in objectively measured physical activity (the FAB study): a randomised controlled trial. PloS one. 2013;8(9):e75398.

109. Vandelanotte C, Caperchione CM, Ellison M, George ES, Maeder A, Kolt GS, et al. What kinds of website and mobile phone-delivered physical activity and nutrition interventions do middle-aged men want? Journal of health communication. 2013;18(9):1070-83.

110. Pronk NP, Anderson LH, Crain AL, Martinson BC, O'Connor PJ, Sherwood NE, et al. Meeting recommendations for multiple healthy lifestyle factors. Prevalence, clustering, and predictors among adolescent, adult, and senior health plan members. American journal of preventive medicine. 2004;27(2 Suppl):25-33.

111. Poortinga W. The prevalence and clustering of four major lifestyle risk factors in an English adult population. Preventive medicine. 2007;44(2):124-8.

112. Prochaska JJ, Prochaska JO. A Review of Multiple Health Behavior Change Interventions for Primary Prevention. American journal of lifestyle medicine. 2011;5(3). 
113. Norman GJ, Zabinski MF, Adams MA, Rosenberg DE, Yaroch AL, Atienza AA. A review of eHealth interventions for physical activity and dietary behavior change. American journal of preventive medicine. 2007;33(4):336-45.

114. Schulz DN, Schneider F, de Vries H, van Osch LA, van Nierop PW, Kremers SP. Program completion of a web-based tailored lifestyle intervention for adults: differences between a sequential and a simultaneous approach. Journal of medical Internet research. 2012;14(2):e26.

115. Campbell MK, Tessaro I, DeVellis B, Benedict S, Kelsey K, Belton L, et al. Tailoring and targeting a worksite health promotion program to address multiple health behaviors among bluecollar women. American Journal of Health Promotion. 2000;14(5):306-13.

116. Schulz DN, Kremers SP, van Osch LA, Schneider F, van Adrichem MJ, de Vries H. Testing a Dutch web-based tailored lifestyle programme among adults: a study protocol. BMC public health. $2011 ; 11: 108$.

117. Schulz DN, Kremers SPJ, De Vries H. Tailored eHealth Lifestyle Promotion: Which Behavioral Modules Do Users Prefer? Journal of health communication. 2015;20(6):663-72.

118. Reinwand DA, Schulz DN, Crutzen R, Kremers SP, de Vries H. Who Follows eHealth Interventions as Recommended? A Study of Participants' Personal Characteristics From the Experimental Arm of a Randomized Controlled Trial. Journal of medical Internet research. 2015;17(5):e115.

119. Schulz DN, Kremers SP, Vandelanotte C, Van Adrichem MJ, Schneider F, Candel MJ, et al. Effects of a web-based tailored multiple-lifestyle intervention for adults: a two-year randomized controlled trial comparing sequential and simultaneous delivery modes. Journal of medical Internet research. 2014;16(1).

120. Kohl LF, Crutzen R, de Vries NK. Online prevention aimed at lifestyle behaviors: a systematic review of reviews. Journal of medical Internet research. 2013;15(7).

121. Spittaels H, De Bourdeaudhuij I. Who participates in a computer-tailored physical activity program delivered through the Internet? A comparison of participants' and non-participants' characteristics. The international journal of behavioral nutrition and physical activity. 2007;4:39.

122. Verheijden MW, Jans MP, Hildebrandt VH, Hopman-Rock M. Rates and determinants of repeated participation in a web-based behavior change program for healthy body weight and healthy lifestyle. Journal of medical Internet research. 2007;9(1):e1.

123. King K, Meader N, Wright K, Graham H, Power C, Petticrew M, et al. Characteristics of interventions targeting multiple lifestyle risk behaviours in adult populations: a systematic scoping review. PloS one. 2015;10(1):e0117015.

124. Vakili S, Caudill MA. Personalized nutrition: nutritional genomics as a potential tool for targeted medical nutrition therapy. Nutr Rev. 2007;65(7):301-15.

125. Chao S, Roberts JS, Marteau TM, Silliman R, Cupples LA, Green RC. Health behavior changes after genetic risk assessment for Alzheimer disease: The REVEAL Study. Alzheimer disease and associated disorders. 2008;22(1):94-7.

126. Marteau TM, French DP, Griffin SJ, Prevost AT, Sutton S, Watkinson C, et al. Effects of communicating DNA-based disease risk estimates on risk-reducing behaviours. The Cochrane database of systematic reviews. 2010(10):CD007275.

127. Nielsen DE, El-Sohemy A. A randomized trial of genetic information for personalized nutrition. Genes \& nutrition. 2012;7(4):559-66.

128. Hietaranta-Luoma HL, Tahvonen R, Iso-Touru T, Puolijoki H, Hopia A. An intervention study of individual, apoE genotype-based dietary and physical-activity advice: impact on health behavior. Journal of nutrigenetics and nutrigenomics. 2014;7(3):161-74.

129. Bloss CS, Schork NJ, Topol EJ. Effect of direct-to-consumer genomewide profiling to assess disease risk. New England Journal of Medicine. 2011;364(6):524-34.

130. Bloss CS, Wineinger NE, Darst BF, Schork NJ, Topol EJ. Impact of direct-to-consumer genomic testing at long term follow-up. Journal of medical genetics. 2013:jmedgenet-2012-101207.

131. Frankwich KA, Egnatios J, Kenyon ML, Rutledge TR, Liao PS, Gupta S, et al. Differences in Weight Loss Between Persons on Standard Balanced Versus Nutrigenetic Diets in a Randomized Controlled Trial. Clinical Gastroenterology and Hepatology. 2015. 
132. Arkadianos I, Valdes AM, Marinos E, Florou A, Gill RD, Grimaldi KA. Improved weight management using genetic information to personalize a calorie controlled diet. Nutrition Journal. 2007;6(1):29.

133. Vernarelli JA, Roberts JS, Hiraki S, Chen CA, Cupples LA, Green RC. Effect of Alzheimer disease genetic risk disclosure on dietary supplement use. Am J Clin Nutr. 2010;91(5):1402-7.

134. Tate DF, Finkelstein EA, Khavjou O, Gustafson A. Cost effectiveness of internet interventions: review and recommendations. Annals of behavioral medicine : a publication of the Society of Behavioral Medicine. 2009;38(1):40-5.

135. Cummins CO, Evers KE, Johnson JL, Paiva A, Prochaska JO, Prochaska JM. Assessing stage of change and informed decision making for Internet participation in health promotion and disease management. Managed care interface. 2004;17(8):27-32.

136. Brug J, Oenema A, Kroeze W, Raat H. The internet and nutrition education: challenges and opportunities. European journal of clinical nutrition. 2005;59 Suppl 1:S130-7; discussion S8-9.

137. Cobiac LJ, Vos T, Barendregt JJ. Cost-effectiveness of interventions to promote physical activity: a modelling study. PLoS Med. 2009;6(7):e1000110.

138. Lewis BA, Williams DM, Neighbors CJ, Jakicic JM, Marcus BH. Cost Analysis of Internet vs. Print Interventions for Physical Activity Promotion. Psychology of sport and exercise. 2010;11(3):246-9.

139. Peels DA, Hoogenveen RR, Feenstra TL, Golsteijn RH, Bolman C, Mudde AN, et al. Long-term health outcomes and cost-effectiveness of a computer-tailored physical activity intervention among people aged over fifty: modelling the results of a randomized controlled trial. BMC public health. 2014;14:1099.

140. Schulz DN, Smit ES, Stanczyk NE, Kremers SP, de Vries H, Evers SM. Economic evaluation of a web-based tailored lifestyle intervention for adults: findings regarding cost-effectiveness and costutility from a randomized controlled trial. Journal of medical Internet research. 2014;16(3):e91.

141. Wetterstrand KA. DNA sequencing costs: data from the NHGRI Genome sequencing program (GSP). [updated 2015-10-022015-10-12]. Available from: www.genome.gov/sequencingcosts.

142. Katsnelson A. Momentum grows to make 'personalized' medicine more 'precise'. Nat Med. 2013;19(3):249-.

143. Toward Precision Medicine: Building a Knowledge Network for Biomedical Research and a New Taxonomy of Disease. The National Academies Collection: Reports funded by National Institutes of Health. Washington (DC)2011.

144. Collins FS, Varmus H. A new initiative on precision medicine. N Engl J Med. 2015;372(9):793-5.

145. National Institutes of Health. NIH framework points the way forward for building national, largescale research cohort, a key component of the President's Precision Medicine Initiative 2015 [updated 17-09-201513-10-2015]. Available from: http://www.nih.gov/news/health/sep2015/od17.htm.

146. Bayer R, Galea S. Public Health in the Precision-Medicine Era. N Engl J Med. 2015;373(6):499501.

147. CSDH. Closing the gap in a generation: health equity through action on the social determinants of health. Final Report of the Commission on Social Determinants of Health. Geneva: 2008.

148. National Institutes of Health, Research Portfolio Online Reporting Tools. Estimates of Funding for Various Research, Condition, and Disease Categories (RCDC) 2015 [updated 05-02-201513-102015]. Available from: www.report.nih.gov/categorical_spending.aspx.

149. Das $\mathrm{P}$, Horton R. Rethinking our approach to physical activity. The Lancet.380(9838):189-90.

150. Swinburn BA, Sacks G, Hall KD, McPherson K, Finegood DT, Moodie ML, et al. The global obesity pandemic: shaped by global drivers and local environments. The Lancet.378(9793):804-14.

151. Durkheim E. Suicide: a study in sociology [1897]. Translated by JA Spaulding and G Simpson (Glencoe, Illinois: The Free Press, 1951). 1951.

152. Thorndike EL. Education psychology: briefer course: Routledge; 1923.

153. Thaler $\mathrm{RH}$, Sunstein C. Nudge: improving decisions about health, wealth, and happiness.: Newhaven: Yale University Press; 2008. 
154. Health Do. Healthy lives, healthy people: Our strategy for public health in England: The Stationery Office; 2010.

155. Spears D. Economic decision-making in poverty depletes behavioral control. The BE Journal of Economic Analysis \& Policy. 2011;11(1).

156. Williams J, Clemens S, Oleinikova K, Tarvin K. The skills for life survey: a national needs and impact survey of literacy, numeracy and ICT skills. Norwich: Department of Education and Skills; 2003.

157. Marteau TM, Hollands GJ, Fletcher PC. Changing human behavior to prevent disease: the importance of targeting automatic processes. Science. 2012;337(6101):1492-5.

158. Marteau TM, Ogilvie D, Roland M, Suhrcke M, Kelly MP. Judging nudging: can nudging improve population health? Bmj. 2011;342.

159. Hollands GJ, Shemilt I, Marteau TM, Jebb SA, Kelly MP, Nakamura R, et al. Altering microenvironments to change population health behaviour: towards an evidence base for choice architecture interventions. BMC public health. 2013;13:1218.

160. Frieden TR. Government's role in protecting health and safety. $N$ Engl $J$ Med. 2013;368(20):1857-9. 
Summaries 


\section{English Summary}

Most deaths around the globe-38 million in 2012-are due to noncommunicable diseases (NCDs), such as cardiovascular diseases, cancers, chronic respiratory diseases, and diabetes. They share four common risk factors: tobacco use, harmful use of alcohol, unhealthy diet, and insufficient physical activity (PA). Thus, lifestyle changes, e.g. eating less and better, being more physically active, etc., can greatly reduce NCD risk. Producing these behavior changes in the population is an enormous challenge, given the current obesogenic environments. Public health has been trying to meet this challenge, using generic health communication materials to stir entire populations toward healthier lifestyles. Unfortunately, such "one size fits all" approach has not been very successful. For example, although public knowledge of the PA guidelines is good, the global prevalence of insufficient PA remains much too high. It has been argued that intervention programs may need to be tailored to the individuals' needs and interests in order for them to realize that behavioral changes are necessary and relevant-for them as an individual. Tailored communication is intended to reach one specific person based on characteristics that are unique to that person. It is related to an outcome of interest and has been derived from an individual assessment. In general, as the level of assessment increases: anthropometric data (e.g. body weight), phenotypic data (e.g. blood cholesterol, PA), and more recently even genotypic data (e.g. a mutation in the breast cancer 1, early onset gene $B R C A 1$, or carriage of the risk allele in the fat mass and obesity associated gene FTO), so does the degree of individualization in the feedback provided. Tailoring health messages may have potential, provided that it can be done at low cost, delivered to a large part of the population, and be more effective at changing behaviors than a "one size fits all" approach. Although disclosure of genetic information does not seem to have unintended adverse effects, more randomized controlled trials are needed to establish whether gene-based personalized interventions are useful and promote greater behavior change than non-gene-based interventions. In particular, data on whether providing DNA-based test results would lead to an increase in PA and/or can help one's weight reduction or management are lacking.

The Food4Me 'Proof of Principle' Study, as part of a larger EU project on personalized nutrition, was a 6-month, 4-arm, randomized controlled trial, designed to emulate an Internet-based personalized service. Conducted across seven European countries (Germany, Greece, Ireland, The Netherlands, Poland, Spain, and the United Kingdom), the trial aimed to compare the effects of three levels of personalized advice with standard population advice on health-related outcomes: 
- Level 0 ('control group'): non-personalized dietary and PA advice based on (European) population (generic) guidelines.

- Level 1: personalized dietary and PA advice based on individual dietary intake and PA data alone.

- Level 2: personalized dietary and PA advice based on individual dietary intake, $\mathrm{PA}$, and phenotypic data.

- Level 3: personalized dietary and PA advice based on individual dietary intake, PA, phenotypic, and genotypic data.

Within the Food4Me project, the objective of this thesis was to determine whether a personalized intervention delivered via the Internet was more effective in improving PA and obesity-related traits than providing online standardized (non-personalized) guidelines.

This thesis begins with a description of PA levels in 1,287 residents (539 men and 748 women) across seven European countries, measured objectively with accelerometers and concurrently with the same protocol (Chapter 2). Amounts of PA achieved were also compared with current guidelines from the World Health Organization. Overall, $58 \%$ of men and $37 \%$ of women achieved the recommended 150 min.wk ${ }^{-1}$ of moderate or vigorous PA. Significant between-countries differences were found, but only for women. Notably, Greek and Polish women accumulated less vigorous PA and only $26 \%$ of them met the PA recommendations, in comparison with $49 \%$ of Irish women. Although a larger proportion of our cohort met the PA guidelines compared with other US or European studies, there was room for improvement in PA for all countries in the Food4Me Study. After participants received either non-personalized standard healthy eating and lifestyle guidelines (Level 0), or personalized advice (Levels 1-3), they were followed for 6 months. Among others, body weight was self-measured and reported, while PA was assessed using validated instruments-TracmorD accelerometer and Baecke questionnaire-at 3 and 6 months. Participants were asked to wear the device every day for 6 months. This turned out to be difficult. Only 730 (49\% of 1480 actual study starters) had sufficient accelerometer data for both baseline and month 6 , whereas 1270 participants (86\%) completed the 6-month trial (1233 participants had self-reported data). About three quarters of participants were advised to increase PA. At the end of the intervention, we observed small, significant, improvements in selfreported and objectively measured PA. Greater improvements in self-reported total PA and PA during leisure (nonsport) were observed in personalized groups (Levels 1-3) compared with the control group (Level 0), and changes were larger with increased personalization of the advice (Levels 2-3 vs. Level 1). However, there were no significant differences in accelerometer results between personalized and control 
groups, and no significant effect of adding phenotypic or genotypic information to the tailored feedback at month 3 or 6 (Chapter 3). The FTO gene has provided the strongest evidence to date, in relation to the genetic susceptibility to obesity. Although genetically predisposed individuals may be more susceptible to obesity in an obesogenic environment, with a higher risk of over-consumption as was shown in twin studies, there has been limited evidence of genotype-lifestyle interactions on adiposity outcomes. Importantly, in most studies, PA was self-reported, and measurement error may have attenuated the true strength of the FTO-PA interaction. Only very few studies have used objectively measured PA; thus, in Chapter 4, we investigated whether the effect of FTO polymorphism rs9939609 on obesity-related traits was modified by PA measured by accelerometry. FTO risk genotype was associated with a higher body weight ( $\beta: 1.09 \mathrm{~kg}$ per risk allele), BMI ( $\beta: 0.54 \mathrm{~kg} \cdot \mathrm{m}^{-2}$ ) and waist circumference ( $\beta: 1.07$ $\mathrm{cm})$. PA attenuated the effect of FTO on BMI and waist circumference. For instance, among inactive individuals, FTO significantly increased BMI by $1.06 \mathrm{~kg} \cdot \mathrm{m}^{-2}$ per allele, whereas the increase in BMI was smaller and no longer significant among active individuals $\left(0.16 \mathrm{~kg} \cdot \mathrm{m}^{-2}\right)$. However, whether providing personalized information on FTO genotype would lead to beneficial behavior changes (e.g. increase in PA, weight loss) was unknown. Consequently, we studied if disclosing FTO risk had an impact on changes in PA and obesity-related markers following a 6 months' intervention, in Chapters 5 and 6, respectively. Knowledge of FTO genotype had no impact on PA change in either risk or non-risk carriers encouraged to increase their PA (Chapter 5). Although greater reductions in weight (-1.29 vs. $-2.27 \mathrm{~kg})$, BMl $\left(-0.45 \mathrm{vs} .-0.91 \mathrm{~kg} \cdot \mathrm{m}^{-2}\right)$ and WC $(-2.21$ vs. $-4.44 \mathrm{~cm})$ were observed at month 6 for FTO risk carriers compared with non-carriers in Level 3, who received gene-based advice, surprisingly, similar differences were found for risk vs. non-risk carriers in the other groups who were unaware of their genotype; hence there was no effect of disclosure of FTO genotype on changes in obesity-related markers in our intervention (Chapter 6). Finally, in Chapter 7, the findings of this thesis are put into context. We discuss whether self-reports ought to be abandoned, argue in favor of using accelerometers for PA surveillance, address the issue of compliance with accelerometer wear, provide an overview of the literature on the effectiveness of tailored eHealth interventions on weight and PA, and that of gene-based advice, and encourage cost-effectiveness analyses. We conclude that, to date, tailored eHealth studies have not been effective in improving PA compared with a non-tailored approach. Results for weight loss are more promising but effect sizes remain small. Furthermore, current evidence does not support using genotypic information to personalize interventions. Lastly, we give some future perspectives and place our hopes in choice architecture supported by responsive governments, rather than in precision medicine. 


\section{French Summary - Résumé}

La plupart des décès dans le monde-38 millions en 2012-sont dus aux maladies non transmissibles (MNT), telles que les maladies cardiovasculaires, les cancers, les maladies respiratoires chroniques et le diabète. Elles ont en commun quatre facteurs de risque : le tabagisme, l'usage nocif de l'alcool, la mauvaise alimentation et la sédentarité. Ainsi, changer notre mode de vie, par exemple manger moins et mieux, bouger plus, etc., peut grandement réduire le risque de MNT. Induire ces changements à l'échelle de la population est un défi énorme, compte tenu de l'environnement obésogène actuel. La santé publique a essayé de relever ce défi à travers des campagnes de communication génériques visant à faire évoluer des populations entières vers des modes de vie plus sains. Malheureusement, cette approche « taille unique " n'a pas rencontré beaucoup de succès. Par exemple, alors que les recommandations sur l'activité physique sont bien connues, la prévalence mondiale de la sédentarité reste beaucoup trop élevée. Certains ont avancé que les programmes d'intervention devraient être adaptés aux besoins et souhaits de l'individu, afin que chacun se rende compte que des changements de comportement sont nécessaires et pertinents-pour lui ou elle en tant qu'individu. La communication personnalisée vise un individu spécifique en se basant sur les caractéristiques uniques de cette personne. Elle est liée à un paramètre d'intérêt et provient d'une évaluation individuelle. En général, si le niveau d'évaluation augmente, ajoutant à des données anthropométriques (ex: masse corporelle) des données phénotypiques (ex: cholestérol dans le sang, activité physique), et puis même, plus récemment, des données génotypiques (ex : une mutation dans le gène 1 du cancer du sein $B R C A 1$, la présence de l'allèle à risque au niveau du gène associé à l'obésité et la masse grasse FTO), alors le degré d'individualisation du compte-rendu fourni sera lui aussi plus élevé. Personnaliser les messages liés à la santé peut être potentiellement intéressant, à condition que cela se fasse à grande échelle tout en restant à faible coût, et que cela soit plus efficace qu'une approche générique pour changer les comportements. Bien que le fait de divulguer à quelqu'un des informations sur son patrimoine génétique ne semble pas produire d'effets défavorables, des essais randomisés contrôlés supplémentaires sont nécessaires afin d'établir si les interventions personnalisées à partir de données génétiques sont utiles et conduisent à des changements du comportement plus importants que les interventions qui n'utilisent pas ce genre de données. En particulier, on ne sait pas actuellement si fournir les résultats de certains tests ADN peut conduire à une augmentation de l'activité physique et/ou aider un individu à perdre du poids ou maintenir une perte de poids. 
Au cœur d'un projet de grande envergure sur la nutrition personnalisée, financé par l'union européenne, l'étude Food4Me était un essai randomisé contrôlé de 6 mois, reflétant un service personnalisé sur internet. Menée dans sept pays européens (l'Allemagne, la Grèce, l'Illande, les Pays-Bas, la Pologne, l'Espagne, et le Royaume Uni), cette étude avait pour but de comparer les effets de trois niveaux de personnalisation sur un certain nombre de paramètres liés à la santé, par rapport à des recommandations standard (génériques) :

- Niveau 0 (groupe témoin) : recommandations sur l'alimentation et l'activité physique, non personnalisées, basées sur les recommandations (génériques) disponibles en Europe.

- Niveau 1: recommandations sur l'alimentation et l'activité physique, personnalisées seulement à partir de données individuelles sur le régime alimentaire et l'activité physique.

- Niveau 2: recommandations sur l'alimentation et l'activité physique, personnalisées à la fois à partir de données individuelles sur le régime alimentaire et l'activité physique et de données sur le phénotype.

- Niveau 3: recommandations sur l'alimentation et l'activité physique, personnalisées à la fois à partir de données individuelles sur le régime alimentaire et l'activité physique, de données sur le phénotype, et de données sur le génotype.

Dans le cadre du projet Food4Me, l'objectif de cette thèse était de déterminer si une intervention personnalisée, via internet, serait plus efficace que des recommandations standard (non personnalisées) pour améliorer le niveau d'activité physique ainsi que certains marqueurs liés à l'obésité.

Cette thèse commence par décrire le niveau d'activité physique de 1287 adultes (539 hommes et 748 femmes) provenant de sept pays européens, mesuré simultanément, avec le même protocole, et de manière objective grâce à des accéléromètres (Chapitre 2). Les niveaux d'activité physique atteints sont comparés à ceux recommandés à l'heure actuelle par l'Organisation Mondiale de la Santé. Globalement, $58 \%$ des hommes et $37 \%$ des femmes atteignaient les 150 minutes d'activité physique d'intensité modérée à soutenue recommandées par semaine. II y avait des différences significatives entre les pays, mais seulement chez les femmes. Les participantes grecques et polonaises, en particulier, accumulaient moins d'activité physique d'intensité soutenue, et seulement $26 \%$ d'entre elles atteignaient les recommandations, contre $49 \%$ pour les participantes irlandaises. Bien qu'une part plus large de nos participants atteignait les recommandations en comparaison avec d'autres études, américaines ou européenne, une amélioration du niveau d'activité physique était 
souhaitable pour tous les pays impliqués dans l'étude Food4Me. Après que les participants reçurent soit des recommandations standard, non personnalisées, sur la nutrition et la santé (Niveau 0), soit des conseils personnalisés (Niveaux 1-3), ceux-ci furent suivis pendant 6 mois. Entre autres, le poids fut mesuré et rapporté par les individus eux-mêmes, tandis que l'activité physique fut mesurée grâce des instruments validés-accéléromètre TracmorD et questionnaire BAECKE-à 3 et 6 mois. Les participants étaient priés de porter l'appareil tous les jours pendant 6 mois, ce qui fut difficile. Alors que 1270 participants ( $86 \%$ des 1480 personnes commençant réellement l'intervention) avaient complété les 6 mois d'intervention, seulement 730 d'entre eux $(49 \%)$ avaient suffisamment de données provenant de l'accéléromètre à la fois à $t=0$ et à $\mathrm{t}=6$ mois (1233 avaient des données provenant du questionnaire). Il fut conseillé à environ trois quarts des participants d'augmenter leur activité physique. À la fin de l'intervention, l'activité physique, aussi bien celle rapportée par les participants que celle mesurée objectivement, avait augmenté légèrement mais de manière significative. Pour l'activité physique totale et l'activité pendant le temps libre (hormis sport), rapportée par questionnaire, une augmentation plus importante fut observée dans les groupes personnalisés (Niveaux 1-3) en comparaison avec le groupe témoin (Niveau 0 ), et l'augmentation était de plus en plus forte à mesure que le degré de personnalisation était important (Niveaux 2-3 vs. Niveau 1). Cependant, il n'y eut aucune différence significative entre groupes personnalisés et témoin pour l'activité physique mesurée par accéléromètre, et ajouter des informations phénotypiques ou génotypiques au compte-rendu personnalisé n'eut aucun effet après 3 ou 6 mois (Chapitre 3). Le gène est celui qui, jusqu'à présent, a fourni le plus d'éléments en faveur d'une susceptibilité génétique à l'obésité. Bien que des individus prédisposés génétiquement puissent être plus susceptibles à l'obésité dans un environnement obésogène, avec notamment un risque de surconsommation plus élevé, comme le montrent des études sur des jumeaux, peu de preuves sont disponibles concernant des interactions potentielles entre génotype et mode de vie pour ce qui est de l'obésité. II est également important de noter que dans la plupart des études, l'activité physique est rapportée par questionnaire, et de ce fait, la véritable force de l'interaction entre FTO et activité physique a pu être atténuée par les erreurs liées aux mesures. Dans peu d'études seulement, l'activité physique a été mesurée de manière objective. De ce fait, dans le Chapitre 4, nous avons examiné si l'effet du polymorphisme rs9939609 (situé dans le gène FTO) sur des marqueurs liés à l'obésité était modifié par l'activité physique, lorsque celle-ci est mesurée par accélérométrie. Le génotype risque de FTO était associé avec une masse corporelle plus élevée ( $\beta$ : 1,09 $\mathrm{kg}$ par allèle risque), un IMC plus élevé $\left(\beta: 0,54 \mathrm{~kg} \cdot \mathrm{m}^{-2}\right)$ et un tour de taille plus élevé $(\beta: 1,07 \mathrm{~cm})$. L'activité physique, elle, atténuait l'effet de FTO sur l'IMC et le tour de taille. Par exemple, parmi 
les individus inactifs, FTO augmentait significativement l'IMC de $1,06 \mathrm{~kg} \cdot \mathrm{m}^{-2}$ par allèle risque, alors que l'augmentation de l'IMC n'était que de $0,16 \mathrm{~kg} \cdot \mathrm{m}^{-2}$ pour les individus actifs, ce qui n'était plus statistiquement significatif. En revanche, on ignorait si fournir des informations personnalisées à propos du génotype FTO entrainerait des changements bénéfiques du comportement (par ex: augmentation de l'activité physique ou perte de poids). Par conséquent, nous avons étudié dans les Chapitres 5 et 6 si dévoiler le risque pour FTO avait un impact sur les changements d'activité physique et de marqueurs liés à l'obésité, respectivement. La connaissance du risque pour FTO n'eut aucun impact sur les changements d'activité physique, chez les porteurs de l'allèle risque ou les homozygotes porteurs de l'autre allèle, encouragés à augmenter leur niveau d'activité physique au début de l'étude (Chapitre 5). Pour le Niveau 3, c.-à-d. le groupe ayant reçu des recommandations incluant des informations génétiques, des réductions plus importantes en terme de poids $(-1.29$ vs. $-2.27 \mathrm{~kg})$, d'IMC $\left(-0.45\right.$ vs. $\left.-0.91 \mathrm{~kg} \cdot \mathrm{m}^{-2}\right)$ et de tour de taille $(-2.21 \mathrm{vs} .-4.44 \mathrm{~cm})$ furent observées après 6 mois pour les individus à risque pour FTO, que pour les personnes n'étant pas à risque. Étonnamment, des résultats similaires furent observés dans les autres groupes, pour qui le patrimoine génétique était pourtant inconnu; ainsi, révéler le génotype FTO n'eut pas d'effet sur les changements de marqueurs liés à l'obésité dans notre intervention (Chapitre 6). Enfin, au Chapitre 7, les résultats ont été mis en contexte. Nous nous sommes demandés si les questionnaires devraient être abandonnés. Nous nous sommes également exprimés en faveur de l'utilisation d'accéléromètres pour la surveillance de l'activité physique et avons adressé certaines difficultés liées au port d'accéléromètres. Ensuite, nous avons fait un bilan sur l'efficacité des interventions internet personnalisées qui visent poids et activité physique, et sur l'efficacité des recommandations qui incluent des données génétiques, et avons encouragé les analyses coûts-bénéfices. Nous avons conclu que, jusqu'à présent, les études internet personnalisées ne semblent pas être plus efficaces pour améliorer le niveau d'activité physique qu'une approche non-personnalisée. Les résultats pour la perte de poids semblent, eux, plus prometteurs, mais les effets restent faibles. De plus, les données actuelles ne semblent pas être en faveur d'une utilisation de données génotypiques pour personnaliser les interventions. Pour terminer, nous avons donné quelques perspectives d'avenir. Nous sommes plus optimistes vis-à-vis de l'architecture du choix, soutenue par des gouvernements réactifs, que vis-à-vis de la médecine de précision. 


\section{Dutch Summary - Samenvatting}

De meeste sterfgevallen wereldwijd-38 miljoen in 2012-zijn te wijten aan nietoverdraagbare ziekten (NOZ), zoals hart- en vaatziekten, kanker, chronische respiratoire ziekten en diabetes. Ze delen vier gemeenschappelijke risicofactoren: het gebruik van tabak, het schadelijke gebruik van alcohol, ongezonde voeding en te weinig lichamelijke activiteit. Veranderingen in leefstijl, bijv. minder en beter eten, actiever zijn, enz., kunnen het NOZ risico dus sterk verminderen. Zulke gedragsveranderingen in de bevolking mogelijk maken is een enorme uitdaging, gezien de huidige obesogene omgeving. Vanuit de gezondheidsvoorlichting is geprobeerd om deze uitdaging aan te gaan, met behulp van algemene communicatie middelen, om te proberen hele bevolkingsgroepen in de richting van een gezondere leefstijl te bewegen. Helaas, is deze 'one size fits all' benadering niet erg succesvol gebleken. Hoewel de kennis over richtlijnen van lichamelijke activiteit bij het publiek algemeen bekend is, is de wereldwijde prevalentie van onvoldoende lichamelijke activiteit nog veel te hoog. $\mathrm{Er}$ is een groeiend besef dat interventieprogramma's mogelijk moeten worden afgestemd op de behoeften van het individu, zodat men zich realiseert dat gedragsveranderingen voor hen nodig en relevant zijn. Op maat gemaakte communicatie is bedoeld om het individu te bereiken op basis van kenmerken die uniek zijn voor dat individu. Het is gekoppeld aan individuele metingen en resultaten van het individu. Over het algemeen neemt de mate van individualisatie van de feedback toe naarmate de hoeveelheid verzamelde gegevens toeneemt: antropometrische gegevens (bijv. lichaamsgewicht), fenotypische gegevens (bijv. cholesterol, lichamelijke activiteit), en meer recent zelfs genotypische gegevens (bijv. een mutatie in het borstkanker gen, BRCA1, of het dragen van het risico allel in het FTO gen wat geassocieerd wordt met een verhoogd risico op obesitas.. Op maat gemaakte gezondheidsvoorlichting kan veelbelovend zijn, mits deze met lage kosten aan een groot deel van de bevolking geleverd kan worden en mits deze effectiever is dan de een "one size fits all" benadering. Hoewel, in het algemeen, het geven van individuele genetische informatie geen negatieve effecten lijkt te hebben, zijn meer gerandomiseerde gecontroleerde studies nodig om vast te stellen of gepersonaliseerde voorlichting met genetische informatie nuttiger is en grotere gedragsverandering kan bevorderen dan andere gepersonaliseerde interventies (zonder genetica). Er ontbreken voornamelijk resultaten of het leveren van DNAtestresultaten tot een toename van lichamelijke activiteit leidt en / of dat iemand kan helpen om af te vallen of het gewichtsverlies te behouden.

De Food4Me 'Proof of Principle' Studie, als onderdeel van een groter EU-project over gepersonaliseerde voeding, was een gerandomiseerde gecontroleerde interventie van 6 maanden met 4 groepen. Deze studie was ontworpen om op een gepersonaliseerde 
internet service te lijken. De studie is uitgevoerd in zeven Europese landen (Duitsland, Griekenland, lerland, Nederland, Polen, Spanje en het Verenigd Koninkrijk) en had als doel om de effecten van drie niveaus met een op maat gemaakt advies op gezondheidgerelateerde uitkomsten te vergelijken met standaard advies voor de bevolking:

- Niveau 0 ('controlegroep'): niet-gepersonaliseerd (algemene) voedings en lichamelijke activiteit advies op basis van (Europese) richtlijnen voor de bevolking.

- Niveau 1: gepersonaliseerd voedings en lichamelijke activiteit advies op basis van individuele voedselinname en lichamelijke activiteit.

- Niveau 2: gepersonaliseerd voedings en lichamelijke activiteit advies op basis van individuele voedselinname, lichamelijke activiteit, en fenotypische gegevens zoals mate van overgewicht.

- Niveau 3: gepersonaliseerd voedings en lichamelijke activiteit advies op basis van individuele voedselinname, lichamelijke activiteit, fenotypische gegevens en genotypische gegevens.

Het doel van dit proefschrift was te bepalen of een gepersonaliseerde, via het internet geleverde voorlichting, effectiever zou zijn om lichamelijke activiteit en obesitas gerelateerde kenmerken te verbeteren, dan het verstrekken van online gestandaardiseerde (niet-gepersonaliseerde) voorlichting via standard richtlijnen voor de gehele bevolking.

Dit proefschrift begint met een beschrijving van de lichamelijke activiteit van 1287 inwoners (539 mannen en 748 vrouwen) in zeven Europese landen, gemeten met accelerometers volgens een gestandariseerd protocol (Hoofdstuk 2). De niveaus van lichamelijke activiteit werden ook vergeleken met de huidige richtlijnen van de World Health Organization. Over het algemeen bereikten 58\% van de mannen en $37 \%$ van de vrouwen de aanbevolen 150 min. $\mathrm{wk}^{-1}$ van matige of zware lichamelijke activiteit. Significante verschillen tussen landen werden gevonden, maar alleen voor vrouwen. Met name Griekse en Poolse vrouwen hadden dagelijks minder zwaar lichamelijke activiteit en slechts $26 \%$ van hen voldeden aan de aanbevelingen voor lichamelijke activiteit in vergelijking met bijvoorbeeld $49 \%$ van de lerse vrouwen. Hoewel een groter deel van ons cohort aan de richtlijnen voor lichamelijke activiteit voldeed in vergelijking met andere Amerikaanse en Europese studies, was er voldoende ruimte voor verbetering in alle landen van de Food4Me Studie. De deelnemers werden gedurende 6 maanden gevolgd nadat ze ofwel niet-gepersonaliseerde gezonde voeding en leefstijl richtlijnen (Niveau 0), of gepersonaliseerd advies (Niveaus 1-3) kregen. Lichaamsgewicht werd zelf gemeten en gerapporteerd, terwijl lichamelijke activiteit met gevalideerde instrumenten-TracmorD accelerometer en Baecke vragenlijst-werd 
bepaald, na 3 en 6 maanden. De deelnemers werden gevraagd om de accelerometer elke dag gedurende 6 maanden te dragen. Dit bleek moeilijk te zijn. Slechts 730 deelnemers (49\% van de 1480 die met het onderzoek zijn begonnen) hadden voldoende accelerometer gegevens voor zowel baseline en 6 maanden, terwijl 1270 deelnemers $(86 \%)$ de studie hebben afgerond (1233 deelnemers hadden zelfgerapporteerde gegevens). Ongeveer driekwart van de deelnemers kreeg het advies om hun lichamelijke activiteit te verhogen. Aan het einde van de interventie zagen we kleine significante verbeteringen in zelf-gerapporteerde en objectief gemeten lichamelijke activiteit. Grotere verbeteringen in zelf-gerapporteerde totale lichamelijke activiteit en lichamelijke activiteit tijdens vrije tijd (exclusief sporten) werden waargenomen in gepersonaliseerde groepen (Niveaus 1-3) in vergelijking met de controlegroep (Niveau 0). De veranderingen waren groter naarmate het advies meer gepersonaliseerd werd (Niveaus 2-3 vs. Niveau 1). Er waren echter geen significante verschillen in resultaten gemeten met de accelerometer tussen gepersonaliseerde en controlegroepen, en geen significant effect van het toevoegen van fenotypische of genotypische informatie aan de op-maat-gemaakt feedback bij maand 3 of 6 (Hoofdstuk 3). Voor het FTO gen is tot op heden de sterkste relatie gevonden met betrekking tot de genetische aanleg voor obesitas. Hoewel individuen met een genetische predispositie meer ontvankelijk zijn voor obesitas in een obesogene omgeving, en een hoger risico hebben op verhoogde consumptie zoals werd aangetoond in studies met tweelingen, is er weinig bewijs van genotype-leefstijl interacties op overgewicht uitkomsten. Belangrijk is dat lichamelijke activiteit zelfgerapporteerd werd in de meeste studies, en dus meetfouten kunnen de werkelijke relatie tussen FTO en lichamelijke activiteit hebben vervaagd. Slechts enkele studies hebben lichamelijke activiteit objectief gemeten; daarom hebben we in Hoofdstuk 4 onderzocht of het effect van het FTO polymorfisme rs9939609 in relatie tot obesitas gerelateerde kenmerken werd gewijzigd door lichamelijke activiteit gemeten met accelerometrie. Het FTO risico genotype werd geassocieerd met een hoger gewicht ( $\beta$ : $1,09 \mathrm{~kg}$ per risico allel), BMI ( $\beta$ : $0,54 \mathrm{~kg} \cdot \mathrm{m}^{-2}$ ) en middelomtrek $(\beta: 1,07 \mathrm{~cm})$. Lichamelijke activiteit verzwakte het effect van FTO op BMI en middelomtrek. Een voorbeeld: bij inactieve deelnemers was er een significante verhoging van BMI van $1,06 \mathrm{~kg} \cdot \mathrm{m}^{-2}$ per FTO risico allel, terwijl de stijging in BMI kleiner en niet meer significant was bij actieve deelnemers $\left(0,16 \mathrm{~kg} \cdot \mathrm{m}^{-2}\right)$. Echter, of het verstrekken van persoonlijke informatie over het FTO genotype tot gunstige gedragsveranderingen (bijv. toename van lichamelijke activiteit of gewichtsverlies) kan leiden, was onbekend. Daarom hebben we onderzocht of de bekendmaking van het FTO risico een impact had op veranderingen in lichamelijke activiteit en obesitas gerelateerde markers na een 6 maanden durende interventie, uiteengezet in Hoofdstukken 5 en $\mathbf{6}$, respectievelijk. De 
kennis van het FTO genotype had geen invloed op verandering in lichamelijke activiteit bij zowel risico- als niet-risicodragers, die als advies hadden gekregen om hun lichamelijke activiteit te verhogen (Hoofdstuk 5). Hoewel grotere verminderingen in gewicht $(-1,29$ vs. $-2,27 \mathrm{~kg})$, BMI (-0,45 vs. -0,91 kg.m-2) en middelomtrek (-2,21 vs. $4,44 \mathrm{~cm}$ ) waargenomen werden na 6 maanden bij FTO risicodragers in vergelijking met niet-risicodragers in Niveau 3 (m.a.w. deelnemers die gen-gebaseerde adviezen hadden gekregen), werden vergelijkbare verschillen gevonden voor risico- versus nietrisicodragers in de andere groepen, voor wie het genotype niet werd verstrekt. Er was dus geen effect van de bekendmaking van het FTO genotype op de veranderingen in de obesitas gerelateerde markers in onze interventie (Hoofdstuk 6). Tenslotte, worden de bevindingen van dit proefschrift in Hoofdstuk 7 in een algemenere context geplaatst. We pleiten ervoor om zelf-rapportages (m.a.w. vragenlijsten op het gebied van voedsel opname en lichamelijke activiteit) niet meer te gebruiken gezien de grote onbetrouwbaarheid van de verkregen resulaten. We bemoedigen het gebruik van objectieve metingen, zoals met accelerometers, voor het monitoren van lichamelijke activiteit, alhoewel we moeilijkheden zien voor het dragen van zulke apparten. Daarnaast geven we een overzicht van de literatuur over de effectiviteit van gepersonaliseerde eHealth interventies gericht op gewicht en lichamelijke activiteit, alsmede op de adviezen die gebaseerd zijn op genetische gegevens. We pleiten ook voor kosteneffectiviteit-analyses. We concluderen dat, tot op heden, gepersonaliseerde eHealth studies niet effectiever zijn om lichamelijke activiteit te verbeteren vergeleken met een niet-gepersonaliseerde aanpak. De resultaten voor gewichtsverlies hebben meer potentie, maar de effecten op gewichtsverandering blijven klein. Bovendien, wordt het gebruik van genotypische informatie om voorlichting te personaliseren en effectiever te maken niet ondersteund door de huidige literatuur. Tot slot, geven we enkele toekomstperspectieven en stellen onze hoop in architectuurkeuze (de verschillende manieren waarop keuzes voor de consument kunnen worden gepresenteerd, en de impact van die presentatie over besluitvorming), ondersteund door actieve overheden, in plaats van een meer gepersonaliseerde geneeskunde als het gaat om de NOZ's. 
Valorization 


\section{Valorization}

\section{Social Relevance}

According to recent projections, as much as 52 million people will die of noncommunicable diseases, such as cardiovascular diseases, in 2030. Many of these deaths can be prevented by tackling the four risk factors common to noncommunicable diseases: tobacco use, harmful use of alcohol, unhealthy diet, and insufficient physical activity.

Currently, far too many people are not sufficiently physically active worldwide. Surveillance is necessary to detect whether the situation improves or worsens. We have shown that it is feasible to dispatch devices that can measure physical activity objectively, across several countries, and discussed why this should be done instead of continuing to rely on biased self-reports.

Obesity is also still a major global concern. Thus, finding long-lasting strategies to help individuals manage their weight and be sufficiently physically active is a huge challenge. In the Food4Me project, we set out to test whether personalized advice was more effective in changing unhealthy behaviors, such as unhealthy diet and low physical activity, than non-personalized health guidelines. We also wondered whether the intervention could be delivered via the Internet.

These questions are relevant for society for several reasons. Almost any adult with an interest in personalized nutrition was free to volunteer for the Food4Me study (with the exception of persons with very specific needs because of a medical condition or food allergy, who were excluded for safety reasons). Great interest was raised, more than 5,500 people starting the screening procedure and even more visiting the Food4Me website. Thus, the interest in personalized nutrition goes well beyond the scientific community.

Using the Internet is also very relevant because it is probably the only feasible way to deliver a tailored intervention at such a scale at reasonable costs. Nowadays, $78.5 \%$ of the population in the European Union uses the Internet, and it is the place where many people go to find information about health or help.

At the same time, researchers, but also private companies, have sought to use the rapid advances in genotyping of the last two decades to tailor health-related advice to the individual. However, this has raised a number of issues: whether we understand gene-lifestyle interactions well enough to derive recommendations based on genetic 
make-up, whether gene-based advice is more effective in changing unhealthy behaviors than non-gene-based advice, whether collecting DNA information and providing such feedback is ethical, and so forth. The discussion of our findings contributes to answering these questions.

Internet proved a good medium for the delivery of our intervention and most individuals who started the trial completed it. However, we also found that individualized feedback was not always enough to motivate people to engage in healthier behaviors. Although people were interested in monitoring their physical activity themselves, detailed feedback in real time will be necessary for more compliance. In terms of effectiveness of gene-based advice, large, good-quality randomized controlled trials were needed to inform the scientific community, as well as companies selling genetic tests. Our findings argue against using genetic test results to tailor advice on physical activity and body weight. In addition, as discussed in this thesis, we are in favor of tampering the enthusiasm for precision medicine and would encourage measures that more directly serve the prevention of noncommunicable diseases, i.e. can be implemented now. Personalized advice can be an effective strategy to help individuals to make healthy changes, and Internet can be an appropriate platform for support, if additional features (e.g. online coaches) are put into place next to an interactive website and online tailored feedback. Tailoring the advice is necessary but gene-based advice does not seem justified.

\section{Target groups}

Low physical activity, as well as overweight and obesity are major risk factors for noncommunicable diseases, such as type 2 diabetes, cardiovascular diseases, and some cancers. Our results can help raise awareness that it is important to monitor oneself and consciously look for ways to make sustainable changes. Hence, this thesis can be of interest to any individuals at risk. It may also interest those curious about having their DNA sequenced and the accuracy of health advice based on such genetic tests. It will hopefully also interest the private companies that are promoting those tests, and make them reflect on their practices and how these can be improved.

We have identified a number of gaps in the literature. Thus, the discussions in this thesis may inform researchers on future steps, as well as engineers who ought to develop better ways to measure dietary intake and physical activity energy expenditure. We have concluded that we believe in choice architecture to promote healthier behaviors but that regulation is necessary, especially to limit unhealthy nudges. In that respect, our results are also addressed to governments. They can make a tremendous difference, if they respond readily to maintain that people are responsible for their own 
health, while also taking public health actions that change default choices to make it easier for people to stay healthy.

\section{Activities}

All research described in this thesis stems from a close collaboration between eight European universities or research centers and also involved industrial partners. This successful collaboration is a good example of interdisciplinary research and how it can lead to a large-scale pan-European intervention. Research can only have an impact if it is shared within the scientific community and without, in order to kindle relevant future research, raise awareness and support from the society, and push policy makers to get involved. To this end, the results described in this thesis have been communicated in multiple ways. Results have been written in original research articles, which have been published or submitted in high-impact peer-reviewed journals in the field of medicine, obesity, or mobile health. These articles are or will be open access, available online to anyone (scientist or not) with an interest in the topic. Furthermore, a white paper has been written (which includes part of the findings from this thesis) for the attention of the European Commission. Results have also been presented at several local, national and international conferences. In addition, regular updates are posted on the Food4Me website.

\section{Innovation}

The work described in this thesis is part of the Food4Me Study, which is the largest randomized controlled trial on personalized nutrition and lifestyle to date. It answers an identified need to know more about the effect of genetic-based advice on nutrition and lifestyle (physical activity, body weight). Personalized nutrition, as well as precision medicine, is in the spot light and it is necessary to carefully assess whether they represent an immediate future, or one farther away. Our study was innovative; it was designed to emulate an Internet-based personalized service, and therefore all contact between researchers and subjects was via the Internet or the postal services. This study was the first to use gene-based advice to try to increase physical activity levels. To our knowledge, we were also the first to monitor physical activity with accelerometers for 6 months, using a system, which allowed us to see participants' physical activity levels directly upon data upload on their computer.

The Food4Me Study was part of a larger EU project, which aimed to explore all elements of personalized nutrition using a multi-disciplinary approach. Food4Me recognized that without a detailed understanding of consumer attitudes to personalized 
nutrition, any foresight in this field would fall well short of ideal. Thus a significant part of the work-program was devoted to probing the opinions of EU consumers. Allied to an understanding of consumer attitudes to personalized nutrition is the need to understand the viability of any personalized nutrition enterprise whether driven by either social or private entrepreneurship. Across a series of workshops with stakeholders from across a wide range of interested sectors, a number of scenarios were developed which will help shape our thinking of the viable alternatives for the creation of a sustainable personalized nutrition offering. This work-package on business models drew on the findings of the consumer research group in developing its final set of scenarios. Personalized nutrition is largely driven by technology, with regards to what can be measured to best characterize health status and nutritional needs. The efficiency of assessment and delivery of personalized nutrition advice is also technology-dependent. For this reason, exploring the technologies needed in personalized nutrition was a central focus of the project, with a specific work-package dedicated to the theme. The researchers involved set up a Global Network and online knowledge base to establish the most relevant genes in relation to dietary interactions for health outcomes. In addition, the work-package has developed algorithms for the delivery of personalized nutrition advice and has pioneered novel methods for assessing health parameters using very small blood-spot samples. In the USA, personalized nutrition, specifically personalized nutrition based on genomic data, has come under the scrutiny of regulatory authorities from time to time. In addition, fears are frequently expressed at personalized genomic data becoming available to third parties such as health insurance companies. Thus Food4Me established an ethics and legal work-package devoted entirely to this topic. Several ethical issues have been raised and explored via workshops and scientific publications.

\section{Schedule and implementation}

In this thesis, we have shown that disclosure of genetic information was not effective in motivating people to increase their physical activity or reduce their body weight. The research team currently investigates whether this absence of effect is also true for other lifestyle aspects, such as changes in diet. The research team is also looking at whether the disclosure of a low-risk genetic test result leads to poorer outcome changes in terms of dietary components. It was not very clear for physical activity and body weight changes.

More research is also needed to identify the features that are necessary to the success of a tailored eHealth intervention. A number of components were judge essential (e.g. online coaches), but other studies need to confirm this. Assessing physical activity 
levels using accelerometers was successful in our pan-European study, and we hope it will encourage any new large-scale trial assessing physical activity to do the same instead of only relying on self-reports.

Another aspect, in which the research team is currently not involved but hopefully will in the future, is the development of better, more objective, methods to measure dietary intake. Dietary intake data are mostly collected using self-report instruments, such as food frequency questionnaires, food records (or diaries) and 24-hour dietary recalls but there is a large body of evidence showing that self-reported dietary intake is poorly related to actual energy or nutrient consumption. Alternatives to self-report instruments for dietary assessment include nutritional biomarkers, but they do not reflect total energy intake and are cumbersome and expensive. The intake-balance method involves measuring changes in energy expenditure as well as changes in body energy stores, but is also demanding and costly. Other technologies are being developed for self-tracking dietary intake, including devices that count bites and measure chewing and swallowing but they give no information on which foods are consumed. Probably the most promising are food recognition systems. They are still in their infancy, but are promising and more researchers ought to get involved in that area.

Finally we believe in choice architecture, i.e. the careful design of the environments in which people make choices, and that a top priority should be to study how this can promote healthier behaviors. This cannot happen without close collaboration with responsive governments because regulation is necessary, especially to limit unhealthy nudges. A government that responds readily can maintain that people are responsible for their own health while also taking appropriate public health actions to make healthy choices, the default choices. 
Acknowledgements 


\section{Acknowledgements}

Well, this book is almost finished and I reckon it is past time to thank some people, lots of people actually. Although... given that this section will undoubtedly be read the most, I wonder if I should write some of my conclusions in here... Just kidding, you can safely read on.

I want to start with the person that has been most influential in the last 4,5 years, the great mentor to whom I owe so much... Beste Wim, above all, thank you for all the unique opportunities you have given me. I look around and I believe I could not have had a better supervisor. The last 4,5 years have not simply been about becoming a good scientist and working towards obtaining a $\mathrm{PhD}$, far from it. Self-development was at the core of everything, on a professional level of course, but also on a personal one. You have inspired me in many ways, given me the power to develop into the person I am today, and for this I will forever be in your debt. Coming to Maastricht to do my PhD was a tough decision. As you will remember I even refused the position at first! But you convinced me to change my mind and I don't regret it. On my first official day at work, you sent me to Ulster in Northern Ireland, where I learnt I should guide focus groups in Dutch only a few months later, although I barely spoke any Dutch! I doubt many PhD students can claim having such an exciting start. Anyway, everything worked out in the end, just as it always has in the past years. We had our ups and downs, with the doubly labeled water from Diogenes and the FeedEX study, but you were always of good counsel and I learnt from these experiences. You had warned me I would need to be able to work on my own, that you would not be in the office every week. And yet, I cannot recall more than a couple of times when you did not respond to my queries within the hour by email! Even my draft manuscripts would always be reviewed within 3 days tops! I think we worked well together, because we have the same drive to get things done. But I learnt so much from you... I am a perfectionist and tended to get lost in details. You taught me to focus on the important issues, make hard decisions, and accept those (Not look back). I was able to go abroad, to meetings, conferences, and symposia, even without poster or talk, because you saw it as a chance for me to keep learning. You gave me the possibility to follow the ENLP seminar and you know how grateful I am for that... and towards the end, you were genuinely concerned about my future, asking what I wanted to do next, if I had started sending out applications; you even coached me for my interviews for ILSI...

Wim, for all of this, thank you! Officially I am your last PhD student; it has been an honor, privilege and pleasure! Wim, take good care of yourself, I will see you around. 
I would also like to thank my co-supervisor. Dear John, I enjoyed working with you very much. Thank you for your reviewing my work ever so carefully (and the precious advice to "keep it lean and clean!"), and for the stimulating talks. Your edits were always spot on, your comments helpful and sharp! I was lucky to have such a talented and experienced scientist on my side. I wish you many more years of success!

To the members of my assessment committee: prof. Marleen van Baak, prof. Ellen Blaak, prof. Stef Kremers, prof Willem van Mechelen, and prof. Jean-Michel Oppert, thank you very much for taking the time to carefully review my dissertation.

I will never forget my $\mathrm{PhD}$ time within the Human Biology department and I want to thank the whole staff for the great time I had among you. Some of you I of course know more than others, but I want to thank you all for making or having made HB such a nice department: Alex, Annemieke, Anouk, Birgitta, Boris, Charlotte B., Charlotte, Claudia, Cleo, Daisy, Dennis, Desiree, Dirk, Dorien P., Dorien R., Dorit, Edwin, Emanuel, Emmani, Erik, Eva, Freek, Gabby, Gijs, Giulio, Guy, Hannah, Herman, Jakob, Jan, Jasper, Johan J., Johan R., Jonathan, Jos, Laura, Loek, Lotte, Maarten, Margriet, Marije, Marjet, Mark, Marlies, Mathijs, Maurice, Max, Nadia, Paul, Peter, Roel, Rudi, Sabine, Sophie, Stefan, Tanja, Yolanda... Bedankt voor de gezelligheid en al de hulp de afgelopen jaren!

Désirée! To you in particular a gazillion thanks! I am not quite sure how I will manage without you now... In those last 4,5 years, you have helped me more times than I can count. Supportive, listening and caring, always positive and efficient, kind of a Wonder Woman really, thanks for always being there for me!

Yolanda, Claudia and Cleo, whom I have also bothered so many times, thanks for being so kind and helpful.

Loek, thanks for fixing any computer issue so quickly, and for sharing your expertise of doubly labeled water measurements with me (and for not complaining when l'd ask you to prepare a DLW bottle for me at the very last minute!!). Marc, I'm grateful for your help with the respiration chambers. Paul, you too were a big help there! Thanks for improving the indirect calorimetry interface so that I could get the data in real time, and for picking up your phone (coming to the lab even!), even at 11 PM when I was afraid something was wrong with the calibration gas or the freezing toilets! 
Emanuel, you were one of my first Maastricht mate, even before VLAG week! Best of luck my friend, keep up the excellent work; you are well on your way to become Prof Canfora ;-)!

Dorien R., thanks for your kindness, the energy you devote to social activities, and taking lots of pictures (you're a memory maker!), I wish you all the best in the US with Jasper!

Birgitta (Bertine!!!), you are a great person with whom to share an office! We have been together at an important time for me in my PhD: the last phase. Thanks for listening to me when I really needed to talk to evacuate stress or frustration, and also when I rambled on about finding work, interviews, finding an apartment, etc. Thanks also for not complaining (too much) about my leaving the window open all night in winter. I know you will be happy to be rid of me to finally feel warm in your office ;-). Best of luck with your PhD, you will manage, I have no doubt!

Jan ("chess mate!"), Johan and Boris, and Stefan, thanks for being my chess buddies! It was great to have a game (or several...) to relax. Keep practicing and let me know when you've gotten better (just kidding... or am I? :-P). And Boris, I'll remember our time as office roommates with a smile on my face. I have to admit it was not the most productive time for me, but that was fun (especially talking to each other using google translate;-)).

Peter, Guy, Dirk, Roel and Max, thanks for the poker evenings! I know you've enjoyed taking my money, but I will get better one day, yes I will!

Peter (Pierre Joris pour les amis!), I hope you are having a wonderful time in the US. You don't know it yet but I moved to Belgium so we won't live so far away from each other when you come back. I'm looking forward to seeing you again soon. You always made me laugh when you spoke French or called me "caveman"!

Jokes aside, you are one hell of a guy, Guy. Next to the good fun we've had playing poker or drinking beer together, you've also helped me a lot during my PhD, answering all my questions about accelerometry, energy expenditure or body composition measurements and the set up of the overfeeding and exercise study. And thank you for accepting to be in the corona on the D-day. If Flemish people are like you, and like Peter, Johan J. and Rudi, I have nothing to worry about!

Mark, my man! Gonna miss you dude. You're really incredible. Always working so hard, I'm glad you finished your 'boekje' in time and managed to plan this amazing around the world 5-month trip! So deserved! Can't wait to hear all about it! I promise I WILL organize a barbecue when you're back $(:)$. 
Florian, the PBL course was worth it simply because I met you there! My R Master, I would not have been able to complete my analyses without your programming knowledge! Thanks for saving me, you're a great teacher! Apart from science, I very much enjoyed our talks about TV shows, heroic fantasy, board games and other geeky stuff. I'm definitely going to miss our lunch breaks $*$. I wish you lots of happiness with Pam' and your soon-to-be-born little girl!

Charlotte, Marlies, Dirk and Roel! I LOVED watching Game of Thrones with you! Although let me be clear (oooh spoiler alert): Ser Barristan is NOT dead! (What about Jon???). You're awesome! Loved hanging out with you guys (films, dinners, pub quizzes...), it was all a lot of fun and I hope we can keep seeing each other despite the distance (and the fact that winter is coming!).

Alex, I'm glad you made the French PhD student group bigger! You're great to chill with. Good luck tasting all beers at the Gouverneur before your contract ends;-).

Charlotte and Roel, I have mentioned you a couple of times already, but you deserve more! I cannot thank you enough and I am really happy you accepted to be my paranymphs! Charlotte, ever since you arrived in Maastricht, you've brightened my PhD time. We share so many interests! It has been so refreshing to chat about Friends (Eddie: "That's very thoughtful of you. It's very thoughtful."), Star Wars, Game of Thrones, Back to the Future... and be able to joke around with you so much. Gonna miss you Jeanine, but l'm sure there'll be plenty of occasions for us to meet up (and eat tartiflette!). Roel! From the start you took me in, made me feel like I had a mate. You were a colleague and a friend, and not only at work! Thanks to you I met great people (Dirk you're one of them!!), your door was always open to talk about work or make plans to play tennis, squash, have dinner or chill, you name it! Roel, Charlotte, thank you both of you for your friendship. It is very, very precious to me!

Next to the people in Maastricht, I still have some more people to thank:

Carlos, muchas gracias amigo! My favourite co-author ;-). Your knowledge, experience and advice have been essential during my whole PhD. Thank you for supporting me and bearing with me even when I sent you 10 emails all on the same day (or sometimes even within a single hour...)! Keep up the great work; I wish you a lot of success in Glasgow and a lot of happiness with your expanding family! 
Marianne!!!, Anna, Roz, Hannah, Clare and Clara, Silvia and Santiago, and the whole Food4Me team, it has been amazing to work with you.

Some special thanks also to Graham and John in Leeds, for my wonderful time there, which has been the starting point of my career in Nutrition and Health. I'm glad we have managed to bump into each other at conferences.

Guillaume and Payam, Erik and Marlinda, Marine and Tuan (now so far away!), my friends in Wageningen, thank you for the good memories, the squash games, hikes, dinners and parties! Big thanks also to Wenya and Nicole for the great NZ reunions. Pascalle and I always have the best times with all of you!

Un grand merci aussi à mes amis en France. À chaque fois que je rentre, c'est presque comme si je ne vous avais jamais quitté (presque...). Merci en particulier à Thibaud, Dam', Aymeric, Max, Arnaud, M-rik, Clémich', Titi et Fanny, et surtout JB et Pierrot, qui sont venus me voir dans cette contrée lointaine :) Merci les gars!

Ook heel erg bedankt aan de hele "schoon" familie: Elisabeth en Marcel, Alexandra en Martien, Vincent, Anna-Maria, Peter en Sebastiaan, en Bonma! voor jullie interesse in mijn werk, jullie ondersteuning en dat jullie mij sinds dag 1 een deel van de familie hebben gemaakt!

Et bien sûr, un merci infini à toute ma famille!

Maman, Papa, Solange et Ben. Merci pour votre soutien tout au long de mon doctorat, pour votre compréhension, votre amour, que jamais vous ne me reprochiez d'avoir choisi les Pays-Bas (et maintenant la Belgique), que vous soyez venus me voir aussi souvent et que je puisse toujours rentrer à la maison. Merci d'être toujours présents dans les moments importants.

And finally, the most important of all: Pascalle, thank you for understanding me, for always supporting me, for never doubting me, for loving me; you are my hero! I look forward to spending the rest of my life with you $:$ !!! 
About the author 


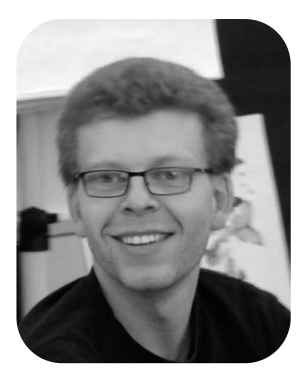

\section{About the Author}

Cyril Marsaux was born in Nantes, France, on the $6^{\text {th }}$ of May 1987. He completed secondary school at Lycée Saint Joseph du Loquidy in Nantes in 2005. He stayed in Nantes to follow a 2-year post-secondary subject-specific preparation program for selective entry to French 'Grandes Écoles' (graduate-level engineering schools) at Lycée Clémenceau, with intensive coursework in biology, math, physics, and chemistry. In September 2007, he started at AgroParisTech, France's top post-graduate engineering school in Agricultural and Life Sciences, in Paris. Between April and July 2009, he took courses at the Technische Universität München, in Munich, Germany. After this Erasmus program, Cyril completed a 6-month internship on eating behavior, studying 'liking' and 'wanting' at the Human Appetite Research Unit of the Institute of Psychological Sciences, University of Leeds, UK, under supervision of Professor John Blundell and Dr. Graham Finlayson. It is over there that he discovered his passion for Human clinical studies (and for squash!). Between February 2010 and August 2010, he worked to optimize emulsion stability of nutritional beverages at Fonterra Research Center in Palmerston North, New Zealand, with Dr. Hasmukh Patel. After that, he did a final 6-month internship at Wageningen University, Netherlands, working on different types of fiber with Dr. Anne Wanders and Dr. Monica Mars. He then went back to AgroParisTech and obtained his Master's degree in Nutrition and Health in 2011. In October 2011, Cyril started as $\mathrm{PhD}$ candidate on the Food4Me project under supervision of Professor Wim Saris, at the department of Human Biology of Maastricht University. Food4Me was a European project on Personalized Nutrition and Lifestyle in seven European countries. During his PhD, he ran the Dutch-arm of the intervention and focused on the effects of providing different levels of personalized advice via the Internet, on physical activity and obesity-related markers. These 4 years also gave him the opportunity to supervise one bachelor and four master students and to take part in various teaching activities. On the $1^{\text {st }}$ of February 2016, Cyril started as scientific project manager at the International Life Sciences Institute (ILSI) Europe in Brussels. 
Publications 


\section{Publications}

\section{Under review}

1. Celis-Morales, C. ${ }^{*}$, K. M. Livingstone ${ }^{\star}$, C. F. Marsaux, A. L. Macready, R.

Fallaize, C. B. O'Donovan, C. Woolhead, H. Forster, M. C. Walsh, S. NavasCarretero, R. San-Cristobal, L. Tsirigoti, C. P. Lambrinou, C. Mavrogianni, G. Moschonis, S. Kolossa, J. Hallmann, M. Godlewska, A. Surwillo, I. Traczyk, C. A. Drevon, J. Bouwman, B. van Ommen, K. Grimaldi, L. D. Parnell, J. N. Matthews, Y. Manios, H. Daniel, J. Alfredo Martinez, J. A. Lovegrove, E. R. Gibney, L. Brennan, W. H. Saris, M. Gibney and J. C. Mathers. "Effect of personalized nutrition on health-related behavior change: outcomes from the food4me randomized controlled trial."

*Joint first authors

\section{Accepted for publication}

1. Marsaux, C. F., C. Celis-Morales, J. Hoonhout, A. Claassen, A. Goris, H. Forster, R. Fallaize, A. L. Macready, S. Navas-Carretero, S. Kolossa, M. C. Walsh, C-P Lambrinou, Y. Manios, M. Godlewska, I. Traczyk, J. A. Lovegrove, J. A. Martinez, H. Daniel, M. Gibney, J. C. Mathers, and W. H. Saris. "Objectively measured physical activity in European adults". PLOS ONE (forthcoming)

2. Celis-Morales, C. ${ }^{*}$, C. F. Marsaux ${ }^{\star}$, K. M. Livingstone, S. Navas-Carretero, R. San-Cristobal, C. B. O'Donovan, H. Forster, C. Woolhead, R. Fallaize, A. L. Macready, S. Kolossa, J. Hallmann, L. Tsirigoti, C-P Lambrinou, G. Moschonis, M. Godlewska, A. Surwillo, K. Grimaldi, J. Bouwman, Y. Manios, I. Traczyk, C.A. Drevon, L. D. Parnell, H. Daniel, E. R. Gibney, L. Brennan, M. C. Walsh, M. Gibney, J. A. Lovegrove, J. A. Martinez, W. H. Saris, and J. C. Mathers.

"Physical activity attenuates the effect of the FTO genotype on obesity traits in European adults: findings from the Food4Me Study". Obesity (forthcoming)

*Joint first authors

\section{Published}

3. Marsaux, C. F. ${ }^{*}$, C. Celis-Morales*, K. M. Livingstone, R. Fallaize, S. Kolossa, J. Hallmann, R. San-Cristobal, S. Navas-Carretero, C. O'Donovan, C. Woolhead, H.Forster, G. Moschonis, C-P Lambrinou, A. Surwillo, M. Godlewska, J. Hoonhout, A. Goris, A. L. Macready, M. C. Walsh, E. R. Gibney, L. Brennan, Y. Manios, I. Traczyk, C. A. Drevon, J. A. Lovegrove, J. A. Martinez, H. Daniel, M. J. Gibney, J. C. Mathers, and W. H. Saris (2016). "Changes in physical activity following a genetic-based Internet-delivered personalized intervention in European adults: findings from the Food4Me randomized controlled trial". J Med Internet Res 18(2):e30

*Joint first authors 
4. Livingstone, K. M., C. Celis-Morales, S. Navas-Carretero, R. San-Cristobal, H. Forster, C. B. O'Donovan, C. Woolhead, C. F. Marsaux, A. L. Macready, R. Fallaize, S. Kolossa, L. Tsirigoti, C. P. Lambrinou, G. Moschonis, M. Godlewska, A. Surwillo, C. A. Drevon, Y. Manios, I. Traczyk, E. R. Gibney, L. Brennan, M. C. Walsh, J. A. Lovegrove, J. A. Martinez, W. H. Saris, H. Daniel, M. Gibney and J. C. Mathers (2016). "Fat mass- and obesity-associated genotype, dietary intakes and anthropometric measures in European adults: the Food4Me study." Br J Nutr 115(3): 440-448.

5. Albani, V., C. Celis-Morales, C. F. Marsaux, H. Forster, C. B. O'Donovan, C. Woolhead, A. L. Macready, R. Fallaize, S. Navas-Carretero, R. San-Cristobal, S. Kolossa, C. Mavrogianni, C. P. Lambrinou, G. Moschonis, M. Godlewska, A. Surwillo, T. E. Gundersen, S. E. Kaland, Y. Manios, I. Traczyk, C. A. Drevon, E. R. Gibney, M. C. Walsh, J. A. Martinez, W. H. Saris, H. Daniel, J. A. Lovegrove, M. J. Gibney, A. J. Adamson, J. C. Mathers and L. Brennan (2015). "Exploring the association of diary product intake with the fatty acids $C_{15: 0}$ and $C_{17: 0}$ measured from dried blood spots in a multi-population cohort: findings from the Food4Me study." Mol Nutr Food Res.

6. Hoeller, U., M. Baur, F. F. Roos, L. Brennan, H. Daniel, R. Fallaize, H. Forster, E. R. Gibney, M. Gibney, M. Godlewska, K. Hartwig, S. Kolossa, C. P. Lambrinou, K. M. Livingstone, J. A. Lovegrove, A. L. Macready, Y. Manios, C. F. Marsaux, J. A. Martinez, C. Celis-Morales, G. Moschonis, S. Navas-Carretero, C. B. O'Donovan, R. San-Cristobal, W. H. Saris, A. Surwillo, I. Traczyk, L. Tsirigoti, M. C. Walsh, C. Woolhead, J. C. Mathers and P. Weber (2015). "Application of dried blood spots to determine vitamin $D$ status in a large nutritional study with unsupervised sampling: the Food4Me project." Br J Nutr: 1-10.

7. Marsaux, C. F., C. Celis-Morales, R. Fallaize, A. L. Macready, S. Kolossa, C. Woolhead, C. B. O'Donovan, H. Forster, S. Navas-Carretero, R. San-Cristobal, C. P. Lambrinou, G. Moschonis, A. Surwillo, M. Godlewska, A. Goris, J. Hoonhout, C. A. Drevon, Y. Manios, I. Traczyk, M. C. Walsh, E. R. Gibney, L. Brennan, J. A. Martinez, J. A. Lovegrove, M. J. Gibney, H. Daniel, J. C. Mathers and W. H. Saris (2015). "Effects of a Web-Based Personalized Intervention on Physical Activity in European Adults: A Randomized Controlled Trial." J Med Internet Res 17(10): e231.

8. Hallmann, J., S. Kolossa, K. Gedrich, C. Celis-Morales, H. Forster, C. B. O'Donovan, C. Woolhead, A. L. Macready, R. Fallaize, C. F. Marsaux, C. P. Lambrinou, C. Mavrogianni, G. Moschonis, S. Navas-Carretero, R. San-Cristobal, M. Godlewska, A. Surwillo, J. C. Mathers, E. R. Gibney, L. Brennan, M. C. Walsh, J. A. Lovegrove, W. H. Saris, Y. Manios, J. A. Martinez, I. Traczyk, M. J. Gibney, $H$. Daniel (2015). "Predicting fatty acid profiles in blood based on food intake and the FADS1 rs174546 SNP." Mol Nutr Food Res. 
9. Celis-Morales, C., K. M. Livingstone, C. Woolhead, H. Forster, C. B. O'Donovan, A. L. Macready, R. Fallaize, C. F. Marsaux, L. Tsirigoti, E. Efstathopoulou, G. Moschonis, S. Navas-Carretero, R. San-Cristobal, S. Kolossa, U. L. Klein, J. Hallmann, M. Godlewska, A. Surwillo, C. A. Drevon, J. Bouwman, K. Grimaldi, L. D. Parnell, Y. Manios, I. Traczyk, E. R. Gibney, L. Brennan, M. C. Walsh, J. A. Lovegrove, J. A. Martinez, H. Daniel, W. H. Saris, M. Gibney and J. C. Mathers (2015). "How reliable is internet-based self-reported identity, sociodemographic and obesity measures in European adults?" Genes Nutr 10(5): 476.

10. Livingstone, K. M., C. Celis-Morales, S. Navas-Carretero, R. San-Cristobal, C. B. O'Donovan, H. Forster, C. Woolhead, C. F. Marsaux, A. L. Macready, R. Fallaize, S. Kolossa, L. Tsirigoti, C. P. Lambrinou, G. Moschonis, M. Godlewska, A. Surwillo, C. A. Drevon, Y. Manios, I. Traczyk, E. R. Gibney, L. Brennan, M. C. Walsh, J. A. Lovegrove, J. Alfredo Martinez, W. H. Saris, H. Daniel, M. Gibney and J. C. Mathers (2015). "Profile of European adults interested in internet-based personalised nutrition: the Food4Me study." Eur J Nutr.

11. Celis-Morales, C., K. M. Livingstone, C. F. Marsaux, H. Forster, C. B. O'Donovan, C. Woolhead, A. L. Macready, R. Fallaize, S. Navas-Carretero, R. San-Cristobal, S. Kolossa, K. Hartwig, L. Tsirigoti, C. P. Lambrinou, G. Moschonis, M. Godlewska, A. Surwillo, K. Grimaldi, J. Bouwman, E. J. Daly, V. Akujobi, R. O'Riordan, J. Hoonhout, A. Claassen, U. Hoeller, T. E. Gundersen, S. E. Kaland, J. N. Matthews, Y. Manios, I. Traczyk, C. A. Drevon, E. R. Gibney, L. Brennan, M. C. Walsh, J. A. Lovegrove, J. Alfredo Martinez, W. H. Saris, H. Daniel, M. Gibney and J. C. Mathers (2015). "Design and baseline characteristics of the Food4Me study: a web-based randomised controlled trial of personalised nutrition in seven European countries." Genes Nutr 10(1): 450.

12. Finlayson, G., C. Marsaux, P. Barrilet, J. Blundell (2011). "Implicit wanting determines incidental eating when hunger is suppressed" Appetite 57(2):537-537. 
Overview of completed training and activities 


\section{Overview of completed training and activities}

\section{Discipline specific activities}

Epigenesis and epigenetics, 2011, Wageningen, NL

diXa Microarray analysis using $\mathrm{R}$ and Bioconductor, 2014, Maastricht, NL

Peripheral cannulation, 2014, Maastricht, NL

Recent Advances and Controversies in Measuring Energy Metabolism, 2011, Maastricht, NL

European Congress on Obesity, 2012, Lyon, FR

International Congress of Nutrition, 2013, Granada, ES

European Congress on Obesity, 2015, Prague, CZ

European College of Sport Science congress, 2015, Malmö, SE

Annual symposia on Global and European Health, 2013, 2015, Maastricht, NL

Annual NUTRIM symposia, 2011, 2012, 2014, 2015, Maastricht, NL

Nutrition Science Day, 2011, 2012, 2014, Deurne, NL

Food4Me project meetings, 2011-2014, NL, UK, IE, ES, GR, IT

Research Line meetings, 2011-2015, Maastricht, NL

Capita Selecta parts 1 and 2, 2012-2013, Maastricht, NL

\section{General courses}

VLAG PhD week, 2012, Baarlo, NL

Problem-based learning, 2012, Maastricht, NL

Good Clinical Practice, 2012, Maastricht, NL

Statistics parts 1 and 2, 2012, Maastricht, NL

Maître Media training seminar, 2013, Newcastle, UK

Master Class “Nutrition Science and the Media”, 2014, Maastricht, NL

European Nutrition Leadership Platform essentials edition, 2015, Luxembourg, LU

\section{Optional courses and activities}

Writing Medical Ethics Committee applications, 2012, 2014

Dutch courses: modules B2-, B2+ and C1-, 2012, Maastricht, NL 